University of South Florida

DIGITAL COMMONS

Digital Commons @ University of

@ UNIVERSITY OF SOUTH FLORIDA

South Florida

$10-18-2010$

\title{
A STELLA Model for Integrated Algal Biofuel Production and Wastewater Treatment
}

Ivy Cormier

University of South Florida

Follow this and additional works at: https://digitalcommons.usf.edu/etd

Part of the American Studies Commons

\section{Scholar Commons Citation}

Cormier, Ivy, "A STELLA Model for Integrated Algal Biofuel Production and Wastewater Treatment" (2010). USF Tampa Graduate Theses and Dissertations.

https://digitalcommons.usf.edu/etd/3562

This Thesis is brought to you for free and open access by the USF Graduate Theses and Dissertations at Digital Commons @ University of South Florida. It has been accepted for inclusion in USF Tampa Graduate Theses and Dissertations by an authorized administrator of Digital Commons @ University of South Florida. For more information, please contact digitalcommons@usf.edu. 
A STELLA Model for Integrated Algal Biofuel Production and Wastewater

Treatment

by

Ivy Cormier

A thesis submitted in partial fulfillment

of the requirements for the degree of

Master of Science in Engineering Science

Department of Civil and Environmental Engineering

College of Engineering

University of South Florida

Major Professor: Daniel Yeh, Ph.D.

Piet Lens, Ph.D.

Qiong Zhang, Ph.D.

Date of Approval:

October 18, 2010

Keywords: mass balance, carbon dioxide, algae economics, nitrogen, phosphorous, Monod kinetics

Copyright @ 2010 Ivy Cormier 


\section{Acknowledgements}

I would like to express my utmost gratitude to those who have listened to, supported, helped, and pushed me throughout the design and implementation of this project. Although I have had countless influences while conducting this research, I would like to explicitly thank the following: Dr. Daniel Yeh for his continued support, advice, and ideas; committee members Dr. Piet Lens and Dr. Qiong Zhang for their insightful comments; the Hillsborough County Health Department for their support and flexibility; Miss Caryssa Joustra for her expertise; Miss Ana Lucia Prieto for her insight and patience; Mr. Robert Bair for his opinions, humor, and input on economic variables; Mr. Timothy Ware from the Howard F. Curren Advanced Wastewater Treatment Plant for providing plant data; and my friends and family who have endured long discussions regarding algae and biofuel. 


\section{Table of Contents}

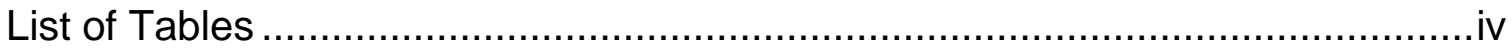

List of Figures ................................................................................... viii

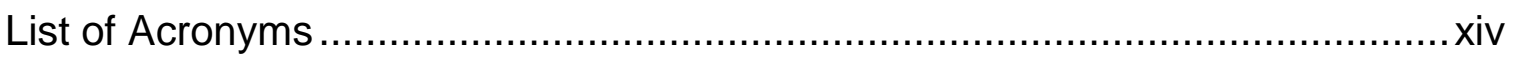

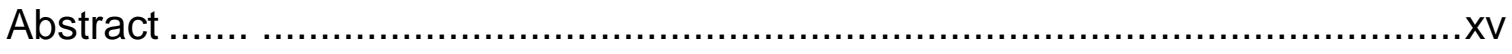

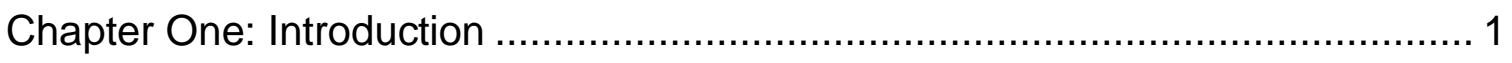

Chapter Two: Background ............................................................................ 3

Background of Wastewater Treatment Plant Case Study ......................... 3

Shortcomings of Conventional Wastewater Treatment............................ 5

Basic Wastewater Treatment................................................................ 7

Carbon Removal ..................................................................... 8

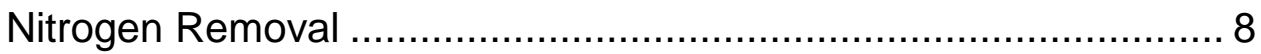

Phosphorous Removal ................................................... 9

Algae and Wastewater Treatment............................................ 10

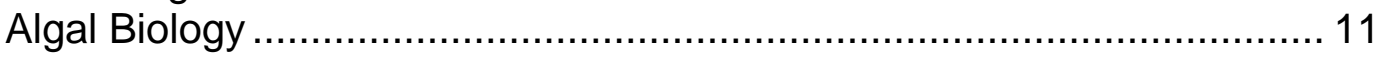

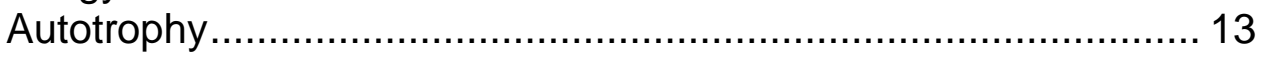

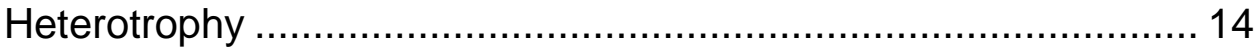

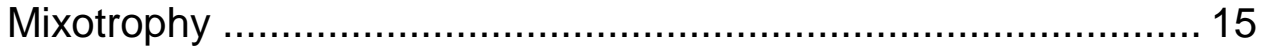

Synergy of Wastewater Treatment and Algae Cultivation....................... 16

Environmental Conditions Affecting Growth........................................ 17

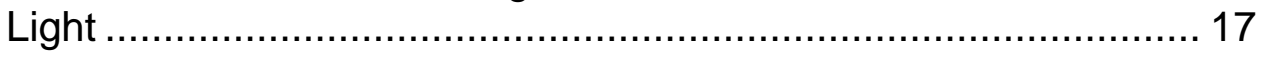

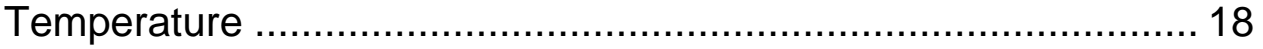

$\mathrm{pH}$

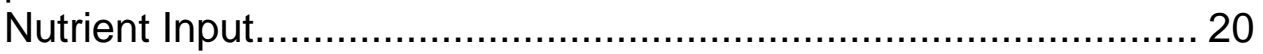

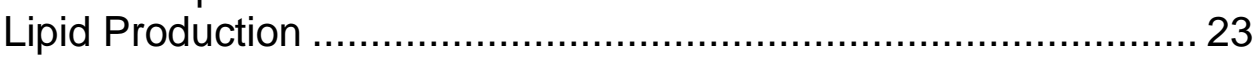

Carbon Dioxide Retrieval ........................................................... 25

Oxygen and Chemical Demand Reduction ................................. 26

Secondary Use of Algal Biomass.................................................... 26

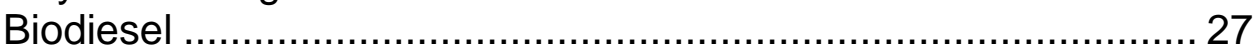

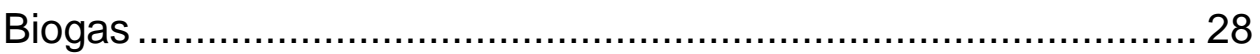

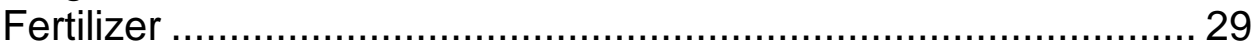

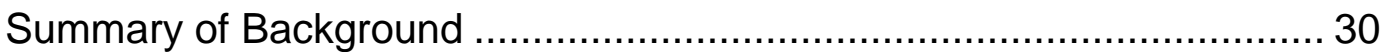




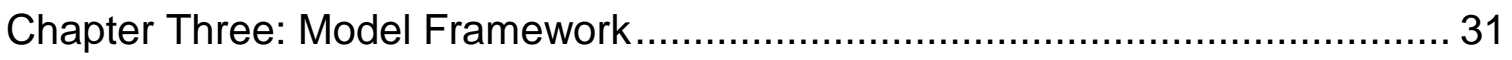

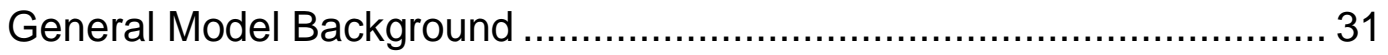

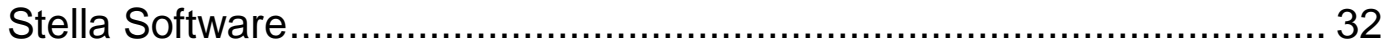

Conceptual Approach .................................................................... 34

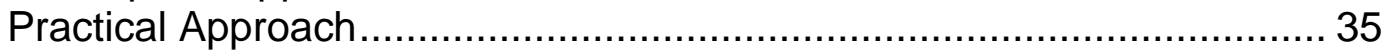

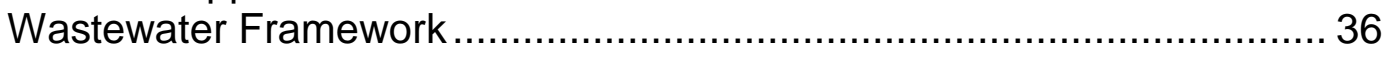

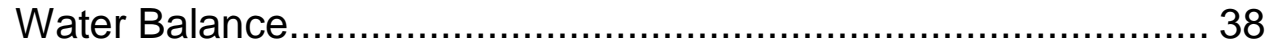

Carbon Balance .............................................................. 41

Nitrogen Balance............................................................. 47

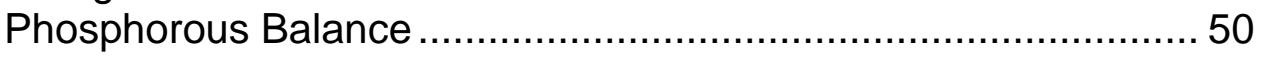

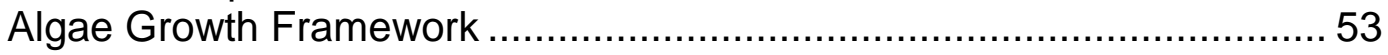

Maximum and Calculated Specific Growth Rate .......................... 55

Algae Growth ................................................................. 59

Determining Substrate Utilization Rate and Yield Coefficient ....... 61

Determining Substrate Removal via Biomass Assimilation ............ 64

Hydraulic Retention Time in Algae Basins ...................................6 68

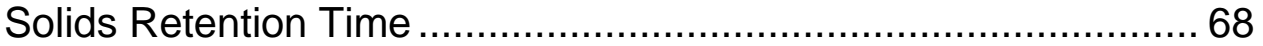

Algae Production Costs \& Benefits Calculations...................................... 69

Benefits of Reduced Aeration ............................................... 71

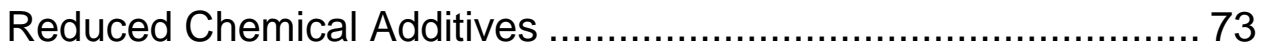

Biomass Production Costs ................................................... 74

Biomass Harvesting Costs ................................................... 75

Secondary Product Calculations ..................................................... 75

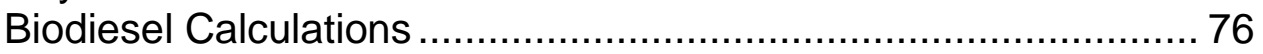

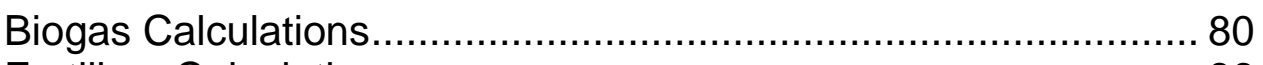

Fertilizer Calculations ..................................................... 86

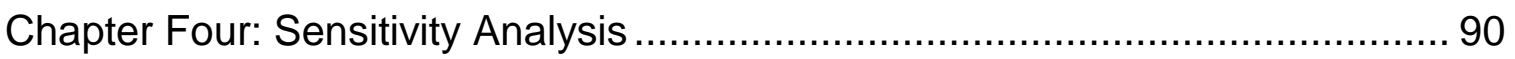

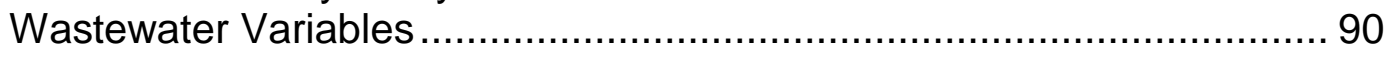

Wastewater Influent Characteristics ......................................... 90

Other Wastewater Parameters ................................................... 94

Algae Growth Variables ….................................................................. 95

Specific Growth Rate and Harvest Waste Rate .......................... 95

Half Saturation Constants .................................................... 98

Yield Coefficient ............................................................ 100

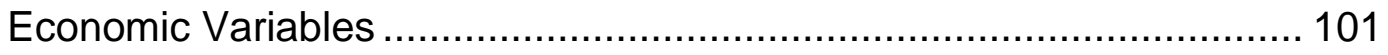

Cost Savings from Reduced Aeration ..................................... 101

Cost Savings from Reduced Chemical Addition......................... 102

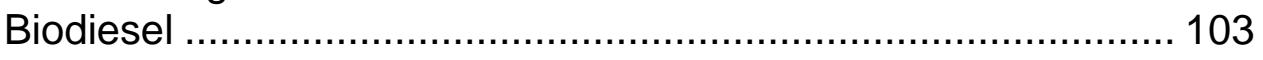

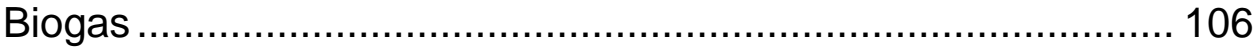

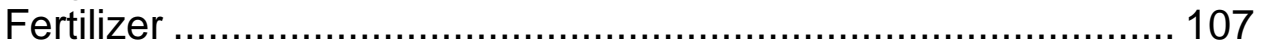

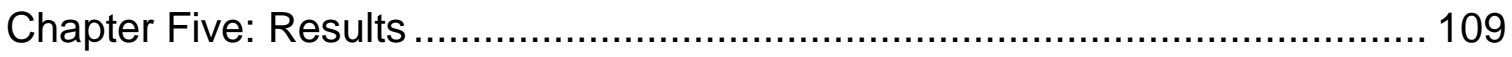

Potential Biomass Production at HFCAWTP ……............................. 110

Economic Viability ............................................................................ 117 
Chapter Six: Conclusions and Future Research......................................... 124

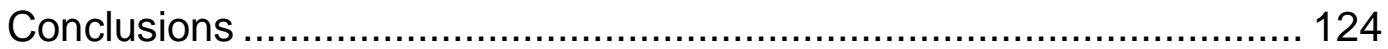

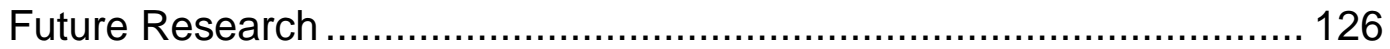

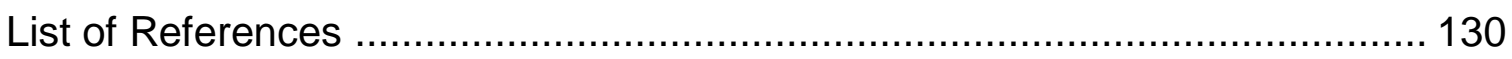

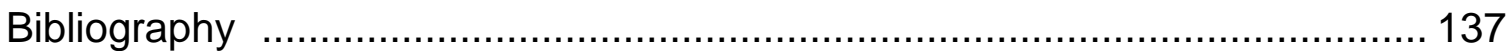

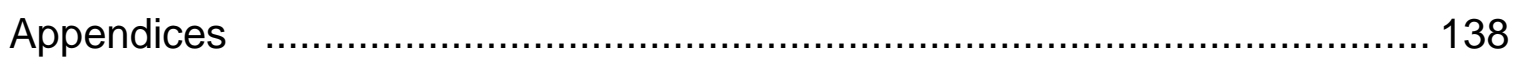

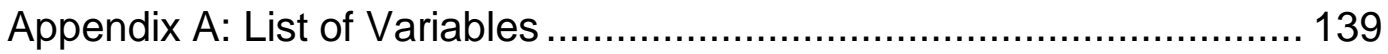

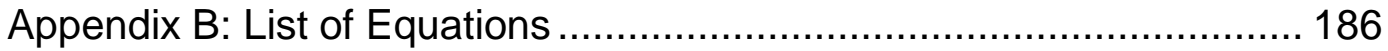

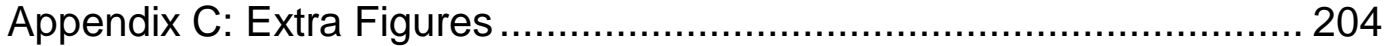

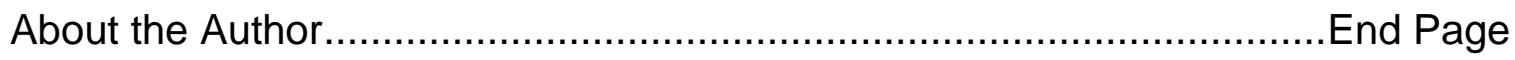




\section{List of Tables}

Table 1. Varying lipid content per cell dry weight among algae species reported in different studies

Table 2. List of nutrient groups tracked within the model and their associated species

Table 3. Calculated yield coefficients for determination of $q_{t}$ 64

Table 4. Concentration ranges of influent ammonia, soluble phosphorous, and carbon dioxide selected for wastewater characteristics sensitivity analysis.

Table 5. Trial matrix for varying influent wastewater characteristics. 91

Table 6. Simulation parameters for case studies at HFCAWTP. 111

Table 7. Parameter settings for economic viability analysis 119

Table 8. Potential profits under best, average, and worst case scenario conditions per $\mathrm{kg}$ of algae produced

Table A1. List of variables in the water balance framework 139

Table A2. List of equations in the water balance framework 140

Table A3. List of variables within water loss to algae harvest framework

Table A4. List of equations in water loss to algae harvest framework 141

Table A5. List of variables in phosphorous flow framework .......................... 142

Table A6. List of equations in phosphorous flow framework........................ 143

Table A7. List of variables in phosphorous mass balance framework ............ 144

Table A8. List of equations in phosphorous mass balance framework 145 
Table A9. List of variables in the nitrogen flow framework for organic $\mathrm{N}$ and ammonia

Table A10. List of equations in the nitrogen flow framework for organic $\mathrm{N}$ and ammonia

Table A11. List of variables in the nitrogen flow framework for nitrate and nitrogen gas

Table A12. List of equations in the nitrogen flow framework for nitrate and nitrogen gas

Table A13. List of variables in nitrogen mass balance................................. 150

Table A14. List of equations in nitrogen mass balance ............................... 151

Table A15. List of variables in soluble and nonsoluble carbon species model framework.

Table A16. List of equations in soluble and nonsoluble carbon species model framework.

Table A17. List of variables in organic carbon and carbon dioxide species model framework.

Table A18. List of equations in organic carbon and carbon dioxide species model framework. 156

Table A19. List of variables in carbon mass balance framework 157

Table A20. List of equations in carbon mass balance framework. 158

Table A21. List of variables in calculating specific growth rate in the PPOR .... 159

Table A22. List of equations in calculating specific growth rate in the PPOR 160

Table A23. List of variables for SRT framework in the PPOR ........................ 160

Table A24. List of equations for SRT framework in the PPOR ...................... 161

Table A25. List of variables for algae growth in the PPOR ............................ 161

Table A26. List of equations for algae growth in the PPOR ............................ 162

Table A27. List of variables in nitrogen utilization framework in the PPOR ...... 162 
Table A28. List of equations in nitrogen utilization framework in the PPOR ..... 163

Table A29. List of variables in carbon utilization framework in the PPOR ........ 164

Table A30. List of equations in carbon utilization framework in the PPOR ....... 164

Table A31. List of variables in phosphorous utilization framework in the PPOR

Table A32. List of equations in phosphorous utilization framework in the PPOR. 166

Table A33. List of variables for substrate utilization rate framework in the PPOR. 167

Table A34. List of equations for substrate utilization rate framework in the PPOR. 167

Table A35. List of variables for specific growth rate in the PNR …................. 168

Table A36. List of equations for specific growth rate in the PNR .................... 169

Table A37. List of variables for SRT framework in the PNR ........................... 169

Table A38. List of equations for SRT framework in the PNR .......................... 170

Table A39. List of variables for algae growth in the PNR ............................. 170

Table A40. List of equations for algae growth in the PNR …....................... 171

Table A41. List of variables in nitrogen utilization framework in the PNR ......... 171

Table A42. List of equations for nitrogen utilization framework in the PNR ...... 172

Table A43. List of variables in carbon utilization framework in the PNR .......... 173

Table A44. List of equations in carbon utilization framework in the PNR .......... 173

Table A45. List of variables in phosphorous utilization framework in the PNR 174

Table A46. List of equations in phosphorous utilization framework in the PNR 175

Table A47. List of variables for substrate utilization rate framework in the PNR 
Table A48. List of equations for substrate utilization rate framework in the PNR

Table A49. List of variables for cost savings from reduced aeration................. 177

Table A50. List of equations for cost savings from reduced aeration .............. 177

Table A51. List of variables for cost savings from reduced chemical

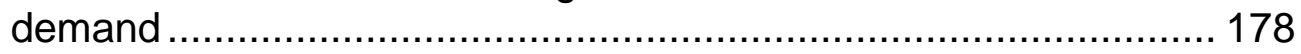

Table A52. List of equations for cost savings from reduced chemical demand

Table A53. List of variables for biogas processing framework........................ 179

Table A54. List of equations for biogas processing framework ..................... 180

Table A55. List of variables for biodiesel processing framework .................... 181

Table A56. List of equations for biodiesel processing framework .................... 183

Table A57. List of variables for fertilizer processing framework..................... 184

Table A58. List of equations for fertilizer processing framework .................... 185 


\section{List of Figures}

Figure 1. Schematic of HFCAWTP........................................................ 4

Figure 2. Areas of potential synergy between algae growth and wastewater treatment................................................................ 16

Figure 3. Basic components of a STELLA model. ...................................... 33

Figure 4. Schematic of the section of the treatment process at the HFCAWTP modeled in this study ............................................. 34

Figure 5. Conceptual framework of model components ................................ 35

Figure 6. Model interface for manipulating physical parameters of the treatment plant and influent flow characteristics ........................... 38

Figure 7. Conceptual flow of water through treatment plant and algae reactors.

Figure 8A. Model framework for water flow in STELLA model ....................... 40

Figure 8B. Conceptual water flow in STELLA model .................................... 40

Figure 9. Model framework for water loss due to algae harvesting............... 41

Figure 10. Routing of electrons from an electron donor, such as BOD........... 42

Figure 11A. Mass balance of carbon species ............................................. 44

Figure 11B. Conceptual figure of carbon mass balance …............................. 44

Figure 12A. Conceptual figure of carbon flow through the STELLA framework shown in Figure 12A. ............................................ 45

Figure 12B. Carbon flow in STELLA model ................................................. 46

Figure 13A. Mass balance of nitrogen species in STELLA model .................... 48 
Figure 13B. Conceptual figure of nitrogen mass balance.

Figure 14A. Nitrogen flow in STELLA model .............................................. 49

Figure 14B. Conceptual figure of nitrogen flow through the STELLA framework shown in Figure 14A .............................................. 50

Figure 15A. Mass balance of phosphorous species in STELLA model ............. 51

Figure 15B. Conceptual figure of nitrogen mass balance .............................. 51

Figure 16A. Phosphorous flow in STELLA model......................................... 52

Figure 16B. Conceptual figure of phosphorous flow through the STELLA framework shown in Figure 16A .............................................. 52

Figure 17. Model interface for manipulating parameters related to algae growth kinetics and the physical characteristics of the algae

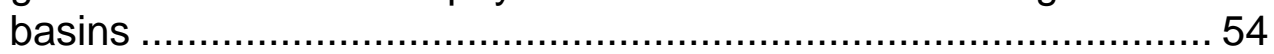

Figure 18A. Model framework for determination of specific growth rate in the PPOR from Monod kinetics................................................. 58

Figure 18B. Conceptual illustration of equation used to determine specific growth rate in the PPOR ....................................................... 58

Figure 19A. Model framework for algae production in the PPOR .....................6 60

Figure 19B. Conceptual figure of algae production in the PPOR ......................60

Figure 20A. Model framework for calculating the substrate utilization rate

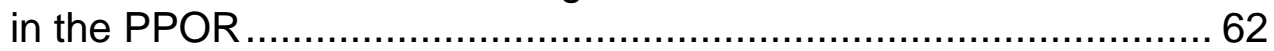

Figure 20B. Equations for substrate utilization rate framework in the PPOR shown in Figure 20A.

Figure 21A. Model framework for ammonia-nitrogen removal from the PPOR

Figure 21B. Conceptual illustration of ammonia utilization in the PPOR 66

Figure 22. Model framework for movement of nitrogen in the wastewater treatment plant.

Figure 23. Example of ammonia-nitrogen being removed from wastewater framework after assimilation by algae. 
Figure 24. Model framework for calculating the volume of the PPOR as a function of HRT and flow diverted to algae basin, which are entered on the interface of the model.

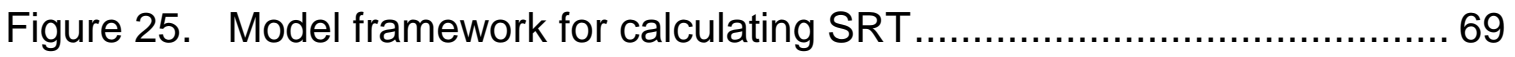

Figure 26. Model interface for entering the cost per unit of secondary product produced...................................................................... 70

Figure 27. Detail of model interface where user can define the route for

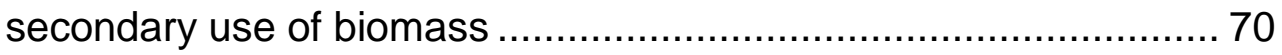

Figure 28A. Model framework for cost savings due to algae assimilation and photosynthetic oxygenation ............................................... 72

Figure 28B. Conceptual illustration for reduced aeration demand .................... 73

Figure 29A. Model framework to calculate the benefits of reduced chemical additives

Figure 29B. Conceptual illustration of savings due to reduced chemical

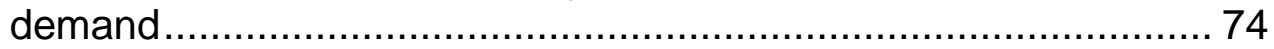

Figure 30A. Model framework for biodiesel production calculations .................. 77

Figure 30B. Conceptual illustration of economic calculations in biodiesel

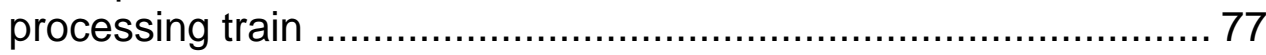

Figure 31. Model framework for calculating biogas production costs .............. 81

Figure 32A. Model framework for biogas calculations .................................... 82

Figure 32B. Conceptual illustration of economic calculations in biogas

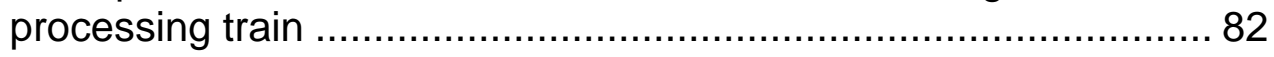

Figure 33A. Model framework for fertilizer cost-benefit analysis...................... 86

Figure 33B. Conceptual illustration of economic calculations in fertilizer

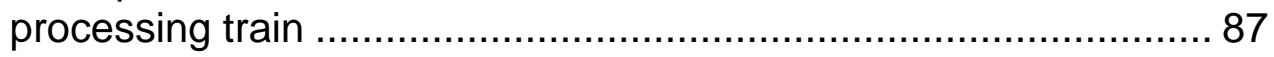

Figure 34. Model framework for calculating fertilizer production costs ............ 87

Figure 35. Model parameter settings for influent wastewater characteristics sensitivity test 
Figure 36. Biomass production in the PPOR as a function of influent nutrient concentration.

Figure 37. Biomass production in the PPOR as a function of influent $\mathrm{NH} 3$

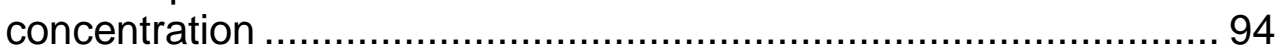

Figure 38. Biomass production in the PPOR with increasing $\mu$ max................. 96

Figure 39. Biomass production as a function of harvest rate.......................... 97

Figure 40. Specific growth rate as a function of harvest schedule................... 98

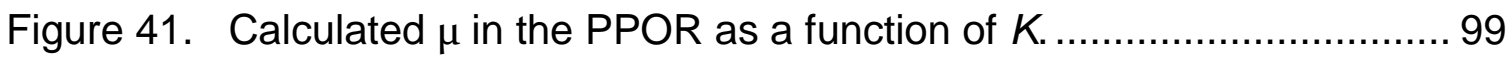

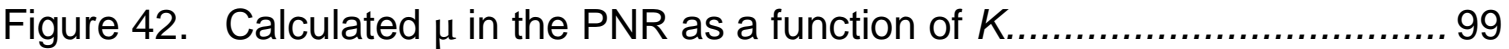

Figure 43. The effect of $Y_{-} N H 3$ on algae growth variables in the PPOR. ...... 101

Figure 44. Cost savings from reduced aeration as a function of cost per

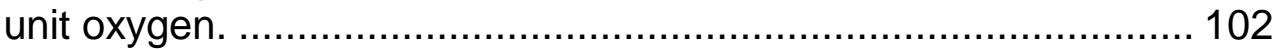

Figure 45. Cost savings from reduced chemical addition as a function of the cost of methanol................................................................. 103

Figure 46. Cost of biodiesel production as a function of processing costs ..... 104

Figure 47. Cost of biodiesel production over varying biomass harvesting costs.

Figure 48. Cost of biodiesel production over varying biomass production costs

Figure 49. Cost of biodiesel production with added cost of secondary

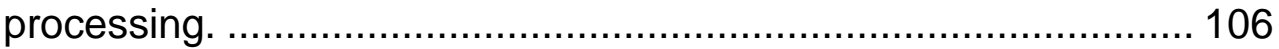

Figure 50. Cost of biogas production as a function of processing costs. ....... 107

Figure 51. Cost of fertilizer production as a function of processing costs. ...... 108

Figure 52. Parameter settings for HFCAWTP case study ........................... 110

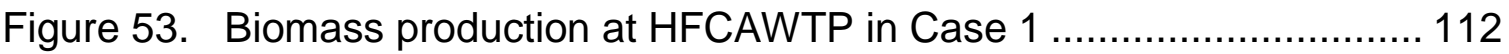

Figure 54. Biomass production at HFCAWTP in Case 2........................... 113

Figure 55. Biomass production at HFCAWTP in Case 3........................... 113 
Figure 56. Monod fractions in Cases 1 and 3.

Figure 57. Biomass production as a function of specific growth rate at the HFCAWTP.

Figure 58. Biomass production as a function of initial harvest. 116

Figure 59. Biomass production as a function of harvest amount, Case 1 conditions.

Figure 60. Biomass production as a function of harvest amount, Case 2 conditions.

Figure 61. Potential profits from biodiesel as a function of processing costs 120

Figure 62. Potential profits from biodiesel as a function of market price 121

Figure 63. Potential profit from biogas as a function of energy content .... 122

Figure 64. Potential profit from fertilizer production as a function of market price. 123

Figure A1. Detailed view of the water balance 139

Figure A2. Detailed view of water loss to algae harvest 141

Figure A3. Phosphorous flow through treatment plant................................ 142

Figure A4. Phosphorous mass balance framework in STELLA model 144

Figure A5. Nitrogen flow framework for organic $\mathrm{N}$ and ammonia in the STELLA model.

Figure A6. Nitrogen flow framework for organic $\mathrm{N}$ and ammonia in STELLA model.

Figure A7. Nitrogen mass balance in STELLA model. 150

Figure A8. Flow of soluble and nonsoluble carbon species in STELLA model 152

Figure A9. Flow of organic carbon and carbon dioxide in STELLA model ...... 155

Figure A10. Carbon mass balance in STELLA model 157 
Figure A11. Calculated specific growth rate in the PPOR 159

Figure A12. SRT in the PPOR …......................................................... 160

Figure A13. Algae growth framework in the PPOR in the STELLA model........ 161

Figure A14. Nitrogen utilization in the PPOR ............................................ 162

Figure A15. Carbon utilization in the PPOR ............................................... 163

Figure A16. Phosphorous utilization in the PPOR ….................................. 165

Figure A17. Substrate utilization in the PPOR in STELLA model .................... 166

Figure A18. Specific growth rate in the PNR …......................................... 168

Figure A19. SRT framework in the PNR in the STELLA model ...................... 169

Figure A20. Algae growth framework in the PNR …................................... 170

Figure A21. Nitrogen utilization framework for the PNR ............................. 171

Figure A22. Carbon utilization framework in the PNR ................................ 172

Figure A23. Phosphorous utilization framework in the PNR .......................... 174

Figure A24. Substrate utilization rate framework in the PNR .......................... 175

Figure A25. Cost savings from reduced aeration framework in the STELLA model

Figure A26. Cost savings from reduced chemical demand framework ............. 178

Figure A27. Biogas processing framework in the STELLA model ................... 179

Figure A28. Biodiesel processing framework in the STELLA model................ 181

Figure A29. Fertilizer processing framework in the STELLA model................. 184

Figure C1. Biomass production as a function of influent nutrient

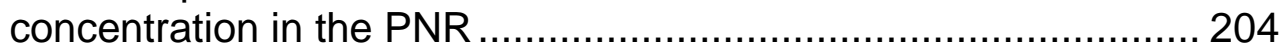

Figure C2. Biomass production in the PNR as a function of $\mu \max \ldots \ldots \ldots \ldots \ldots . . . .205$

Figure C3. Biomass production as a function of initial harvest rate, Case 2 205 


\section{List of Acronyms}

\begin{tabular}{|l|l|}
\hline BOD & biochemical oxygen demand \\
\hline BNR & biological nutrient removal \\
\hline BPR & biological phosphorus removal \\
\hline COD & chemical oxygen demand \\
\hline DO & dissolved oxygen \\
\hline HFCAWTP & $\begin{array}{l}\text { Howard F. Curren Advanced } \\
\text { Wastewater Treatment Plant }\end{array}$ \\
\hline MGD & million gallons per day \\
\hline MJ & megajoules \\
\hline PAO & phosphorous accumulating organisms \\
\hline PNR & post-nitrification reactor \\
\hline PP & pentose phosphate pathway \\
\hline PPOR & post-pure oxygen reactor \\
\hline TCA & tricarboxylic acid (citric acid) cycle \\
\hline TKN & total Kjeldhal nitrogen \\
\hline TN & total nitrogen \\
\hline TSS & total suspended solids \\
\hline VFA & volatile fatty acids \\
\hline
\end{tabular}




\begin{abstract}
Based on a municipal wastewater treatment plant (WWTP) in Tampa, FL, a dynamic multiple-systems model was developed on the STELLA software platform to explore algae biomass production in wastewater by incorporating two photobioreactors into the WWTP's treatment train. Using a mass balance approach, the model examined the synergy through algal growth and substrate removal kinetics, as well as macroeconomic-level analyses of algal biomass conversion to biodiesel, biogas, or fertilizer. A sensitivity analysis showed that biomass production is highly dependent on Monod variables and harvesting regime, and profitability was sensitive to processing costs, market prices of products, and energy environment. The model demonstrated that adequate nutrients and carbon dioxide are available in the plant's influent to sustain algal growth. Biogas and fertilizer production were found to be profitable, but biodiesel was not, due to high processing costs under current technologies. Useful in determining the growth potential on a macro-level, the model is a tool for identifying focus areas for bench and pilot scale testing.
\end{abstract}




\section{Chapter One:}

\section{Introduction}

Domestic and industrial wastewater was aptly named for how it has historically been viewed: as a 'waste' to be disposed of. However, as resources have become depleted and more difficult to extract, alternative sources of nutrients, water, and energy are being sought. Wastewater has been recognized as an accessible, abundant, and viable resource with great potential to be exploited as a renewable source of nutrients and energy.

Modern agriculture and standard of living exerts an ever-increasing demand for nutrients and energy, especially as the world population continues to grow. However, virgin nutrient sources such as phosphorous are finite, and others, such as ammonia, are produced at high energy costs. Fossil fuel based energy is also finite, and produces byproducts, such as greenhouse gases, that are detrimental to the environment. There is no doubt that a more sustainable method of harvesting nutrients and energy is necessary to maintain a healthy global future.

Algae cultivation in wastewater is one potential solution for nutrient and energy recovery. Although commercial algal culturing is not a new concept, it has gained more attention in the past decade and is recently gaining momentum. Algae have been shown to thrive in polluted water, removing nutrients and 
sequestering carbon as they grow. Microalgae, in particular, are a diverse group adaptable to many environments, and many species are well suited to thrive in wastewater conditions. Algal biomass grown in wastewater can be used as a renewable fertilizer or fermented to produce biogas. Some species also produce significant quantities of lipids per dry cell weight, which can be turned into biofuel. Instead of losing nutrients through chemical precipitation or release to the atmosphere, as occurs in traditional wastewater treatment, incorporating algae into the process helps to close the nutrient loop and concentrate the energy source for subsequent use.

This paper will begin by examining conventional wastewater treatment processes, and then explore the synergy of algae with those processes. Algal biology, metabolism, environmental conditions affecting growth and lipid production will be discussed. Secondary products, including biodiesel, fertilizer, and biogas, potentially produced from algal biomass grown in wastewater will then be explored.

With the aid of a model developed using STELLAC software, the theoretical yield of algae biomass based on nutrient availability and cycling through the Howard F. Curren Advanced Wastewater Treatment Plant (HFCAWTP) in Tampa, Florida will be examined. Two potential placements of an algae cultivation basin are explored, and the economic benefit of algal biomass production as biodiesel, biogas, and fertilizer will be examined. Other potential cost savings resulting from incorporating algae into the treatment process, such as reduced aeration and chemical demand, will be investigated. 


\section{Chapter Two:}

\section{Background}

\section{Background of Wastewater Treatment Plant Case Study}

The plant simulated in this model is the Howard F. Curren Advanced Wastewater Treatment Plant (HFCAWTP) in Tampa, Florida, a three stage biological nutrient removal (BNR) plant. The first stage consists of a pure oxygen aerobic treatment basin for removal of influent BOD; the nitrification basin is the second stage, using air for aeration rather than pure oxygen. The third step is an anoxic denitrification filter, where an oxygen depleted environment allows denitrifiers to use nitrate as their electron acceptor. The plant does not have a dedicated phosphorus removal process, as the background phosphorus in receiving water is higher than the typical effluent concentration. The plant layout is shown in Figure 1. 


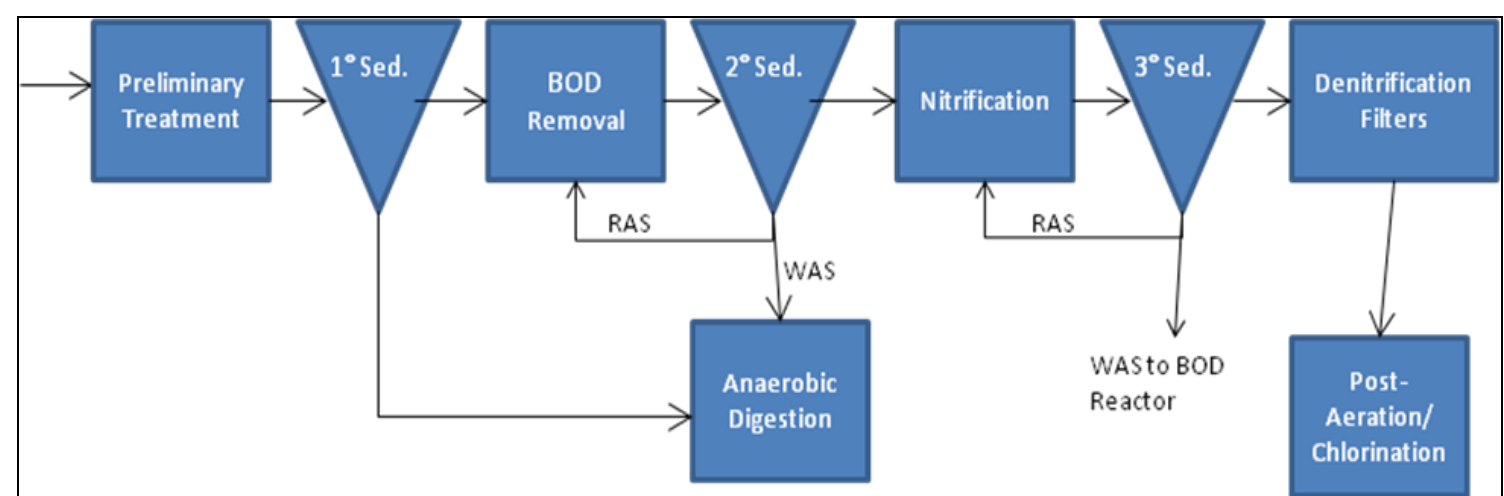

Figure 1. Schematic of HFCAWTP. The BNR plant consists of BOD removal, nitrification, denitrification, and post-aeration/chlorination. Sedimentation basins follow each treatment basin, where wasted sludge is either recycled into the treatment process or routed to anaerobic digestion.

As shown in Figure 1, the plant includes sedimentation basins and an anaerobic digester, with a digestion capacity of approximately 10 million gallons spread throughout seven tanks. The solids handling and sidestream waste, however, were not included in this model analysis.

The wastewater flow through the plant is approximately 54.2 million gallons per day (MGD). The permit effluent requirements are less than $5 \mathrm{mg} / \mathrm{L}$ BOD, $5 \mathrm{mg} / \mathrm{L}$ total suspended solids (TSS), and $3 \mathrm{mg} / \mathrm{L}$ total nitrogen (TN). On average, the plant achieves over $99 \%$ removal of BOD and TSS, and over $92 \%$ removal of total nitrogen.

The HFCAWTP was used as a case study for a number of reasons. First, although it is somewhat unique for utilizing a pure oxygen system for BOD removal, the overall set up of the plant is rather conventional, giving the model applicability to other plant designs. Second, the plant's location in Tampa, Florida makes it a good candidate for algae production due to the abundance of sunlight and high temperatures. Third, the plant is currently utilizing biogas produced from 
its anaerobic digester to offset energy costs, and therefore may be open to digesting algae biomass for further energy production.

\section{Shortcomings of Conventional Wastewater Treatment}

Although nutrients are essential for proper ecosystem function, discharges of high concentrations of biologically available nutrients can be detrimental to the balance of aquatic ecosystems. An increase of nutrients can lead to eutrophication, depleting the oxygen availability within the receiving water (Barsanti and Gualtieri, 2006; deBashan, 2004; Olguin, 2003). Because phosphorous is typically the limiting nutrient in freshwater ecosystems, wastewater discharges can potentially exceed the background phosphorous in these systems. Excess nitrogen can also not only disrupt the nutrient balance in aquatic ecosystems, but can interfere with chlorine disinfection regimes in tertiary wastewater treatment as well (Ahn, 2006).

Nitrogen and phosphorous are both important ingredients in many commercial products, including fertilizer and detergents. Nitrogen can be fixed from the atmosphere by certain bacteria or converted into ammonia by the energy intensive Haber-Bosch process. However, this process requires $45 \mathrm{~kJ} / \mathrm{kg}$ $\mathrm{N}$ fixed (Maurer et al., 2003) when compared to $5 \mathrm{~kJ} / \mathrm{kg}-\mathrm{N}$ when nitrogen comes from organic sources, such as sludge (Fadare et al., 2010).

Phosphorus, on the other hand, is not a renewable resource, but only enters the ecosystem through mining or the weathering of rocks. Phosphorus, an essential element in synthetic fertilizers, is a limited resource, and worldwide production of phosphate is expected to run out in 50-135 years (Jasinki, 2006; 
Dery et al., 2007). Because there is no adequate substitute for phosphorus, and ammonia production consumes considerable energy, recovering these nutrients from wastewater may not only be essential for sustaining modern agriculture, but important for reducing global energy use as well (deBashan, 2004).

Despite high energy inputs, conventional activated sludge processes do not allow for nutrient recovery, as nitrogen is lost as a gas and phosphorous typically precipitates in the sludge (Gonzalez, 2008). Although employing BNR technology can save wastewater treatment plants the cost of chemical additives (deBashan, 2004), the nutrient cycle remains open. As discharge regulations become more stringent, treatment processes become more energy and operationally intensive. One means to recuperate added costs may be to harness the nutrient and energy supplied in wastewater through algae cultivation and resell the biomass as a value-added product.

Although biomass production is one option for nutrient recovery in wastewater treatment, other techniques for nutrient recovery include struvite precipitation and nitrite recovery through pervaporation. Struvite recovery occurs by raising the $\mathrm{pH}$ to precipitate struvite $\left(\left(\mathrm{NH}_{4}\right) \mathrm{MgPO}_{4} \cdot 6 \mathrm{H}_{2} \mathrm{O}\right)$ from excess ammonia, phosphorous, and magnesium (Saidou et al., 2009). Pervaporation uses a membrane to separate constituents from water; it removes water using pressure gradients to change volatile constituents to a vapor, thereby passing it through the membrane (Bhat and Aminabhavi, 2007). These nutrient recovery techniques, however, require energy input to create necessary environmental 
conditions. For a comprehensive review of nitrogen and phosphorous removal techniques, see Ahn (2006) and Parson and Smith (2008), respectively.

Typical BNR plants can be energy intensive, require external inputs, and necessitate specialized maintenance that can be costly and time consuming. Based on calculations provided by the Department of Energy and the Environmental Protection Agency (2000), for each kWh of energy used, $0.61 \mathrm{~kg}$ of carbon dioxide is produced. Therefore, as approximately $3 \%$ of the nation's energy is used for drinking or wastewater services, roughly 45 million tons of greenhouse gases are added to the atmosphere from this sector (US EPA, 2000). Autotrophic algae sequester carbon dioxide during growth, helping to reduce the dependence on external energy and close the energy loop. Further, algae biomass can be utilized for biofuel or biogas to offset this carbon footprint.

The HFCAWTP is able to mitigate energy use by utilizing biogas produced from the anaerobic digester, saving the plant approximately $\$ 1,104,954$ annually (City of Tampa, 2010). Incorporating algal cultivation into the treatment process could contribute supplementary biogas production, further reducing the plant's dependence on external energy. Other potential savings lie in the reduced oxygen demand for nitrification and reduced methanol addition for denitrification as a result of algal nutrient removal. These two cost reduction mechanisms will be discussed in more detail later in this paper.

\section{Basic Wastewater Treatment}

Although configurations of wastewater treatment plants can vary considerably, most municipal BNR plants focus on the removal of carbon, 
nitrogen, and occasionally phosphorous. Because the model employed in this study focused on a mass balance of these constituents, the typical fate of carbon, nitrogen, and phosphorous in standard treatment is briefly explained in this section.

\section{Carbon Removal}

Because wastewater constituents can be very diverse, carbon entering the plant is typically categorized with other electron donors as biochemical oxygen demand (BOD) or chemical oxygen demand (COD). Carbon can be synthesized into biomass, removed via adsorption, or oxidized to carbon dioxide under aerobic conditions (Rittman and McCarty, 2001). Influent organics can be coupled with denitrification to reduce both the oxygen demand in the influent and the carbon source needed for heterotrophic nitrogen removal. Typical treatment processes lose carbon as carbon dioxide, but incorporating autotrophic algal growth can help sequester it for future energy production.

\section{Nitrogen Removal}

Conventional nitrogen removal typically occurs in two steps: nitrification and denitrification. Nitrification is the oxidation of ammonia to nitrate by autotrophic bacteria, using oxygen as an electron acceptor and carbon dioxide as the carbon source (Rittman and McCarty, 2001). Denitrification is typically the heterotrophic conversion of nitrate to nitrogen gas (through nitrite) under anoxic conditions, but can also be achieved by autotrophic bacteria utilizing hydrogen or sulfur as an electron donor. Many carbon sources for denitrification have been used, including acetate, glucose, and methanol (Ahn, 2006; Rittman and 
McCarty, 2001). Found in peptides, enzymes, chlorophylls, ATP, ADP, RNA, DNA, among other components of the cell, nitrogen is a critical ingredient for cellular function (Barsanti and Gualtieri, 2006), and will thereby be assimilated within growing and reproducing biomass (Rittman and McCarty, 2001). Phosphorus Removal

Most phosphorous in wastewater is dissolved, partitioned as $50 \%$ orthophosphate, $35 \%$ condensed phosphates, and $15 \%$ organic phosphates (Parson, 2008) and can be removed both biologically and chemically. Because biological phosphorus removal (BPR) relies on an organism's ability to store excess phosphorus under specific environmental conditions, the process can be fragile and complex (Mulkerrins et al., 2004; Lopez-Vazquez et al., 2008; Rybicki, 1997). Algae have exhibited similar luxury uptake capabilities as phosphorous accumulating organisms (PAO) under certain environmental conditions (Powell et al., 2008).

Phosphorus can also be removed by physical means, such as adsorption or precipitation. Common chemicals used include alum or lime (Mulkerrins et al., 2004; Rybicki, 1997), and pH regimes can influence precipitation with iron (Parsons, 2008) or as struvite (Saidou et al., 2009). Algal treatment can be used in conjunction with chemicals to remove phosphorous from a system; algae interact with mineral complexes and both precipitate out together, enhancing removal (Hoffman, 1998). Phosphorous is also removed from a system through assimilation in growing and reproducing biomass (Rittman and McCarty, 2001), though in smaller amounts than nitrogen and carbon. 


\section{Algae and Wastewater Treatment}

Algae have been investigated for their potential use in wastewater treatment since the 1950s (Hoffman, 1998) with a strong emphasis on suspended growth in shallow open ponds. Algae have gained attention in the wastewater industry for their potential for nutrient removal in domestic wastewaters (de-Bashan and Bashan, 2010; Powell et al., 2009), industrial wastewater (Bordel et al., 2009), and agricultural wastewater (Olguin, 2003; Gonzalez et al., 1997; Gonzalez et al., 2008; Kamilya et al., 2006), as regulations push for better effluent quality (Powell et al., 2009). More recently, researchers have focused on a wider spectrum of algae technology in water treatment, such as immobilization in polymeric substances to enhance nutrient removal (De la Noue and Proulx, 1988; de-Bashan and Bashan, 2010; Travieso et al., 1996), utilization of heterotrophic metabolism (Lee, 2004; Miao and Wu, 2004; Ogbonna and Tanaka, 1996; Ogbonna et al., 2000; Yang et al., 2000), and potential uses of the algal biomass produced (Mulbry et al., 2008; Amin, 2009; Chisti, 2007; Tran et al., 2010). Algae are also being investigated as a means to bioaccumulate phosphorus (Powell et al., 2008).

Theoretically, algae and activated sludge bacteria can cooperate in a symbiotic relationship; algae produce oxygen during photosynthesis that bacteria, namely nitrifiers, utilize for growth, while consuming carbon dioxide produced by the bacteria (Bordel et al., 2009; Gonzalez et al., 2008). Utilizing algae's ability to grow in cyclic light/dark conditions can potentially save energy and increase effluent quality at wastewater treatment plants (Lee and Lee, 2001; 
Bordel et al., 2009). Algae also have the potential to recover more nutrients in sludge than conventional systems using chemical precipitation (Hoffman, 1998).

Many algae species produce high volumes of lipids per cell weight (Xiong et al., 2010), making them excellent candidates for biofuel production. In fact, microalgae have the highest oil yield among all other plants grown for biofuel, including palm, coconut, castor, and sunflower oils (Amin, 2009). More importantly, algae have demonstrated their tolerance to the wastewater

environment, giving them great potential to produce energy and capture nutrients without squandering arable land and scarce freshwater resources consumed during other biofuel production, such as corn-based ethanol.

\section{Algal Biology}

Although algae are not recognized as a taxonomically distinct group, they have much in common with each other and share many differences from other plants. Containing both prokaryotic and eukaryotic species, this diverse group of organisms includes both micro- and macro-algae. Algae known as picoplankton can be as small as $0.2-2.0 \mu \mathrm{m}$, but microalgae, in general, range from a few micrometers to a few hundred micrometers (Barsanti and Gualtieri, 2006). Algal biology encourages their potential for biomass cultivation; among the most photosynthetically efficient organisms, algae are non-vascular and carry out simple cell division (Amin, 2009). Most research regarding the combination of algae and wastewater treatment has focused on the growth of microalgae.

Algae have many commercial uses, including aquaculture feed, sources of pigments, oils, stable isotope-labeled biochemicals, new pharmaceuticals 
(Zaslavskaia et al., 2001), and biofuel (Xiong et al., 2010). Algae have been commercially grown for decades by the pharmaceutical and food industries, but their use for biofuel has been limited due to biological requirements. Growing algae on a large scale can necessitate large amounts of land, freshwater, and nutrients. However, coupling algae growth with wastewater treatment provides freshwater and nutrients essentially for free, while only requiring moderate space (Hoffman, 1998).

Algae can utilize ammonium, nitrate, or nitrite as a nitrogen source for growth and production of amino acids, proteins, or other cell constituents (Barsanti and Gualtieri, 2006; Lee and Lee, 2001). Although nitrate is typically the most available form of nitrogen, it appears that many species prefer ammonia for growth (Yang et al., 2000; Ogbonna et al., 2000). Algae have been shown to utilize a significant portion of ATP produced (45-82\%) for cell maintenance (Yang et al., 2000). In general, the elemental make up of algae is about $50 \%$ carbon, 10\% nitrogen, and 2\% phosphorous (Rittman and McCarty, 2001).

Although the mechanisms of phosphate metabolism in algae cultivated in wastewater are not well studied (Lee and Lee, 2001), some information is available for phosphorous partitioning within algae and wastewater.

Orthophosphate is typically the limiting nutrient in freshwater ecosystems and is readily available for uptake by autotrophic organisms (Barsanti and Gualtieri, 2006), but environmental conditions can influence the partitioning and uptake of phosphorous in algae (Powell et al., 2008). Similar to PAO, algae accumulate phosphorous in aerobic conditions and release it under anaerobic conditions, as 
it is consumed to produce energy (Rybicki, 1997). Cells may store phosphates in cytoplasmic inclusions as polymers, polysaccharides, polymerized $\beta$ hydroxybutyric acid (PHB), or fatty materials (Rittman and McCarty, 2001). Aside from utilizing phosphorous for growth, algae also store 'luxury' reserves as polyphosphate under appropriate conditions (Powell et al., 2008).

Most algae are photoautotrophic, using carbon dioxide as their carbon source, but some can survive heterotrophically, using acetate or another organic carbon source for cell metabolism (Rittman and McCarty, 2001). Some species are mixotrophic, which allows them to utilize both metabolic strategies. Each metabolic strategy is exploited in different proportions (Barsanti and Gualtieri, 2006) and little is known about the partitioning of metabolic types under varying conditions (Yang et al., 2000).

\section{Autotrophy}

Phototrophic metabolisms are energized through photosynthesis, where energy from the sun is used to reduce carbon dioxide to organic carbon (Barsanti and Gualtieri, 2006). NADPH and ATP are formed using light energy in the first step of photosynthesis, followed by the reduction of carbon dioxide in the dark reactions of the Calvin cycle. A high oxygen concentration can inhibit photosynthesis, causing the organisms to favor photorespiration (Yang et al., 2000).

Autotrophy can be summarized by the generic reaction adapted from Barsanti and Gualtieri (2006):

$\mathrm{CO}_{2}+\mathrm{H}_{2} \mathrm{O}+$ light $\rightarrow\left(\mathrm{CH}_{2} \mathrm{O}\right) \mathrm{n}+\mathrm{O}_{2}$ 
The subsequent carbon compounds produced are then later oxidized during respiration to release energy for the cell (Barsanti and Gualtieri, 2006).

Autotrophs can assimilate dissolved phosphates from their environment, incorporating them into their cell membranes, coenzymes, DNA, RNA, and ATP (Barsanti and Gualtieri, 2006). According to Agren (2004), the ratio of carbon, nitrogen, and phosphorous changes within the cell depending on the organism's growth rate. As growth rate increases, $N: C$ ratio increases linearly, while $P: C$ ratio increases quadratically. The effect of growth rate on the N:P ratio in autotrophs is not as apparent and can be affected by other environmental conditions other than nutrient supply.

Approximately $40 \%$ of ATP produced by autotrophs is formed from mitochondrial oxidative phosphorylation (Yang et al., 2000). Yang et al. (2000) found that fixing carbon dioxide used about $77 \%$ of total ATP generated by algae, making the Calvin cycle the main energy sink for autotrophic algae.

\section{Heterotrophy}

There are three main pathways of organic carbon utilization in a heterotrophic metabolism: glycolysis, pentose phosphate (PP) pathway, and TCA (tricarboxylic acid or citric acid) cycle (Yang et al., 2000). Heterotrophs, like autotrophs, increase their cellular N:C and P:C ratios at high growth rates. Their $\mathrm{N}: \mathrm{P}$ ratio decreases, however, because the cell produces more rRNA with growth, which requires an increased concentration of phosphorous (Agren, 2004). 
In a study by Yang et al. (2000) investigating algae growth via different metabolic pathways, heterotrophic cultivations yielded the most ATP, because carbon dioxide fixation was not necessary. Mixotrophic cultivations yielded the second highest amount, followed by autotrophic cultivations. Photosynthesis contributed about $63 \%$ of ATP production under mixotrophic conditions. Each type of cultivation required between $45-82 \%$ of total ATP yield for cell maintenance.

Heterotrophic or mixotrophic growth does have some practical advantages over promoting solely autotrophic growth. Algae utilizing a heterotrophic metabolism can grow in light limited areas, such as cultures with high concentrations of biomass, where an organism utilizing an autotrophic metabolism would have difficulty (Ogbonna and Tanaka, 1996), which may allow the reactor footprint to be reduced, as the depth of the culture is not limited by light penetration. Furthermore, light dependent biomass may grow in lower concentrations, making harvesting more difficult (Zaslavskaia et al., 2001). Eliminating the need to continuously mix reactors to intermittently expose the organisms to sunlight (Olguin, 2003) could decrease energy costs.

\section{Mixotrophy}

Mixotrophy occurs when a culture utilizes both an autotrophic and a heterotrophic metabolism. Culture conditions require proper light intensity and duration, as well as an organic carbon source. In a study by Yang et al. (2000), microalgae cultivated under heterotrophic conditions were able to generate the most ATP per supplied energy than those cultivated under mixotrophic or 
autotrophic conditions. However, cycling between autotrophic and heterotrophic conditions yielded the highest biomass production, as algae used the available energy most efficiently in these conditions.

\section{Synergy of Wastewater Treatment and Algae Cultivation}

Algae have the potential to help close the wastewater treatment loop on four fronts: sequestering carbon while utilizing an autotrophic metabolism, assimilating nutrients in growth and reproduction, harnessing energy for biofuel production, or reducing external inputs to the treatment process. This section summarizes a few of the most important conditions that affect algae growth, examined through conditions typical in wastewater. Figure 2 highlights the areas of potential synergy between algae growth and wastewater treatment.

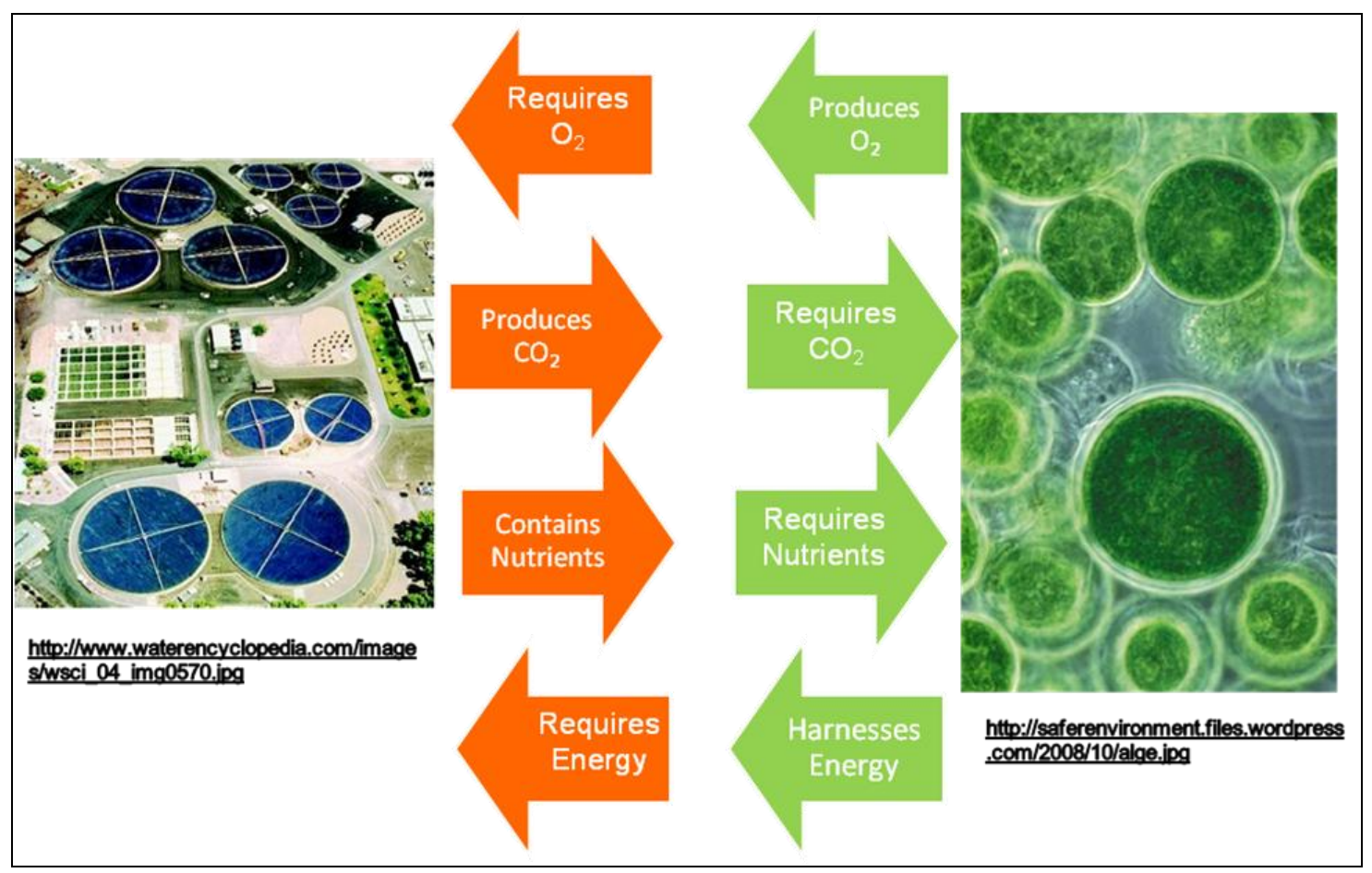

Figure 2. Areas of potential synergy between algae growth and wastewater treatment. 


\section{Environmental Conditions Affecting Growth}

Removal of nitrogen and phosphorous by algal assimilation varies depending on environmental conditions. As nutrient removal efficiency is directly related to algal productivity (Olguin, 2003), it is important to understand the environmental conditions that inhibit or promote maximum biomass yield. Environmental conditions can affect different species to varying extents, but this survey will examine overall trends throughout the algal group.

\section{Light}

Light intensity and duration can affect the specific growth rate and nutrient removal capability of algae. Photosynthetic algae are typically cultured in the laboratory under light intensities in the range of $100-200 \mu \mathrm{E} \mathrm{sec}^{-1} \mathrm{~m}^{-2}$, which is approximately equal to $5-10 \%$ of full daylight (Barsanti and Gualtieri, 2006).

Typical outdoor light intensity in equatorial areas is $2000 \mu \mathrm{E} \mathrm{sec}^{-1} \mathrm{~m}^{-2}$, which can increase specific growth rate to a certain extent. However, algae reach a light saturation point when an increase in light intensity does not increase photosynthetic activity. In fact, photoinhibition can occur if sunlight becomes too intense for the organisms, which subsequently reduces the algae growth rate (Chisti, 2007). Although it can be more intense, nutrient removal has been shown to increase when algae are exposed to natural light instead of artificial (Travieso, et al. 1995).

In some cases, higher light intensity increases specific growth rate (Lee, 2004), therefore more phosphate is consumed in metabolism and less is stored 
in the cells (Powell et al., 2008). Luxury phosphorous uptake is thereby more efficient at lower light intensities $\left(\sim 60 \mu \mathrm{E} / \mathrm{m}^{2} \mathrm{~s}\right)$ (Powell et al., 2008).

Higher light intensity can lead algae to store more carbohydrates in the cell, but carbohydrate storage could lead to night biomass loss in cyclic light/dark cultivation (Ogbonna and Tanaka, 1996); when light energy is not available, stored carbohydrates are used for metabolic processes. In fact, night biomass loss can be up to $35 \%$ of biomass produced under daylight conditions.

Decreasing the temperature at night can reduce night biomass loss, possibly due to decreased respiration (Ogbonna and Tanaka, 1996).

In two studies comparing the growth rate of Chlorella species under continuous light conditions and cyclic light/dark conditions, algae achieved a higher biomass production in a shorter time under continuous light conditions, due to biomass loss during the night in cyclic culture (Ogbonna and Tanaka, 1996; Lee and Lee, 2001). Furthermore, nutrient removal of $C$. sorokiniana was highest under aerobic light conditions (Ogbonna and Tanaka, 1996) and C. kessleri achieved a higher nitrate removal rate in continuous light cultivation compared to cyclic light/dark conditions (Lee and Lee, 2001). However, cultivation under light/dark cycles yielded slightly better phosphorus and organic carbon removal than continuous light conditions (Lee and Lee, 2001).

\section{Temperature}

Temperature can have a significant effect on all biological wastewater treatment processes, including nitrification, denitrification, and algae biomass production. In fact, each $10^{\circ} \mathrm{C}$ increase in temperature can cause specific growth 
rates to double in some species (Rittman and McCarty, 2001). Also, temperature can affect cellular composition, including fatty acid composition, protein concentration, and nitrogen to carbon ratio, which would affect nutrient requirements and uptake of microalgae (Powell et al., 2008). For example, carbohydrate content of algae increased with lower temperatures, and protein content decreased (Ogbonna et al., 1996). Most algal species are typically cultured in a temperature range of $16-27^{\circ} \mathrm{C}$ (Barsanti and Gualtieri, 2006), but can grow in the cooler temperatures typical of wastewater.

Temperature can affect phosphorus use by microalgae in a number of ways, including the rate of metabolic processes, the ionic speciation of phosphate, and the physical properties of the water (Powell et al., 2009). For example, acid nonsoluble polyphosphate, which is typically used for storage of phosphorus, is more prevalent in warmer water $\left(25^{\circ} \mathrm{C}\right)$ (Powell et al., 2008). Increased temperature also increased the percentage of phosphorous in the biomass of microalgae cultured in waste stabilization ponds (Powell et al., 2008).

Temperature can also affect the biomass loss during the night by photosynthetic algae. In a study conducted by Ogbonna et al. (1996), night biomass loss decreased when night temperatures remained a constant $30^{\circ} \mathrm{C}$ and day temperatures ranged from $25-37^{\circ} \mathrm{C}$. This temperature requirement, however, may be difficult to achieve under typical wastewater treatment conditions. $\mathrm{pH}$

Biological and chemical processes are both affected by $\mathrm{pH}$, as nutrient speciation, and therefore availability, is strongly affected by this parameter. The 
acceptable $\mathrm{pH}$ range for most algal species is between 7 and 9 , with an optimum range of 8.2-8.7 (Barsanti and Gualtieri, 2006), which is slightly higher than typical wastewater $\mathrm{pH}$. Although slight $\mathrm{pH}$ differences in wastewater have not been shown to completely inhibit algae growth, nutrient removal can be affected by high $\mathrm{pH}$ in wastewater. Ammonia removal by algae cultured in swine wastewater was inhibited by pH levels above 9 (Gonzalez et al., 2008). In a study conducted by de-Bashan and Bashan (2010), phosphate removal by immobilized C. pyrenoidosa was affected by $\mathrm{pH}$ in the range of $5-10$, whereas nitrate removal was not affected.

Autotrophic culture can affect solution $\mathrm{pH}$, which in turn can affect nonbiological nutrient removal. As autotrophic algae remove carbon dioxide from solution, the increased $\mathrm{pH}$ can encourage the volatilization of ammonia (Olguin, 2003). Elevated pH can also aid phosphorous precipitation with metal cations such as $\mathrm{Ca}^{2+}, \mathrm{Mg}^{2+}$, and $\mathrm{Fe}^{2+}$ (Powell et al., 2008), or in algal-mineral complexes (Hoffman, 1998). The addition of carbon dioxide can help mitigate elevated $\mathrm{pH}$ in high density algal culture (Barsanti and Gualtieri, 2006).

\section{Nutrient Input}

Nutrient loading can affect the use and storage of nitrogen and phosphorous during algal growth and maintenance. For instance, concentrations of ammonia up to $400 \mathrm{mg} / \mathrm{L}$ did not inhibit growth in $C$. sorokiniana, but did affect the growth of $S$. platensis, whereas high concentrations of other nutrients, such as acetate, propionate, and phosphate, did not adversely affect growth (Ogbonna et al., 2000). Similarly, manipulating nutrient concentrations in water can affect 
the biochemical composition of cells (Ogbonna and Tanaka, 1996). For example, in a study conducted by Aslan et al. (2006), chlorophyll a production increased with increasing initial influent nutrient concentrations; increased chlorophyll production may limit light penetration and thereby limit growth. However, Mulbry et al. (2008) concluded that algal biomass production increased with increasing nitrogen and phosphorous loading.

High ammonia concentrations have been shown to inhibit the growth of algae species in certain environments and affect removal rates. In one study comparing growth of three algae species in high nutrient conditions, ammonia removal rates decreased as loading rate increased (Ogbonna et al., 2000). Ogbonna et al. (2000) noted that growth of $C$. sorokiniana or $R$. sphaeroides was not inhibited up to $400 \mathrm{mg} \mathrm{N}-\mathrm{NH}_{4}+/ \mathrm{L}$, but growth of $S$. platensis was completely inhibited when concentrations exceeded $200 \mathrm{mg} \mathrm{N}-\mathrm{NH}_{4+} / \mathrm{L}$. Likewise, photosynthetic cultures of $C$. sorokiniana grown in aerobic conditions were inhibited by high ammonium concentrations (up to $1180 \mathrm{mg} \mathrm{N}-\mathrm{NH}_{4}+$ per liter) in piggery wastewater with high pH (Gonzalez et al., 2008).

Nitrate concentrations do not appear to affect algal growth to the extent that high ammonia concentrations can. Lee and Lee (2001) concluded that growth of $C$. kessleri was not inhibited by nitrate concentrations up to 149.9 $\mathrm{mg} / \mathrm{L}$, and Ogbonna et al. (2000) concluded that the growth of the three species mentioned in the above paragraph was not inhibited even up to concentrations of $700 \mathrm{mg} / \mathrm{L}$. 
In a study by Ogbonna et al. (2000), ammonia appeared to be the preferred nitrogen source, as nitrate was only utilized when ammonia was no longer available. On the other hand, nitrogen limiting environments can trigger carbohydrate accumulation in cells, which could lead to biomass loss in cyclically cultivated (light/dark) Chlorella cells (Ogbonna and Tanaka, 1996).

High concentrations of phosphorous have been shown to be less inhibitive to algal growth than high nitrogen concentrations. In fact, algae have been successful at removing phosphorous from high strength wastewater. For example, $C$. vulgaris removed from $30-55 \%$ of phosphates, depending on incubation time, in dairy and pig farming wastewater with initial total phosphorous concentrations up to $111 \mathrm{mg} / \mathrm{L}$ (Gonzalez et al., 1997). Likewise, phosphate concentrations up to $100 \mathrm{mg} / \mathrm{L}$ did not significantly affect the growth or removal rate of three algal species studied by Ogbonna et al. (2000). B. braunii was also able to successfully remove nitrate and phosphate from pretreated domestic and piggery wastewater (Metzger and Largeau, 2005). C. vulgaris, immobilized in polyurethane cubes and submerged in pretreated cattle manure, was able to remove between $48-64 \%$ of orthophosphate, with influent orthophosphate concentration of $34 \mathrm{mg} / \mathrm{L}$ (Travieso et al., 1995). In fact, a high initial phosphate concentration may trigger microalgae to store 'luxury' reserves (Powell et al., 2009).

Typical domestic wastewater influent characteristics fall within the range that algae can tolerate. Total nitrogen is typically around $50 \mathrm{mg} / \mathrm{L}$, with about 30 $\mathrm{mg} / \mathrm{L}$ as ammonia. Total phosphorus can range from $10-16 \mathrm{mg} / \mathrm{L}$, with most 
phosphorous as orthophosphate (Henze et al., 2002). As demonstrated in the studies mentioned above, algae can also tolerate higher nutrient concentrations associated with agricultural waste.

\section{Lipid Production}

Environmental conditions and availability of metabolic constituents can affect lipid production and quality within algae. Algae typically produce lipids when carbon is present in excess but another nutrient, such as nitrogen, is limited (Ratledge and Cohen, 2008). Likewise, the fatty acid composition of lipids in cells cultivated under different metabolic environments varies depending on cultivation method (Yang et al., 2000). Heterotrophic lipid production is more efficient in nitrogen-limited environments, but phototrophic cultivation requires more abundant nitrogen (Xiong et al., 2010). Algae cultivated under heterotrophic conditions have been shown to produce more lipids than autotrophically cultivated cells (Tran et al., 2010), yielding 55.2\% compared to $14.57 \%$ lipids respectively (Miao and Wu 2004), and the resulting bio-oil is of higher quality.

Heterotrophic cultivation may be more efficient for producing lipids because these cells do not need chlorophyll. In a study by Xiong et al. (2010) where cultivation switched from phototrophic to heterotrophic conditions, the amount of chlorophyll within the algae cells decreased from 0.45 to $0.029 \mathrm{mg} / \mathrm{g}$ dry cell weight over a time period of 120 hours. When thylakoid membranes in chloroplasts disappeared within 48 hours after switching to heterotrophic conditions, large lipid droplets appeared within the cytoplasm. In another study 
by Miao and Wu (2004), no chlorophyll was detected in heterotrophic cells after 120 hours of cultivation.

Mixotrophic cultivation has also shown to be successful in producing lipids as cells can take advantage of multiple carbon sources. Lipid production in $C$. protothecoides reached up to $58.4 \%$ of dry cell weight under an optimized autotrophic-fermentation cultivation model that used glucose as the carbon source in fermentation (Xiong et al., 2010). The increased lipid production was attributed to the continued fixing of carbon dioxide by Rubisco while cells simultaneously fermented sugar. In a strictly heterotrophic environment, the carbon dioxide released was a net loss of carbon. In the mixtotrophic cultivation, however, the cells were able to refix the carbon dioxide and route it to lipid production, decreasing the net carbon release (Xiong et al., 2010).

Autotrophic cultivation does have its advantages as well. Botryococcus braunii, microalgae with up to $80 \%$ of dry mass as lipids, has been shown to increase doubling time and hydrocarbon production with the introduction of air enriched with carbon dioxide (Tran et al., 2010).

Table 1 shows reported lipid yields of different algae species according to various studies. It is generally accepted that a lipid content of $40 \%$ by dry weight is needed for oil extraction and processing to be considered economically viable (Ratledge and Cohen, 2008). The key to economical lipid production is to maximize biomass growth; however, many fast growing organisms contain less than $20 \%$ of their dry weight as lipids, and species with high lipid contents (40$50 \%$ of dry weight) are generally slow growers (Xiong et al., 2010). 
Table 1. Varying lipid content per cell dry weight among algae species reported in different studies.

\begin{tabular}{|l|l|c|c|}
\hline \multicolumn{1}{|c|}{ Species } & \multicolumn{1}{c|}{ Source } & H/A & \% Lipids/DW \\
\hline B. braunii & Qin 2005, Metzger 2005 & A & $15-76$ \\
\hline Chlorella sp & Tran et al. 2010 & A & $25-32$ \\
\hline I. galbana & Ratledge and Cohen 2008 & A & $22-38$ \\
\hline H. pluvialis & Ratledge and Cohen 2008 & A & $30-40$ \\
\hline Nannachloropsis sp & Ratledge and Cohen 2008 & A & $31-68$ \\
\hline Nitzschia sp & Ratledge and Cohen 2008 & A & 45 \\
\hline P. incisa & Ratledge and Cohen 2008 & A & $30-45$ \\
\hline P. carterae & Ratledge and Cohen 2008 & A & 33 \\
\hline C. protothecoides & $\begin{array}{l}\text { Miao and Wu 2004, Xiong et } \\
\text { al. 2010 }\end{array}$ & H & $53-57.9$ \\
\hline
\end{tabular}

Note: 'A' denotes autotrophic cultivation; ' $\mathrm{H}$ ' denotes heterotrophic cultivation.

As described above, lipid production can be somewhat unpredictable, depending on the environmental characteristics. Further research is needed in this area to determine optimal lipid production in wastewater conditions. However, because wastewater is typically not nutrient limiting, high lipid production may not be viable; to the knowledge of the author, this has not yet been demonstrated.

\section{Carbon Dioxide Retrieval}

Almost half of the dry weight of algae is carbon, which often originates as carbon dioxide. Due to the stoichiometric relationship of algae synthesis, algae has the potential to fix 183 tons of carbon dioxide per ton of biomass produced (Chisti, 2008). Furthermore, by replacing a $100 \mathrm{MW}$ coal thermal plant with liquid fuel from microalgae, $1.5 \times 10^{\wedge} 5$ tons of carbon dioxide per year would be mitigated (Tran et al., 2010). Autotrophic algal growth can reduce the carbon footprint of a wastewater treatment plant by sequestering carbon to offset energy needs of treatment. 


\section{Oxygen and Chemical Demand Reduction}

Typical wastewater treatment plants run their aeration basins with a dissolved oxygen (DO) concentration between 4-10 mg/L (Bitton, 1994). The plant modeled in this study maintains a DO concentration of $9.5 \mathrm{mg} / \mathrm{L}$ in the pure oxygen basin and $6 \mathrm{mg} / \mathrm{L}$ in the nitrification basin. When cultivated in photobioreactors, algae have demonstrated an oxygen production up to $10 \mathrm{~g} \mathrm{O}_{2}$ per $\mathrm{m}^{3}$ per min (Chisti, 2008), which could help alleviate aeration requirements in aerobic reactors, thereby reducing energy needs and costs.

Likewise, the demand for methanol or other external carbon sources for denitrification is reduced as algae uptake nitrate. Reduced need for methanol reduces plant external input costs, storage requirements, and operating needs.

\section{Secondary Use of Algae Biomass}

Algae cultivation has recently attracted more attention because the biomass produced can be used for a number of secondary products, with benefits that help close the nutrient and energy cycle of conventional water treatment. If coupled with wastewater treatment, algae do not compete with food crops for arable land and nutrient supply is virtually unlimited. Some species maintain a high lipid content, making them candidates for biofuel production. Algae biomass itself can also be processed into fertilizer or digested to produce biogas. Other products are possible, such as animal feed, but only biofuel, biogas, and fertilizer will be analyzed in this model.

Harvesting methods are an important area of current research and can create a bottleneck to algae cultivation. Physical means, such as microscreens, 
centrifugation, or flocculation can be used for harvesting algae (Molina Grima et al., 2003), or chemical means, such as chitosan, alum, or ferric chloride can be used to flocculate the biomass (Amin, 2009). Other innovative means utilizing natural processes such as evaporation are helping to bring costs down (Silberman, 2010), while reducing carbon dioxide concentration may also cause algae to autoflocculate (Amin, 2009). An appropriate harvesting method is important, however, in maintaining low processing costs, and sustaining a concentrated biomass typically helps keep these costs down (Chisti, 2007).

\section{Biodiesel}

Biodiesel is manufactured by transesterification, which occurs when an alkoxy group is switched with an alcohol in an ester compound. Catalyzed by an acid or base, the oil combines with alcohol to form esters and glycerol (Amin, 2009), and the solvent used to extract the oil from the biomass can be recovered and recycled (Chisti, 2007). This process is already utilized to produce biodiesel from vegetable oil or animal fat. Many other extraction methods, such as using multiple solvents, enzymes, osmotic shock, or carbon dioxide, have been developed, some allowing more than $95 \%$ retrieval of the oil present in the algae (Amin, 2009). Algae can also be thermochemically converted to fuel through gasification, pyrolysis, and liquefaction (Amin, 2009).

Bio-oil produced using pyrolysis of algae cells yielded an oil product more suited for fuel and closer to the properties of fuel-oil than oil from lignocellulosic materials, such as woody plants (Miao and Wu, 2004). An energy consumption ratio that compares the amount of energy required for fast pyrolysis to the 
amount of energy produced in the process demonstrated that fast pyrolysis was a net energy producer for both heterotrophic and autotrophic cells (Miao and Wu, 2004). Furthermore, fast pyrolysis extracted approximately $58 \%$ of dry weight from microalgae, compared to $49 \%$ of dry weight of pine wood, cotton straw and stalk, and sunflowers (Tran et al., 2010). Biodiesel produced from algae have shown similar properties to diesel fuel (Amin 2009).

Biodiesel is subject to standards in both the United States and European Union that restrict the amount of fatty acids that contain four or more double bonds, as these bonds can oxidize in storage. Although vegetable and algal oils tend to have higher amounts of double bonded fatty acids, partial catalytic hydrogenation can help mitigate the amount (Chisti, 2007). Biodiesel production can be expensive, but the costs can be recovered by selling the residual algae biomass for tertiary uses (Chisti, 2008).

Biogas

Biogas can be produced through anaerobic digestion of residual algal biomass, similar to how anaerobic digesters treating sludge are currently utilized at many wastewater treatment plants. The resulting biogas contains methane and carbon dioxide, which can be bubbled back into the algae reactor as a carbon source or burned for energy. Depending on the type and quality of the biomass, biogas yield ranges from 0.15 to $0.65 \mathrm{~m}^{3}$ per $\mathrm{kg}$ of dry biomass, containing an energy content of between $16,200 \mathrm{~kJ}$ per $\mathrm{m}^{3}$ to $30,600 \mathrm{~kJ}$ per $\mathrm{m}^{3}$ (Chisti, 2007). 
Furthermore, algae cells do not have the lignin and cellulose that other plant derived feedstock may have, making them easier to break down (Zamalloa et al., 2010). Also, the higher lipid content of certain species can yield more methane per gram of biomass during digestion than cells higher in proteins or carbohydrates (Zamalloa et al., 2010). However, although preliminary research shows that digestion of algae cells may take longer than conventional feedstock due to the degradability of the cell wall, further research is needed to optimize this process (Zamalloa et al., 2010).

\section{Fertilizer}

Algae biomass has comparable properties and thereby produces similar results as commercial fertilizers. Corn and cucumber seedlings grown in commercial potting mix augmented with either algal biomass or commercial fertilizer showed no significant difference in seedling mass, suggesting that algal biomass is an adequate substitute for commercial fertilizers (Mulbry et al., 2005).

Utilizing algal biomass has a number of advantages over land applying conventional fertilizers. Applying dry biomass to fields prevents ammonia volatilization that occurs with land applied manure. Algal biomass can also be applied without tilling, which allows for fertilization while crops are growing. The use of algae fertilizers also keeps heavy metals concentrations well below the limit mandated by the US EPA Part 503 biosolids rule (Mulbry et al., 2005; Mulbry et al., 2008). Further, a study conducted by Mulbry et al. (2006) suggests that nitrogen mineralization from algal biomass is more predictable than that of manure, making fertilizer application more reliable and reducing the threat of 
nutrient pollution. Algal biomass can be easily and safely stored between applications, and is less likely to contain pathogenic material than composted manure (Wilkie and Mulbry, 2002).

\section{Summary of Background}

Algae growth in wastewater treatment has many facets, making it a complex and somewhat unpredictable process. However, the potential benefits for this marriage in closing the nutrient and energy loop in conventional wastewater treatment are substantial. Algal biology is compatible with conditions inherent in municipal and some industrial wastewaters, allowing for the chance to exploit this renewable resource.

Although incorporating algae into wastewater treatment adds operational costs, the potential benefits may outweigh this added expense. While numerous studies have been conducted on algae growth within wastewater, as well as some calculations of the economics of processing and growing the biomass, little has been studied on combining the economics of the process with the biology. The model presented in this thesis will attempt to provide a macro-scale view of the synergy between wastewater treatment and algae, and evaluate the potential costs and benefits viewed from biological and market constraints. 


\section{Chapter Three:}

\section{Model Framework}

\section{General Model Background}

Models have long been used to gain a better understanding of wastewater treatment processes. Although these models have become quite sophisticated over time, they still have many limitations, which can restrict their widespread application (Gernaey and Sin, 2008). However, models continue to be a useful tool in predicting influent and effluent characteristics and biological responses to environmental conditions.

According to Gernaey et al. (2004), there are important steps in creating a valid model, including: defining the purpose of the model, selecting the proper model, collecting data, reconciling the data, and calibrating and unfalsifying the model. The purpose of the model will mainly steer the outcome of the subsequent steps. It is also important to understand the model's assumptions and simplifications to ensure it is applied properly within its boundaries.

This chapter will discuss the purpose of the model, the model framework and equations, and how the framework provides a connection between wastewater, algae, and macroeconomics. 


\section{STELLA Software}

This model is built within the Systems Thinking Experimental Learning Laboratory with Animation (STELLA) software version 9.1.3 (@ 1985-2009, ISEE systems). STELLA uses a multilayer approach to model building, including an equation, model, map, and interface layer. Each layer allows the user to oversee a different aspect of the model, creating manageable mechanisms for keeping track of variables.

Although STELLA software is typically used for environmental systems models, its user-friendly interface allowed the end-product to be highly interactive with inexperienced users. This was an important goal of the study; as many parameters within the model framework are subject to change considerably (i.e. specific growth rates, influent characteristics), it was imperative that it have the flexibility to adapt to individual circumstances, conditions, or case studies.

STELLA software was chosen to build the model due to the flexibility of the system components. Because STELLA does not have predefined processes and systems, a model could be constructed from scratch, adapting it to the unique goal of investigating a mass balance relationship in a macroeconomic framework. The interaction between system variables, including carbon, nitrogen, phosphorous, biomass, and economic outputs could all be simultaneously investigated in one software package.

STELLA models have unique individual components that come together to illustrate relationships between inputs and variables. The general components, shown in Figure 3, are described as follows: 
Figure 3. Basic components of a STELLA model.

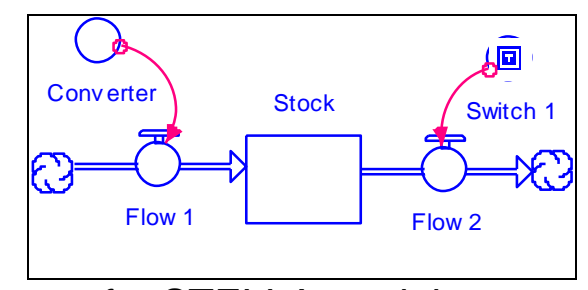

Stocks represent the accumulation portion of the model. Their value is equal to the inflows minus the outflows. Stocks can be related to or affected by any other variable within the model.

Flows link the relationship between two stocks, or represent a process inflow or outflow. Their main purpose is to keep materials flowing within the model, i.e. to deplete accumulation. Although flows can be uniflow or biflow, all flows within this model are uniflow. Flows can only be affected by or related to variables directly connected to them.

Converters serve a number of roles within the model framework. They can hold a constant value, receive external inputs, or perform algebraic calculations. As stated by STELLA, they "convert inputs to outputs," which is where they get their name. Converters can be related to or affect only those items directly connected to them.

Switches are converters that can trigger other specified converters to turn on or off. Multiple switches were installed in the model to turn on and off flow to the algae basin or select the desired secondary product process train. 


\section{Conceptual Approach}

The model was designed after the HFCAWTP, a BNR plant in Tampa, FL. Further discussion of the layout of the plant can be found in Chapter 2. Figure 4 shows the portion of the plant that is the focus of the model, specifically the BOD removal basin, the nitrification basin, and the denitrification basin. Sedimentation tanks follow the first two stages of the treatment process, but their individual contributions were not considered in this model. Overall removal of BOD, ammonia, and nitrate as individual stages was considered, which did take into account settling of constituents within these basins.

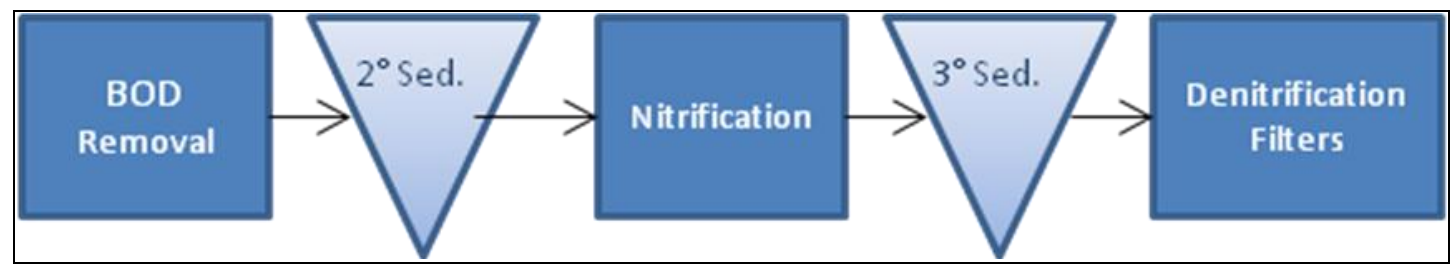

Figure 4. Schematic of the section of the treatment process at the HFCAWTP modeled in this study. Sedimentation basins were not considered individually, but removal rates due to settling were considered.

The model can be conceptually separated into two groups: the wastewater treatment processes and the algae production processes. The two groups are linked by water and nutrient flow within the system. Mass balances were maintained within each nutrient group as described within each section. Figure 5 shows the conceptual framework of the movement of constituents and processes included in the model. Three treatment basins were modeled, representing a pure oxygen BOD removal reactor, a nitrification reactor, and a denitrification reactor. Clarifiers and anaerobic digesters were not included in the analysis. 


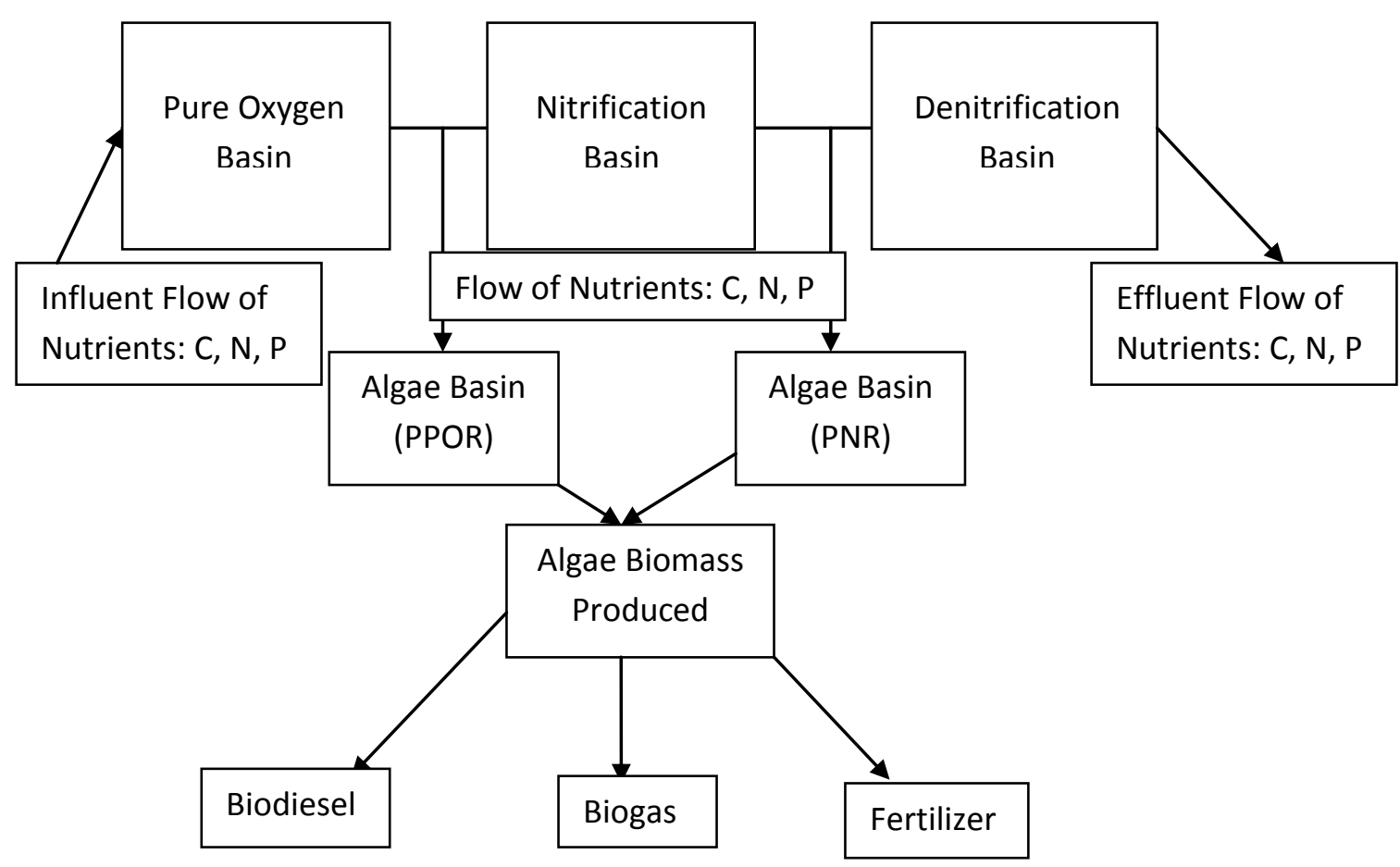

Figure 5. Conceptual framework of model components. Post-clarifier flow between the reactors is diverted to the interstage algae basins: PPOR, the postpure oxygen reactor, and the PNR, post-nitrification reactor. Potential biomass production can be evaluated under various conditions. Results are then analyzed economically in one of three process trains: biodiesel, biogas, or fertilizer.

Two algae basins were incorporated into the conventional treatment process train: a post-pure oxygen reactor (PPOR) and a post-nitrification reactor (PNR). An economic analysis was then conducted on turning the potential biomass produced into biodiesel, biogas, or fertilizer.

\section{Practical Approach}

The conceptual model was built with STELLA software to create a user friendly, flexible model. Although the model is based on a case study of a BNR plant in Tampa, Florida, it can be easily adapted to represent other facilities. The model framework, variables, and inputs are described below. 


\section{Wastewater Framework}

The movement of nitrogen, phosphorous, and carbon species were tracked within the model. Within each nutrient group, subgroups were defined as described in Table 2. Nutrients were tracked to maintain a mass balance, following speciation changes within each subgroup, as described below.

Table 2. List of nutrient groups tracked within the model and their associated species.

\begin{tabular}{|c|l|l|l|}
\hline Nutrient Group & $\begin{array}{l}\text { Model } \\
\text { Nomenclature }\end{array}$ & Model Group & Species Included \\
\hline \multirow{3}{*}{ Phosphorous } & $\mathrm{P} 1$ & soluble P & phosphates \\
\cline { 2 - 4 } & $\mathrm{P} 2$ & nonsoluble P & phosphate complexes \\
\hline \multirow{4}{*}{ Nitrogen } & $\mathrm{N} 1$ & organic N & organic nitrogen \\
\cline { 2 - 4 } & $\mathrm{N} 2$ & $\mathrm{NH}_{3}$ & ammonia \\
\cline { 2 - 4 } & $\mathrm{N} 3$ & $\mathrm{NO}_{\mathbf{x}}$ & nitrate/nitrite \\
\cline { 2 - 4 } & $\mathrm{N} 4$ & nitrogen gas & $\mathrm{N}_{2}$ \\
\hline \multirow{4}{*}{ Carbon } & $\mathrm{C} 1$ & Soluble & dissolved organics \\
\cline { 2 - 4 } & $\mathrm{C} 2$ & Nonsoluble & unavailable carbon \\
\cline { 2 - 4 } & $\mathrm{C} 3$ & cellular carbon & carbon assimilated \\
\cline { 2 - 4 } & $\mathrm{C} 4$ & carbon dioxide & $\mathrm{CO}_{2}$ \\
\hline
\end{tabular}

Data from the HFCAWTP was analyzed to determine average removal rates. Effluent concentrations were subtracted from the influent concentrations and the difference was divided by influent concentrations in order to determine the percent removal of each nutrient. Ammonia, nitrate/nitrite, and soluble carbon species were tracked in this manner as illustrated

Removal Rate $(\%)=\left(\mathrm{S}_{\circ}-\mathrm{S}_{\text {eff }}\right) / \mathrm{S}_{0}$

where $S_{o}$ and $S_{\text {eff }}$ are the substrate influent and substrate effluent concentrations, respectively. Because the plant does not have a designated phosphorous 
removal process, the only soluble phosphorous removal mechanism considered was algae assimilation.

Wastewater kinetics were determined based on plant data from the HFCAWTP. Plant data was analyzed to determine average removal rates of carbon, nitrogen, and phosphorous within each basin. To maintain overall nutrient mass balance, the disappearance of one species triggered the appearance of another. For example, during denitrification, the removal of ammonia from the system indicated an increase of $\mathrm{NO}_{\mathrm{x}}$.

Temperature and available substrate were not directly included in the model for nitrification and denitrification rates, but would be reflected in plant data. Appropriate removal rates for the season under investigation should be selected to ensure adequate representation of removal efficiency under desired conditions. Because nutrient removal rates are derived from plant data, decay of bacteria and subsequent release of nutrients is considered to be included in removal rate calculations.

Methanol $\left(\mathrm{CH}_{3} \mathrm{OH}\right)$ was chosen as the organic carbon source because the HFCAWTP is currently using it for denitrification. Furthermore, it is readily available to most treatment plants and the most widely used external carbon source. Due to its high biodegradability, it yields the highest denitrification rate of the most commonly used energy sources (Henze et al., 2002).

Because the model is assuming that influent wastewater is of domestic origin, toxicity within the water is assumed to be negligible, and is therefore not included in the analysis (Henze et al., 2002). Likewise, it is assumed that only 
nitrogen, phosphorous, and carbon will limit algae growth, and other constituents, such as heavy metals, are not present in high enough concentrations to inhibit growth.

\section{Water Balance}

Water flow was tracked as shown in Figures 7, 8A, 8B, and 9 to monitor mass balance. Figure 6 below shows the interface where flow and basin characteristics can be defined by the user. Influent flow is entered on the interface of the model in gallons per day. The model calculates the flow to liters per day via a converter, ensuring all flows would be in liters per time throughout model calculations. Reactor volumes, in liters, were also entered on the interface.

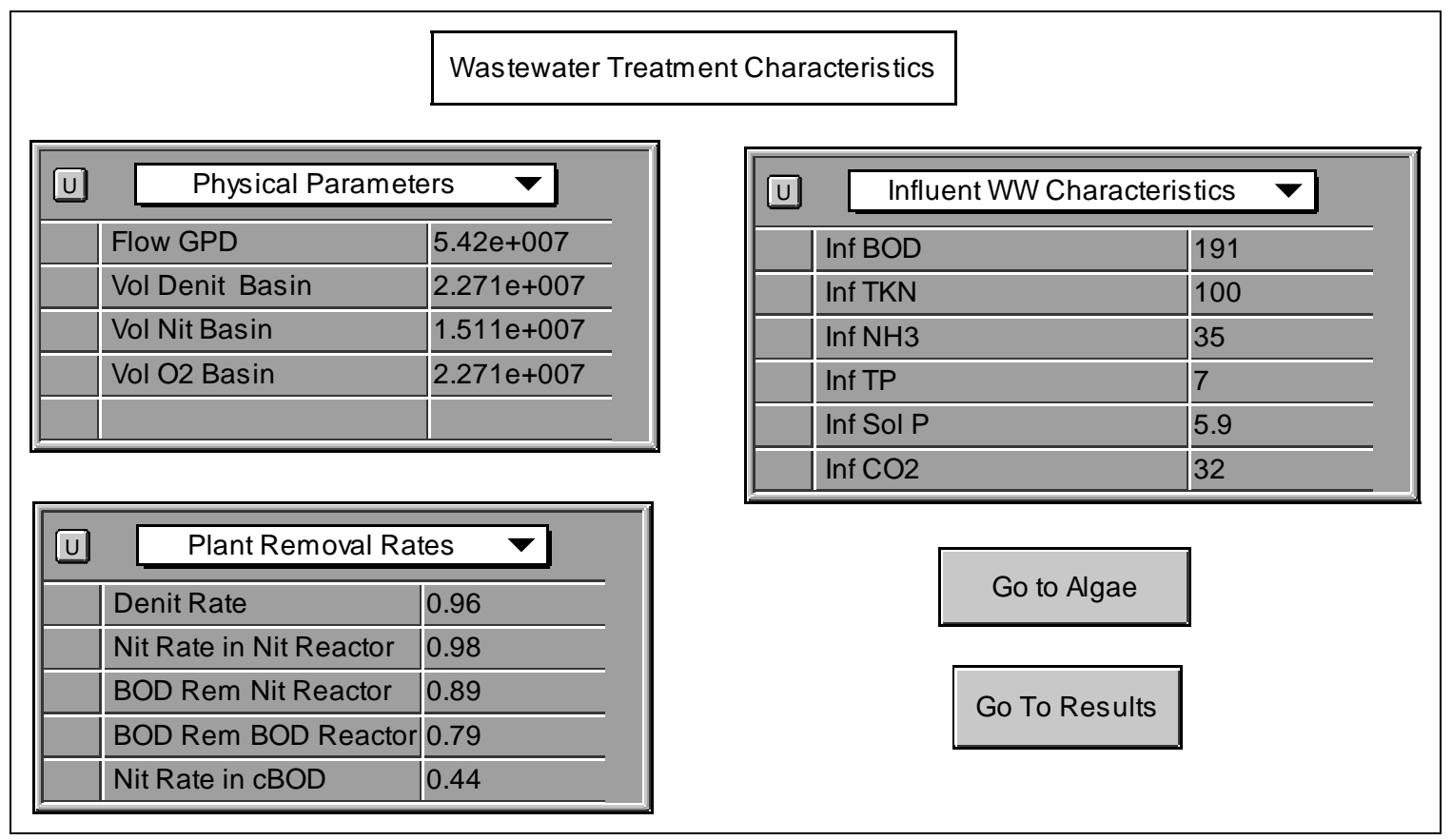

Figure 6. Model interface for manipulating physical parameters of the treatment plant and influent flow characteristics. 
Water flow followed the conceptual path as shown in Figure 7. Flow to algae was diverted to the PPOR before the nitrification reactor and returned to the nitrification reactor. Similarly, flow was diverted after the nitrification reactor to the PNR and returned to the denitrification reactor.

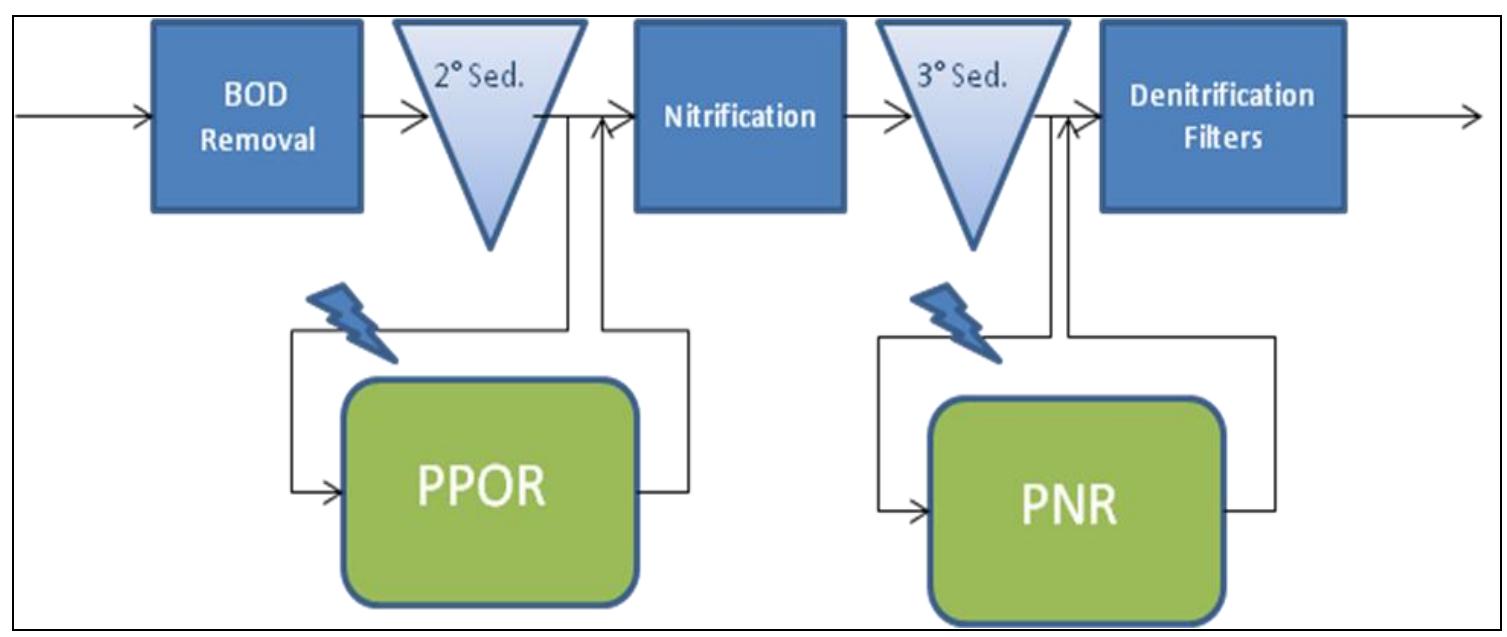

Figure 7. Conceptual flow of water through treatment plant and algae reactors. Lightning bolts signify locations of 'switches' or valves to control flow to algae reactors.

Water flow was tracked in the model by the framework shown in Figures $8 \mathrm{~A}$ and 9 . Water flow to the algae reactors was controlled by two switches that turned the flow 'on' or 'off' based on the user defined selection on the interface. The user could also determine how much flow would be diverted to the algae reactors. A percentage of flow was considered lost during the harvesting stage; this value could also be entered on the user interface (see Figure 17). This loss was removed from the wastewater treatment flow, but tracked in a separate train to ensure mass balance was maintained, as shown in Figure 9. This flexibility allows the user to account for water loss via harvesting and intracellular 
assimilation. The model currently does not explicitly model the harvesting process, but in future versions, the water will be returned to the headworks.

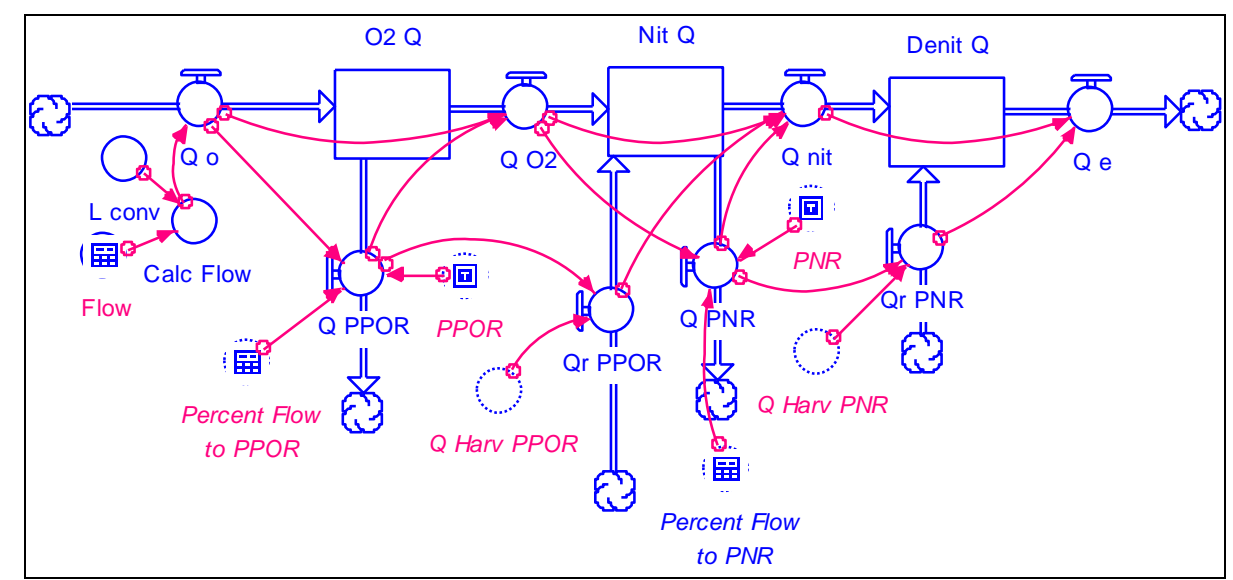

Figure 8A. Model framework for water flow in STELLA model. See Tables A1 and A2 in Appendix A for full list of variables and equations.

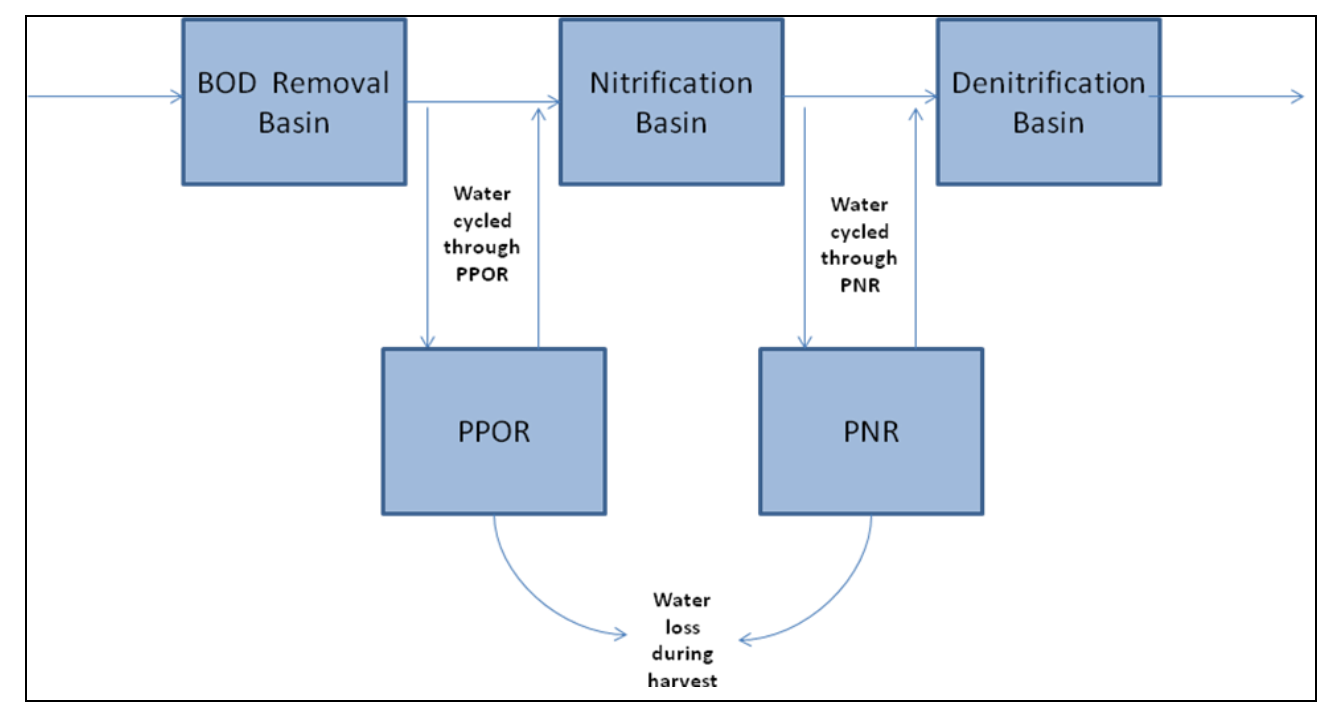

Figure 8B. Conceptual water flow in STELLA model. This conceptual figure illustrates the movement of water in Figures $8 \mathrm{~A}$ and 9. 


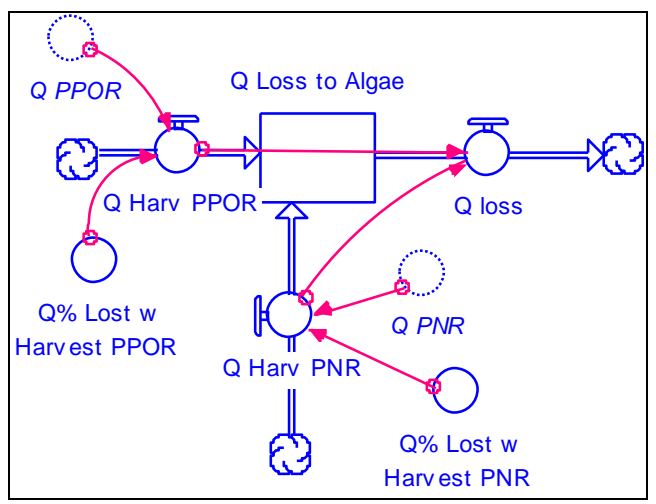

Figure 9. Model framework for water loss due to algae harvesting. See Tables A3 and A4 in Appendix A for full list of variables and equations.

Nutrient availability by mass was calculated based on the flow and nutrient concentration within the water flow. All nutrients were considered available for Monod growth equations and those assimilated were subtracted from overall nutrient concentration on a stoichiometric basis, as described below.

\section{Carbon Balance}

Carbon species were tracked in four parallel trains, one for each species: soluble carbon (C1), nonsoluble carbon (C2), cellular carbon (C3), and carbon dioxide (C4). Influent carbon is entered on the interface as BOD; this value was subsequently connected to the influent flow of the soluble carbon train. (See Figure 6 for interface diagram). Carbon dioxide concentration is also entered in the interface; cellular and nonsoluble carbon are changed within the model framework only.

Figure $12 \mathrm{~A}$ shows the framework for the carbon species. Influent flow was multiplied by the influent concentrations, resulting in each species having the units of mass/time, as shown in the generic equation below:

$C \mathrm{mg} / \mathrm{L} \times Q \mathrm{~L} /$ day $=W \mathrm{mg} /$ day 
where $C$ is concentration of any constituent (i.e. nonsoluble carbon, cellular carbon, etc.), $Q$ is the flow of water through the system, and $W$ is the mass of the substrate (i.e. nonsoluble carbon, cellular carbon, etc.) per unit time.

The removal rate of BOD was calculated based on plant data, as described above. During a biological reaction, electrons flow from the electron donor to either synthesize biomass or reduce an electron acceptor, as shown in Figure 10. The fraction of electrons routed to synthesizing biomass is $f_{s}$, and the fraction of electrons routed to reducing an electron acceptor is $f_{e}$. The sum of $f_{s}$ and $f_{e}$ is equal to 1 (Rittman and McCarty, 2001).

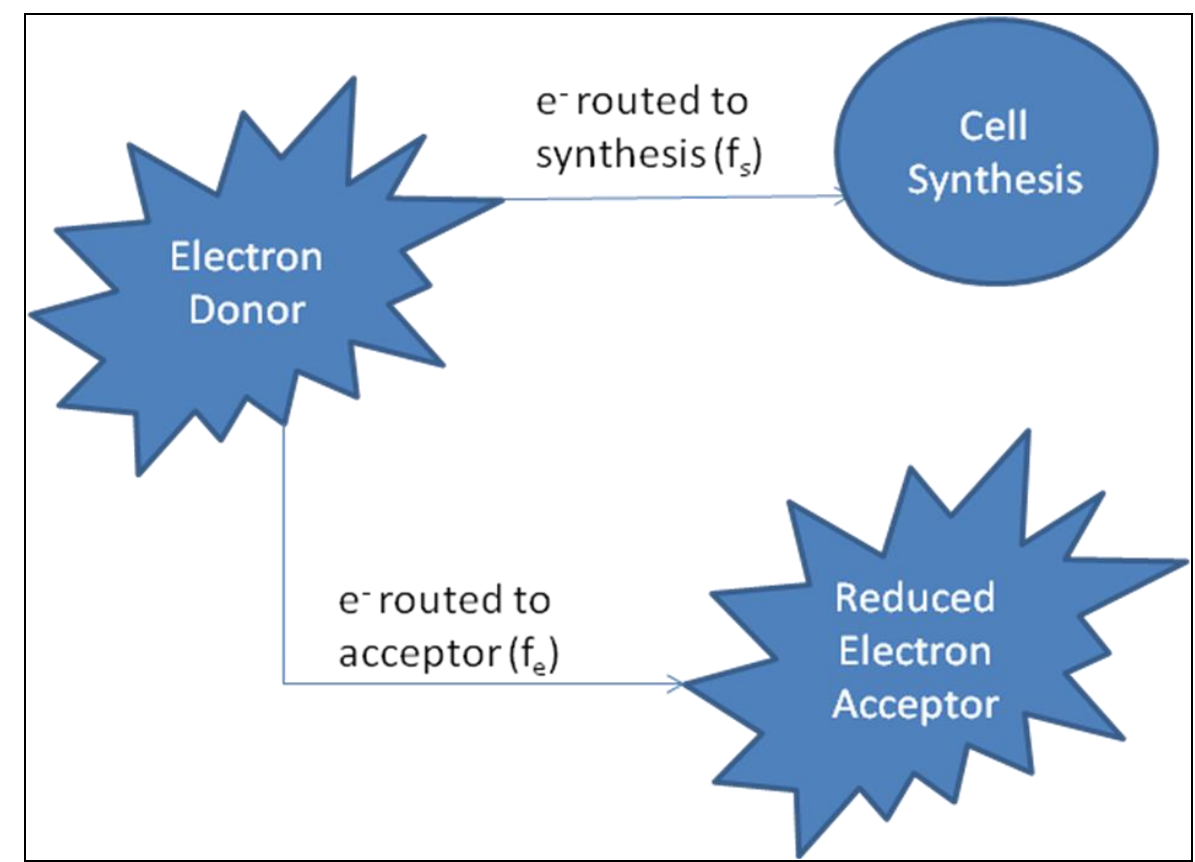

Figure 10. Routing of electrons from an electron donor, such as BOD. Electrons are routed to biomass synthesis $\left(f_{s}\right)$ and reducing an electron acceptor $\left(f_{e}\right)$.

The partitioning of electrons is important when determining a complete reaction from redox half reactions. The electron acceptor half reaction is multiplied by the $f_{e}$, and the synthesis half reaction is multiplied by the $f_{s}$. The 
electron donor half reaction is added to the resulting electron acceptor and synthesis half reactions to obtain the overall reaction $(R)$, as shown in Equation

$R=f_{e}{ }^{\star} R_{a}+f_{s}{ }^{*} R_{c}+R_{d}$

$\mathrm{BOD}$ is an electron donor; during its removal, some electrons are routed to algae synthesis $\left(f_{s}\right)$, whereas another fraction is used to reduce an electron acceptor $\left(f_{e}\right)$. An $f_{s}$ of 0.73 and $f_{e}$ of 0.27 was used to determine how the soluble carbon removed was partitioned into cellular carbon and carbon dioxide. The $f_{s}$ and $f_{e}$ values were multiplied by the removal rate as determined by plant data to determine final end product mass. Figure 12A shows where soluble carbon (C1) was converted to cellular carbon (C3) and carbon dioxide (C4) in the pure oxygen and nitrification basins.

Carbon dioxide was removed from the system based on the stoichiometry of algae growth. This will be further defined in the Algae Processes section of this chapter.

Mass balance was tracked as shown in Figure 11A. Influent carbon species were added together to track the total mass of influent carbon. The mass of carbon species leaving the denitrification basin (i.e. soluble, nonsoluble, cellular, and carbon dioxide) were added to the mass of carbon assimilated in algae in order to maintain mass balance through the system. 


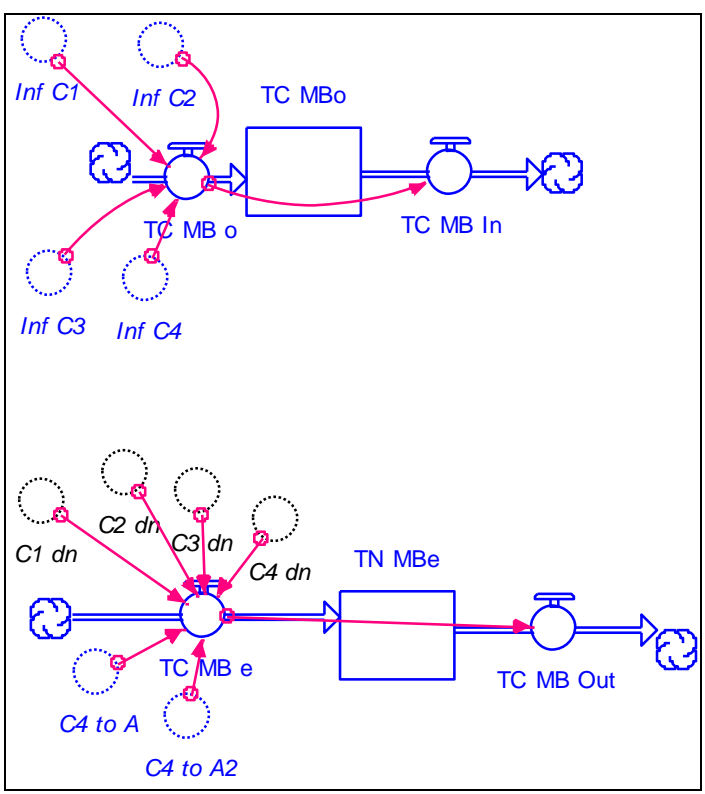

Figure $11 \mathrm{~A}$. Mass balance of carbon species. Total influent carbon was compared to total effluent carbon species using the framework above. TC MB In and TC MB Out were plotted on graphs and numerically monitored to maintain mass balance throughout different simulations. See Tables A19 and A20 in Appendix A for full list of variables and equations.

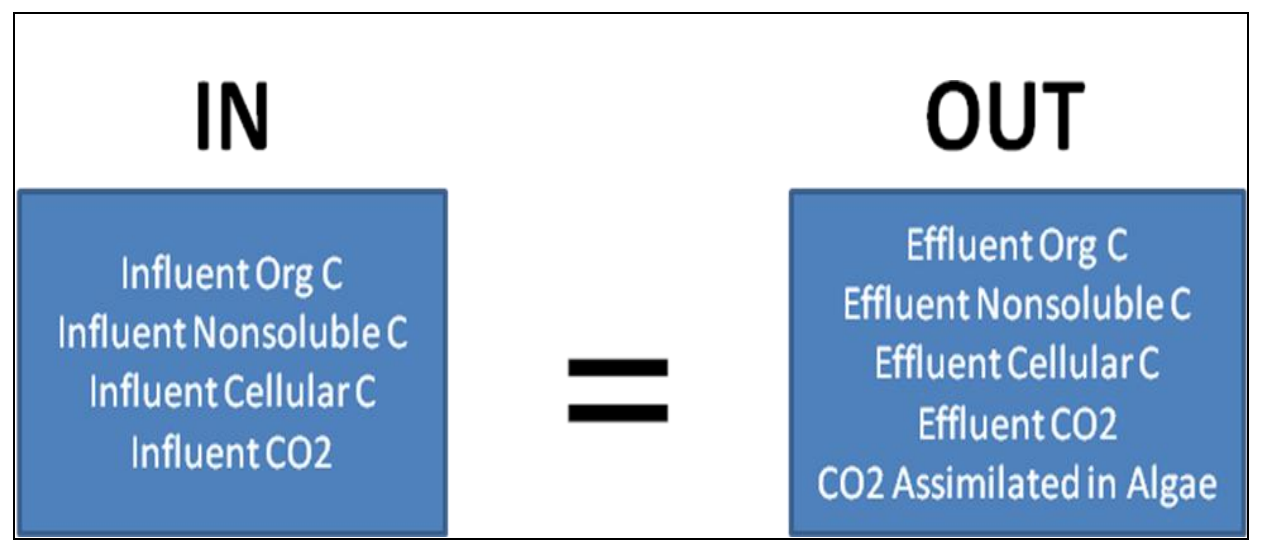

Figure 11B. Conceptual figure of carbon mass balance. This figure illustrates how the mass balance was tracked using the STELLA framework in Figure 11A. 


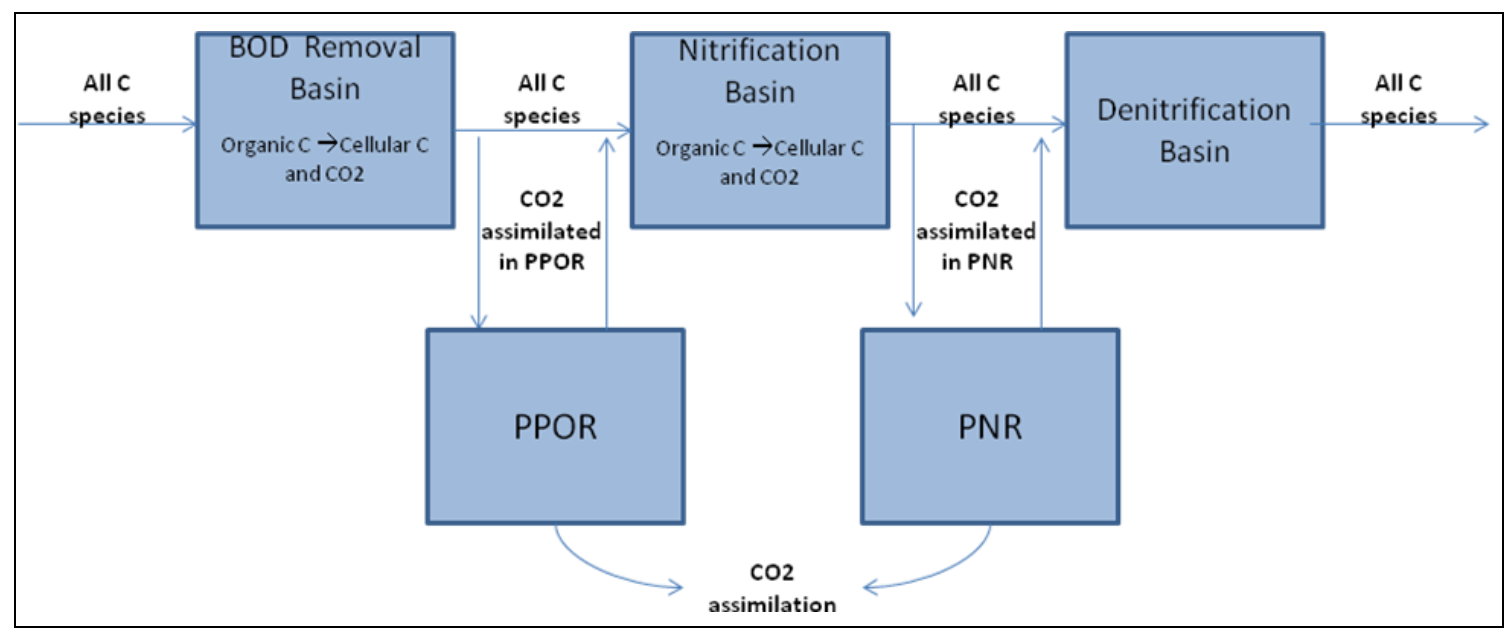

Figure 12A. Conceptual figure of carbon flow through the STELLA framework shown in Figure 12B. 


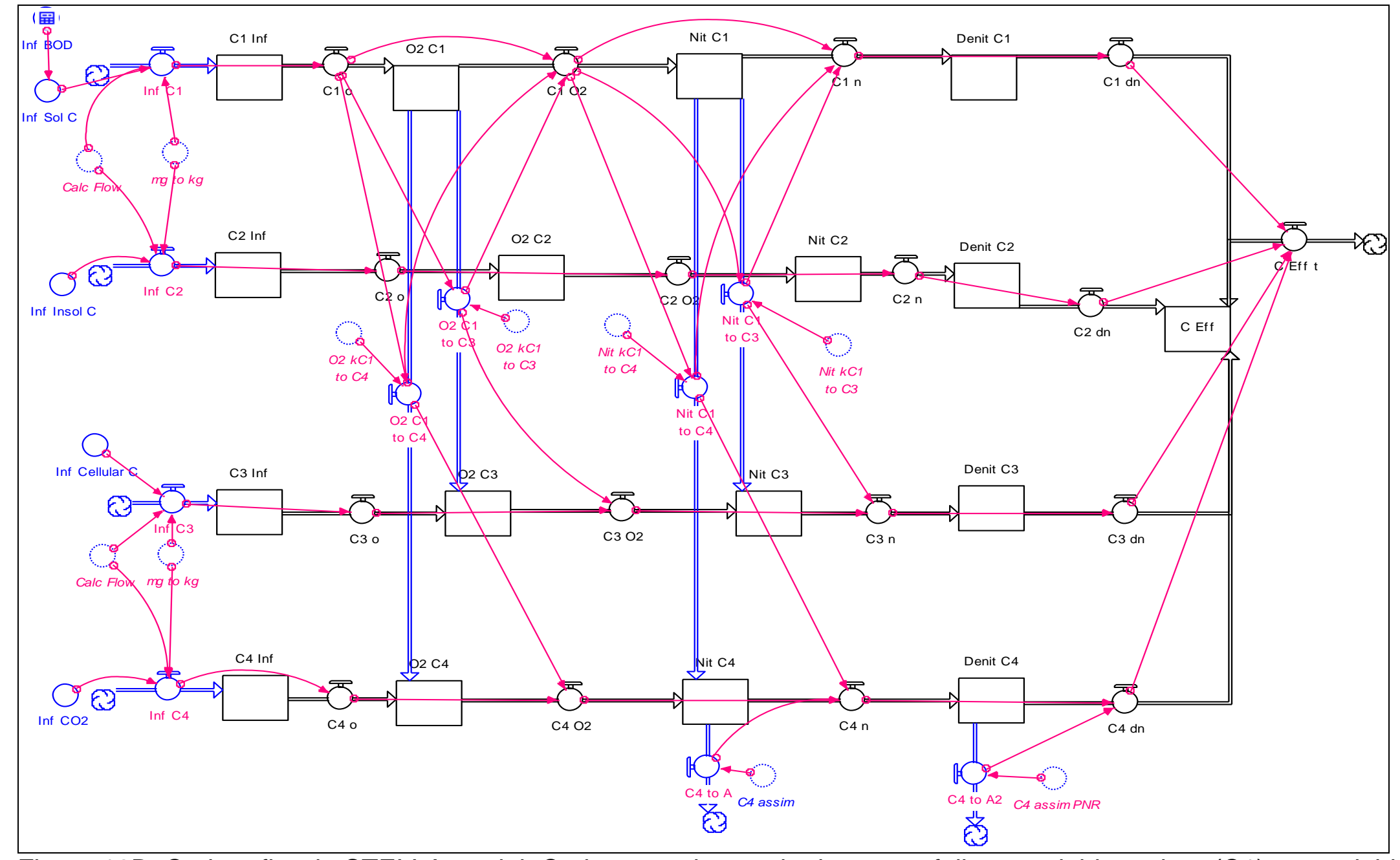

Figure 12B. Carbon flow in STELLA model. Carbon species tracked were as follows: soluble carbon (C1), nonsoluble carbon (C2), cellular carbon (C3), carbon dioxide (C4). See Tables A15, A16, A17, and A18 in Appendix A for full list of variables and equations. 


\section{Nitrogen Balance}

Nitrogen species were tracked in four parallel trains: organic nitrogen (N1), ammonia (N2), nitrate/nitrite (N3), and nitrogen gas (N4). Influent nitrogen was dependent on concentrations entered on the interface for TKN and ammonia (See Figure 6 for interface diagram). Influent nitrate/nitrite and nitrogen gas were entered directly into the model through a converter. The framework of the nitrogen species is shown in Figure 14A. Influent concentrations were multiplied by the influent flow to put each species in units of mass per time as described above with Equation (3).

Nitrogen removal was determined from plant data as described above. Nitrogen removal occurred in the pure oxygen basin and the nitrification basin, where ammonia was converted to nitrate/nitrite. Nitrate/nitrite was then converted to nitrogen gas in the denitrification basin. The movement of each species through the system is shown in Figure $14 \mathrm{~A}$ as flows connecting stocks in parallel trains.

Ammonia and nitrite/nitrate were removed in the nitrification basin and denitrification basin due to algae assimilation, as described in the Algae Processes section of this chapter. Nitrite was considered an intermediary species; therefore all nitrate/nitrite in the nitrogen reservoir was available for algae growth.

Nitrogen mass balance was monitored as shown in Figure 13A.The mass of all influent nitrogen species were summed and compared against the total mass of effluent nitrogen to verify the mass balance. Effluent mass included each 
species flow from the denitrification basin as well as the nitrogen assimilated during algae growth.

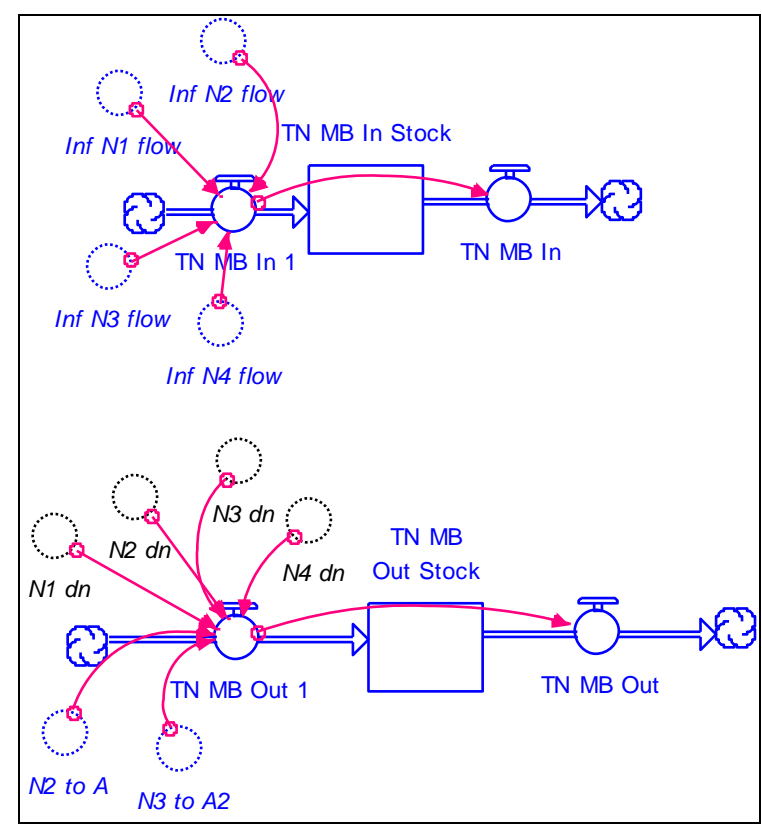

Figure 13A. Mass balance of nitrogen species in STELLA model. Total influent nitrogen was compared to total effluent nitrogen species using the framework above. TN MB In and TN MB Out were plotted on graphs and numerically monitored to maintain mass balance throughout different simulations. See Tables A13 and A14 in Appendix A for full list of variables and equations.

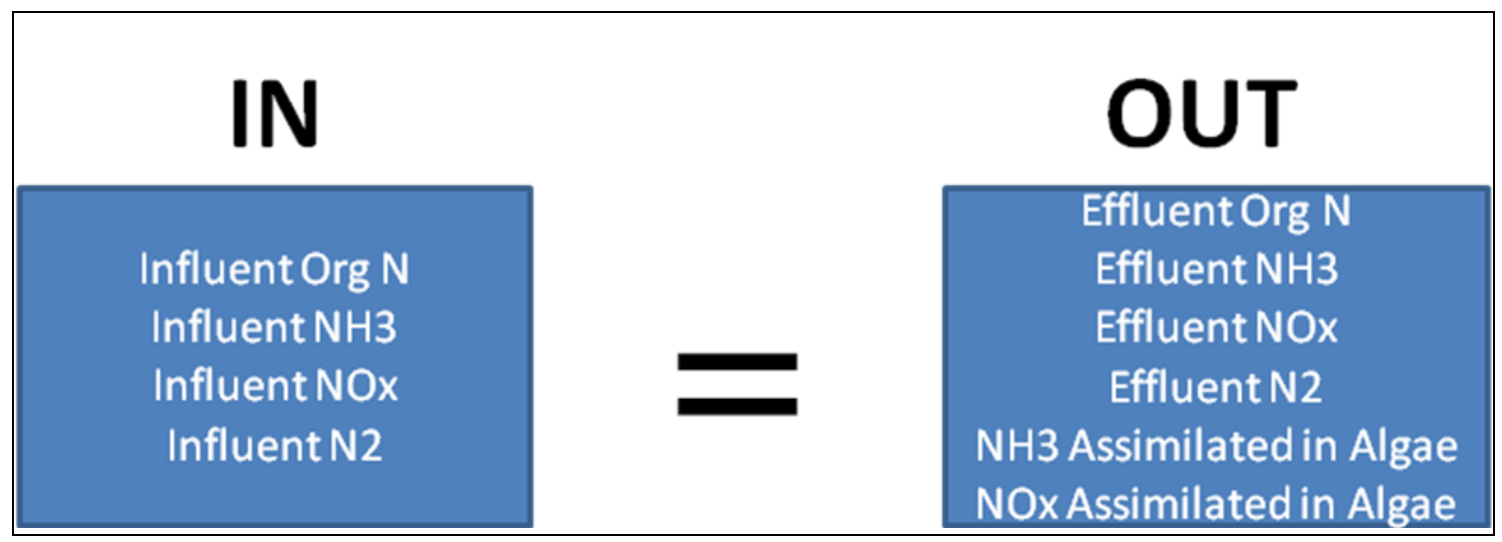

Figure 13B. Conceptual figure of nitrogen mass balance. This figure illustrates how the mass balance was tracked using the STELLA framework in Figure 13A. 


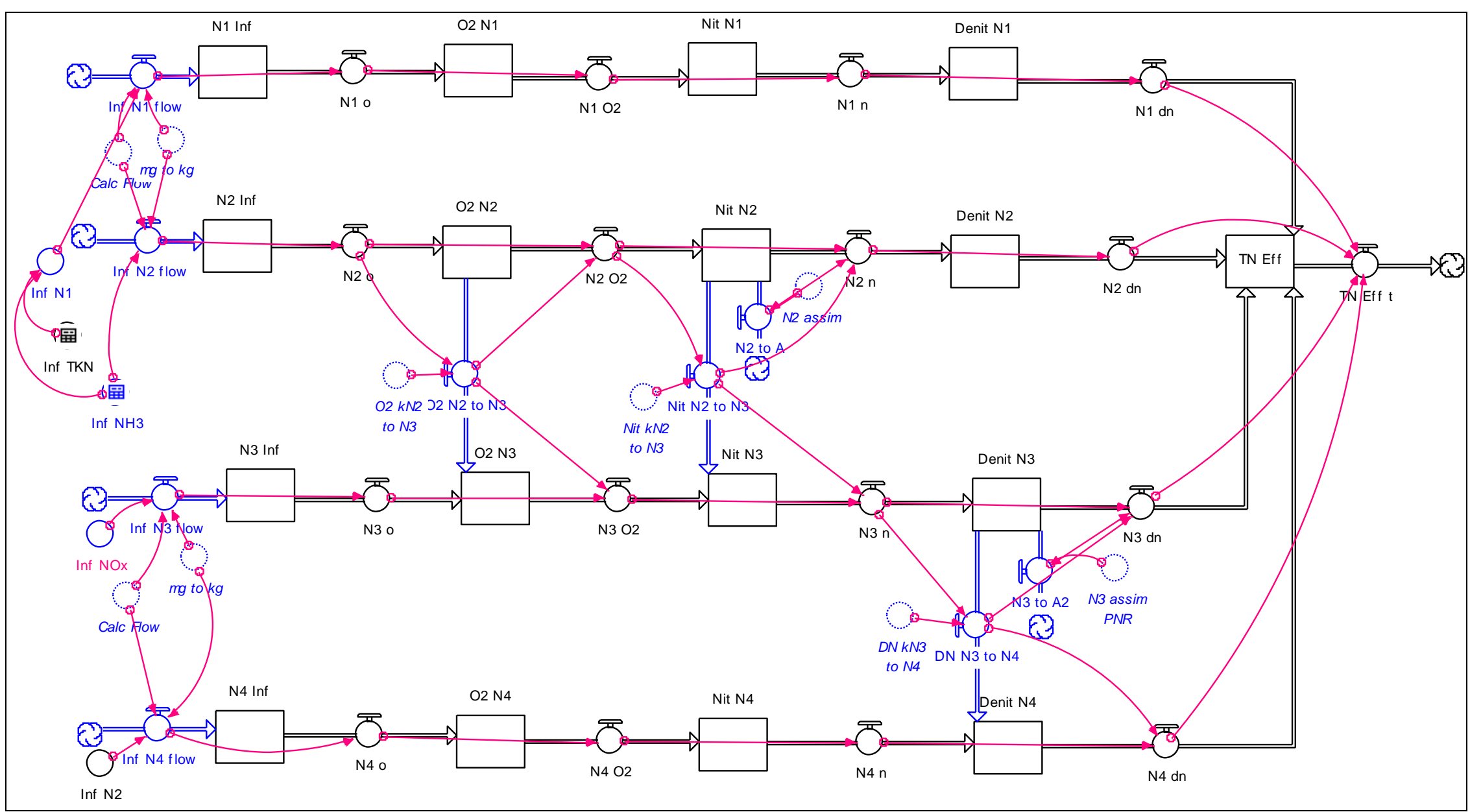

Figure 14A. Nitrogen flow in STELLA model. Species tracked included organic nitrogen (N1), ammonia (N2), nitrate/nitrite (N3), nitrogen gas (N4). See Tables A9, A10, A11, and A12 in Appendix A for full list of variables and equations. 


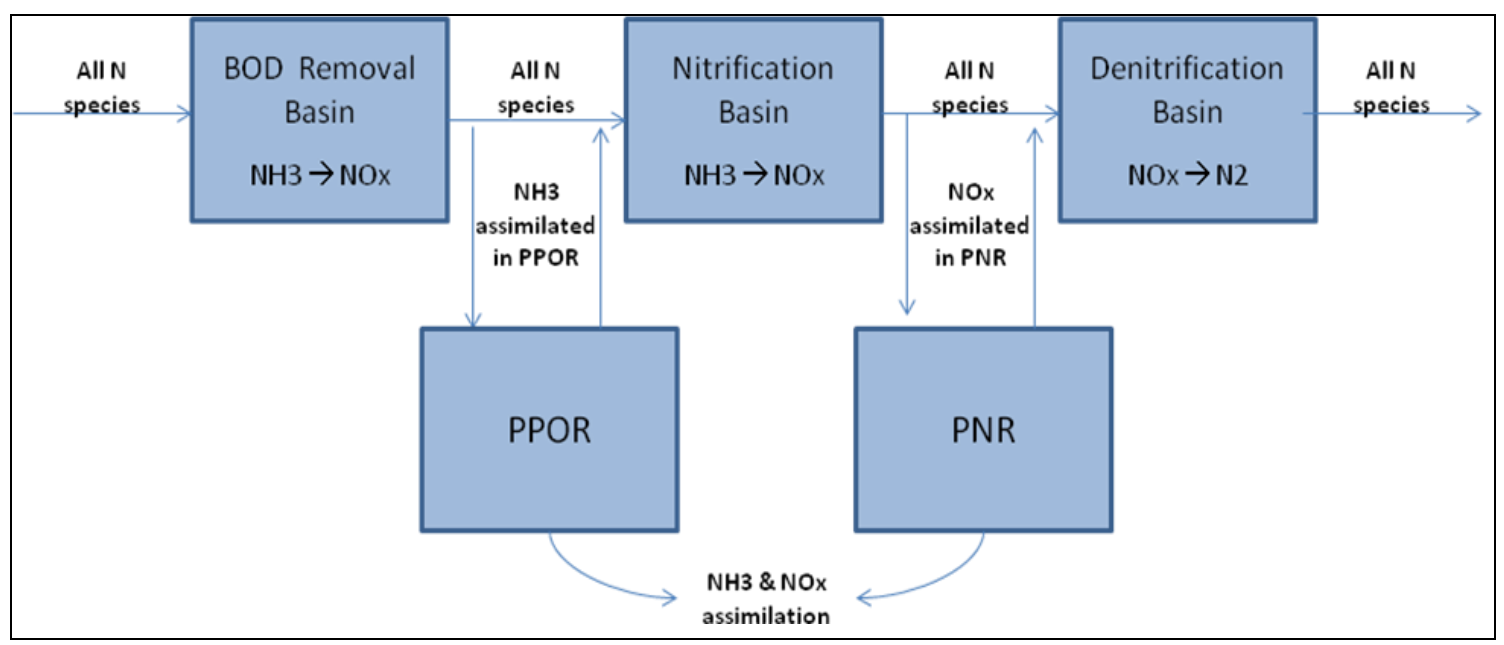

Figure 14B. Conceptual figure of nitrogen flow through the STELLA framework shown in Figure 14A.

\section{Phosphorous Balance}

Phosphorus was tracked in two parallel trains; species included soluble (P1) and nonsoluble (P2) phosphorus. Influent phosphorous was dependent on the value entered on the interface of the model (See Figure 6 for diagram of interface). Nonsoluble phosphorous was calculated as the difference between the influent total phosphorus and influent soluble phosphorus. The framework of the phosphorous sector of the model is shown in Figure 16A.

As mentioned previously, a phosphorous removal rate was not calculated since the HFCAWTP does not have a designated phosphorous removal process; The only phosphorous removal mechanism in the model was algae assimilation.

Phosphorous mass balance was tracked in the same way as nitrogen and carbon was verified. Total influent mass of phosphorous was summed in one stock, and total effluent mass of phosphorous was summed in a parallel stock; effluent phosphorous included mass of phosphorous leaving the denitrification 
reactor as well as that assimilated by algae. The utilized stock and flow framework is shown in Figure 15A.

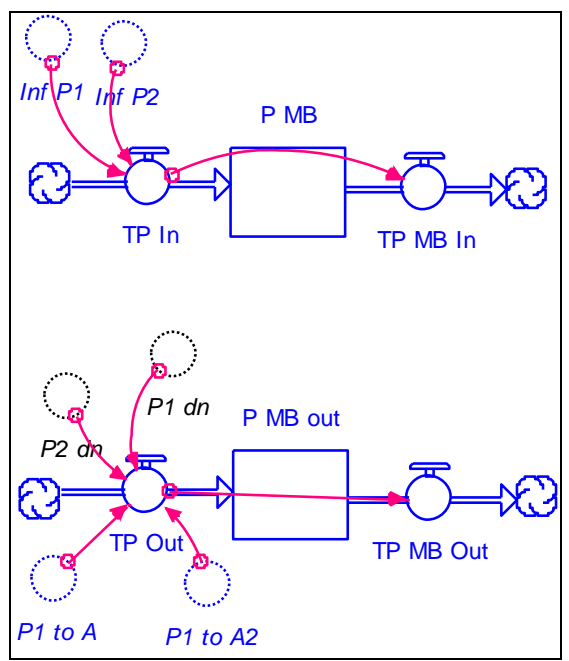

Figure 15A. Mass balance of phosphorous species in STELLA model. Total influent phosphorous was compared to total effluent phosphorous species using the framework above. TP MB In and TP MB Out were plotted on graphs and numerically monitored to maintain mass balance throughout different simulations. See Tables A7 and A8 in Appendix A for full list of variables and equations.

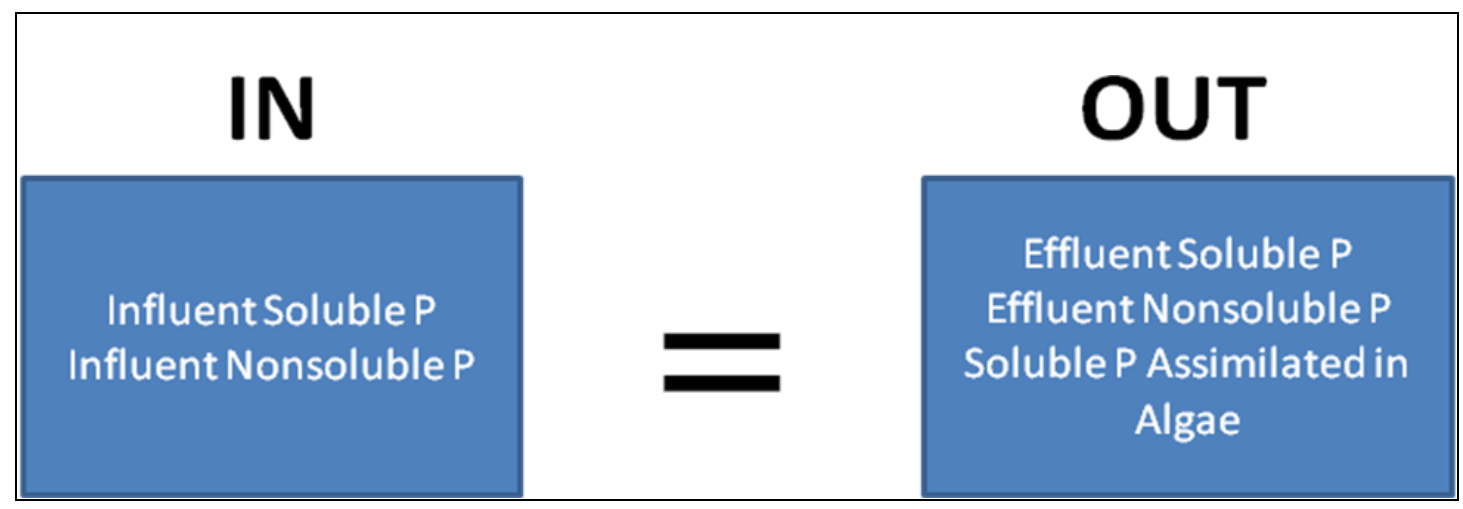

Figure 15B. Conceptual figure of nitrogen mass balance. This figure illustrates how the mass balance was tracked using the STELLA framework in Figure 15A. 


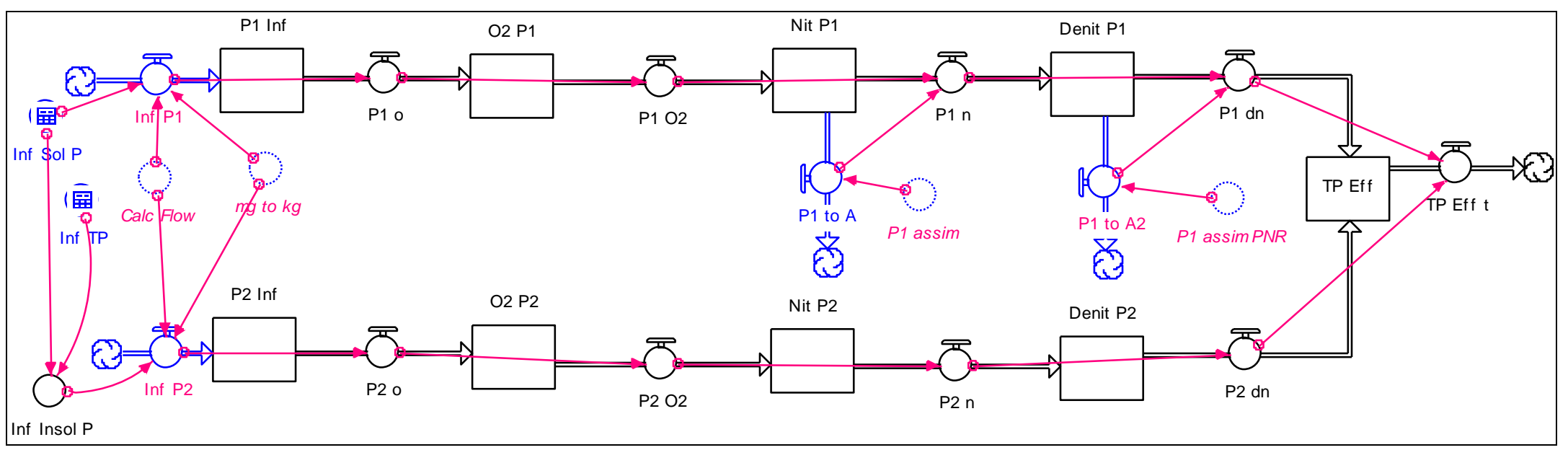

Figure 16A. Phosphorus flow in STELLA model. Species include soluble (P1) and nonsoluble (P2). See Tables A5 and A6 in Appendix A for full list of variables and equations.

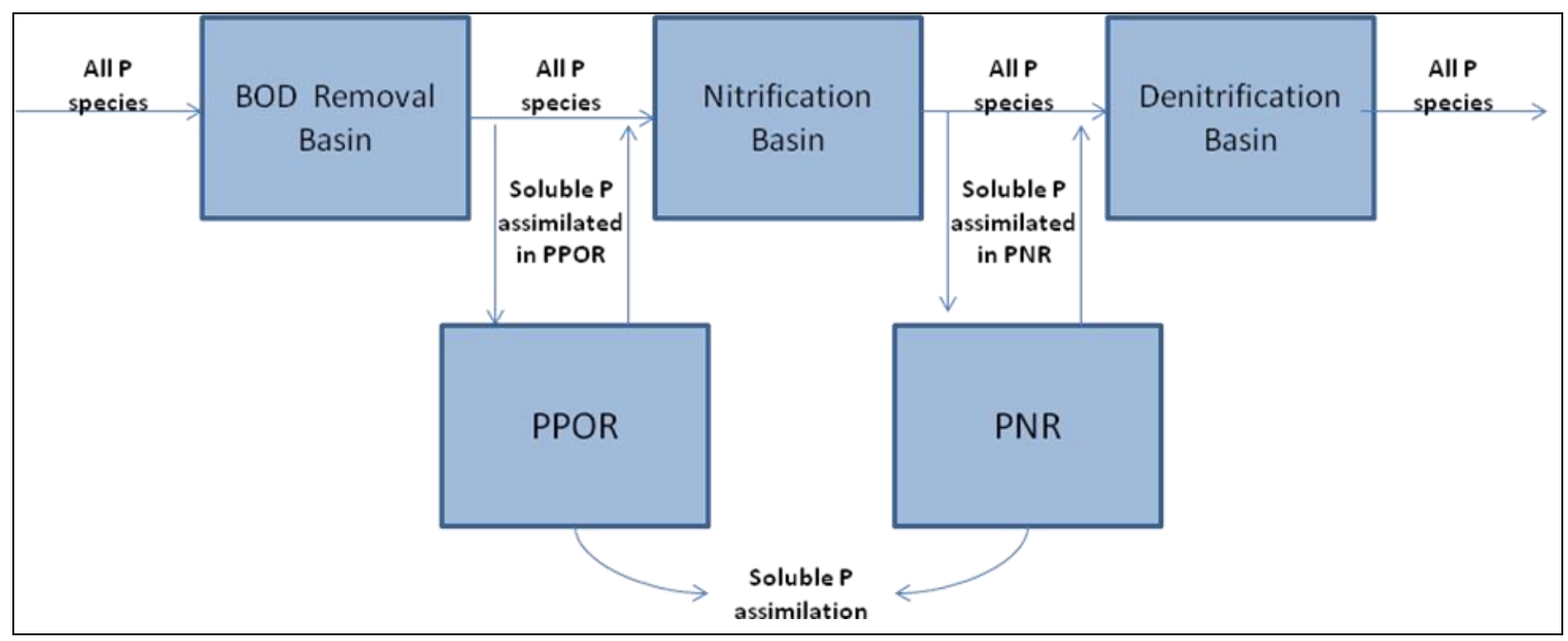

Figure 16B. Conceptual figure of phosphorous flow through the STELLA framework shown in Figure 16A. 


\section{Algae Growth Framework}

As shown in Figure 5, two algae basins were incorporated into the HFCAWTP facility: a post-pure oxygen reactor (PPOR) and a post-nitrification reactor (PNR). Nutrients were diverted from the conventional treatment plant process based on the amount of flow sent to the basins, which can be determined on the user interface. As influent to the algae basins was considered to be post-clarifier effluent in both cases, it is assumed that only dissolved species of nutrients are available.

Algae are assumed to remain in the algae basin and do not contribute to nutrient input to the wastewater treatment process, i.e. it is assumed a solids separation step, such as a clarifier, will be used to retain algae within the PPOR and PNR. Likewise, algae are not entering the algae basin from the wastewater process. Algae are removed from the system through harvesting and added to the process through growth.

Figure 17 shows the model interface for entering variables related to algae growth. The values entered on the interface give the model important flexibility for adapting to site-specific conditions. Certain variables, such as specific growth rate, can also represent environmental conditions not explicitly considered by the model.

Algae basins could be turned on or off at the model interface by two buttons. Clicking on the button turns the switch 'on,' which diverts flow the algae basin, allowing them to grow. If the button is 'off,' the flow to algae are multiplied by zero, essentially shutting down their growth. Buttons for turning on/off the 


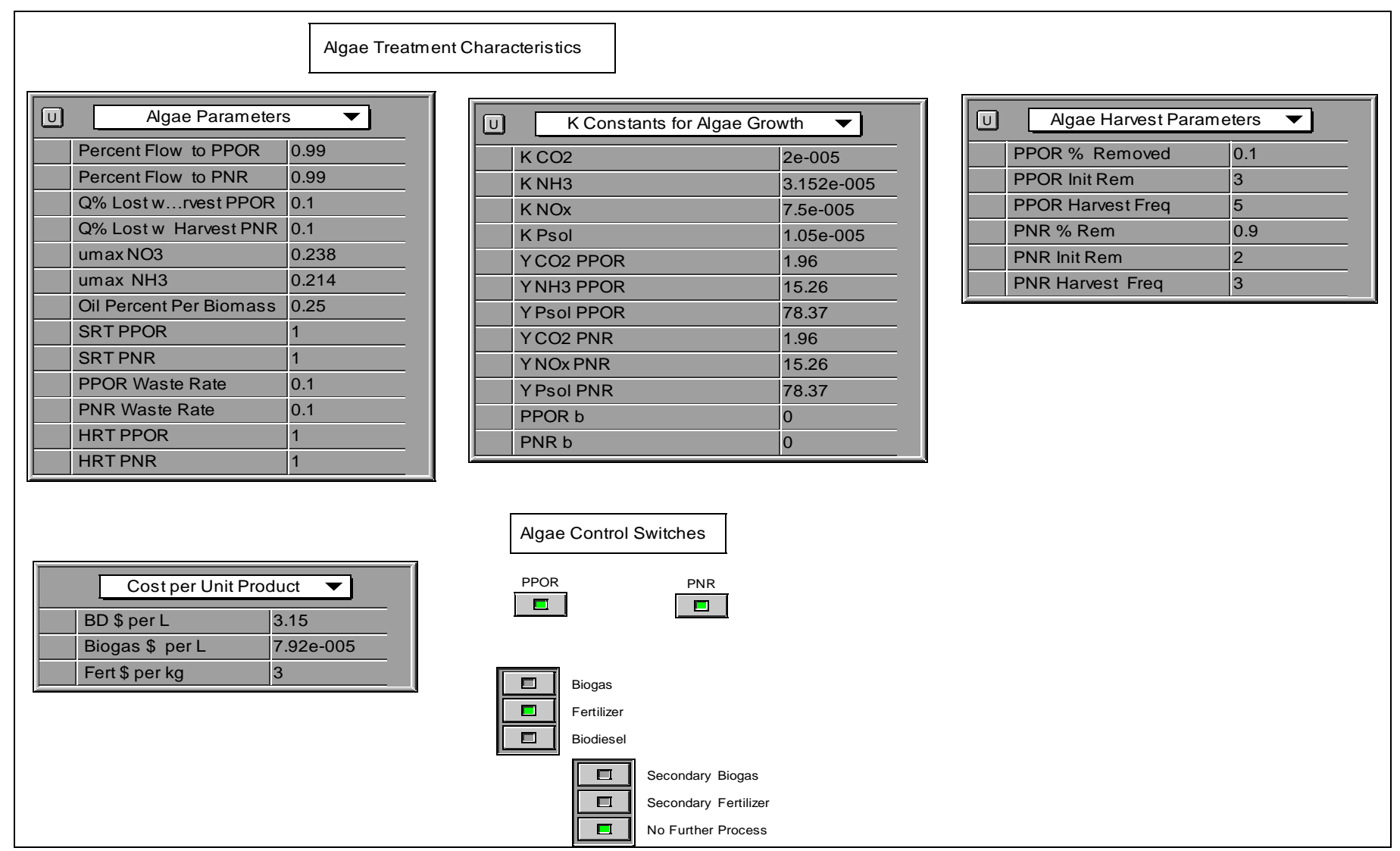

Figure 17. Model interface for manipulating parameters related to algae growth kinetics and the physical characteristics of the algae basins. 
algae basin, as well as selecting the desired process for biomass secondary product (i.e. biodiesel, biogas, fertilizer), are shown in Figure 17.

Maximum and Calculated Specific Growth Rate

Because all variables, such as light intensity and temperature, are not included in the model explicitly, it is assumed such growth constraints are represented within the maximum specific growth rate selected. For example, if the maximum specific growth rate of a species has been determined under certain light conditions, the growth rate can be plugged into the model at the interface to see the projected growth of that species under the set conditions. Similarly, reactor configuration, temperature, and $\mathrm{pH}$ can be represented within the maximum specific growth rate selected.

Although it has been discussed within Chapter Two that algae can grow autotrophically, heterotrophically, and mixotrophically, this model will only consider autotrophic growth. Algae growth equations are written with carbon dioxide as a potential limiting nutrient, assuming organic carbon will not be utilized. This is an important limitation for the model and an area for future improvement, since heterotrophic growth can be quite significant.

Algae growth was determined by Monod kinetics, based on the limiting nutrient of phosphorous, carbon dioxide, or nitrogen. Algae growth in the PPOR was considered to be exclusively due to growth via ammonia assimilation, whereas algae growth in the PNR only considered nitrate as a nitrogen source. However, maximum specific growth rates for either nitrogen source could be set separately within the interface. This allows for flexibility within the model, in that 
one species can theoretically and conceptually be placed in one basin and allow for another species with a different growth rate to be placed in the other. The assumption that algae species will preferentially use one nitrogen source over another has been documented in the laboratory (Aslan et al., 2006; Tam and Wong, 1996; Olguin, 2003).

The model relied on Monod kinetics to determine algae production, kinetics which expresses the relationship between an organism's specific growth rate and the availability of a rate limiting substrate. The half saturation constant, $K$, is the available substrate needed in order for the organism to achieve half its maximum specific growth rate. Ideally, the Monod fraction, shown in Equation (5) would be as close to 1 as possible in order to maintain the calculated specific growth rate as close to the maximum specific growth rate as possible. This is achieved through a high substrate concentration or a relatively low half saturation concentration. The calculated specific growth rate is defined as

$\mu_{\text {calc }}=\left(\frac{1}{X} * \frac{d X}{d t}\right)=\mu_{\max } *\left(\frac{S}{S+K}\right)$

where $\mu_{\text {calc }}$ is the calculated specific growth rate, $X$ is the concentration of active biomass, $d X / d t$ is the rate of change of biomass concentration, $S$ is the concentration of available biomass, $K$ is the half saturation constant, and $\mu_{\max }$ is the maximum specific growth rate (Rittman and McCarty, 2001).

The specific growth rate was calculated based on the Monod relationship shown in Equation (5), but modified to accommodate the use of multiple substrates as discussed in Rittman and McCarty (2001): 


$$
\boldsymbol{\mu}=\boldsymbol{\mu} \max \left(M I N\left[\frac{S_{\mathrm{N}}}{S_{N}+K_{N}}, \frac{S_{C}}{S_{C}+K C}, \frac{S_{P}}{S P+K P}\right]\right)-b
$$

where $\mu_{\max }$ is the maximum specific growth rate, entered at the user interface for either the PPOR or PNR; $b$ is the algae decay rate, also entered on the interface. The equation is written to take the minimum Monod fraction, in order to calculate the $\mu_{\max }$ based on the most limiting condition. The half saturation constants are represented by $K_{N}, K_{C}$, and $K_{P}$ for nitrogen, carbon, and phosphorous, respectively. A separate value for the half saturation constants for either nitrogen source, as well as carbon and phosphorous, can be entered on the interface (see Figure 17). The respective available substrate concentration of nitrogen, carbon, and phosphorous $\left(S_{N}, S_{C}\right.$, and $\left.S_{P}\right)$ are drawn from the remaining substrate concentration in the algae basin after algae growth, as described later in this Chapter.

The specific growth rate was determined at each iteration as described in the following equation

$$
\mu t=\mu \max ^{*}\left[\frac{S_{t}}{S_{t}+K}\right]
$$

where $u_{t+1}$ is the calculated specific growth rate based on the available substrate at that iteration, $S_{t+1}$, and $K$ is the half saturation constant corresponding to each substrate. Each substrate was included as shown in Equation (6).

Figure 18A shows the model framework for determining the specific growth rate for algae utilizing ammonia in the PPOR. An identical framework was also developed for growth in the PNR, using flows and concentrations leaving the nitrification basin of the treatment plant. 


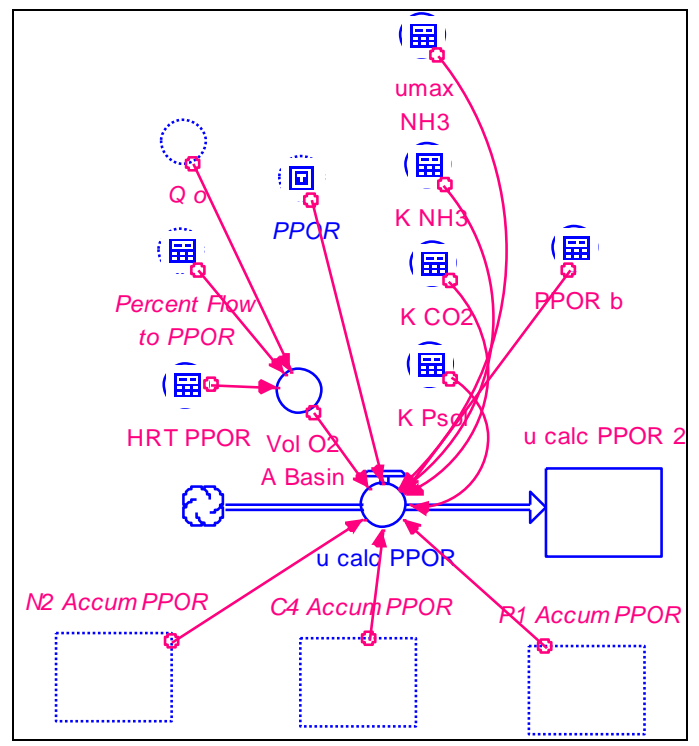

Figure 18A. Model framework for determination of specific growth rate in the PPOR from Monod kinetics. An identical framework was used for the PNR. See Tables A21 and A22 in Appendix A for full list of variables and equations.

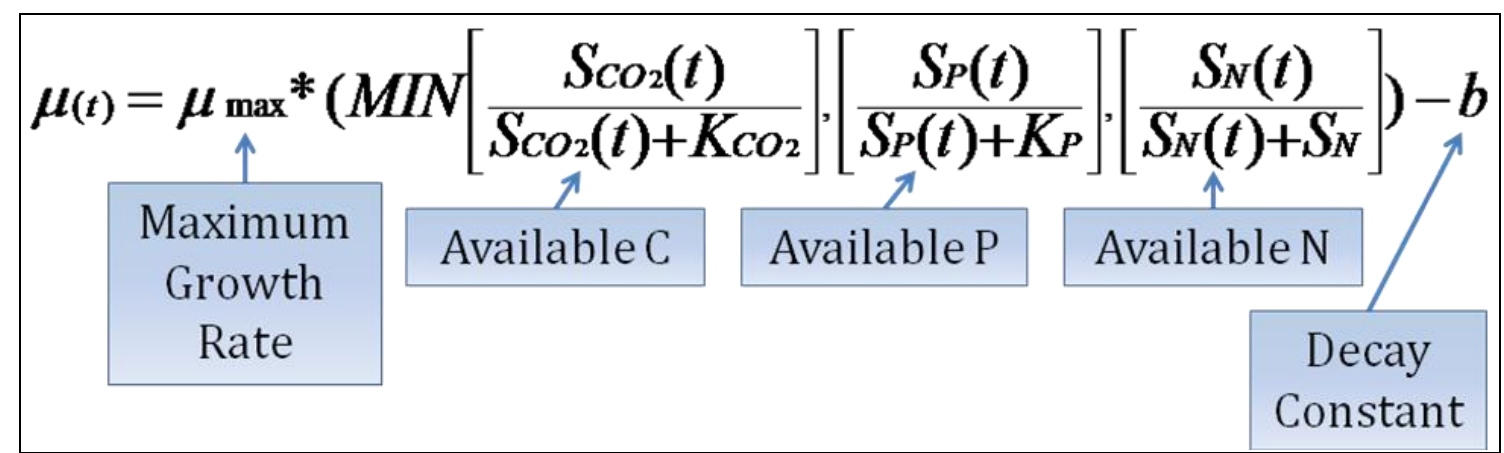

Figure 18B. Conceptual illustration of equation used to determine specific growth rate in the PPOR.

The available substrate is divided by the volume of the algae reactor in order to convert to concentration. The volume is determined by the HRT and flow rate to the algae basin. 


\section{Algae Growth}

Algae growth was determined based on the specific growth rate determined via Monod kinetics as described above. The equation used to determine new algae generated was

$$
R_{\text {gen }}=\mu_{\text {calc }} * X_{t}
$$

where $R_{g e n}$ is rate of generation of algae, $X_{t}$ is the initial mass of algae present and $\mu_{\text {calc }}$ is the calculated specific growth rate determined as described in Equation (6).

Algae accumulation is calculated based on the amount of algae generated minus the amount of algae harvested per day. Algae are pulse harvested based on a percentage of algae accumulated in the basin, i.e. the user can set how much algae to remove, how often, at what time interval over the duration of the simulation on the user interface. The net production in the basin was calculated as

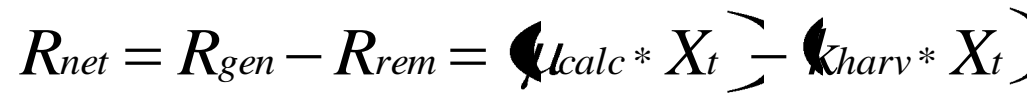

where $R_{\text {net }}$ is net rate of algae generation in mass per day, $R_{g e n}$ is rate of algae generation, $R_{\text {rem }}$ is rate of algae harvest, and $k_{\text {harvest }}$ is the rate of algae harvested per day, set at specific time intervals on the user interface. The amount of algae harvested, represented in the last term, is the algae sent to processing in the byproduct section of the model.

The framework for determining algae biomass production in the PPOR is shown in Figure 19A. An identical framework was built to determine biomass 
production in the PNR. The stock represents the algae accumulating in the algae basin. The flow entering is determined as described in Equation (7).

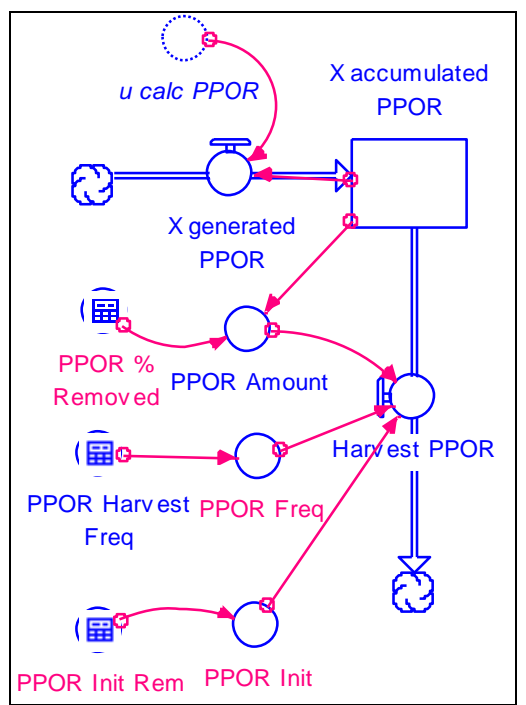

Figure 19A. Model framework for algae production in the PPOR. An identical framework was built for algae growth in the PNR. See Tables A25 and A26 in Appendix A for full list of variables and equations.

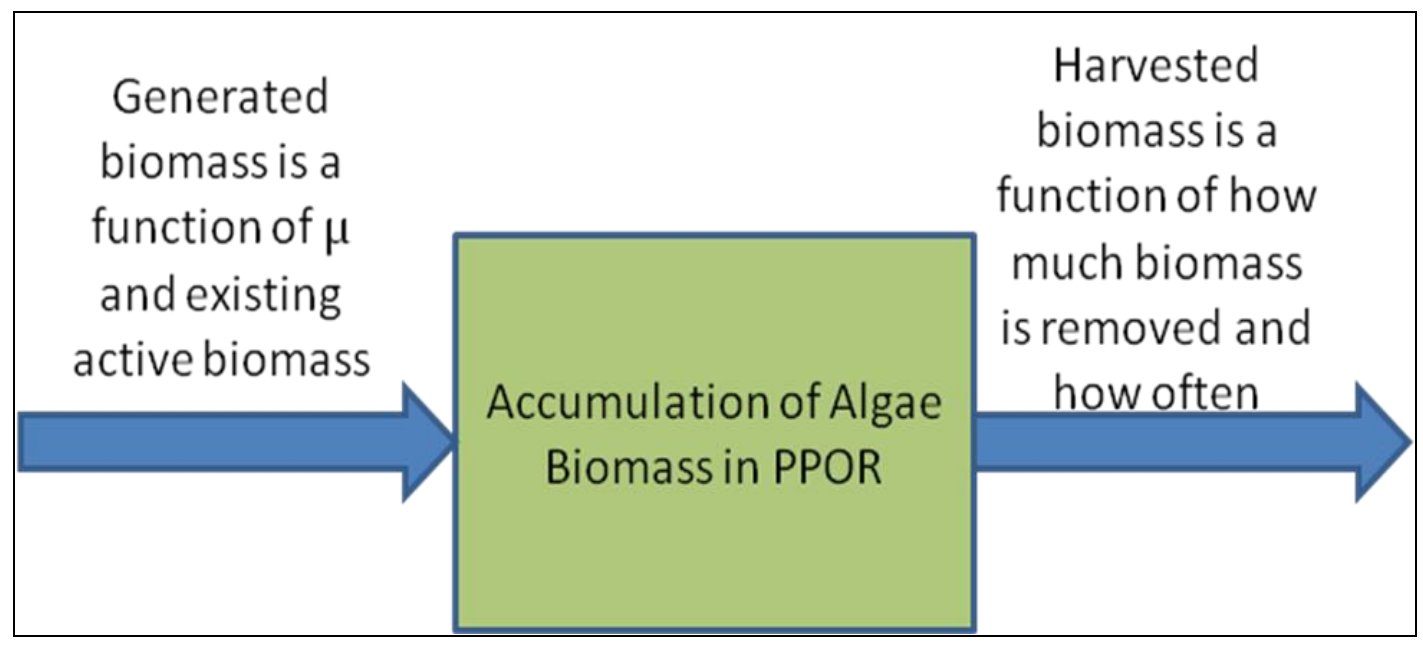

Figure 19B. Conceptual figure of algae production in the PPOR. 
Determining Substrate Utilization Rate and Yield Coefficient

Monod kinetics relates the specific growth rate $(\mu)$, substrate utilization rate $(q)$, and yield coefficient $(Y)$ by the equation

$$
q_{t}=\frac{\mu_{t}}{Y}
$$

where $q_{t}$ is the substrate utilization rate, defined as substrate consumed per biomass produced per unit time; $\mu_{t}$ is the calculated specific growth rate with units of biomass produced per biomass present per time; and $Y$ is the yield coefficient, defined as the amount of biomass produced per substrate consumed. A new $q_{t}$ was calculated at each iteration based on the real-time specific growth rate determined by available substrate, and a separate $q_{t}$ was calculated for each substrate (i.e. ammonia, nitrate, carbon dioxide, phosphorous).

Figure $20 \mathrm{~A}$ shows the model framework for calculating $q_{t}$ for each substrate utilized in the PPOR. The nitrogen source utilized in the PPOR is ammonia. An identical framework was developed for the PNR, where nitrate is utilized as the nitrogen source. 


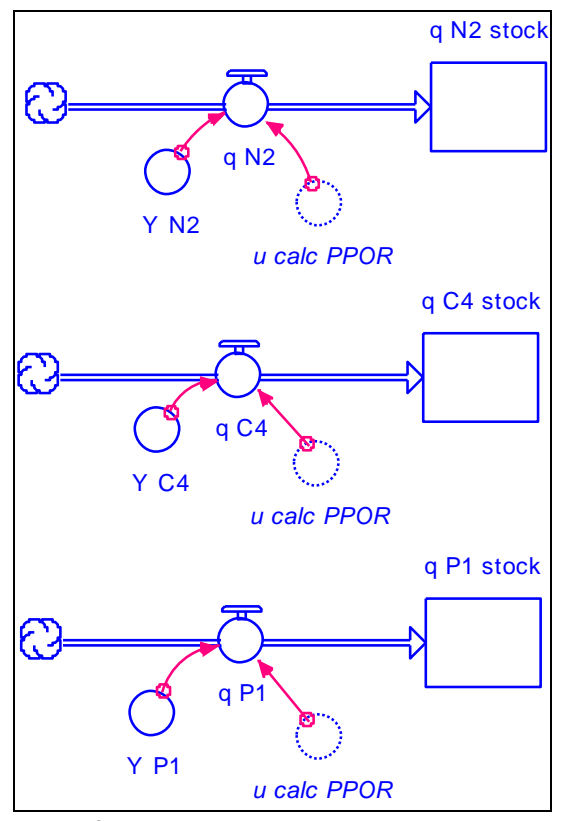

Figure 20A. Model framework for calculating the substrate utilization rate in the PPOR. The $q_{t}$ is determined by the available substrate, calculated specific growth rate, and stoichiometric relationship of each constituent to growth. See Tables A33 and A34 in Appendix A for full list of variables and equations.

$$
q_{P s o l}=\frac{\mu_{\text {calc }}}{Y_{P_{s o l}}} q_{\mathrm{CO}_{2}}=\frac{\mu_{\text {calc }}}{Y_{\mathrm{CO}_{2}}} q_{\mathrm{NH}_{3}}=\frac{\mu_{\text {calc }}}{Y_{\mathrm{NH}_{3}}}
$$

Figure 20B. Equations for substrate utilization rate framework in the PPOR shown in Figure 20A.

The yield coefficient was calculated based on the stoichiometric relationship between each elemental constituent and subsequent algae growth. The following equations were used to determine the yield coefficient using ammonia (10) and nitrate (11) as a nitrogen source to generate algae with the empirical formula of $\mathrm{C}_{100} \mathrm{O}_{48} \mathrm{H}_{183} \mathrm{~N}_{11} \mathrm{P}$. The equations were derived from Rittman and McCarty (2001), and the formula was borrowed from Grobbelaar (2004). This molecular formula was chosen instead of the classic Redfield Ratio of C:N:P of 106:16:1(Redfield, 1934) because the Redfield Ratio describes marine algae 
in the natural environment, whereas the other formula is specific for microalgae cultured in an engineered environment. The Redfield Ratio may be a consequence of the biogeochemical environment within marine ecosystems, which would be quite different than wastewater conditions. Other studies have shown that empirical formulas can change depending on an organisms' growth rate (Agren, 2004) and environmental conditions (Zamalloa et al. 2010). Although the Grobbelaar (2004) formula was chosen for model calculations, the stoichiometric ratios and yield coefficients can be changed within the model if the user decides it is necessary.

$100 \mathrm{CO}_{2}+73.5 \mathrm{H}_{2} \mathrm{O}+11 \mathrm{NH}_{3}+1 \mathrm{H}_{3} \mathrm{PO}_{4}=1 \mathrm{C}_{100} \mathrm{O}_{48} \mathrm{H}_{183} \mathrm{~N}_{11} \mathrm{P}+114.75 \mathrm{O}_{2}$

$100 \mathrm{CO}_{2}+90 \mathrm{H}_{2} \mathrm{O}+11 \mathrm{NO}_{3}+1 \mathrm{H}_{3} \mathrm{PO}_{4}=1 \mathrm{C}_{100} \mathrm{O}_{48} \mathrm{H}_{183} \mathrm{~N}_{11} \mathrm{P}+139.5 \mathrm{O}_{2}$

Specifically, $Y$ for each substrate was calculated using the following equations

$$
\frac{1 \mathrm{molA}}{11 \mathrm{molN}} \times \frac{\frac{2351 g A}{\mathrm{molA}}}{\frac{14 g N}{m o l N}} \times \frac{\frac{k g A}{1000 g A}}{\frac{k g N}{1000 g N}}=\frac{15.26 \mathrm{kgA}}{k g N}
$$

where $A$ denotes algae biomass and $N$ denotes ammonia as nitrogen. Similar calculations were conducted for each growth constituent

$$
\frac{1 \mathrm{molA}}{100 \mathrm{molC}} \times \frac{\frac{2351 \mathrm{gA}}{\mathrm{molA}}}{\frac{12 g C}{\mathrm{molC}}} \times \frac{\frac{\mathrm{kgA}}{1000 \mathrm{gA}}}{\frac{\mathrm{kgC}}{1000 \mathrm{gC}}}=\frac{1.96 \mathrm{kgA}}{\mathrm{kgC}}
$$

where $A$ denotes algae biomass and $C$ denotes carbon dioxide as carbon; 


$$
\frac{1 \text { molA }}{1 \text { molP }} x \frac{\frac{2351 g A}{\text { molA }}}{\frac{31 g P}{\text { molP }}} \times \frac{\frac{k g A}{1000 g A}}{\frac{k g P}{1000 g P}}=\frac{78.37 k g A}{k g P}
$$

where $A$ denotes algae biomass and $P$ denotes $\mathrm{H}_{3} \mathrm{PO}_{4}$ as phosphorous.

Table 3. Calculated yield coefficients for determination of $q$.

\begin{tabular}{|l|l|l|}
\hline & PPOR & PNR \\
\hline N Source as N & 15.26 & 15.26 \\
\hline $\mathrm{CO}_{2}-\mathrm{C}$ & 1.96 & 1.96 \\
\hline $\mathrm{P}$ & 78.37 & 78.37 \\
\hline
\end{tabular}

Note: a low $Y$ demonstrates that more of this substrate is required to produce one unit of biomass.

The stoichiometric relationships were built into the model using converters, which are shown in Figure $20 \mathrm{~A}$ as $Y_{-} N 1, Y_{-} C 4$, and $Y_{-} P 1$. If the yield coefficient changes, for example, with a different molecular formula, this variable can be changed on the model interface.

Determining Substrate Removal via Biomass Assimilation

Substrate removal is calculated for carbon dioxide and phosphorous in both algae reactors. Ammonia is removed in the PPOR, and nitrate is removed in the PNR. Substrate removed is based on the $q_{t}$ and is subsequently related to the specific growth rate at a given point in time. The rate of substrate removal was defined as

$$
\frac{d S}{d t}=q_{t} * X_{t}
$$


where $q_{t}$ is the substrate utilization rate, in mass per unit biomass per time, and $X_{t}$ is the mass of active biomass. To determine the substrate remaining after assimilation, the substrate utilized was subtracted from the influent substrate $S_{t+1}=S_{t}-\frac{d S}{d t} * \Delta t=S_{t-}\left(q_{t} * X_{t} * \Delta t\right)$

where $S_{t+1}$ is the concentration of substrate at the next time step $(t+\Delta t)$, and $S_{t}$ is the available substrate.

Available substrate was calculated in the stock by multiplying the influent mass flow by the HRT, to obtain a given available reservoir mass of nutrient. The substrate utilized was subtracted from the reservoir mass.

Removal was calculated separately for each substrate involved in algae growth and subsequently subtracted from both the algae and wastewater system. Figure $21 \mathrm{~A}$ shows the framework for ammonia-nitrogen removal in the PPOR. Removal of each substrate was driven by a switch built into each framework; the PPOR utilized the O2 switch, whereas the PNR utilized the Nit Switch. 


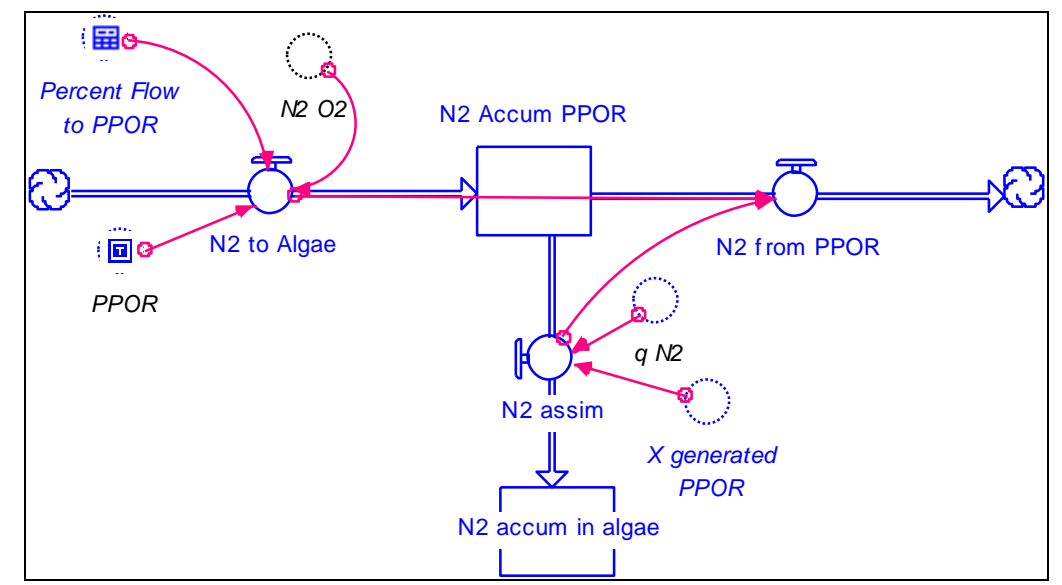

Figure 21A. Model framework for ammonia-nitrogen removal from the PPOR. Similar substrate removal calculations were made for each constituent involved in algae growth. Likewise, an identical framework was developed for the PNR. See Tables A27 and A28 in Appendix A for full list of variables and equations.

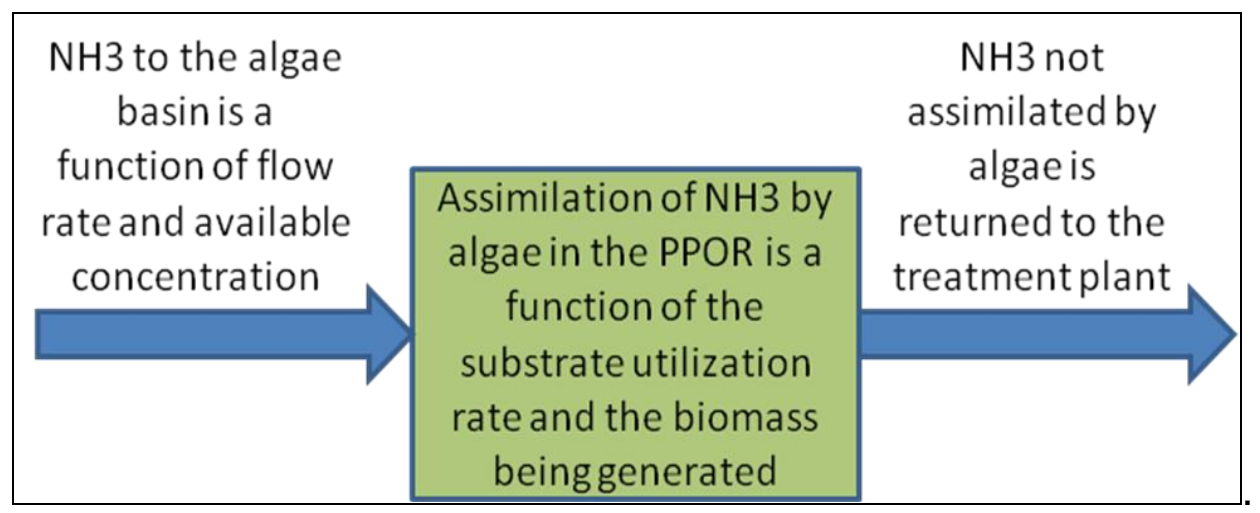

Figure 21B. Conceptual illustration of ammonia utilization in the PPOR.

Figures 22 and 23 show an example of how the ammonia is removed from the wastewater treatment plant once it is assimilated by the algae. Figure 22 shows the overall nitrogen framework; the area highlighted in the box is shown in Figure 23 , with an arrow pointing to the specific region where ammonia-nitrogen is drained from the plant. The substrate is removed from the plant to maintain mass balance. 


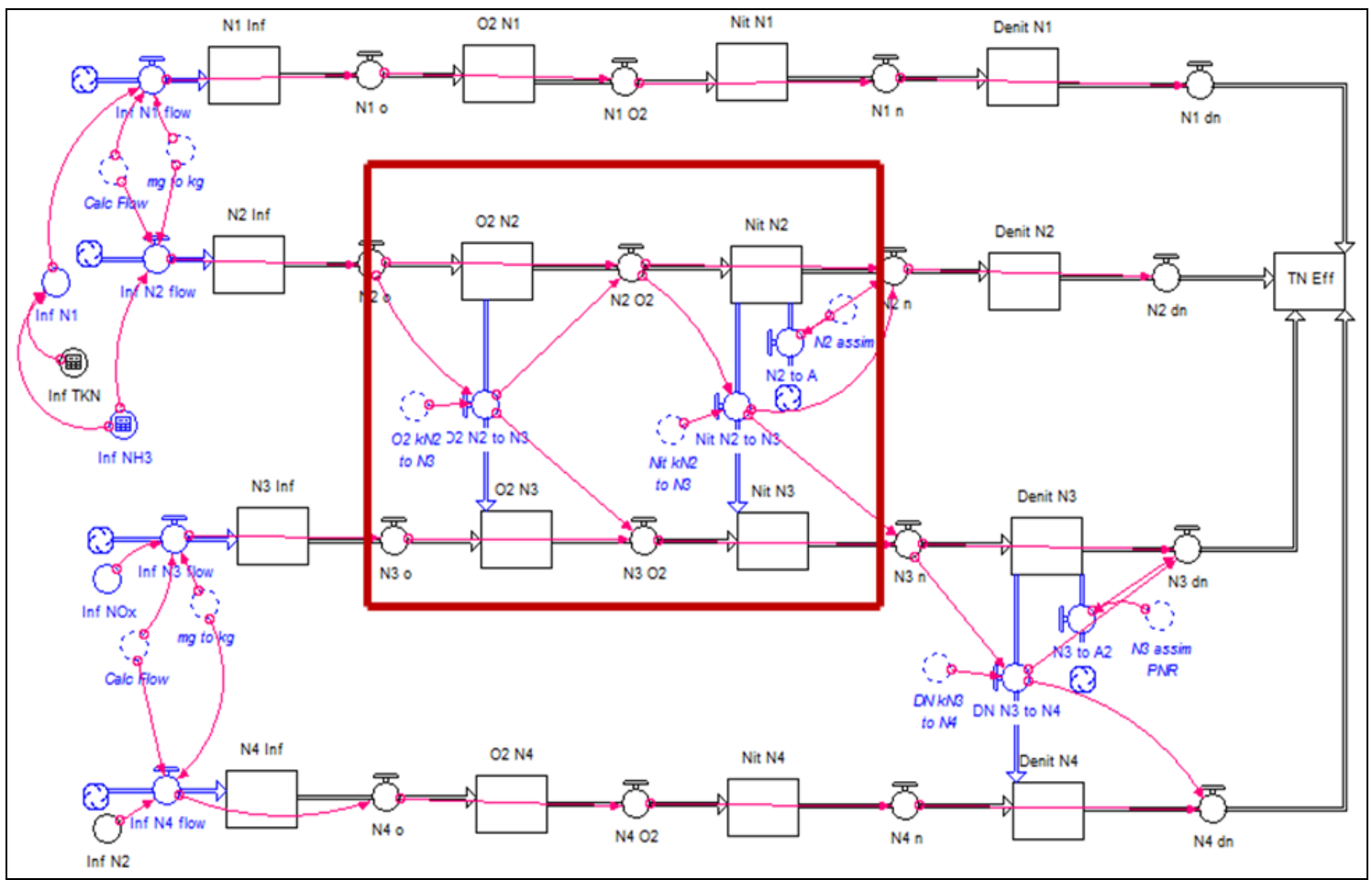

Figure 22. Model framework for movement of nitrogen in the wastewater treatment plant. The highlighted box is shown in more detail in Figure 23.

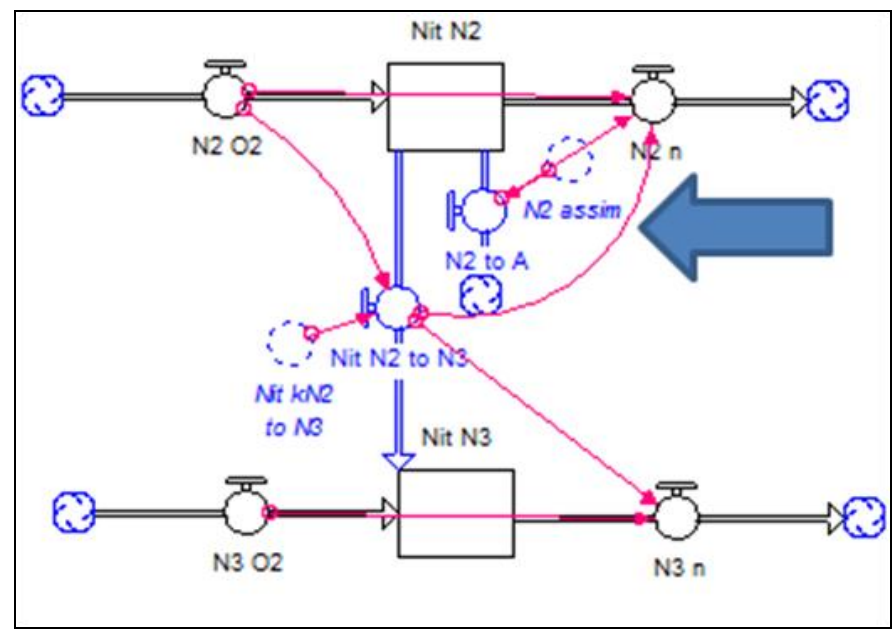

Figure 23. Example of ammonia-nitrogen being removed from wastewater framework after assimilation by algae. N2_to_A is the flow of ammonia to algae via assimilation. 


\section{Hydraulic Retention Time in Algae Basins}

Hydraulic retention time in each algae basin was determined based on the value entered on the interface page of the model (see Figure 17). Basin volume was calculated based on the flow rate diverted to the algae multiplied by the HRT, as shown in the generic equation below:

$$
V_{A}=Q_{A}{ }^{*} H R T
$$

where $V_{A}$ is the volume of the algae reactor and $Q_{A}$ is the flow rate diverted to the respective basin. The model framework for HRT in the PPOR is shown in 24.

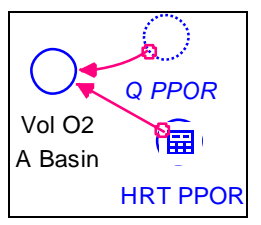

Figure 24. Model framework for calculating the volume of the PPOR as a function of HRT and flow diverted to algae basin, which are entered on the interface of the model.

\section{Solids Retention Time}

The retention time of algae in the PPOR and PNR was determined by the following equation

$$
S R T=\frac{X_{a k g}}{X_{h k g} / t}
$$

where $X_{a}$ is the mass of active algae in the reactor and $X_{h}$ is the mass of algae harvested per time. The mass of algae is the accumulation in the reactor, and the amount and rate of removal is set on the interface as the harvest percentage and frequency. Figure 25 shows the model framework of calculating SRT. 


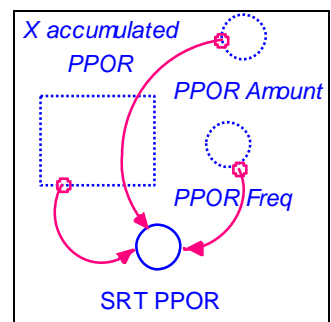

Figure 25. Model framework for calculating SRT. See Tables A23 and A24 in Appendix A for full list of variables and equations.

\section{Algae Production Costs \& Benefits Calculations}

Once the mass of algae produced was determined based on Monod kinetics and stoichiometric relationships as described above, an analysis was conducted to determine the potential macro-economic benefits of incorporating algae into conventional treatment. Certain costs and benefits, such as biomass production costs, harvesting costs, and reduced aeration and chemical additives, were the same for all secondary use processes. However, the process costs as well as benefits for biodiesel, biogas, and fertilizer were calculated separately. All secondary product calculations, variables, and processes are defined below.

Because literature is limited on full-scale algae production and processing, the most appropriate values available were chosen when specific calculations were not available. As research and development of algal production progresses, it is expected that production and processing costs will decrease. Changing market prices and product benefits can be easily reflected through the model interface.

Figure 26 shows the model interface where cost per unit product can be defined by the user, as it is expected that prices will vary depending on market conditions and geographic location. 


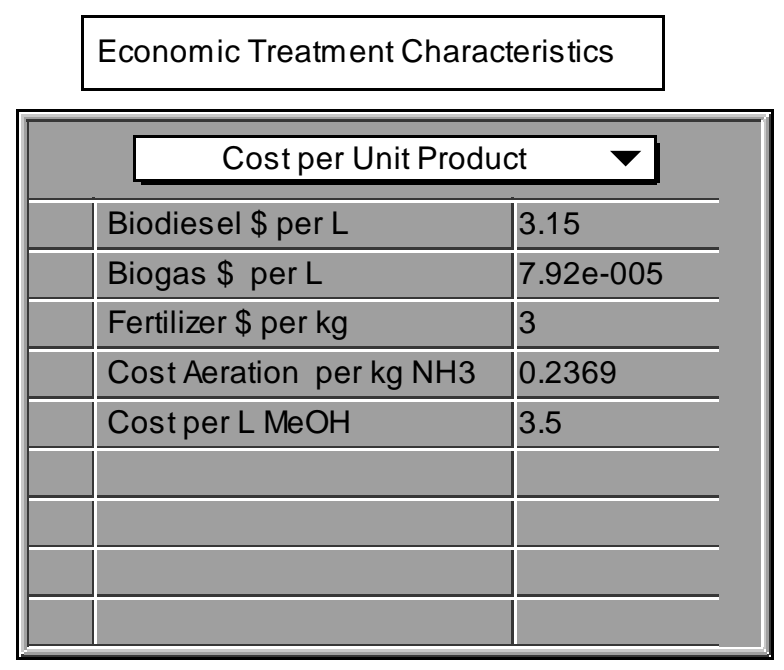

Figure 26. Model interface for entering the cost per unit of secondary product produced.

The user can decide which process to route harvested algae biomass to on the interface. Options included biodiesel, biogas, or fertilizer. If biodiesel is chosen, the user could decide to further process leftover biomass into biogas or fertilizer, or no further processing. These choices are made by the buttons shown in Figure 27.

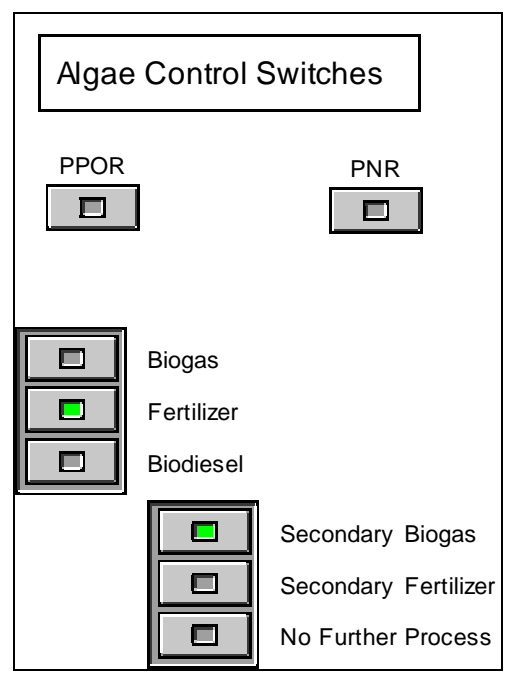

Figure 27. Detail of model interface where user can define the route for secondary use of biomass. 
The following sections define the calculations behind the cost/benefit analysis of the biomass processing step. First, the costs and benefits common to all uses are defined, followed by specific sections for each process.

\section{Benefits of Reduced Aeration}

Cost savings from reduced aeration was considered on two fronts. First, as algae assimilated ammonia, this particular pool of ammonia no longer needed to be nitrified. Second, as the algae are growing, they produce oxygen, as described in Equation (10).

The model considered that as algae would assimilate ammonia-nitrogen, it would no longer be necessary to nitrify that particular pool of nitrogen, thereby creating a cost savings for the plant in terms of aeration energy. According to Maurer et al. (2003), the electricity demand for nitrification is $17 \mathrm{MJ}$ per $\mathrm{kg}$ of nitrogen removed. Using the conversion of $1 \mathrm{kWh}$ per $3.6 \mathrm{MJ}$ and an energy cost of $\$ 0.12$ per $\mathrm{kWh}$, a cost of $\$ 0.5667$ per $\mathrm{kg}$ ammonia was determined; this value was used to convert the reduced demand into monetary savings. Although the stoichiometric relationship between oxygen and nitrogen described below would not change, the value of the cost per $\mathrm{kg}$ ammonia nitrified is dependent on both the aeration technology and electricity costs. For example, Zamalloa et al. (2010) stated the cost of nitrification was $3.5 €(\$ 4.86)$ per $\mathrm{kg} \mathrm{N}$ removed. Because this value can fluctuate, the user can determine the value on the interface of the model. The ramifications of this value are studied more closely in the sensitivity analysis in Chapter Four. 
Furthermore, algae produce oxygen as a byproduct of growth, as shown in Equation (10). Combining the stoichiometric relationships in Equation (10) with those in Equation (19) (Henze et al. 2009) results in Equation (20)

$1 \mathrm{NH}_{4}^{+}+1.86 \mathrm{O}_{2}+1.98 \mathrm{HCO}_{3}{ }^{-}=0.02 \mathrm{C}_{5} \mathrm{H}_{7} \mathrm{O}_{2} \mathrm{~N}+0.98 \mathrm{NO}_{3}{ }^{-}+1.88 \mathrm{H}_{2} \mathrm{CO}_{3}+1.04 \mathrm{H}_{2} \mathrm{O}$

The equation used to calculated costs saving from oxygenic growth was

$$
\$=\frac{114.75 \mathrm{molO}_{2}}{\mathrm{molA}} * \frac{1 \mathrm{molNH} 3}{1.86 \mathrm{molO}_{2}} * \frac{\frac{14 g N H 3-N}{\mathrm{molNH} 3}}{\frac{2351 \mathrm{gA}}{\mathrm{molA}}} * k g A * \frac{\$}{k g N H 3}
$$

where $\mathrm{kgA}$ is the amount of algae biomass produced.

The cost savings calculated through reduced aeration was added to the cost savings resulting from oxygen produced from algal photosynthesis. Figure $28 \mathrm{~A}$ shows the model framework for calculating the cost savings from reduced aeration demand.

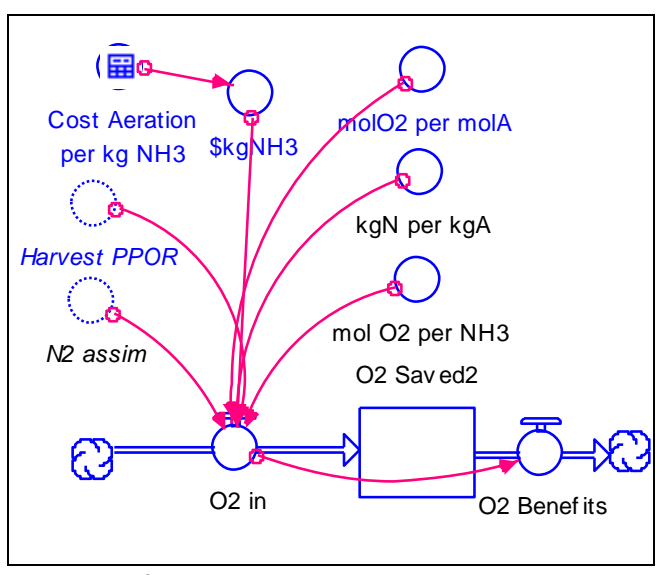

Figure 28A. Model framework for cost savings due to algae assimilation and photosynthetic oxygenation. See Tables A49 and A50 in Appendix A for full list of variables and equations. 


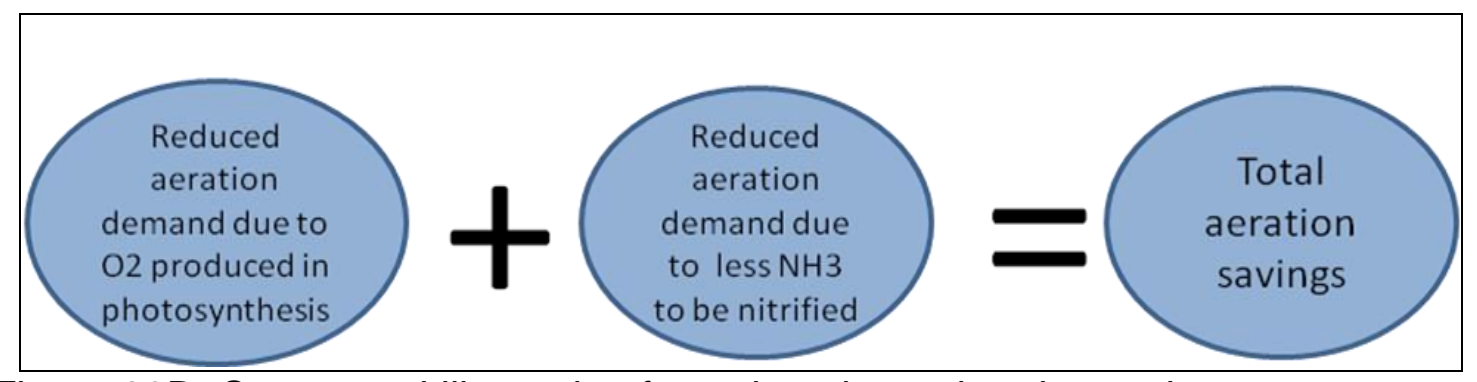

Figure 28B. Conceptual illustration for reduced aeration demand.

It should be noted that denitrification inhibition due to the presence of oxygen was not considered in this model and oxygen produced during growth in the PNR was not tracked.

Reduced Chemical Additives

Denitrification at the HCAWTP occurs through the addition of methanol $\left(\mathrm{CH}_{3} \mathrm{OH}\right)$ as an external carbon source. Based on algae assimilation of nitrate, the reduced amount of chemical additives for denitrification was determined. The chemical demand used was $3.4 \mathrm{~kg}$ methanol required per $\mathrm{kg}$ of nitrate denitrified (Maurer et al. 2003).

Reduced nitrate concentration due to algal assimilation was equated to savings in methanol addition. The cost of methanol can be easily changed on the user interface if the market fluctuates. The equation to determine cost savings is as follows

$\$=\frac{3.4 k g \mathrm{MeOH}}{1 \mathrm{kgNO}_{3}-\mathrm{N}} * \mathrm{kgNO}_{3}-\mathrm{N} * \frac{\$}{\mathrm{LMeOH}} * \frac{\mathrm{LMeOH}}{0.8 \mathrm{kgMeOH}}$

Figure 29A shows the model framework for cost savings due to chemical use reduction. Equation (21) is calculated in the first flow of the diagram. This equation is used to represent cost savings in all secondary process outputs. 


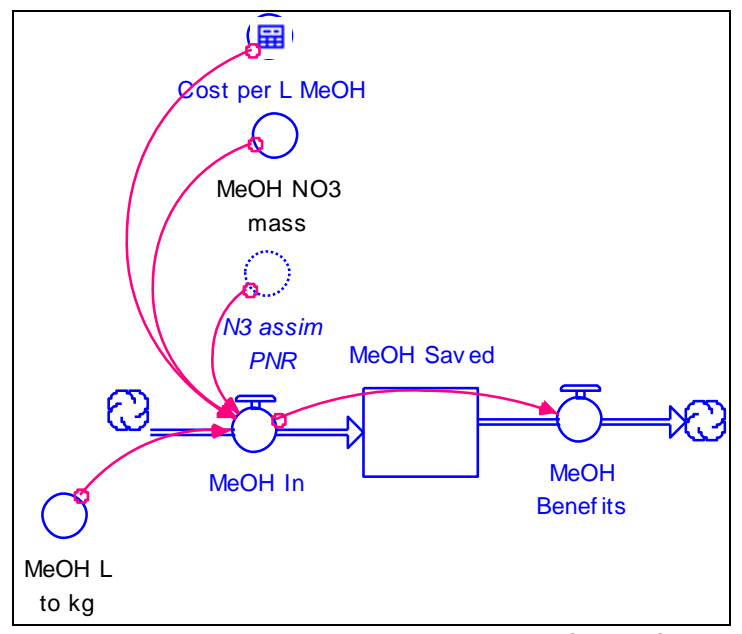

Figure 29A. Model framework to calculate the benefits of reduced chemical additives. See Tables A51 and A52 in Appendix A for full list of variables and equations.

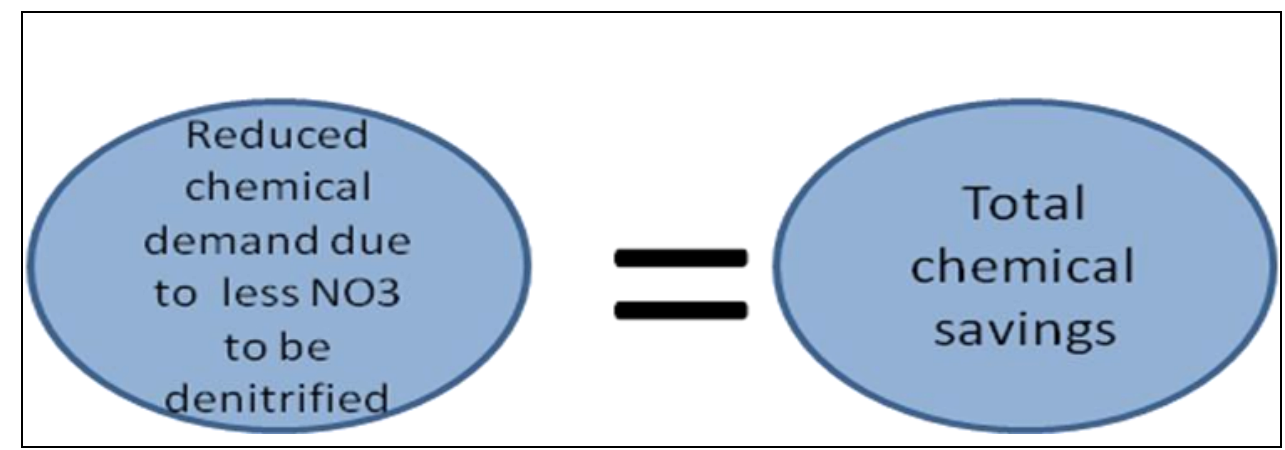

Figure 29B. Conceptual illustration of savings due to reduced chemical demand.

\section{Biomass Production Costs}

Biomass production costs were determined from literature and ranged from $\$ 32 / \mathrm{kg}$ (Molina Grima et al., 2003) to $\$ 3 / \mathrm{kg}$ (Chisti, 2008). A sensitivity analysis was conducted (see Chapter Five) to determine the best estimate, and the value was assumed to be the same for all products. Because neither study accounted for the use of wastewater as a source of nutrients, costs were adapted from published calculations, subtracting those costs, such as media storage and 
production, which would be unnecessary with wastewater incorporated into the process. This assumption was also based on a preliminary life cycle assessment conducted by Aresta et al. (2005) that concluded that producing algae on wastewater effluent could produce a net energy gain.

Biomass production costs were entered into the model using a converter. If production costs fluctuate in the future, as research and development improve process efficiency, this converter can be easily adapted to reflect such changes. Biomass Harvesting Costs

Biomass harvesting costs were broad within the literature, ranging from $\$ 0.12$ per kilogram of algae harvested (Molina Grima et al., 2003) to just $\$ 0.002$ per kilogram (Silberman, 2010). Molina Grima et al. (2003) conducted an extensive study encompassing many different harvesting methods, but the article may be slightly outdated, as more efficient technologies have developed over the past few years. Harvest costs were investigated and further discussed in the sensitivity analysis in Chapter Five.

Similar to biomass production costs, harvesting costs were added to the model using a converter. If costs change depending on technology or conditions at a particular plant, the converter can be adapted to reflect those conditions.

\section{Secondary Product Calculations}

The model is built to conduct a macroeconomic analysis was conducted to assess on processing the harvested algae biomass into biodiesel, biogas, or fertilizer. If biodiesel is the desired end-product, the model is constructed to allow for additional cost-benefit analysis of using the leftover biomass for biogas or 
fertilizer. Each process was evaluated separately, based on best available cost estimates from literature and market prices. Choice of which process to use could be made by depressing buttons on the interface (see Figure 27).

\section{Biodiesel Calculations}

Calculations for biodiesel processing were adapted from Molina Grima et al. (2003). Production costs of crude esterified oil were used based on a list of expenses completed by the authors. The estimation includes raw materials costs, utilities, and fixed capital costs per year. Landfill costs were eliminated from the original calculations because the model assumes the leftover biomass will be used for further processing. The value adapted from the paper was $\$ 71$ per kilogram of algae processed. This cost was then added to the cost of biomass production and harvesting costs. Figure 30A shows the cost framework for biodiesel production in the model. 


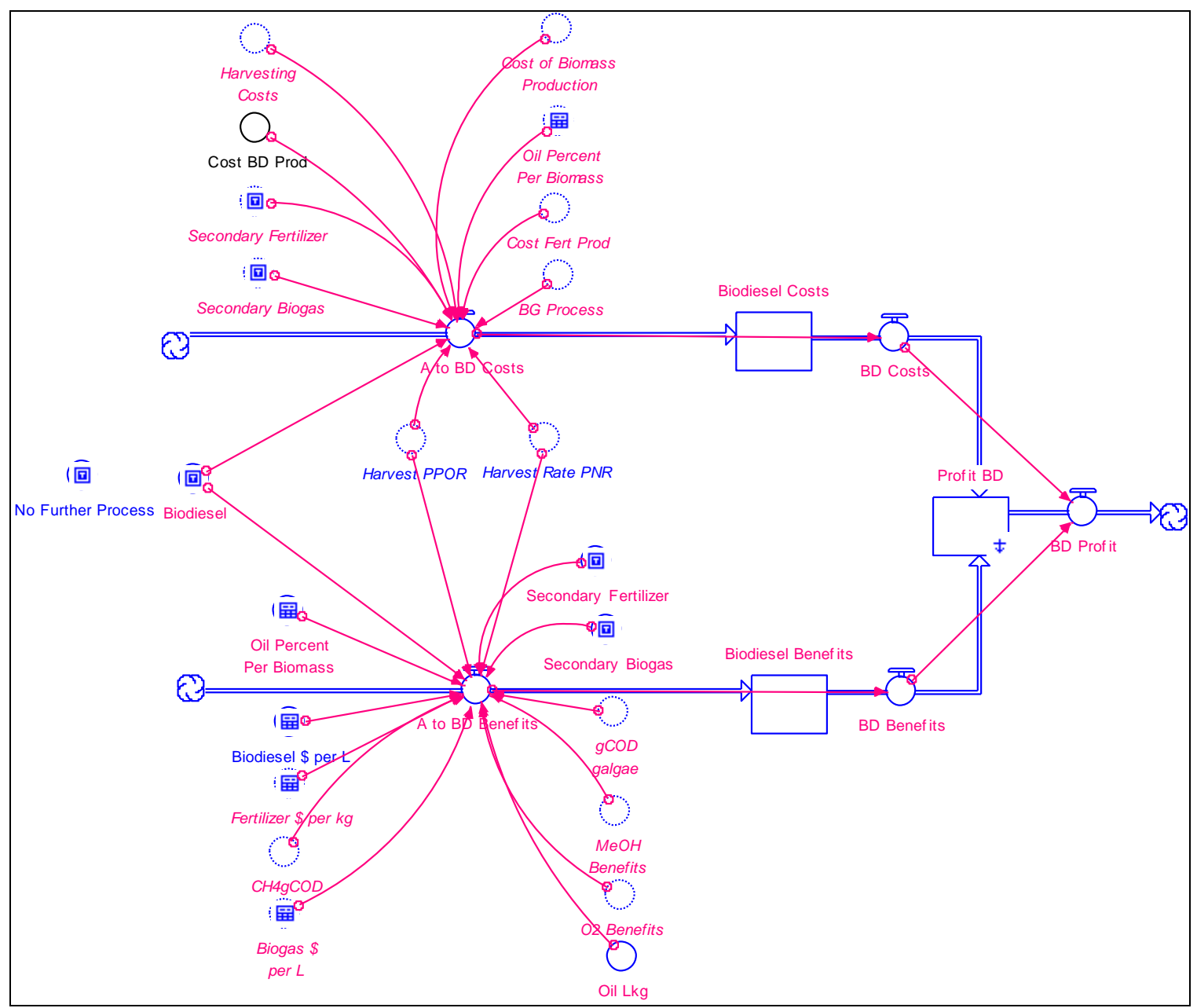

Figure 30A. Model framework for biodiesel production calculations. Individual costs and benefits are summed; costs are then subtracted from benefits to determine overall profit. See Tables A55 and A56 in Appendix A for full list of variables and equations.

\section{BENEFITS}

- Reduced aeration demand

- Reduced chemical demand

-Sale of product on market

Biodiesel (and/or biogas/ fertilizer)

\section{COSTS}

- Biomass Production

- Harvesting Costs

-Processing Costs

PROFITS

Figure 30B. Conceptual illustration of economic calculations in biodiesel processing train. 
Biodiesel calculations can be broken down into cost and benefits. Costs involved in biodiesel production include the cost of biomass production, harvesting costs, and the cost of biodiesel production itself. Other costs factored in were the costs of fertilizer or biogas production associated with further processing of leftover biomass. The equation used to calculate costs was as follows

$\$=\left(k g A^{*} \frac{\$ B D p r o d}{k g A}\right)+\left(k g A^{*} \frac{\$ A p r o d}{k g A}\right)+\left(k g A^{*} \frac{\$ A h a r v}{k g A}\right)$

where $\mathrm{kgA}$ is the mass of algae produced in $\mathrm{kg}, \$ B D$ prod is the cost of biodiesel production per mass of algae processed, $\$$ Aprod is the cost of algae production per unit algae, and $\$ A h a r v$ is the cost of harvesting per unit algae. This calculation occurs in the top portion of the schematic shown in Figure 30A. The equation is turned 'on' by a switch controlled on the interface, which multiplies the equation by 1 or 0 .

Depending on which process the user chooses for further processing of leftover biomass (or the choice of no further processing), additional costs are added to the above equation

$\$=(1-\%$ Oil $) *(k g A) *\left(\frac{\$ \text { process }}{k g A}\right)$

where $\%$ Oil is the percent of algae biomass composed of extractable oil, $\mathrm{kgA}$ is the mass of algae processed, and \$process is the cost of either process (biogas or fertilizer) per unit algae processed. The percent of oil in the algae can be entered on the user interface. The leftover biomass was considered that 
percentage which was not lipids, i.e. one minus the lipid percentage. If the user chooses not to further process the leftover biomass, no additional costs are added to Equation (22).

The monetary benefits of biodiesel processing are also calculated in a series of steps. First, the potential profit for selling biodiesel is calculated based on the amount of oil produced per biomass and the market price of biodiesel. Both these variables are subject to change and are therefore written into the interface of the model. Costs savings realized due to reduced aeration demand and chemical additives are also added to the potential benefits. Figures $30 \mathrm{~A}$ and 30B show the model framework for the cost/benefit analysis of biodiesel; benefits are calculated in the lower flow.

The equation used to calculate economic benefits of biodiesel production was

$$
\$=\$ M e O H+\$ O_{2}+\left(k g A * \frac{k g O i l}{k g A} * \frac{L O i l}{k g O i l} * \frac{\$ B D}{L O i l}\right)
$$

where $\$ M e O H$ is the money saved from chemical additive reduction, $\$ O 2$ is the money saved from reduced aeration demand, $\mathrm{kgOi} / \mathrm{kgA}$ is the percent of oil per unit algae, LOil/kgOil is the volume of oil per mass of oil, defined as the density of biodiesel of $0.88 \mathrm{~kg} / \mathrm{L}$ (Alptekin and Canakci 2008), $\$ B D$ is the market value of biodiesel, based on market prices, which can be entered on the model interface; the value of $\$ 3.10$ was used in model simulations for this study.

Depending on the user selected use of leftover biomass, additional monetary benefits were added such as 
$\$=(1-\% O i l) *(k g A) *\left(\frac{\$ \text { market }}{k g A}\right)$

where \$market is the market value of biogas or fertilizer per unit algae. If the user selects to not further process biomass, no additional benefits are added.

Overall profit from biodiesel was calculated by subtracting the overall costs from the overall benefits

BD_Benefits-BD_Costs $=$ BD_Profit

Profit was reported in USD per day in the outgoing flow of the final stock.

\section{Biogas Calculations}

Costs associated with anaerobic digestion of algae biomass to produce biogas were adapted from Gebrezgabher et al. (2010), a study that analyzed the costs of producing biogas from varying substrates, including labor costs. Calculations related to biogas production from energy maize and food waste were used for this model, as they were the closest in composition to algal biomass and had the highest, and therefore most conservative, values. Values used for biogas production costs and labor costs were $\$ 0.048$ and $\$ 0.054$ per kilogram of biomass processed, respectively. The model framework for this calculation is shown in Figure 31. Labor costs and biogas production costs were added together to obtain process costs. 


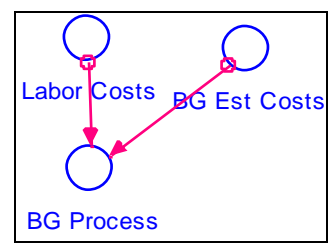

Figure 31. Model framework for calculating biogas production costs. Labor and processing costs were adapted from Gebrezgabher et al. (2010) and were set at $\$ 0.054 / \mathrm{kg}$ algae and $\$ 0.048 / \mathrm{kg}$ algae, respectively.

Costs were calculated by adding all costs associated with biogas

production

$\$=\left(k g A^{*} \frac{\$ B G p r o d}{k g A}\right)+\left(k g A^{*} \frac{\$ A p r o d}{k g A}\right)+\left(k g A^{*} \frac{\$ A h a r v}{k g A}\right)$

where $\mathrm{kgA}$ is the mass of algae processed, $\$ B G$ prod is the cost of biogas production per unit algae, \$Aprod is the production cost of culturing algae per unit algae, and $\$ A$ harv is the harvesting costs per unit algae. 


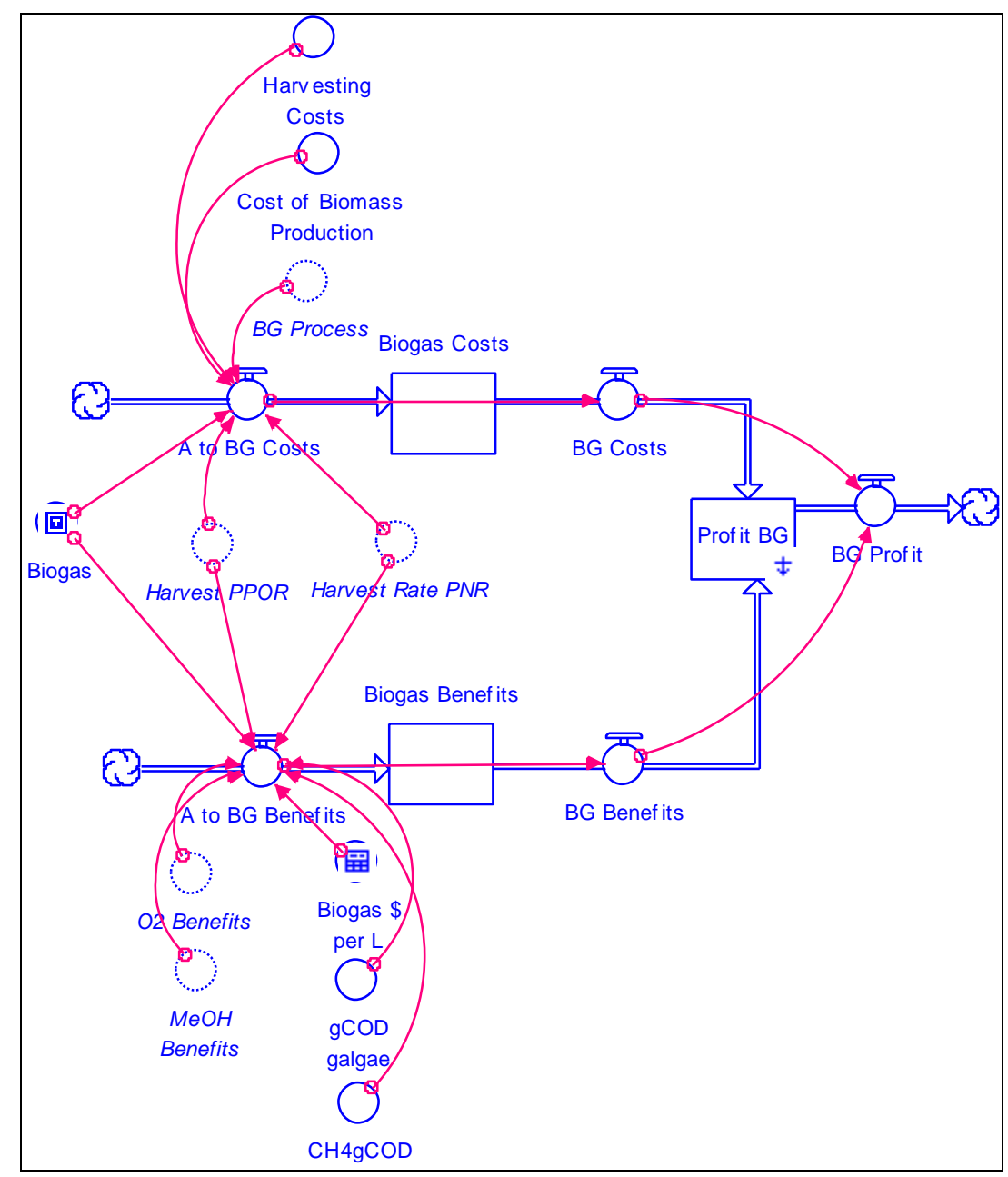

Figure 32A. Model framework for biogas calculations. Costs were subtracted from benefits to calculate overall net profit. See Tables A53 and A54 in Appendix A for full list of variables and equations.

\section{BENEFITS}

- Reduced aeration demand

- Reduced chemical demand

-Sale of biogas in market

\section{COSTS}

-Biomass Production

- Harvesting Costs

-Processing Costs
= PROFITS

Figure 32B. Conceptual illustration of economic calculations in biogas processing train. 
Benefits were calculated by adding the monetary benefit of selling biogas to the amount of money saved via reduced aeration and chemical additives. Biogas yield was based on converting the amount of algae produced to a mass of $C O D$, then subsequently converting the mass of $C O D$ to the volume of methane theoretically possible per mass of COD (Rittman and McCarty 2001). Algae was converted to mass of COD by the following steps:

First, the oxygen equivalent of algae cells was determined based on the following equation

$$
\mathrm{C}_{100} \mathrm{O}_{48} \mathrm{H}_{183} \mathrm{~N}_{11} \mathrm{P}+227 / 2 \mathrm{O}_{2}=100 \mathrm{CO}_{2}+11 \mathrm{NH}_{3}+75 \mathrm{H}_{2} \mathrm{O}
$$

Next, the COD of the cells was determined by the following equation

$$
\frac{113.5 \mathrm{molO}_{2} *\left(32 \mathrm{~g} / \mathrm{molO}_{2}\right)}{1 \mathrm{molA}^{*}(2351 \mathrm{~g} / \mathrm{molA})}=\frac{1.545 \mathrm{kgCOD}}{\mathrm{kgA}}
$$

where $m o l A$ and $k g A$ is the moles of algae and mass of algae, respectively. The value of $1.545 \mathrm{~kg} \mathrm{COD} / \mathrm{kg}$ algae was used.

Methane production was estimated as the grams of methane produced per gram COD, as shown in the following steps (Rittman and McCarty, 2001) A stoichiometric relationship between digested algae and methane produced was determined using the overall equation previously discussed in Equation (4) $R=f_{e}{ }^{*} R_{a}+f_{s}{ }^{*} R_{c}+R_{d}$ where $R_{a}$ is the electron acceptor half reaction, $R_{c}$ is the cell synthesis equation, and $R_{d}$ is the electron donor half reaction. The yield of the digesting organisms is assumed to be $0.07 \mathrm{gVSS} / \mathrm{gCOD}$; therefore, $\mathrm{f}_{\mathrm{s}}$ is equal to 0.1 and $\mathrm{f}_{\mathrm{e}}$ is equal to 0.9. The $R_{d}$ was developed based on the custom organic half reaction equation 
per Rittman and McCarty (2001) and the molecular formula for algae used throughout this report.

The overall $\mathrm{R}$ equation was calculated as follows

$$
\begin{gathered}
\mathrm{Rd}=0.0022 \mathrm{C}_{100} \mathrm{O}_{48} \mathrm{H}_{183} \mathrm{~N}_{11} \mathrm{P}+0.3590 \mathrm{H}_{2} \mathrm{O}=0.1960 \mathrm{CO}_{2}+0.0242 \mathrm{NH}_{4}^{+}+0.0242 \mathrm{HCO}_{3}^{-}+\mathrm{H}^{+}+\mathrm{e}^{-} \\
\mathrm{f}_{\mathrm{e}}{ }^{*} \mathrm{R}_{\mathrm{a}}=0.1125 \mathrm{CO}_{2}+0.9 \mathrm{H}^{+}+0.9 \mathrm{e}^{-}=0.1125 \mathrm{CH}_{4}+0.2250 \mathrm{H}_{2} \mathrm{O} \\
\mathrm{f}_{\mathrm{s}}{ }^{*} \mathrm{R}_{\mathrm{C}}=0.0200 \mathrm{CO}_{2}+0.005 \mathrm{HCO}_{3}^{-}+0.005 \mathrm{NH}_{4}^{+}+0.1 \mathrm{H}^{+}+0.1 \mathrm{e}^{-}=0.005 \mathrm{C}_{5} \mathrm{H}_{7} \mathrm{O}_{2} \mathrm{~N}+0.0450 \mathrm{H}_{2} \mathrm{O} \\
\mathrm{R}=0.0022 \mathrm{C}_{100} \mathrm{O}_{48} \mathrm{H}_{183} \mathrm{~N}_{11} \mathrm{P}+0.0890 \mathrm{H}_{2} \mathrm{O}=0.0635 \mathrm{CO}_{2}+0.0192 \mathrm{NH}_{4}^{+}+0.0192 \mathrm{HCO}_{3}^{-} \\
+0.1125 \mathrm{CH}_{4}+0.005 \mathrm{C}_{5} \mathrm{H}_{7} \mathrm{O}_{2} \mathrm{~N}
\end{gathered}
$$

Using the molar relationships determined from $R$, the amount of biogas (as methane) was calculated

$$
\frac{\mathrm{LCH}_{4}}{\mathrm{kgA}}=\frac{0.1125 \mathrm{molCH}_{4}}{0.0022 \mathrm{molA}} * \frac{\frac{22.4 \mathrm{LCH}_{4}}{\mathrm{molCH}}+\frac{1000 \mathrm{gA}}{2351 \mathrm{gA}}}{\mathrm{molA}}=\frac{487 \mathrm{LCH}_{4}}{\mathrm{kgA}}
$$

where volume of methane is considered at standard temperature $\left(0^{\circ} \mathrm{C}, 273 \mathrm{~K}\right)$ and pressure (1 atm). To convert to a temperature of $20^{\circ} \mathrm{C}(293 \mathrm{~K})$, the following equation was used

$$
V_{2}=V_{1}\left(\frac{T_{2}}{T_{1}}\right) ; \quad V_{2}=487 L_{C H}\left(\frac{293 K}{273 K}\right)=523 L C H_{4}
$$

where $V_{1}$ is the volume of methane calculated from Equation (32) above, $T_{1}$ is at STP, and $T_{2}$ is considered $20^{\circ} \mathrm{C}$. The value of $523 \mathrm{~L}$ methane per $\mathrm{kg}$ algae was used in the model.

The market price for biogas was determined based on Emcon Associates (1980). Assuming a 55\% methane content in biogas produced, the conversion of $20490 \mathrm{~kJ} / \mathrm{m} 3$ biogas was determined. The commodity price of $\$ 4.08 / \mathrm{MmBTU}$ 
was used (www.bloomberg.com/energy, accessed 9/28/2010). To convert the energy content to monetary value the following equation was used

$$
\frac{\$}{L C H 4}=\frac{20490 k J}{m 3} * \frac{1 B T U}{1.055056 k J} * \frac{1 m 3}{1000 L} * \frac{19.42 B T U}{L} * \frac{\$ 4.08 e-6}{B T U} * L C H 4
$$

Benefits from producing algae were calculated by adding the savings from reduced chemical demand and aeration requirements to the estimated profit from selling the biogas produced. Conversions per unit algae were calculated as described above.

$\$=\$ M e O H+\$ O_{2}+\left(k g A * \frac{523 L_{C H} H_{4}}{k g C O D} * \frac{1.545 k g C O D}{k g A} * \frac{\$}{L C H 4}\right)$

where $\$ \mathrm{MeOH}$ is the savings due to reduced chemical additives, $\$ \mathrm{O}_{2}$ is the savings due to reduced aeration needs, $\mathrm{LCH}_{4} / \mathrm{kgCOD}$ is liters of methane produced per mass of COD digested, $\mathrm{kgCOD} / \mathrm{kgA}$ is the mass of COD available per mass of algae biomass and $\$ / L C H 4$ is the market price of biogas. The value per BTU of biogas can be changed on the model interface. Utilizing the leftover digester centrate or biomass as fertilizer was not included as a benefit in this model.

To gain overall net profit, costs are subtracted from benefits such that BG_Benefits-BG_Costs $=$ BG_Profit where $B G$ is an abbreviation for biogas. Profits were reported in USD per day. The biogas process was turned 'on' or 'off' by a switch on the user interface. 


\section{Fertilizer Calculations}

Fertilizer cost-benefit analysis is conducted similarly to biodiesel and biogas. Costs were subtracted from benefits to calculate overall net profit. Figure 33A shows the model framework for fertilizer processing. Fertilizer processing could be turned 'on' or 'off' at the user interface via the button.

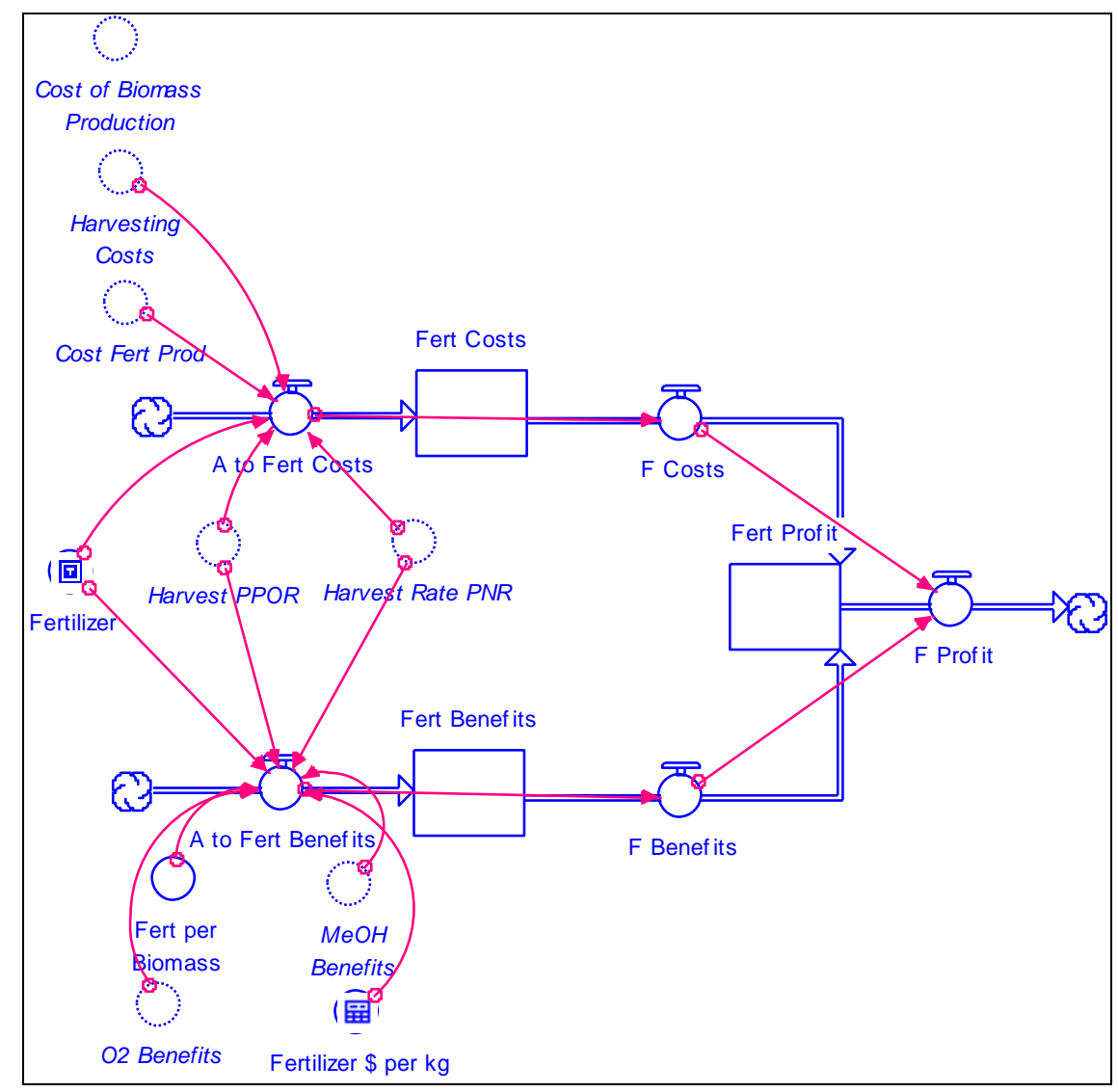

Figure 33A. Model framework for fertilizer cost-benefit analysis. See Tables A57 and A58 in Appendix A for full list of variables and equations. 


\section{BENEFITS}

-Reduced aeration demand

- Reduced chemical demand

- Sale of fertilizer in market

\section{COSTS}

-Biomass Production

-Harvesting Costs

-Processing Costs
PROFITS

Figure 33B. Conceptual illustration of economic calculations in fertilizer processing train.

The cost of fertilizer processing was adapted from Fadare et al. (2010).

Costs adapted for the model were for pelletized fertilizer production, which was chosen to be conservative and because it was similar to the case of HFCAWTP. Figure 34 shows the model framework for calculating fertilizer production costs.

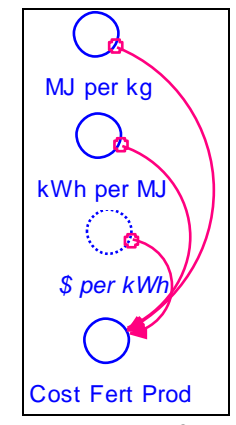

Figure 34. Model framework for calculating fertilizer production costs.

The cost of fertilizer production was calculated with the equation

$\frac{\$}{k g A}=\frac{M J}{k g A} * \frac{k W h}{M J} * \frac{\$}{k W h}$

where $\mathrm{kgA}$ is the mass of algae processed. The values of $0.277 \mathrm{kWh} / \mathrm{MJ}$ and $\$ 0.12$ USD/kWh were used as conversion factors in the equation.

The total energy (MJ) required per kilogram of biomass processed was adapted from Fadare et al. (2010). The inclusion of superfluous steps in the 
process, such as sorting, as well as the higher energy prices, was considered to balance the lower labor costs reflected in the study. A value of $0.33 \mathrm{MJ}$ per $\mathrm{kg}$ of algae processed was used for this model.

Calculations for total fertilizer costs included harvesting and biomass production costs as well as processing costs

$$
\$=\left(k g A^{*} \frac{\$ F p r o d}{k g A}\right)+\left(k g A^{*} \frac{\$ A p r o d}{k g A}\right)+\left(k g A^{*} \frac{\$ h a r v}{k g A}\right)
$$

where $\mathrm{kgA}$ is the mass of algae biomass processed, $\$ F$ prod is the cost of fertilizer processing per unit algae, $\$$ Aprod is the cost of algae production per unit algae, and \$harv is the cost of harvesting per unit algae.

Benefits were calculated by adding cost savings due to reduced chemical additives and aeration demand to profit generated from sale of fertilizer. As not all of the biomass would be directly converted to fertilizer, a conversion factor of 0.5 was used; i.e. half of the biomass was considered to be converted to fertilizer. The cost of fertilizer was taken from market prices of comparable products and could be changed on the interface of the model.

Benefits were calculated based on the following equation

$$
\$=\$ M e O H+\$ O_{2}+\left(k g A * \frac{k g F e r t}{k g A} * \frac{\$ F e r t}{k g F e r t}\right)
$$

where $\$ \mathrm{MeOH}$ is the cost savings from reduced chemicals required, $\$ \mathrm{O} 2$ is the cost savings from reduced aeration, $\mathrm{kgA}$ is the algae biomass processed, $\mathrm{kgFert} / \mathrm{kgA}$ is the conversion factor for fertilizer produced per unit algae, and $\$ F e r t / k g F e r t$ is the monetary value per unit algae. 
Overall profit from fertilizer production was determined by subtracting the total costs from the total benefits as shown in the equation below

F_Benefits-F_Costs $=$ F_Profit

and was reported in USD/day. 


\section{Chapter Four:}

\section{Sensitivity Analysis}

The model was run through a series of sensitivity tests, testing both biological and economic parameters, to determine how and to what extent changes in certain variables affected biomass production and economic viability. The most sensitive ranges for variables were also determined when applicable. Results of the sensitivity analysis are presented in this section. As discussed in the previous section, the model was built to have two algae reactors, the postpure oxygen reactor (PPOR) and the post-nitrification reactor (PNR). In the sensitivity analysis, the effects of the changing parameters were evaluated in terms of algae biomass production unless otherwise noted.

\section{Wastewater Variables}

Because biomass production is intimately connected to wastewater characteristics, the wastewater framework was first tested to determine which variables were most sensitive. Mass balance of water flow and nutrients was maintained throughout all tests, which was verified through the mechanisms described in Chapter Three.

Wastewater Influent Characteristics

Influent wastewater characteristics to a typical domestic wastewater plant can fluctuate daily and/or seasonally. Since algae biomass production is greatly 
influenced by available substrates, the model was tested against varying influent loads to investigate the affect on biomass production. The model was run under typical plant loading, high loading, and under limiting conditions of influent nitrogen, phosphorous, and carbon dioxide.

Figure 35 shows the setting for Trial 1; all settings, except for influent water characteristics, remained constant throughout subsequent trials. Table 4 shows the concentrations selected for influent ammonia, soluble phosphorous, and carbon dioxide under the various trials. Note that the model converts influent ammonia to nitrate at a specific removal rate, so influent nitrate concentration was not varied.

Table 4. Concentration ranges of influent ammonia, soluble phosphorous, and carbon dioxide selected for wastewater characteristics sensitivity analysis.

\begin{tabular}{|l|l|l|l|}
\hline Nutrient & Low & Typical & High \\
\hline $\mathrm{NH}_{3}-\mathrm{N}$ & 5 & 35 & 70 \\
\hline Soluble $\mathrm{P}$ & 2 & 4.3 & 20 \\
\hline $\mathrm{CO}_{2}-\mathrm{C}$ & 10 & 32 & 64 \\
\hline
\end{tabular}

Note: Concentrations are in $\mathrm{mg} / \mathrm{L}$.

Table 5. Trial matrix for varying influent wastewater characteristics.

\begin{tabular}{|l|l|l|l|l|l|}
\hline Nutrient & Trial 1 & Trial 2 & Trial 3 & Trial 4 & Trial 5 \\
\hline $\mathrm{NH}_{3}-\mathrm{N}$ & Typ & High & Low & Typ & Typ \\
\hline Soluble P & Typ & High & Typ & Low & Typ \\
\hline $\mathrm{CO}_{2}-\mathrm{C}$ & Typ & High & Typ & Typ & Low \\
\hline
\end{tabular}




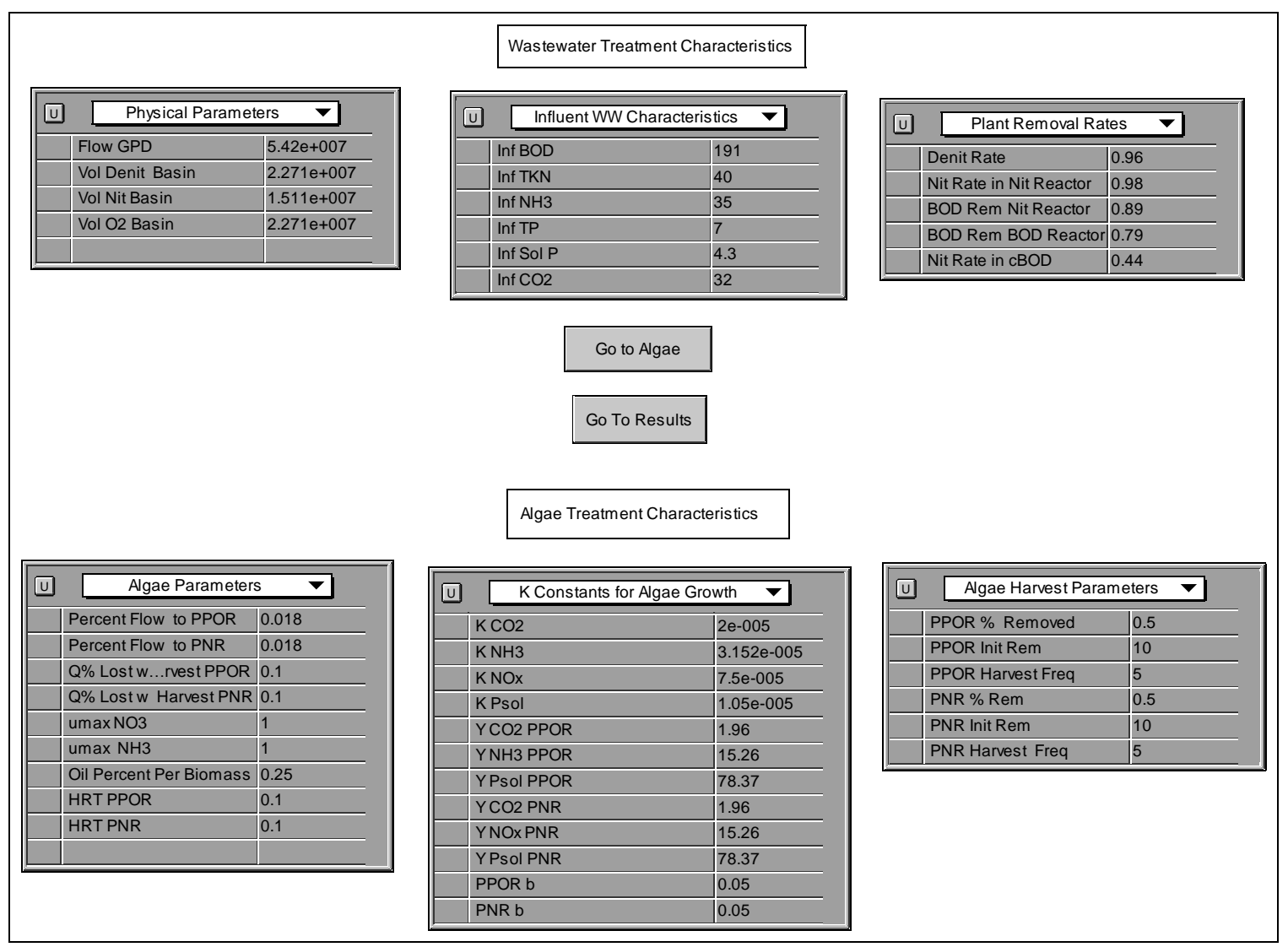

Figure 35. Model parameter settings for influent wastewater characteristics sensitivity test.

All other variables were kept constant during this sensitivity analysis, thereby specifically testing the effect of influent wastewater characteristics on algae biomass production. Figure 36 shows a comparison of the biomass generated under each trial test. Biomass production increased with higher loading (Trial 2); algae in nitrogen and phosphorous limiting trials (Trials $3 \& 4$ ) were washed out, as growth could not keep up with harvest. Biomass production was stable with limited carbon dioxide (Trial 5), although at lower levels than typical or high loading conditions. Lines are jagged due to harvesting. Results for the PNR can be found in Appendix C. 


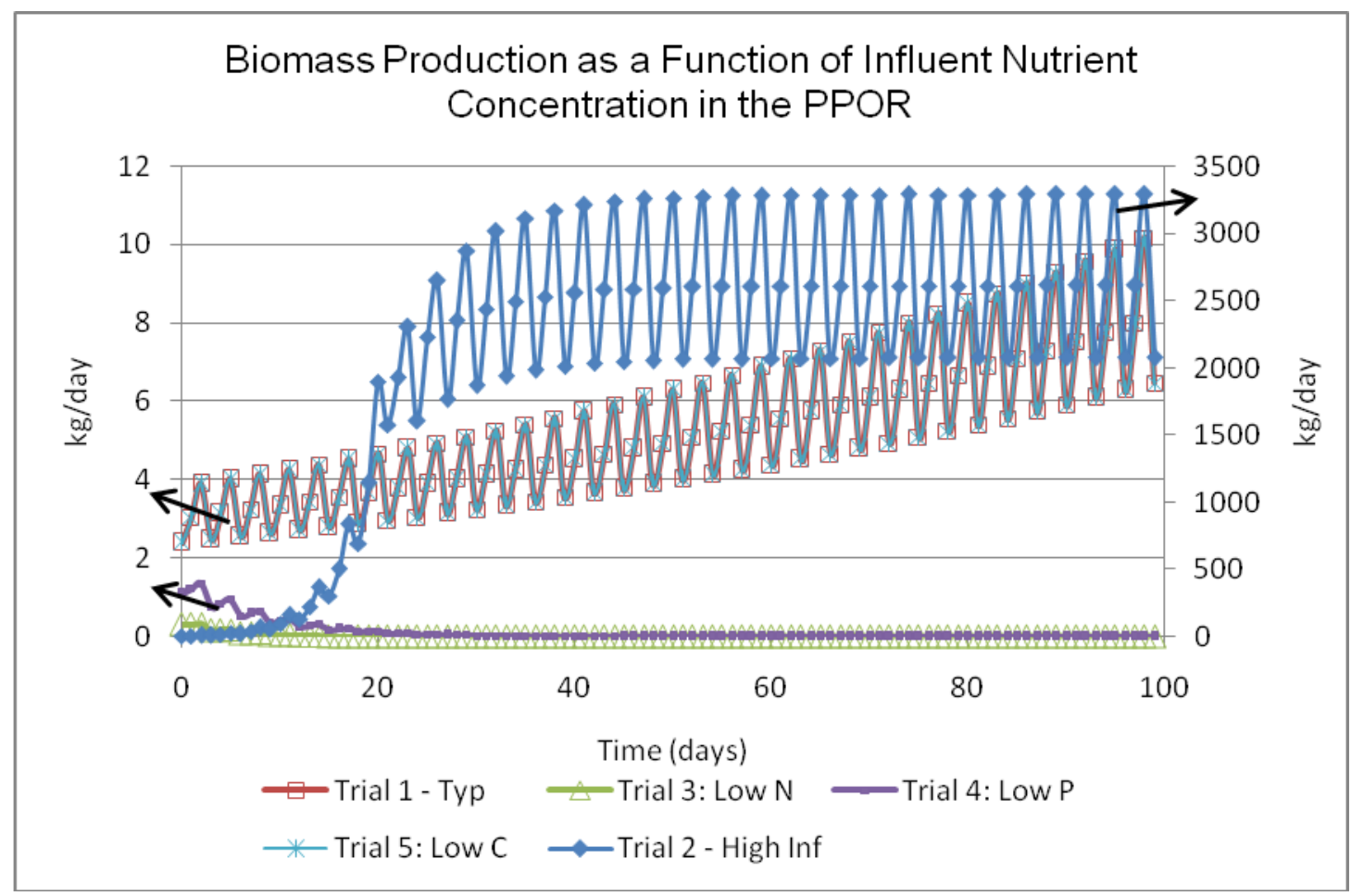

Figure 36. Biomass production in the PPOR as a function of influent nutrient concentration. Trial 2 is on the secondary y-axis; all other Trials are on the primary $y$-axis. For explanation of Trial details, see Tables 4 and 5. Line oscillations are due to harvest events.

Nutrient limitation can be a consequence of varying influent concentrations. Figure 37 show the results of influent ammonia concentration on biomass production in the PPOR when harvest rate was set to $50 \%$ harvest every 3 days. Influent concentration was varied from 5-80 mg/L. Biomass growth is limited at influent concentrations of $5 \mathrm{mg} \mathrm{NH} 3-\mathrm{N} / \mathrm{L}$, but grows at a much higher capacity as influent concentration increases. In fact, biomass production is the same at concentrations above $40 \mathrm{mg} / \mathrm{L}$, indicating another nutrient becomes limiting at this point. 


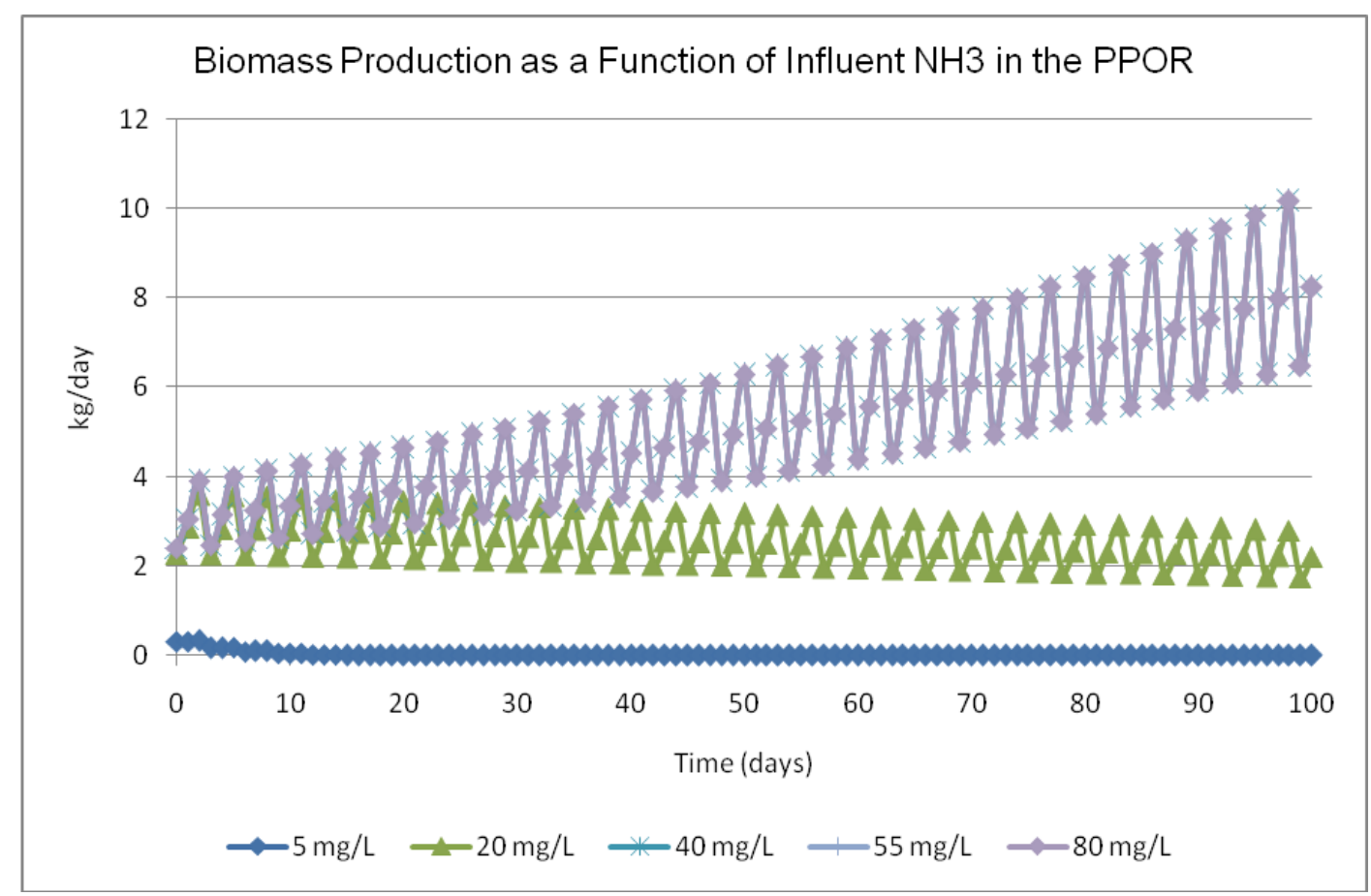

Figure 37. Biomass production in the PPOR as a function of influent $\mathrm{NH} 3$ concentration. Trials with $40 \mathrm{mg} / \mathrm{L}$ and above follow the same upward trend. Line oscillations are due to harvest events.

\section{Other Wastewater Parameters}

Other physical wastewater parameters, such as HRT, flow diverted to the algae basins, and plant removal rates did not affect overall biomass production. This is because algae SRT remained constant through trials for other physical parameters. For example, although HRT or flow is increased, the volume of the algae basin is subsequently increased due to the model framework discussed in Chapter 3. This normalizes the available concentration to volume, equalizing the influent concentration. As harvest rate remained constant, an increase in available substrate would not affect algae growth, as they are limited by the amount of time they have to assimilate the substrate. 


\section{Algae Growth Variables}

As discussed in Chapter Two, algal species are very diverse, ranging in physiology, specific growth rates, metabolic preferences, etc. Therefore, a sensitivity test was conducted on variables that may directly affect the growth of algae.

\section{Specific Growth Rate and Harvest Waste Rate}

Because the model cannot take into account every environmental condition that could affect algae growth, the choice of specific growth rate for simulations is important. Specific growth rate was randomly varied from 0.1 to 2.5 per day. Figure 38 shows how biomass production in the PPOR increases with increasing $\mu$ max, until substrate availability limits growth. The harvest rate was set to remove $50 \%$ of the biomass every 3 days, which was too high for specific growth rates below 0.9/day. For results in the PNR see Appendix C. 


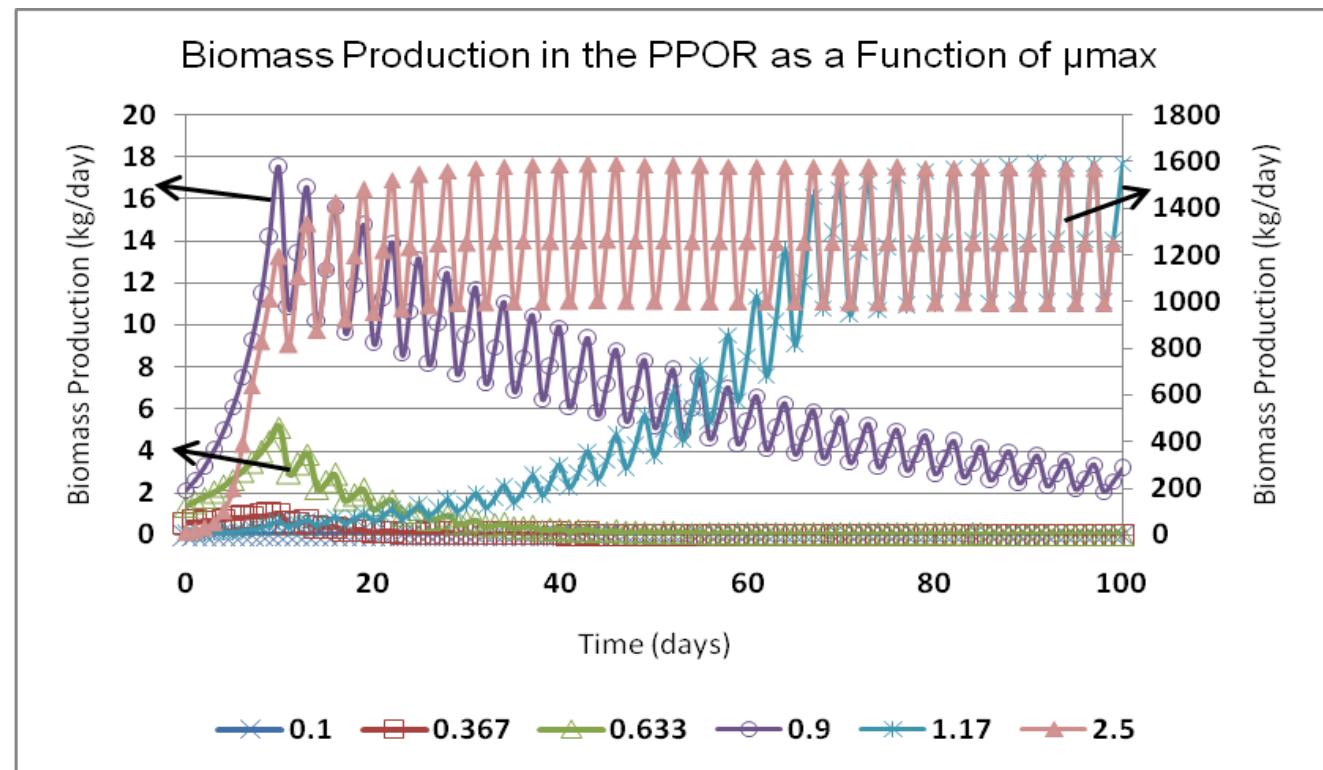

Figure 38. Biomass production in the PPOR with increasing $\mu$ max. $\mu$ max of 1.17 and 2.5 per day are set to the secondary axis. Line oscillations are due to harvest events.

Biomass harvest rate works very closely with specific growth rate; if the harvest rate is too high, all algae will be washed out and no growth will occur. Harvest amount was varied from $10-50 \%$ of accumulated algae, with harvest frequency set constant at every 3 days, and $\mu$ max of 1 /day. Figure 39 shows the biomass production in the PPOR under these conditions. With a $\mu$ max of 1 /day, algae is washed out when harvest rate is $50 \%$, as growth is physiologically limited. 


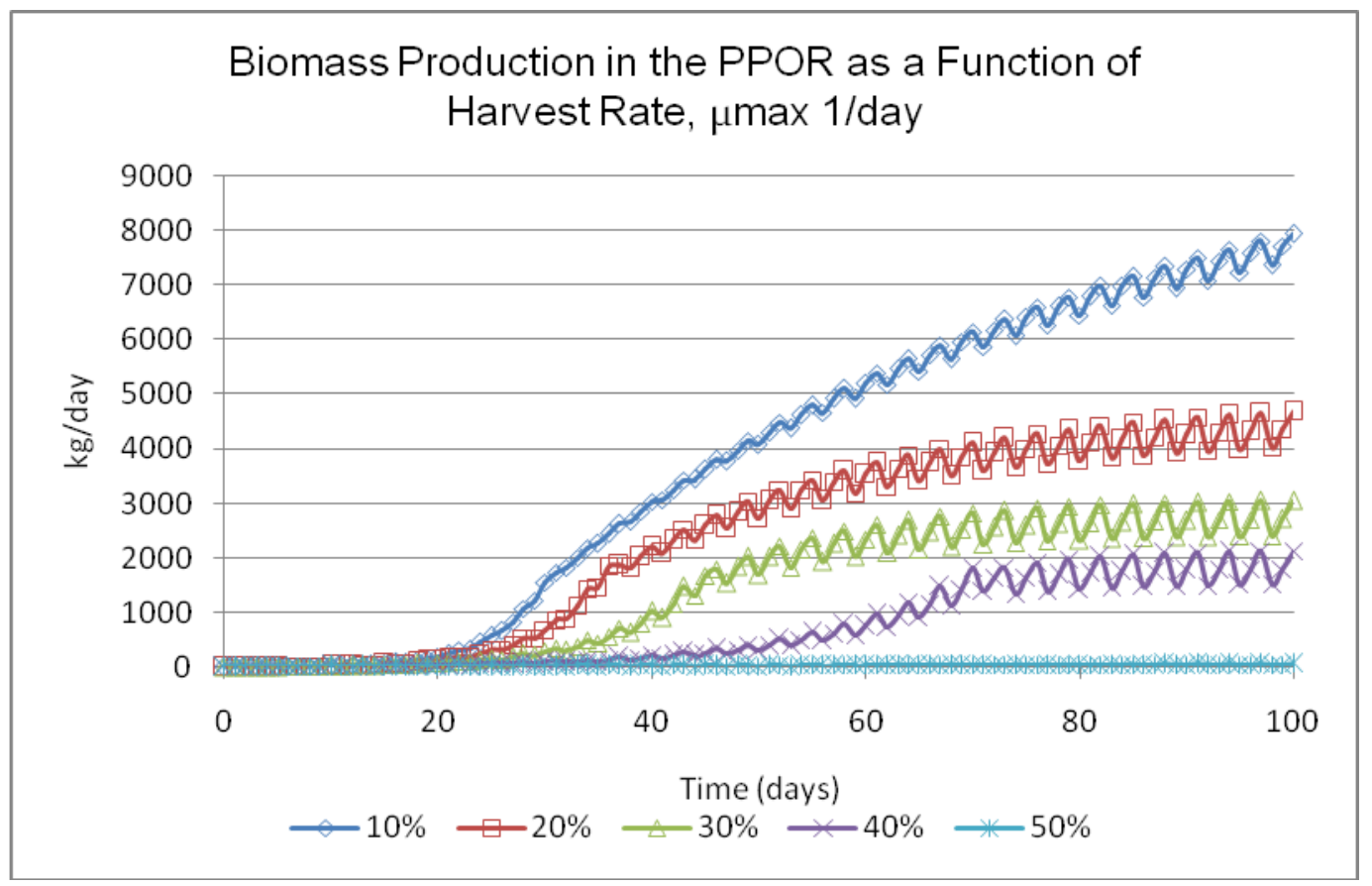

Figure 39. Biomass production as a function of harvest rate. Each line represents a harvest rate in percent of biomass in the basin per day. Algae is washed out of the system when harvest rate becomes too high under conditions tested.

The harvest rate also affected the calculated specific growth rate, as shown in Figure 40. The model was run maintaining all variables the same between the PPOR and PNR, including specific growth rate of 1/day, flow of 1 MGD, and a decay constant of 0.2 /day. Harvest was set in the PPOR to zero, whereas the harvest in the PNR was 50\% every 10 days, beginning on day 10 . As shown in Figure 40, specific growth rate in both reactors starts high, but as algae grow and assimilate substrate, calculated specific growth rate decreases. However, in the PPOR, where no algae was harvested, the specific growth rate decreased faster, as more algae were assimilating more substrate. 


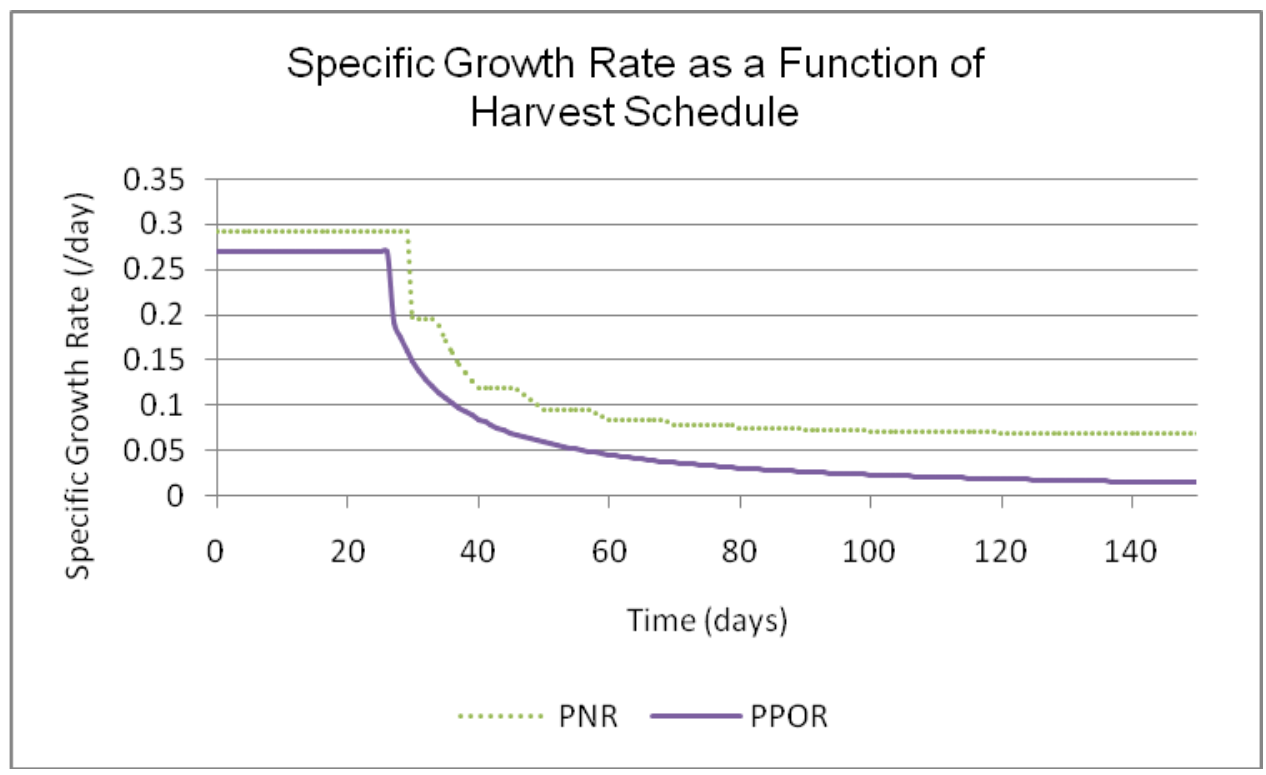

Figure 40. Specific growth rate as a function of harvest schedule. Harvest in the PNR was set to $50 \%$ every 10 days, beginning on day 10 ; harvest was zero in the PPOR.

\section{Half Saturation Constants}

Because the model relies heavily on Monod kinetics, biomass production can be influenced by the selection of the half saturation constant $(K)$ for ammonia, nitrate, carbon dioxide, and soluble phosphorous. Therefore, the model's sensitivity to $K$ for each parameter was tested over a range of $1 \mathrm{e}-7$ to 1e-3 mg/L. Results are shown in Figures 41 and 42.

In the PPOR, varying the half saturation constant of NOx species did not affect the calculated $\mu$, as algae in this basin are only considered to be growing on ammonia. Likewise, $K \_N H 3$ did not affect the $\mu$ in the PNR. However, varying the $K$ for other nutrients did affect calculated $\mu$. In general, as $K$ values increased, $\mu$ decreased. This would be expected; as the $K$ value increases, more substrate is needed in order to keep the fraction close to 1 , thereby maintaining calculated $\mu$ close to $\mu$ max. 


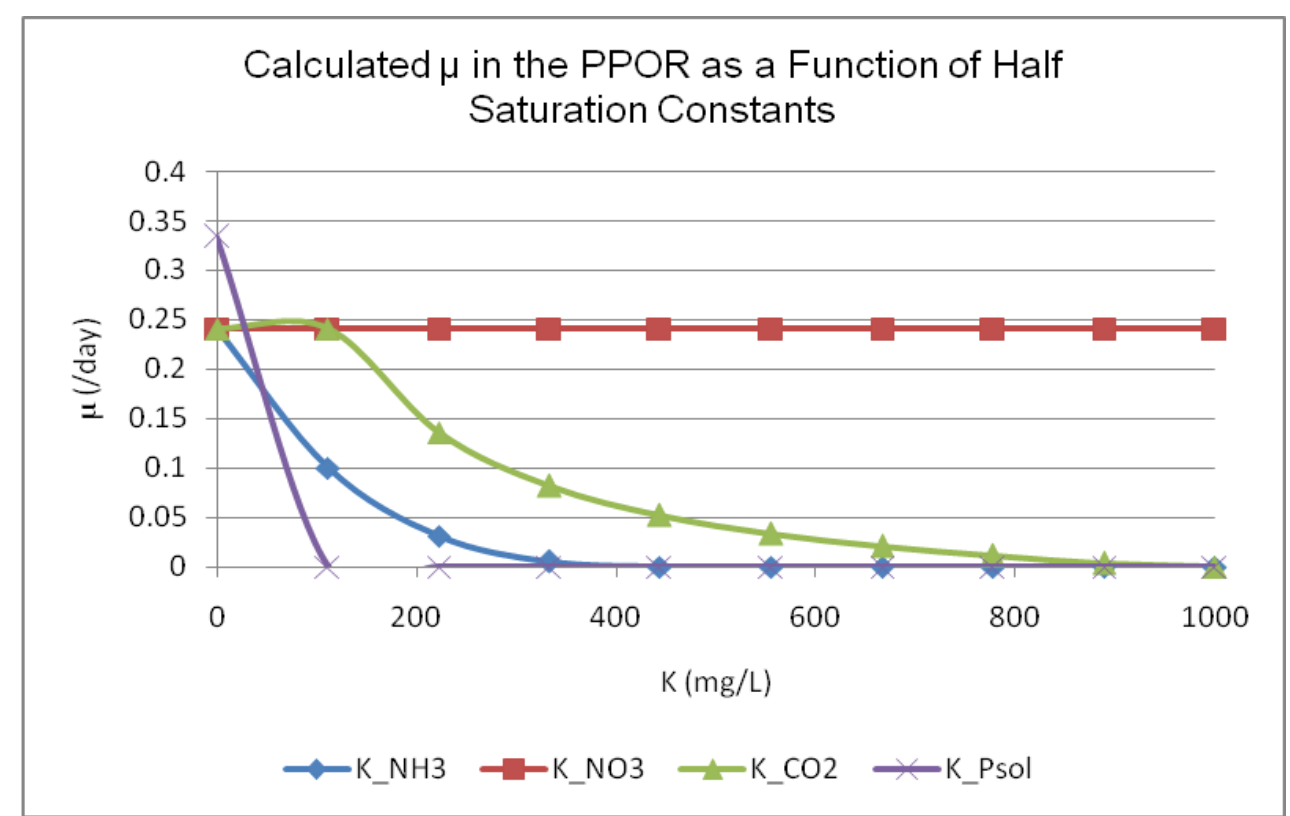

Figure 41. Calculated $\mu$ in the PPOR as a function of $K$. Each line represents a different simulation where the $K$ for each nutrient was independently varied while other $K$ values were kept constant.

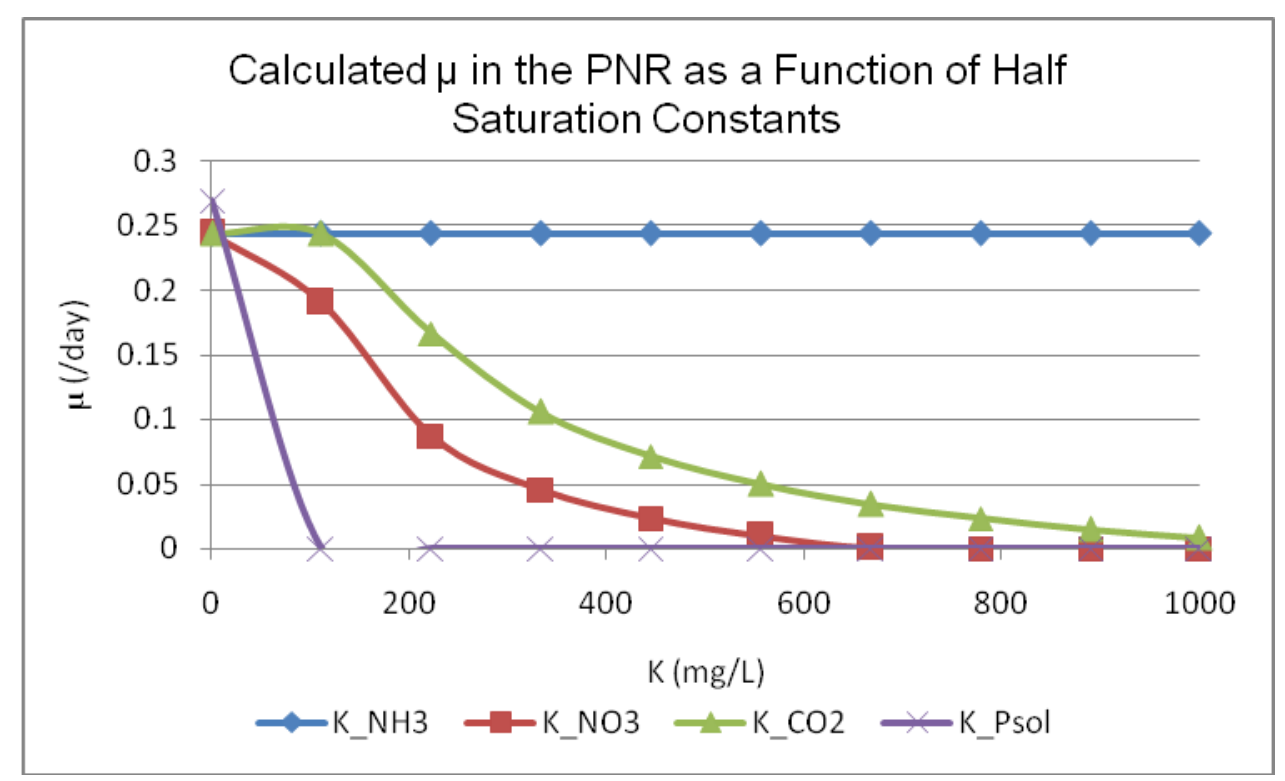

Figure 42. Calculated $\mu$ in the PNR as a function of $K$. Each line represents a different simulation where the $K$ for each nutrient was varied while other $K$ values were kept constant. 


\section{Yield Coefficient}

Biomass yield $(Y)$, or biomass produced per unit substrate consumed, also may affect biomass production when calculated by Monod kinetics. Also, as discussed in Chapter Three, the molecular formula for algae can vary depending on species, growth conditions, or habitat. Therefore, the sensitivity of this variable was tested to identify the effect a different molecular formula may have on overall substrate removal.

In general, as $Y$ increases, more biomass is produced per unit substrate. Empirically, a higher $Y$ means that less substrate is necessary to produce one unit of algae; conversely, more substrate needed per unit algae will decrease yield. In terms of substrate assimilation, a higher yield corresponds to a lower substrate utilization rate (q); therefore, although biomass production may be constant, less substrate is removed per unit algae produced. Figure 43 shows this trend when $Y_{-} N H 3$ is varied from $5-25 \mathrm{~kg}$ biomass produced $/ \mathrm{kg}$ substrate consumed. 


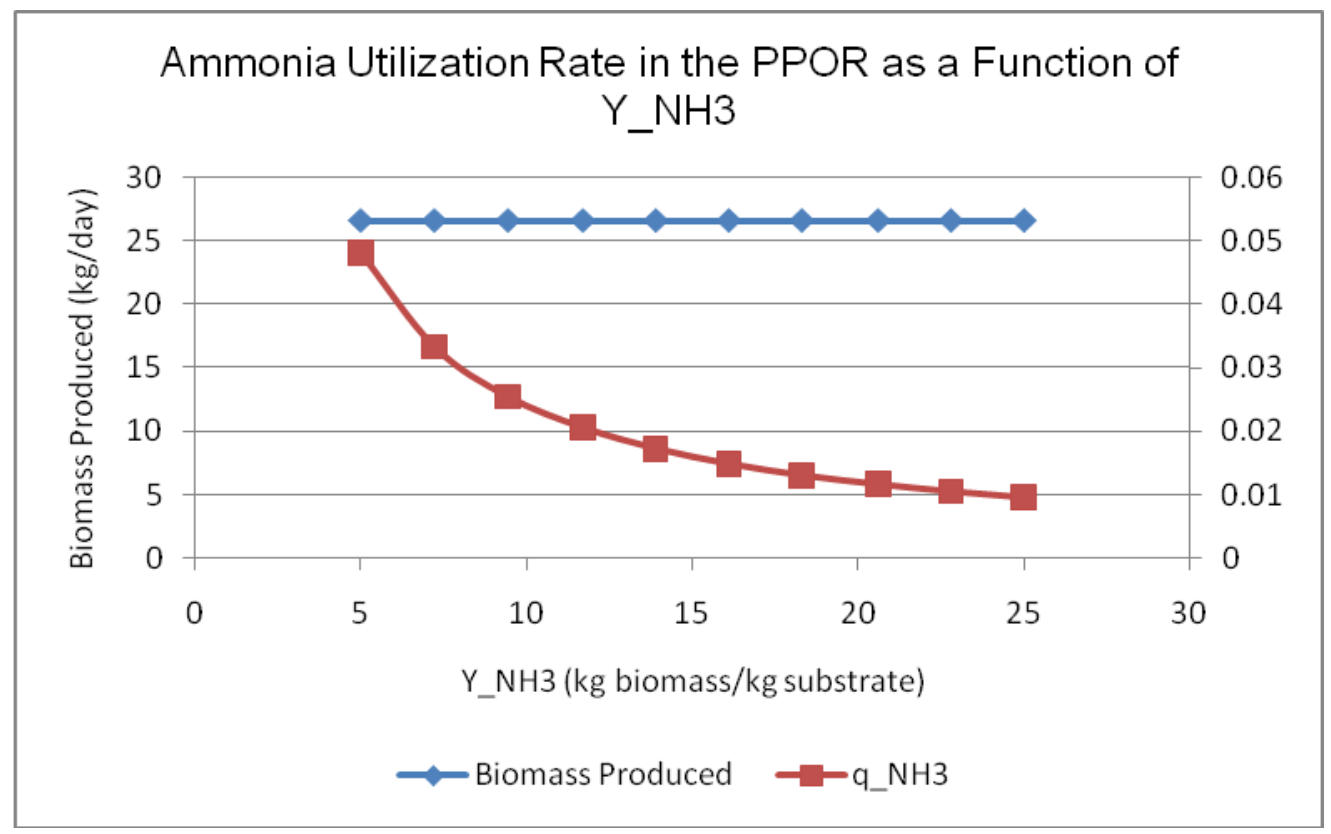

Figure 43. The effect of $Y_{-} N H 3$ on algae growth variables in the PPOR. Biomass produced is plotted on the primary vertical axis, and q_NH3 is plotted on the secondary axis.

Varying $Y$ will not affect algae growth, but may affect the substrate assimilated during algae growth. Therefore, molecular formula and accurate representation via $Y$ is important to predict accurate substrate removal via algae production.

\section{Economic Variables}

All sensitivity tests conducted for the economic variables used specific growth rates of $1 /$ day, harvest rates of $50 \%$ every 3 days, and a flow rate of 1 MGD. Plant influent nutrient characteristics were $35 \mathrm{mg}-\mathrm{N} / \mathrm{L}, 191 \mathrm{mg} / \mathrm{L}$ BOD, 4.3 $\mathrm{mg}-\mathrm{Psol} / \mathrm{L}$, and $32 \mathrm{mg} \mathrm{CO2-C/L.}$ Cost Savings from Reduced Aeration

Energy requirements for nitrification and BOD removal can be a substantial cost sink for a wastewater treatment plant. The model considers 
reduced aeration requirements due to reduced nitrification demand as well as oxygen produced through oxygenic photosynthesis. This section investigates the effect of the price per unit of oxygen on overall cost savings. Figure 44 shows the increase in cost savings realized with increasing cost per unit oxygen. This section is very sensitive to this variable; a quantity of $\$ 0.23$ per unit oxygen was used for further calculations, as explained in Chapter 3.

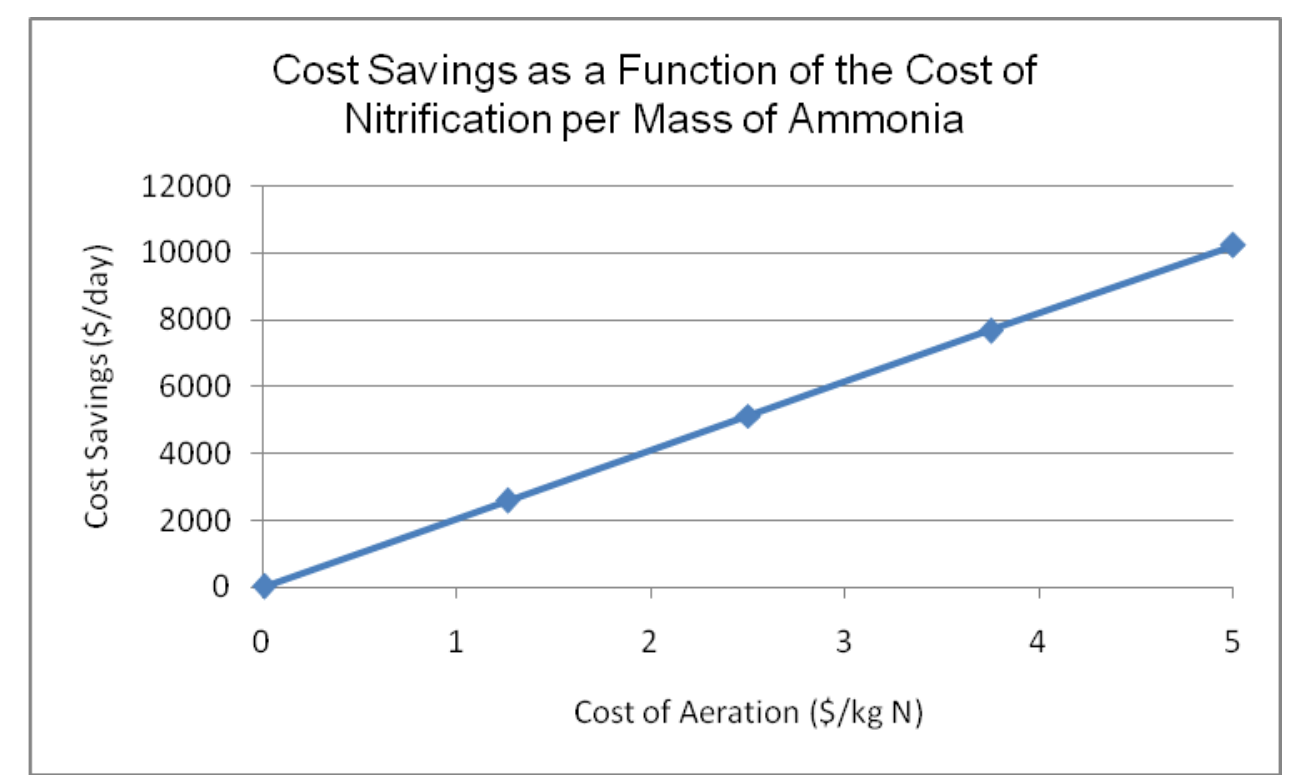

Figure 44. Cost savings from reduced aeration as a function of cost per unit oxygen.

\section{Cost Savings from Reduced Chemical Addition}

Chemical addition can also be a significant portion of a wastewater treatment plant's budget. HFCAWTP, for example, uses about 2 million gallons of methanol per year, which costs between $\$ 1.5$ and $\$ 7$ million USD per year, depending on fluctuating market prices for methanol (ranging between $\$ 0.75$ and \$3.50) (personal communications, Tim Ware, September 2010). This section tests the sensitivity of the cost of methanol on overall cost savings benefits from 
reduced chemical addition. As shown in Figure 45, the cost of methanol does make a significant difference in the cost savings realized from reduced chemical demand.

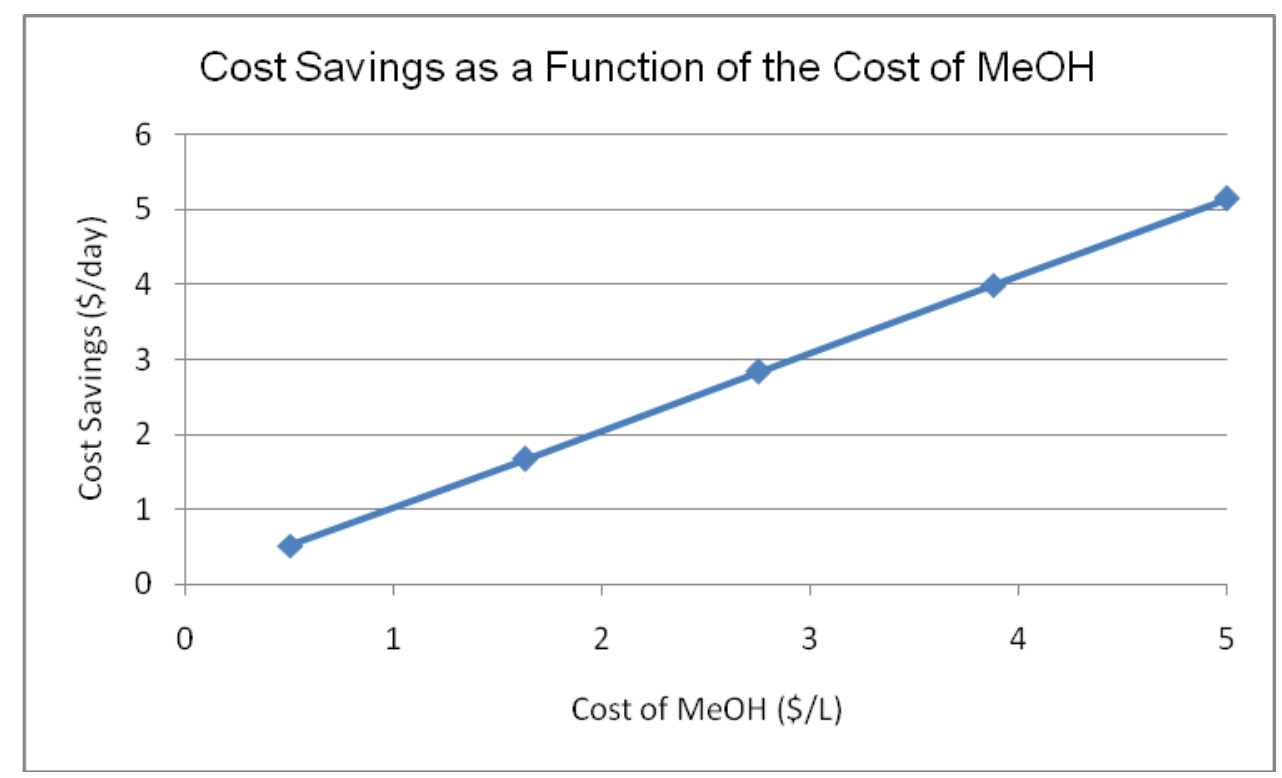

Figure 45. Cost savings from reduced chemical addition as a function of the cost of methanol.

\section{Biodiesel}

Biodiesel production has many variables which could affect the overall profit. Variables tested in this section include the market price of biodiesel and the production costs. This section also investigates whether biogas or fertilizer costs affect the overall profit realized.

Biodiesel processing costs were varied to see the effect on overall biodiesel costs. The results of the sensitivity test are shown in Figure 46; as biodiesel processing costs increased, biodiesel production costs increase as well. 


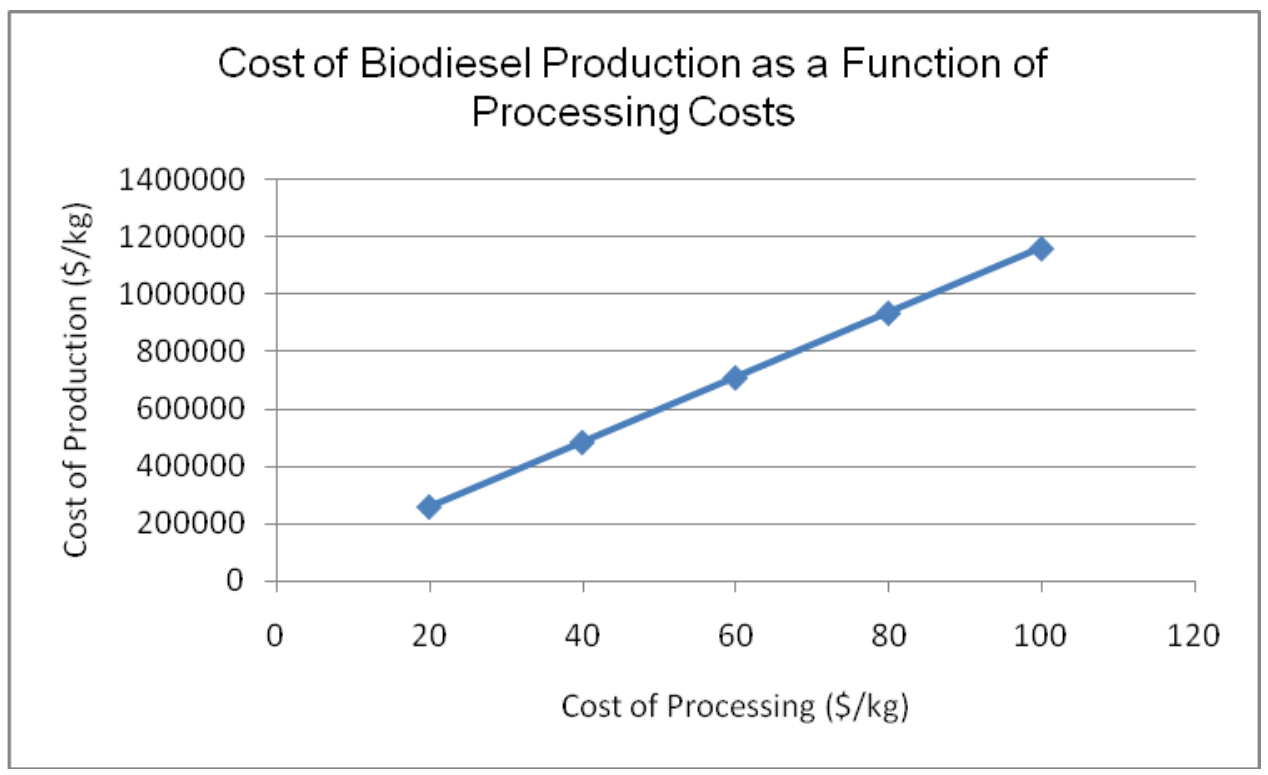

Figure 46. Cost of biodiesel production as a function of processing costs.

Next, harvesting costs and biomass production costs were varied to investigate the sensitivity of overall costs. Harvesting costs were varied from $\$ 0.002$ to $\$ 0.12$ per kilogram harvested, as these were the cost ranges found in literature. As shown in Figure 47, the cost of biomass harvesting does not significantly affect over biodiesel production costs. 


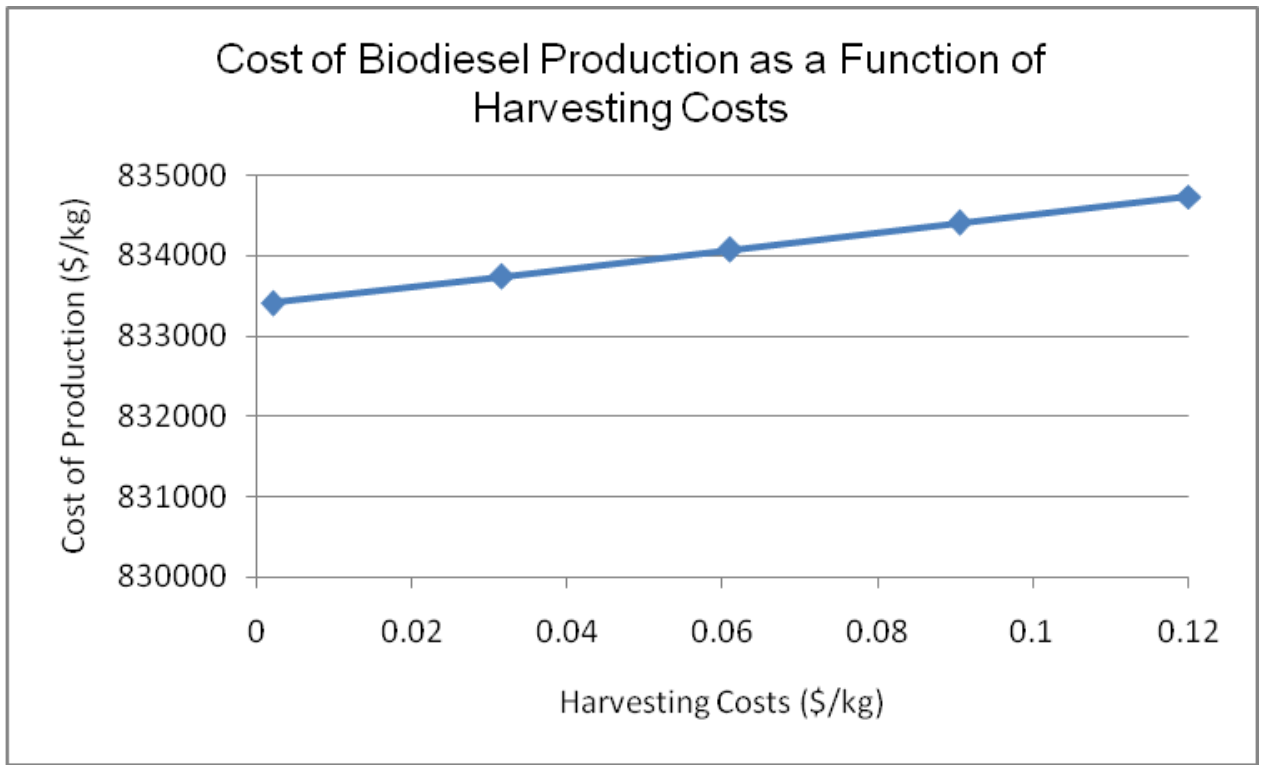

Figure 47. Cost of biodiesel production over varying biomass harvesting costs.

The cost of biomass production was varied from $\$ 3$ to $\$ 32$ based on values found in literature. As shown in Figure 48, varying biomass production costs did not significantly affect overall biodiesel production costs.

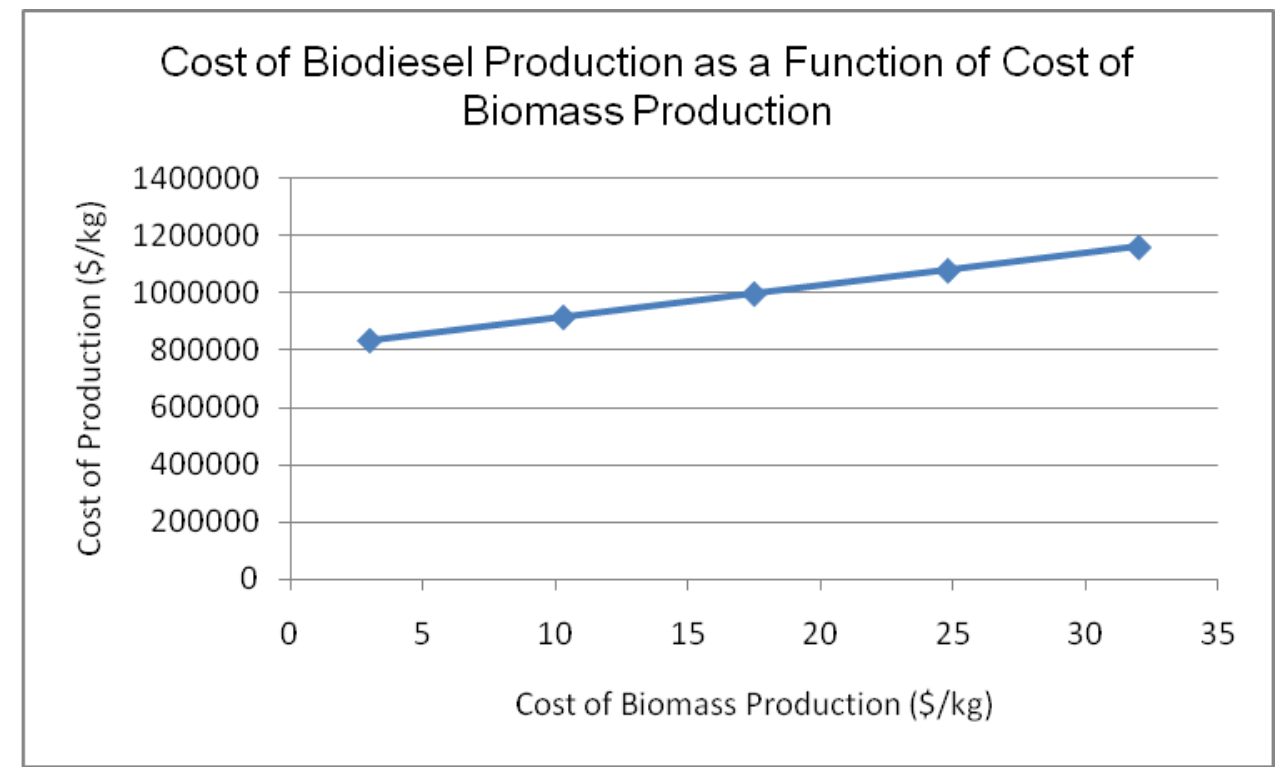

Figure 48. Cost of biodiesel production over varying biomass production costs. 
Because the model gives the option to further process leftover biomass after biodiesel processing, the additional costs from secondary processing were investigated. As shown in Figure 49, the additional production costs of secondary processing do not significantly affect the overall cost of biodiesel production.

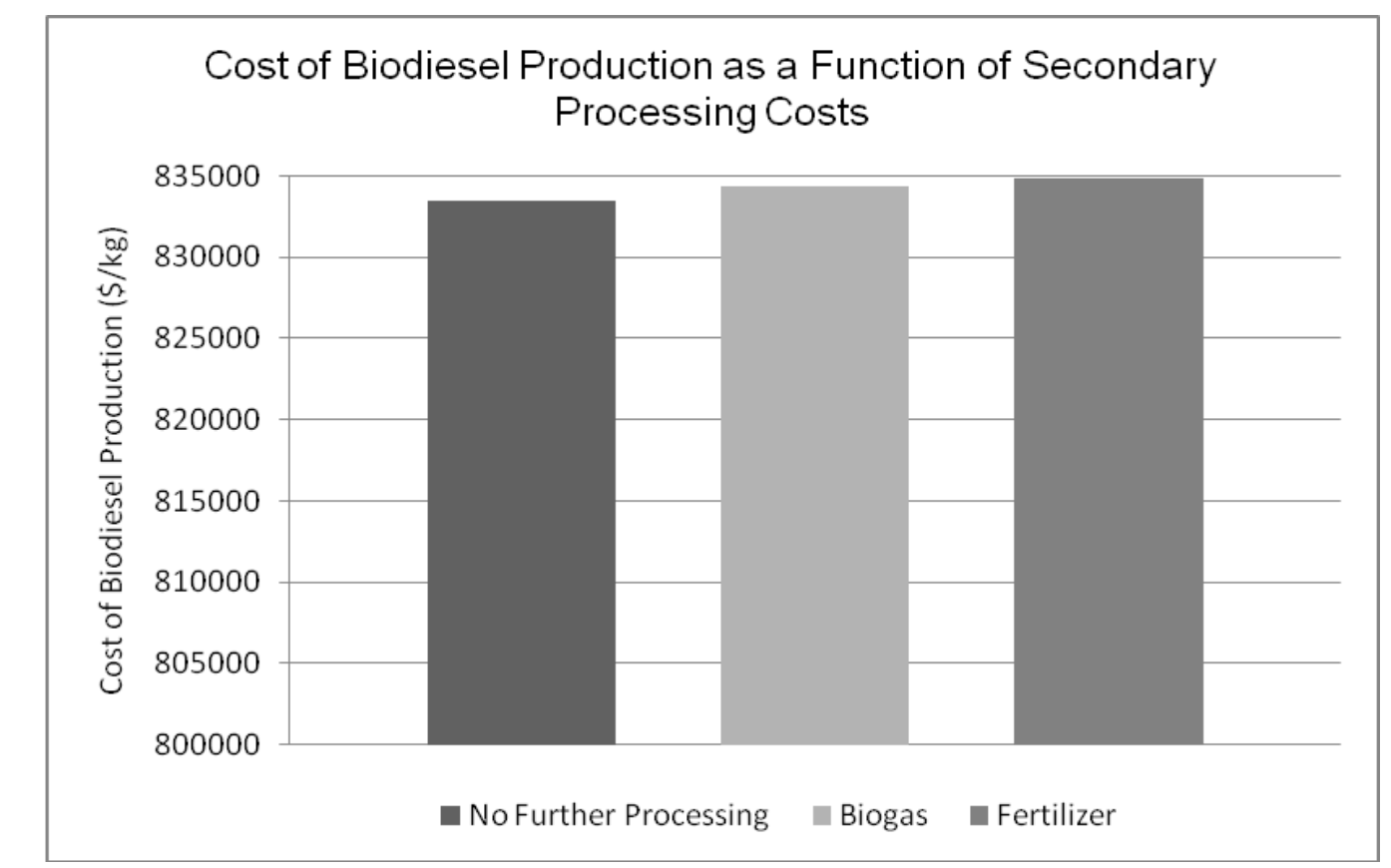

Figure 49. Cost of biodiesel production with added cost of secondary processing.

\section{Biogas}

Variables affecting the overall production costs of biogas were similarly investigated. Biogas production costs were varied from $\$ 0.10$ to $\$ 5.00$ per kilogram processed. Increasing the biogas processing costs did affect the overall production costs, as shown in Figure 50. 


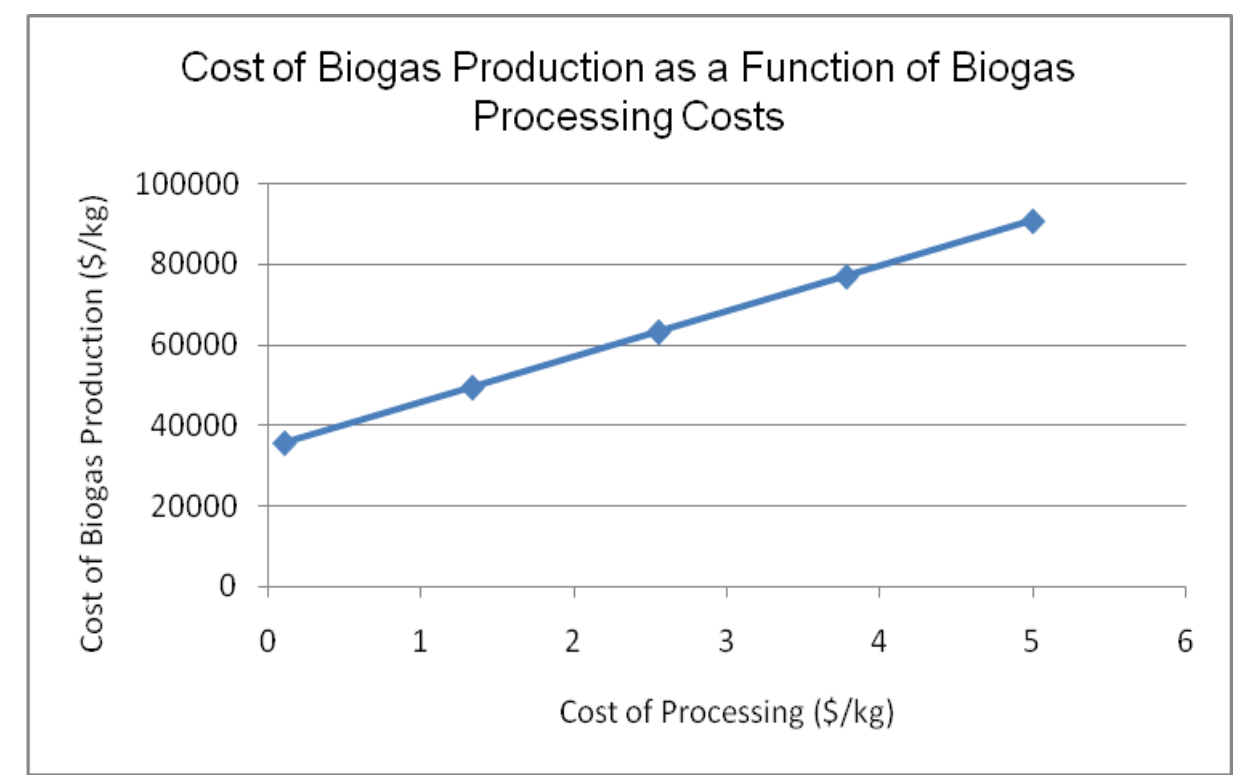

Figure 50. Cost of biogas production as a function of processing costs.

\section{Fertilizer}

Fertilizer costs were analyzed similar to biodiesel and biogas. Processing costs were varied in order to see the effect on overall production costs by varying the energy required for processing. As shown in Figure 51, processing costs do not significantly affect overall production costs of fertilizer. 


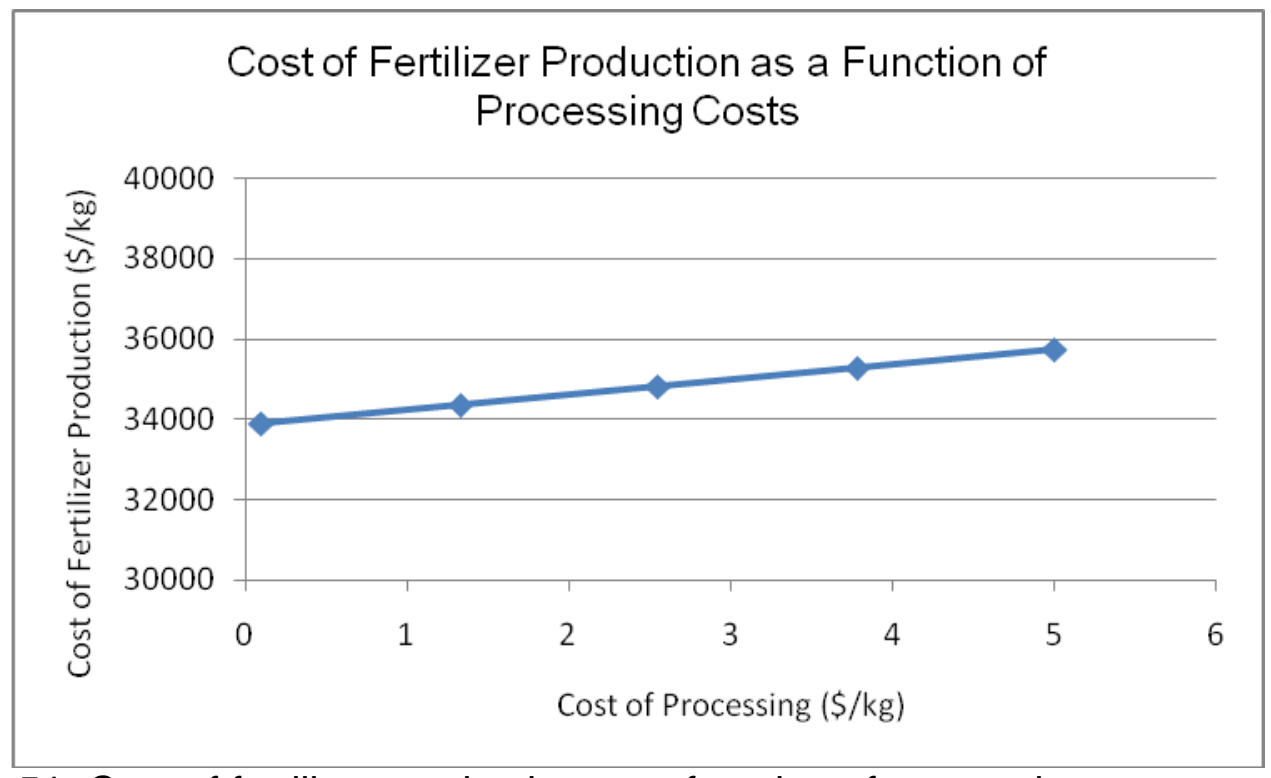

Figure 51. Cost of fertilizer production as a function of processing costs. 


\section{Chapter Five:}

\section{Results}

After verifying the model response to changes in variables as shown in Chapter Four, a case study was conducted on the HFCAWTP. Model parameters were set to mimic the conditions at the treatment plant based on average influent characteristics in 2009. All parameters were set as shown in Figure 52, except those parameteres listed in Table 6, which were varied to represent different cases.

Case 1 used specific growth rates published for Chlorella sp for growth on ammonia of 0.214 /day (Tam and Wong 1996) and nitrate of 0.238 /day (Ong et al. 2010). The growth rate in Case 2 was increased to 1 /day for each nitrogen source to see the effects of a faster growing species on biomass production and economics. Algae death rates have been reported to range between $0.01-0.5$ per day, depending on environmental conditions (Ambrose et al., 2006). For these simulations, a decay rate of 0.02 /day was chosen. Case 3 mimics the conditions of Case 1, but with an increased flow rate and HRT. 


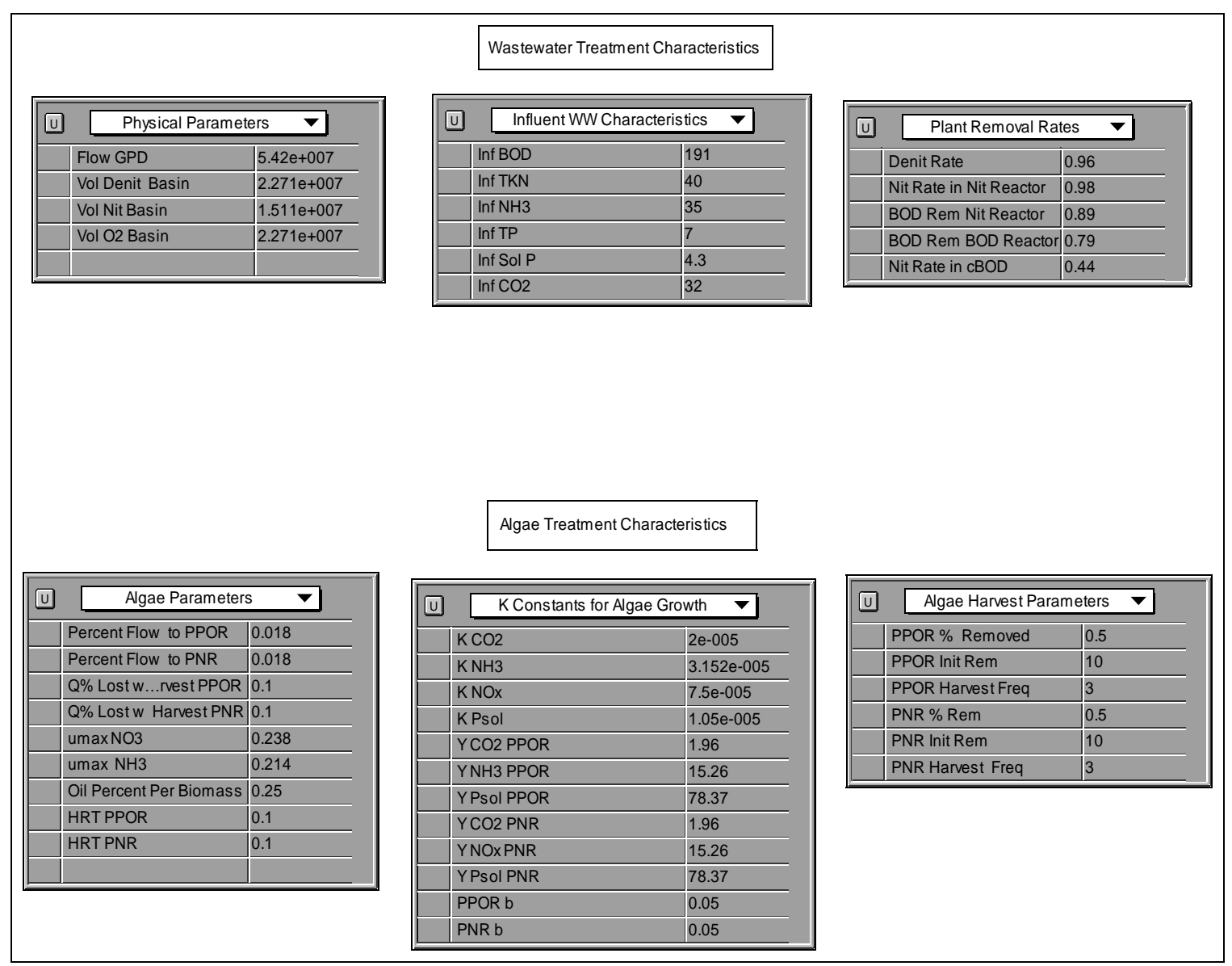

Figure 52. Parameter settings for HFCAWTP case study.

\section{Potential Biomass Production at HFCAWTP}

Three case studies were run under conditions based on the HFCAWTP in Tampa, FL, described in Chapter 3. Parameters for each case are outlined in Table 6. 
Table 6. Simulation parameters for case studies at HFCAWTP.

\begin{tabular}{|c|c|c|c|c|}
\hline & & Case 1 & Case 2 & Case 3 \\
\hline \multirow[t]{7}{*}{ PPOR } & $\mu \max (\mathrm{NH} 3)(/$ day $)$ & 0.214 & 1 & 0.214 \\
\hline & b (/day) & 0.02 & 0.02 & 0.02 \\
\hline & HRT (days) & 1 & 1 & 5 \\
\hline & Flow (MGD) & 1 & 1 & 15 \\
\hline & Harvest Amount & $25 \%$ & $25 \%$ & $25 \%$ \\
\hline & Initial Harvest & 20 & 20 & 20 \\
\hline & Harvest Frequency & 14 & 14 & 14 \\
\hline \multirow[t]{7}{*}{ PNR } & $\mu \max (\mathrm{NO} 3)(/$ day $)$ & 0.238 & 1 & 0.238 \\
\hline & b (/day) & 0.02 & 0.02 & 0.02 \\
\hline & HRT (days) & 1 & 1 & 5 \\
\hline & Flow (MGD) & 1 & 1 & 15 \\
\hline & Harvest Amount & $25 \%$ & $25 \%$ & $25 \%$ \\
\hline & Initial Harvest & 20 & 20 & 20 \\
\hline & Harvest Frequency & 14 & 14 & 14 \\
\hline
\end{tabular}

In Cases 1 and 3, biomass production appears to be limited by specific growth rate, as shown by the longer lag phase in these Cases versus Case 2, which had a higher specific growth rate. Figure 53,54 , and 55 show results from each case. The Monod fractions, i.e. corresponding results from the generic equation

$\frac{S}{K+S}$

where $S$ is available substrate and $K$ is the corresponding half saturation constant, are also shown in the Figures. The Monod fraction with the lowest 
value is the limiting nutrient in each case. As shown, the Monod fraction does not change in Cases 1 and 3, with low specific growth rate. However, in Case 2, when algae is growing at a much faster rate, the Monod fraction for carbon dioxide drops off dramatically during the exponential growth phase, essentially limiting growth in this Case.

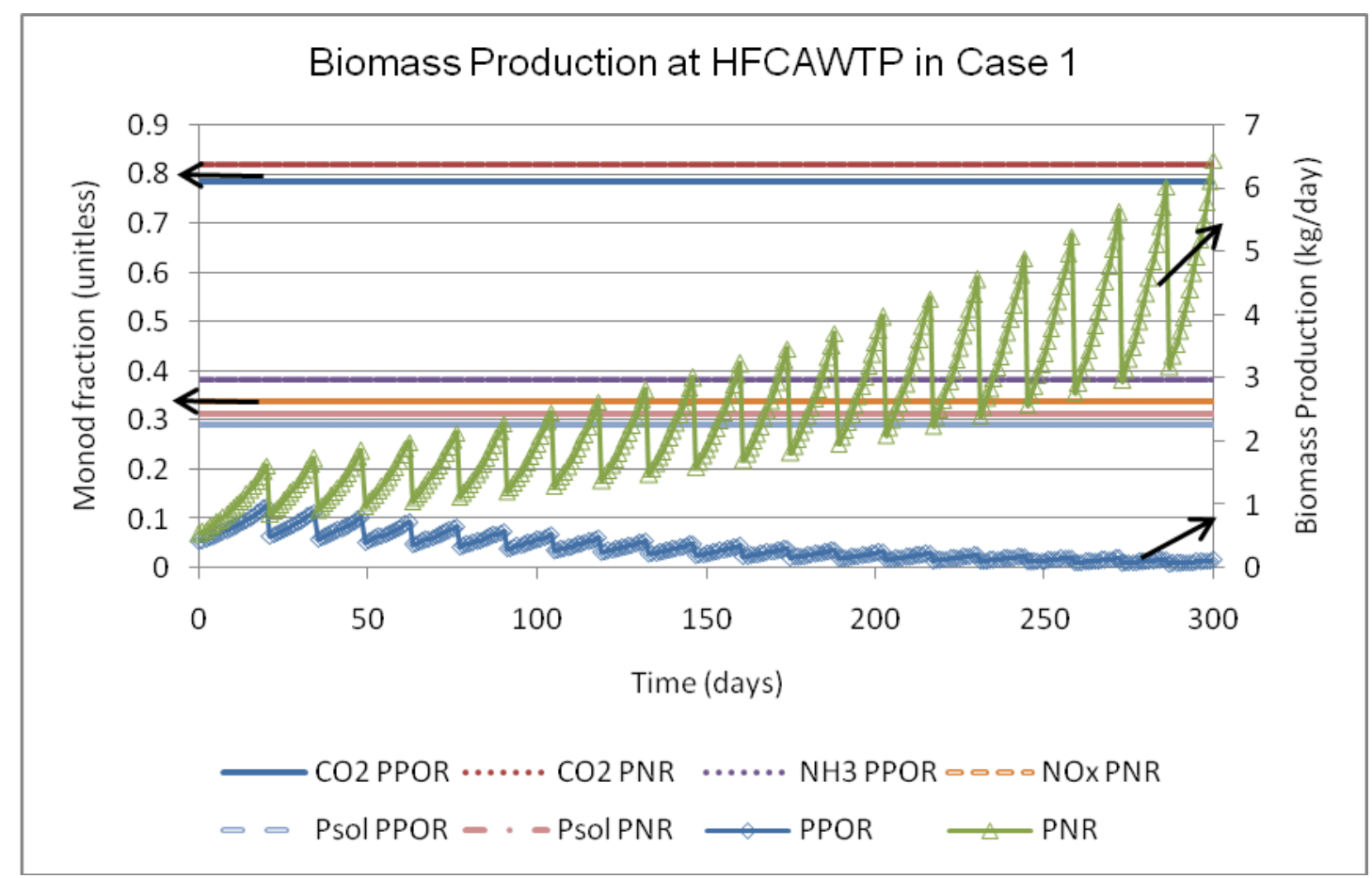

Figure 53. Biomass production at HFCAWTP in Case 1. Note Monod fractions do not change over time, and phosphorous is the limiting nutrient in both basins. Line oscillations are due to harvest events. 


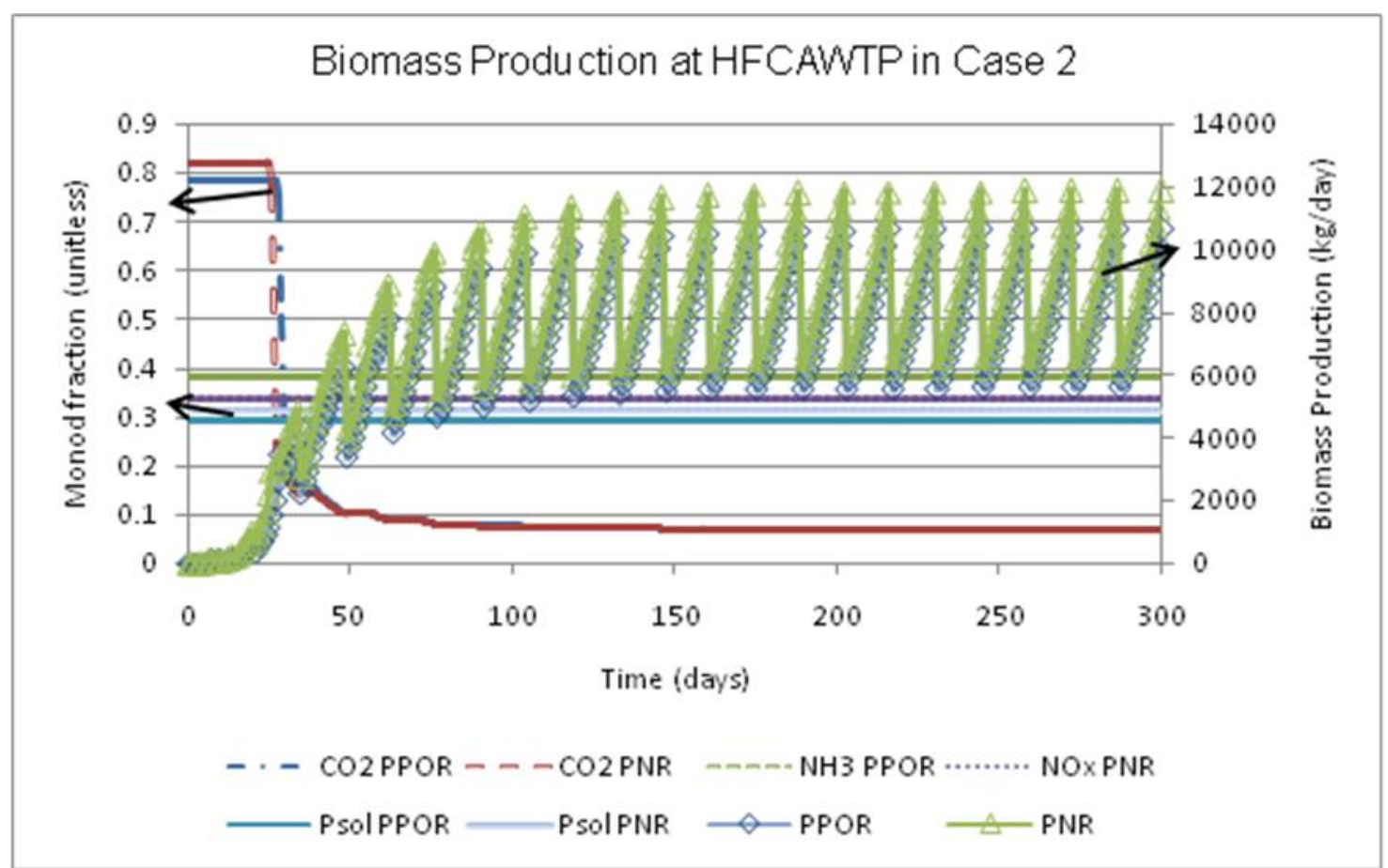

Figure 54. Biomass production at HFCAWTP in Case 2. Note the drop in the Monod fraction for carbon dioxide as the algae reach exponential growth phase.

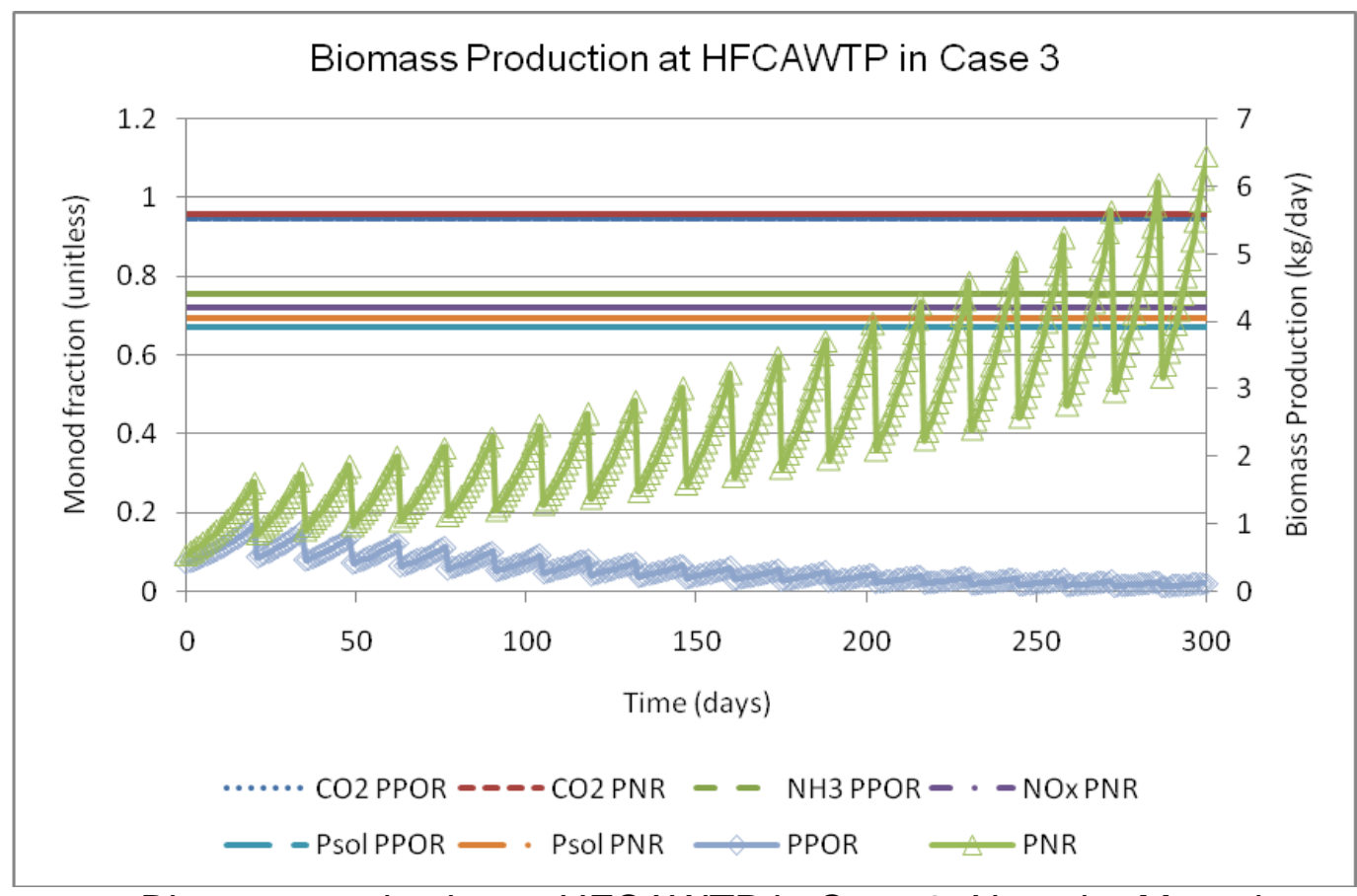

Figure 55. Biomass production at HFCAWTP in Case 3. Note the Monod fractions do not change over time; phosphorous remains the limiting nutrient in this case. 
In all cases, the biomass production was the same regardless whether both reactors were functioning or if only one was functioning at a given time. In Cases 1 and 3 , phosphorous was the limiting nutrient, as evidenced by the Monod fractions shown in Figures 53 and 55. Although phosphorus begins as the limiting nutrient in Case 3, as shown in Figure 55, carbon dioxide becomes limiting as algae reach the exponential growth phase.

Figure 56 compares the Monod fractions in Cases 1 and 3 at start-up. Note that the fractions are higher in Case 3, when HRT and flow to the algae basins are increased, thereby increasing available substrate. Phosphorous is the limiting nutrient in both cases at start-up, as shown in the Figure by the smallest columns. Monod fractions also were not significantly different between the PPOR and the PNR, showing the same limiting factors in both reactors.

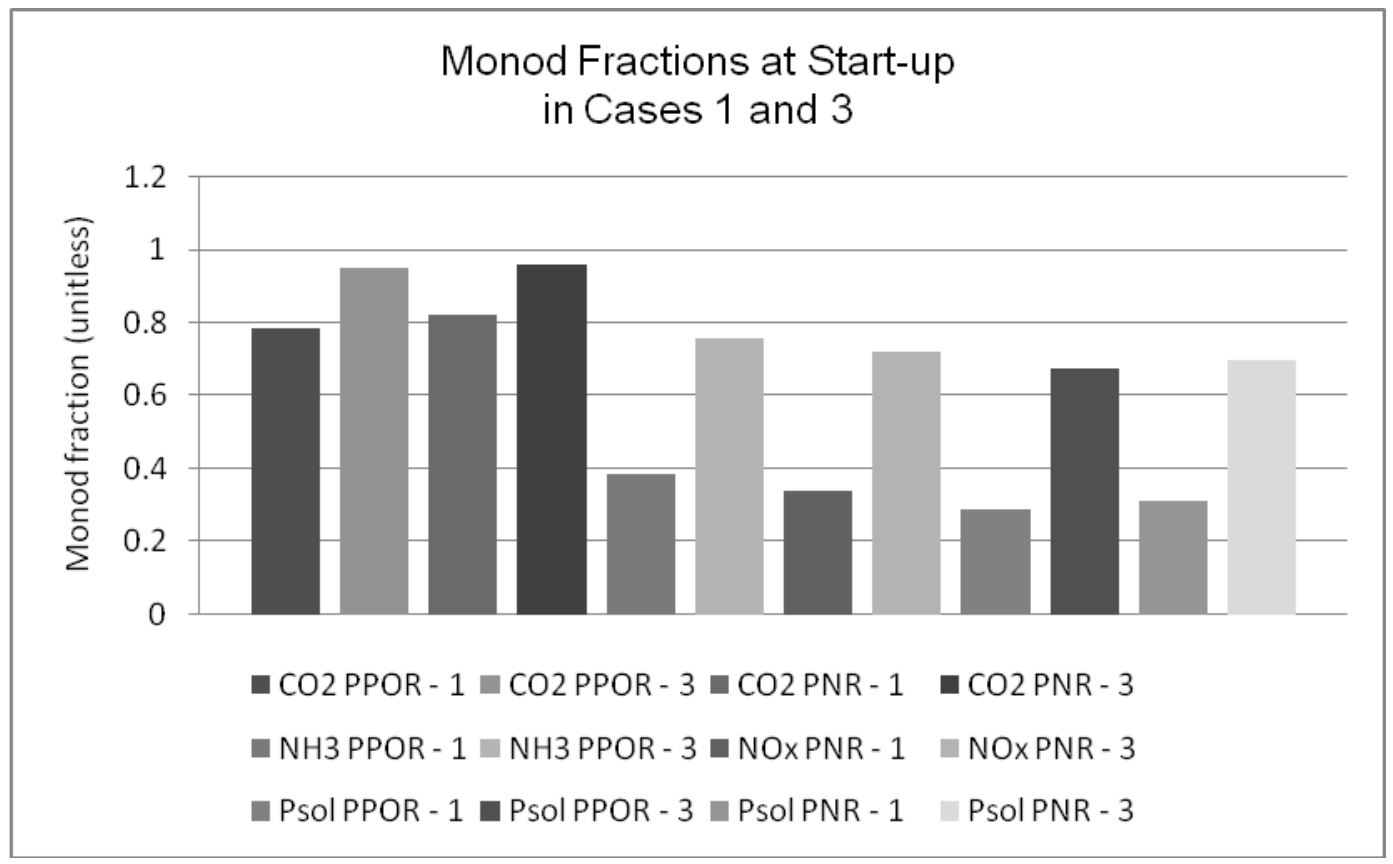

Figure 56. Monod fractions in Cases 1 and 3 . Note that the legend reading from left to right, top to bottom, is the same order asbars reading from left to right. 
As biomass production is dependent on the specific growth rate of the algae species chosen, a sensitivity test was conducted on the case study. All parameters were kept constant as noted above for Case 1, and harvest rate was set to $25 \%$ every 14 days, with initial withdrawal at day 16 . Figure 57 shows the total biomass harvested possible at Day 100 ( $6^{\text {th }}$ harvesting cycle) as a function of specific growth rates with both the PPOR and PNR in operation. As shown in the Figure, specific growth rate has a large impact when it is less than approximately 2 /day, but at higher rates, other factors, such as substrate availability, limit growth.

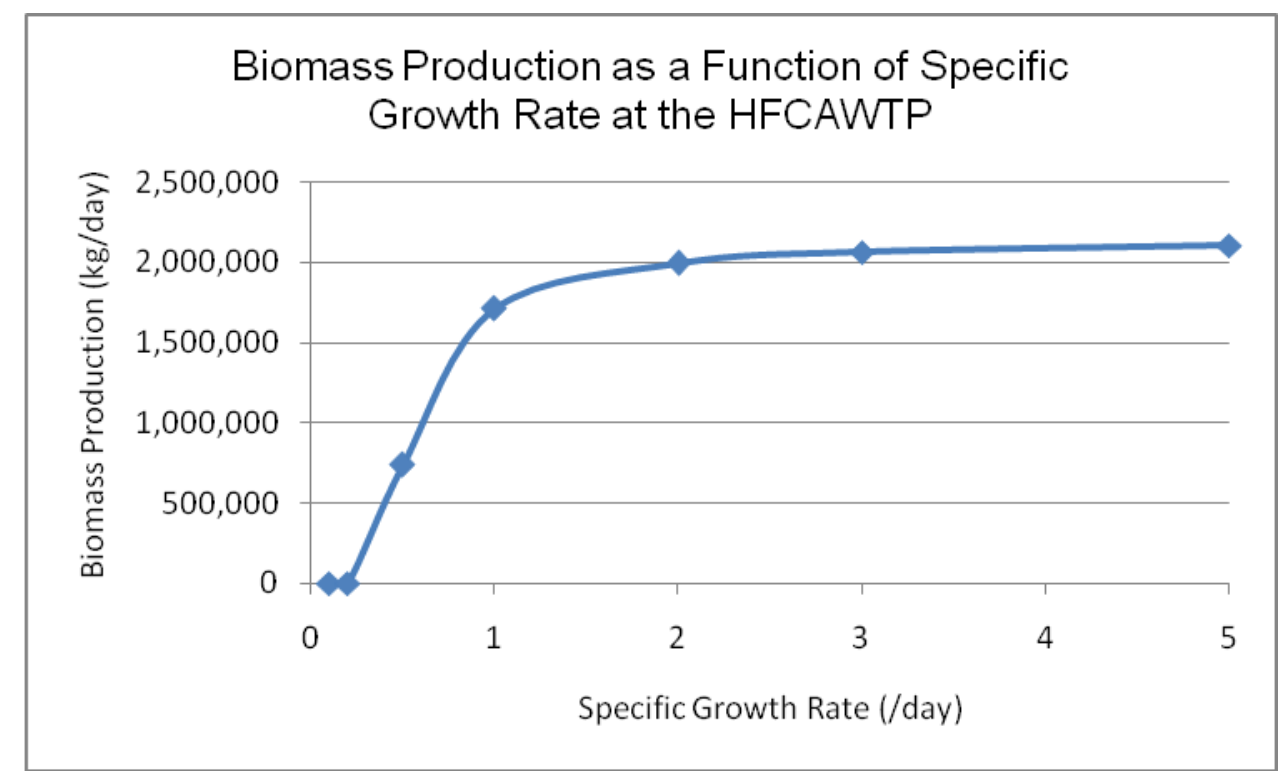

Figure 57. Biomass production as a function of specific growth rate at the HFCAWTP. Note conditions are those of Case 1 from Table 6, with harvest rate of $25 \%$ every 14 days, with initial harvest at 16 days. Values shown are harvest values from day 100 .

Biomass production can also be influenced by the timing of the algae harvest. Figure 58 shows the effect of varying the initial harvest over 20, 50, and 100 days under Case 1 conditions. If harvest is delayed for 100 days, the algae 
reach steady state faster, as they are allowed to gain a better foothold before being washed out. Similar results were found for Case 2; Figure C3 in Appendix C illustrates this data.

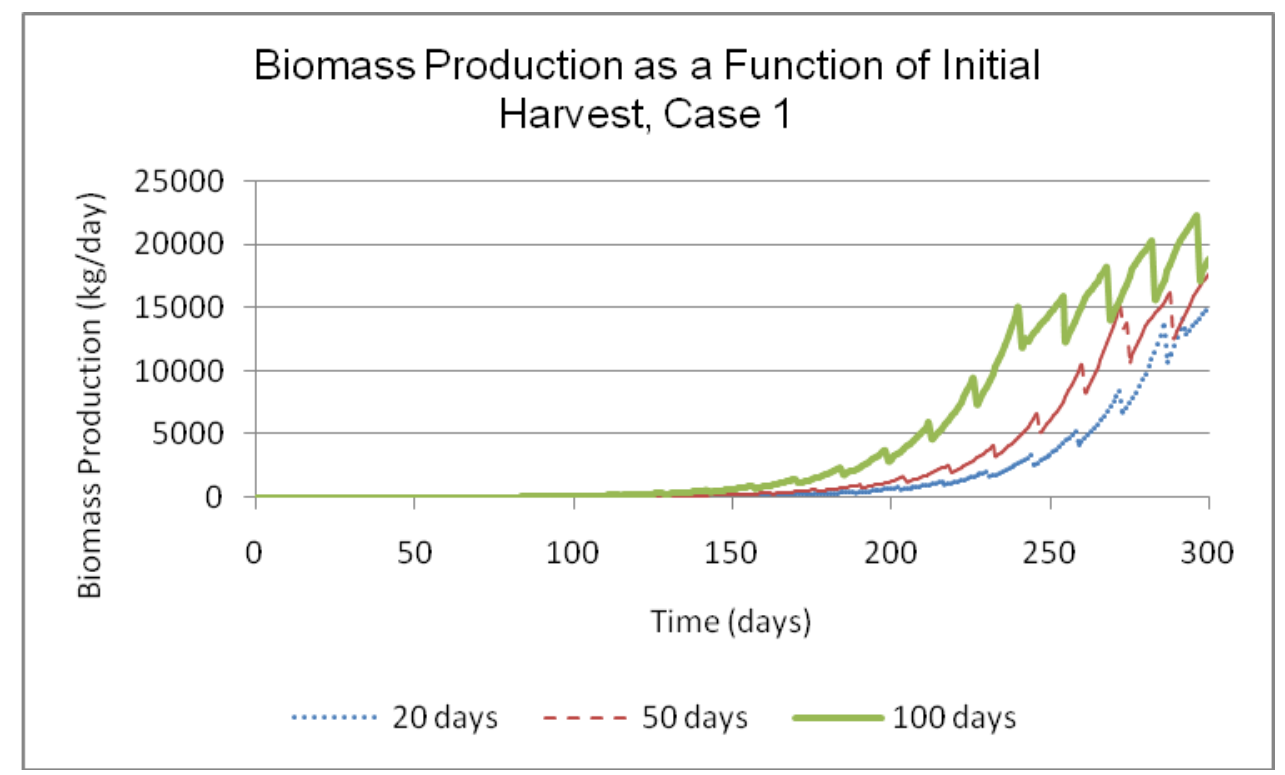

Figure 58. Biomass production as a function of initial harvest. This data is from Case 1 conditions.

Harvest amount will also affect biomass production, as harvesting too much can cause the population to be washed out. This is shown in Figure 59, where harvesting amount was varied from 10 to $50 \%$ removed every 14 days. Under Case 1, algae growth was severly stunted in both reactors when the harvest rate was $50 \%$, and in the PPOR when the harvest rate was $25 \%$. Figure 60 shows the results under Case 2 conditions ( $\mu$ 1/day); production increased with decreasing removal rates. Steady state was obtained in all scenarios, but biomass production was higher when less algae was harvested. 


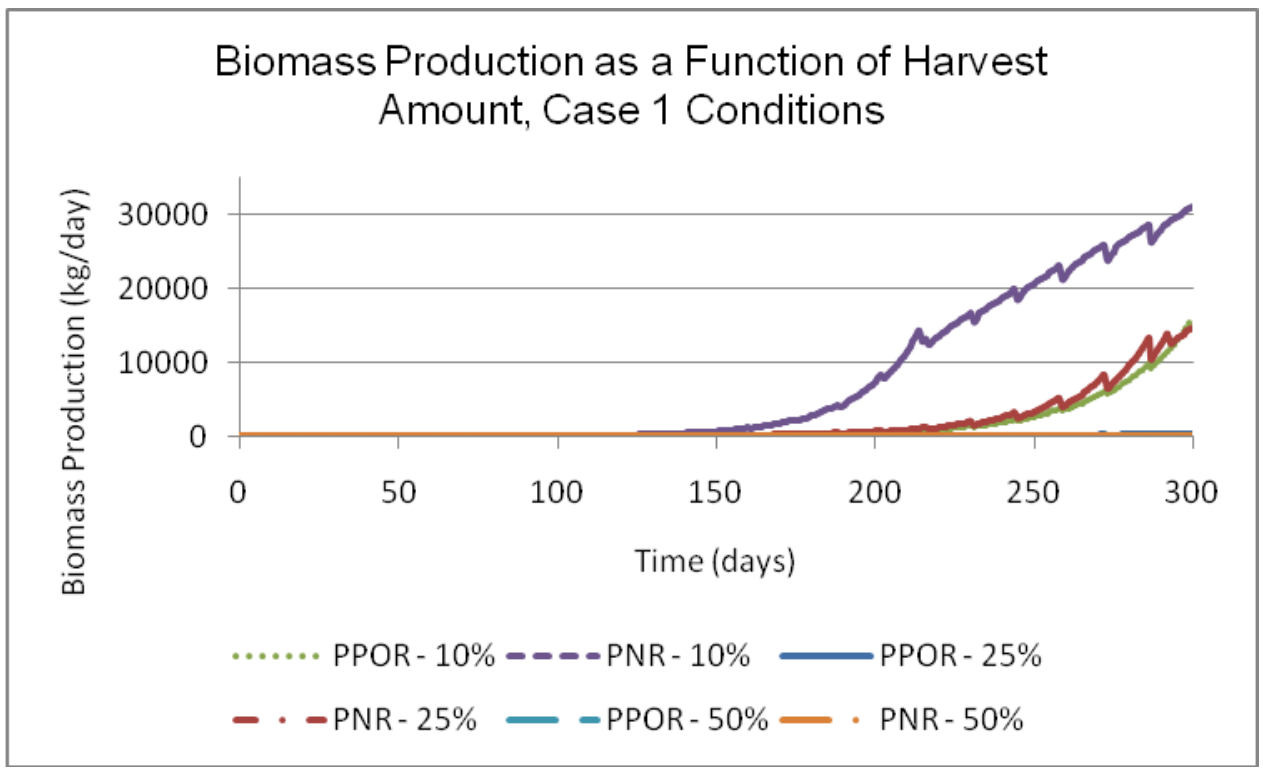

Figure 59. Biomass production as a function of harvest amount, Case 1 conditions.

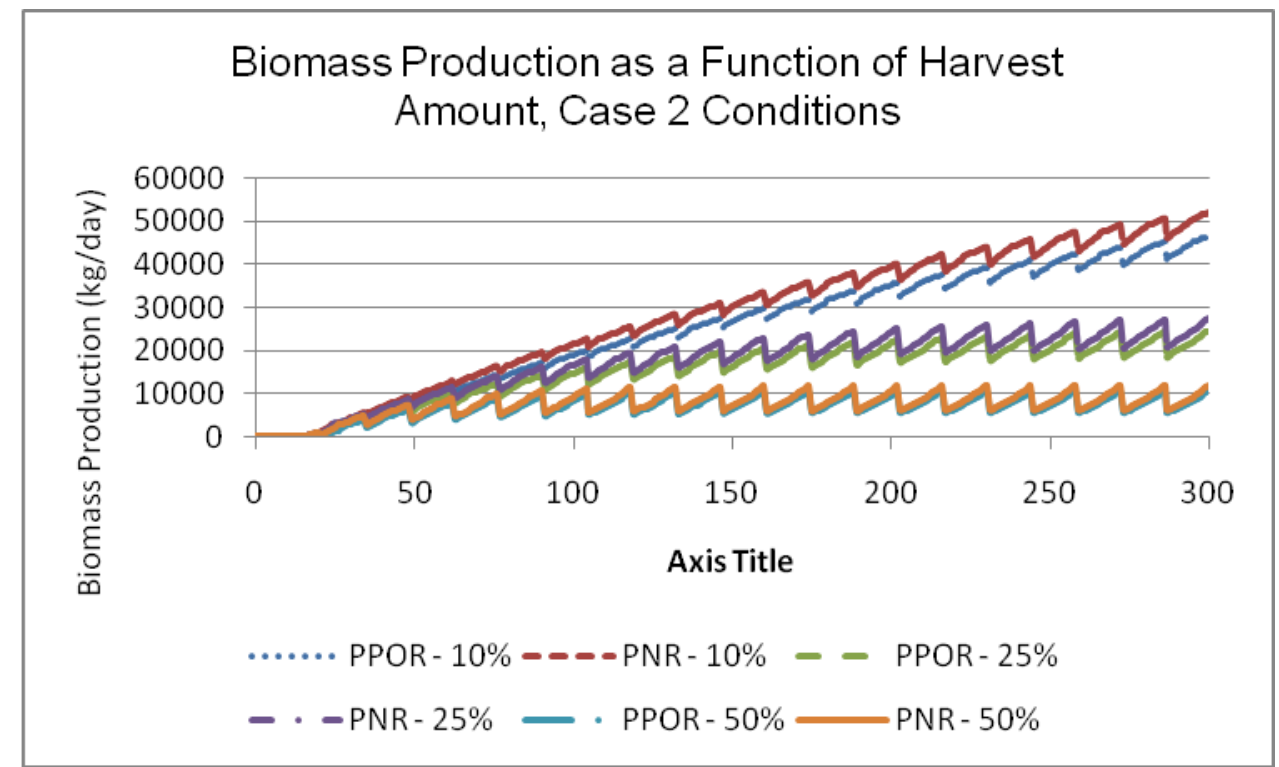

Figure 60. Biomass production as a function of harvest amount, Case 2 conditions.

\section{Economic Viability}

The economic viability for growing algae at the HFCAWTP was evaluated under a best, average, and worst case scenario, as outlined in Table 7. Variables that would affect costs or benefits of algae production were varied over ranges 
either found in literature or from historical price ranges. The best case scenario is meant to represent a time when resources may be scarce and energy prices are high, reflected in the high market price of products, aeration, and methanol. The worst case represents a time when resources may be abundant, and energy is relatively cheap, making algae production less economically attractive. The average case represents a market atmosphere in between these two extremes.

This analysis is important due to the high variability in the energy and commodities market. For example, the cost of methanol has varied between $\$ 0.75$ and $\$ 3.50$ per gallon over the past few years, which greatly affects the budget of a wastewater treatment plant. Similarly, as stated in Chapter Four, the cost of aeration for nitrification can vary depending on electricity costs and oxygen transfer efficiency. The cost per $\mathrm{kg}$ of $\mathrm{N}$ removed has been reported between $17 \mathrm{MJ} / \mathrm{kg} \mathrm{N}$ (approximately \$0.56) (Maurer et al., 2003) and $3.5 €$ (approximately \$4.86) (Zamalloa et al., 2010).

Table 8 shows the potential profits under each scenario per $\mathrm{kg}$ of algae produced. As shown, under the conditions presented, biodiesel production is not profitable, even under the best case scenario. However, biogas and fertilizer production are both profitable under best case scenario. Biogas production is also profitable under average conditions, and very close to profitable under even worst case scenario. 
Table 7. Parameter settings for economic viability analysis.

\begin{tabular}{|c|c|c|c|c|c|c|c|c|c|c|c|c|}
\hline & $\begin{array}{l}\text { Reduced } \\
\text { Aeration }\end{array}$ & $\begin{array}{l}\text { Reduced } \\
\text { Chemical }\end{array}$ & $\begin{array}{l}\text { Harvesting } \\
\text { Costs }\end{array}$ & $\begin{array}{l}\text { Biomass } \\
\text { Production }\end{array}$ & \multicolumn{3}{|c|}{ Biodiesel } & \multicolumn{2}{|c|}{ Biogas } & \multicolumn{3}{|c|}{ Fertilizer } \\
\hline & $\begin{array}{l}\$ / \mathrm{kg}-\mathrm{N} \\
\text { nitrified }\end{array}$ & $\$ / \mathrm{L} \mathrm{MeOH}$ & $\$ / \mathrm{kg}$ & $\$ / \mathrm{kg}$ & \% Oil & $\begin{array}{c}\$ / L \\
\text { Market } \\
\text { Price }\end{array}$ & $\begin{array}{c}\text { BD } \\
\text { Process }\end{array}$ & $\begin{array}{c}\$ / L \\
\text { Market } \\
\text { Price }\end{array}$ & $\begin{array}{c}B G \\
\text { Process }\end{array}$ & $\begin{array}{c}\% \\
\text { Biomass } \\
\text { Converted } \\
\text { to Product }\end{array}$ & $\begin{array}{c}\$ / \mathrm{kg} \\
\text { Market } \\
\text { Price }\end{array}$ & $\begin{array}{l}\text { Fertilizer } \\
\text { Processing }\end{array}$ \\
\hline $\begin{array}{l}\text { Best } \\
\text { Case }\end{array}$ & $\$ 3.50$ & $\$ 3.50$ & $\$ 0.006$ & $\$ 3.00$ & $80 \%$ & $\$ 3.15$ & $\$ 10.00$ & $\$ 0.01$ & $\$ 0.10$ & $80 \%$ & $\$ 3.00$ & $\$ 0.10$ \\
\hline $\begin{array}{c}\text { Average } \\
\text { Case }\end{array}$ & $\$ 1.00$ & $\$ 1.75$ & $\$ 0.12$ & $\$ 3.00$ & $40 \%$ & $\$ 2.00$ & $\$ 20.00$ & $\$ 0.01$ & $\$ 1.00$ & $70 \%$ & $\$ 2.00$ & $\$ 0.17$ \\
\hline $\begin{array}{l}\text { Worst } \\
\text { Case }\end{array}$ & $\$ 0.50$ & $\$ 0.75$ & $\$ 0.12$ & $\$ 3.00$ & $30 \%$ & $\$ 1.00$ & $\$ 70.00$ & $\$ 0.0001$ & $\$ 1.00$ & $50 \%$ & $\$ 1.00$ & $\$ 0.25$ \\
\hline
\end{tabular}


Table 8. Potential profits under best, average, and worst case scenario conditions per $\mathrm{kg}$ of algae produced.

\begin{tabular}{|c|c|c|c|}
\hline & Biodiesel & Biogas & Fertilizer \\
\hline Best Case & $-\$ 8.29$ & $\$ 6.92$ & $\$ 1.80$ \\
\hline Average Case & $-\$ 21.49$ & $\$ 4.33$ & $-\$ 0.97$ \\
\hline Worst Case & $-\$ 72.43$ & $-\$ 3.62$ & $-\$ 2.44$ \\
\hline
\end{tabular}

Next, an analysis was conducted to determine how market prices of the final product and processing costs would affect potential profits. Figure 61 shows the effect of varying the processing costs of biodiesel on the potential profit; processing costs would have to fall below $\$ 1.60$ to turn a profit, with all other best case scenario conditions held constant.

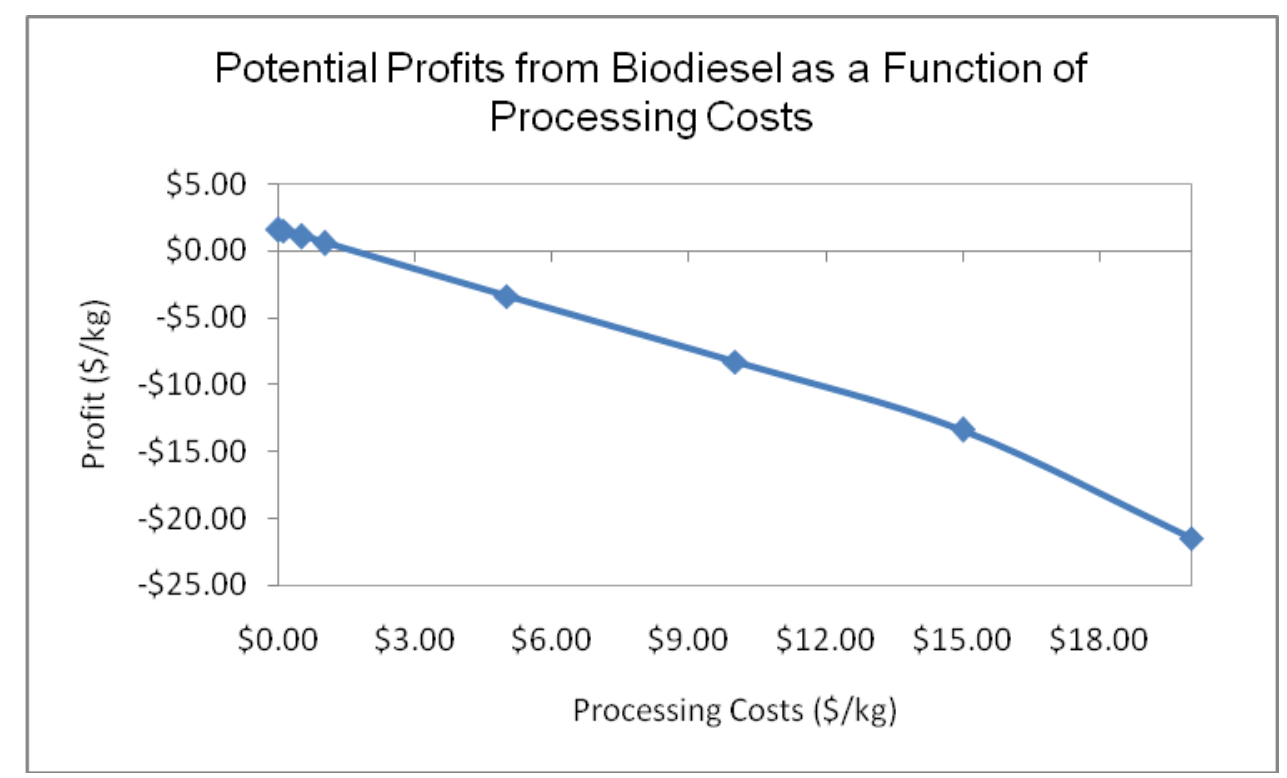

Figure 61. Potential profits from biodiesel as a function of processing costs.

Figure 62 shows the potential profits of biodiesel as a function of market price of biodiesel per liter. As shown, under the best case scenario conditions, the market price of biodiesel would have to reach $\$ 15.00$ per liter before the 
processing became profitable. It should be noted, however, that this value is dependent on many variables and would fluctuate under different conditions.

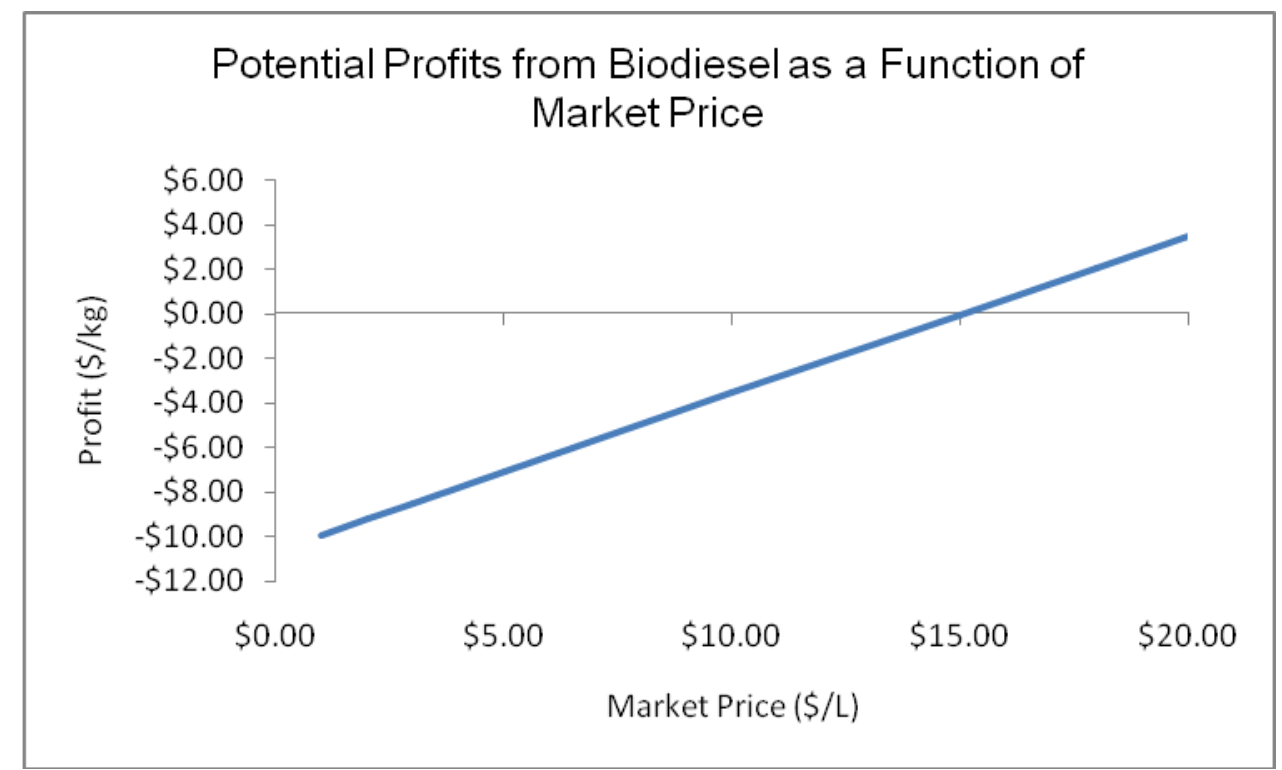

Figure 62. Potential profits from biodiesel as a function of market price.

Biogas production was shown to be profitable under best and average case scenarios. However, under the worst case scenario, it is not profitable, even if production costs were zero. This is due to the low benefit of reduced aeration and methanol costs of the worst case scenario. The market price of biogas can change considerably depending on the BTU content; therefore, an analysis was conducted on the best case scenario to determine the minimum energy content required to maintain profitability. the conversion of $\$ 4.08 / \mathrm{MmBTU}$ was used (www.bloomberg.com/energy, accessed 2010). As shown in Figure 63, biogas content would need to remain above $250 \mathrm{BTU} / \mathrm{L}$, if the price per BTU remained as stated. 


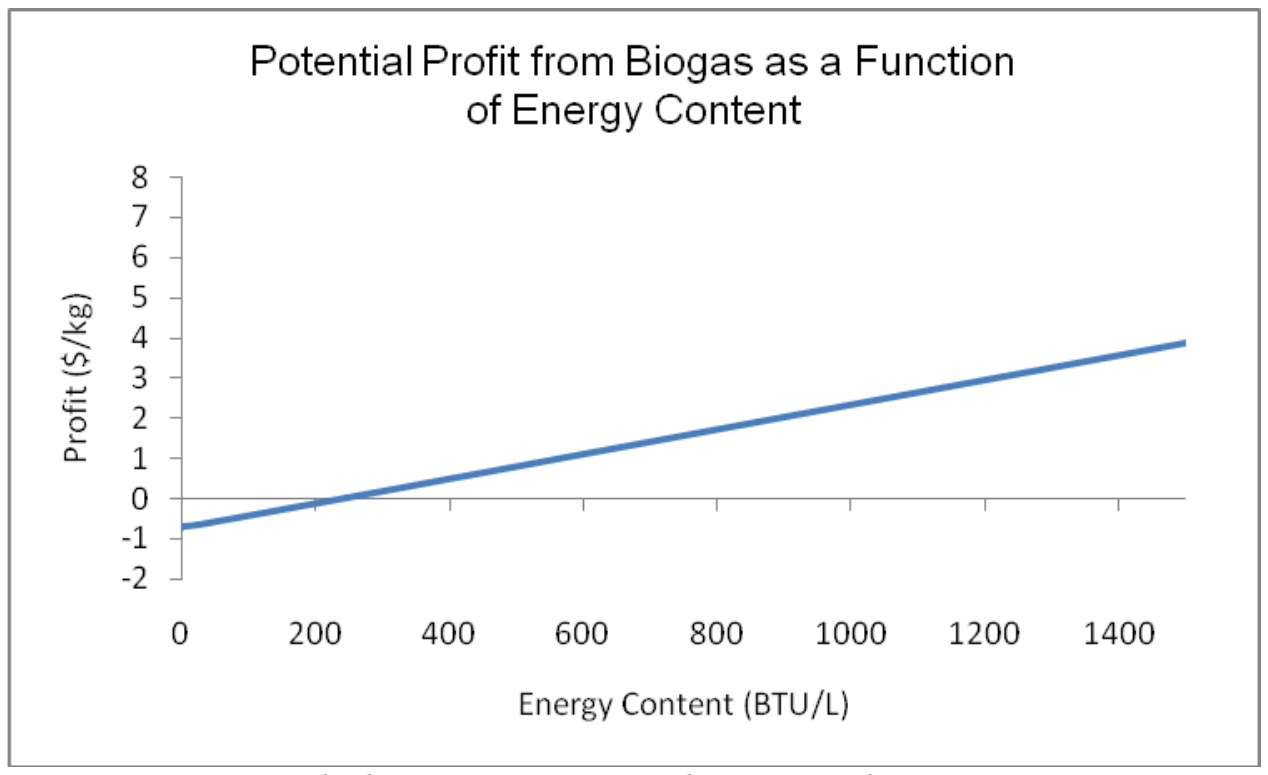

Figure 63. Potential profit from biogas as a function of energy content. BTU content was calculated based on a price conversion of $\$ 4.06 / \mathrm{MmBTU}$.

Although fertilizer production was not profitable under the average and worst case conditions outlined in Table 7, Figure 64 shows how the market price of fertilizer would influence this outcome. As shown, fertilizer production could be profitable if the market price exceed $\$ 3.50$ in the average case and $\$ 6.00$ in the worst case. Again, it should be noted that these numbers are a reflection of all variables in Table 7 and would change if other parameters were varied. 


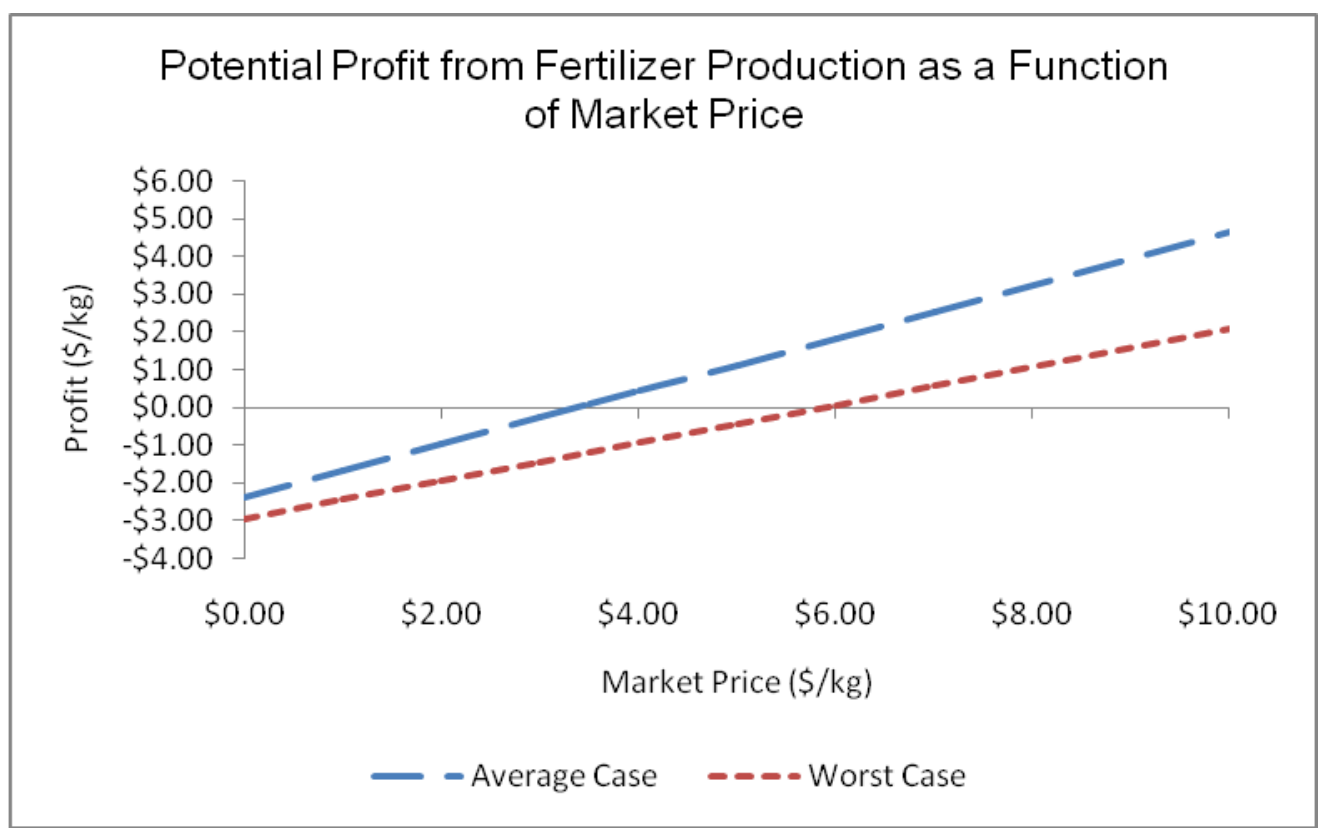

Figure 64. Potential profit from fertilizer production as a function of market price.

The economic analysis determined that algae production can be profitable at the HFCAWTP, depending on the market conditions and cost of energy. Projections are highly dependent on a number of parameters, including the cost and efficiency of aeration, the cost of methanol, the market price of products, and processing costs. This is an area to focus on for further calibration of the model, as pilot studies and full-scale operations make more data available for these values. 


\section{Chapter Six:}

\section{Conclusions and Future Research}

\section{Conclusions}

The synergy of wastewater treatment and algae biomass production has great potential to close the nutrient and energy loop of the wastewater treatment process. This model has demonstrated that on a mass balance scale it is feasible to incorporate an algae reactor at a wastewater treatment facility. Adequate nutrients and carbon dioxide are available for growth, although carbon dioxide and phosphorous can become limiting, as shown with the HFCAWTP case study.

The model has also identified potential important areas of sensitivity within the algae and wastewater marriage before accurate predictions of biomass production can be obtained. Among the most sensitive biological parameters include half saturation constants, specific growth rate, and the frequency and amount of biomass harvested. Assimilation of nutrients is dependent on the yield coefficient, which can also vary depending on the algal species cultivated.

Although many biological parameters are either sensitive or case-specific, the model is a tool for recognizing research areas for pilot scale testing. Monod kinetics coefficients, for example, are very important for accurate predictions. The model is also a tool for assessing the applicability of algae production at different treatment plants with specific waste streams. The model was built with a high 
degree of flexibility in order to be adaptable to a wide range of sites and conditions.

Economic parameters, such as processing costs, can greatly affect model output. As wastewater characteristics, climate, equipment efficiencies, and market prices can fluctuate geographically, bench or pilot scale studies would be important for verifying and/or obtaining accurate values for these sensitive variables. The next version of the model will address economics in more detail, which should aid in more accurate predictions.

Processing costs and biomass production costs are expected to decrease with further research and development of more efficient technologies. This is already evidenced in the reduction of algae harvesting costs over the past few years. Therefore, it is expected that the synergy between algae and wastewater will become more cost efficient in the future. The model has set up a framework for evaluating the linkage between the biological and economic sides of algae biomass production for future research.

Although the model has some limitations, it is an important first step in understanding the potential partnership between wastewater treatment and algae production as a means to close the nutrient and energy cycles. As energy and nutrient demands continue to rise with increasing population, it is imperative to harness and recycle these resources. Wastewater is a potential source of nutrients, freshwater, and energy; algal biology makes them great candidates for efficiently converting these wastes into resources. As demonstrated in the mass balance of the case study, adequate carbon dioxide can exist within an already 
operating treatment facility, eliminating the need for supplemental carbon dioxide addition. This carbon dioxide, typically released by the plant, can be harnessed and rerouted to other forms of energy.

Incorporating algae into a conventional wastewater treatment plant has the potential to harness previously wasted resources for use as a secondary product. The mass balance approach has demonstrated the viability of the process, identified weaknesses for further research, and created a framework to evaluate future case studies. As research and technology become more efficient, and algal growth kinetics under varying environmental conditions are better understood, the model can be adapted and calibrated to reflect these changes.

\section{Future Research}

This model is a first step in examining the potential for algae growth from a mass balance perspective. As the synergy between algae and wastewater is still novel, data from full-scale processes is not yet available. Future research should include studying algae kinetics in actual wastewater, to better understand the relationship between $K, Y, \mu$ and substrate utilization.

Many algae species can utilize both ammonia and nitrate as a nitrogen source, though they may prefer one over the other. Further work on the model should include the ability of algae to use both nitrogen sources in each reactor.

Although, as a group, algae can grow utilizing numerous metabolic strategies, this model only considers autotrophic growth. It would be an important next step to examine the contribution of heterotrophic and mixotrophic algal growth within the mass balance, on a competitive or non-competitive basis. 
Literature has shown that heterotrophic and mixotrophic metabolisms can be more efficient than an autotrophic metabolism, leading to higher growth rates. Heterotrophic growth also could help reduce COD load and contribute to nutrient harnessing. Furthermore, depending on the reactor configuration and mixing, algae may become light limited, making heterotrophic growth more important. Light limitation is another important environmental condition that could affect algae growth. Future versions of the model should include light limitation, as too little or too much light can alter growth kinetics. Currently, light limitation is assumed to be built into the maximum specific growth rate selected for simulations. Similarly, trace elements, such as selenium, can limit or promote algae growth under varying concentrations. Likewise, endocrine disrupting compounds may also affect algae growth. Investigating the effect of trace elements would be an important area to focus future research.

On the economic side, a more detailed breakdown of cost/benefit inputs would aid in identifying key areas for cost reduction, making the entire process more economically viable. Currently costs, in general, are bundled into one overall processing cost; however, this may not be entirely accurate. For instance, due to economies of scale, typically as production increases, costs per unit decrease. This is not easily reflected in the current model, but would be an area for future research in subsequent versions.

Similarly, biomass production and harvesting processes could be broken out into more detail. Future versions of the model could include an algae 
dewatering step, which would allow for increased flexibility with water and nutrient losses with harvesting, as well as testing different technologies.

Like many conventional treatment plants, the HFCAWTP returns the anaerobic digester sidestream waste to the headworks of the plant. This waste stream could be suitable for algae growth due to its high nutrient content. Future work on the model should include an algae basin after the digester to analyze possible nutrient reductions before the sidestream is returned to the treatment plant headworks.

The current model uses removal rates from plant data, but a future version of the model could include wastewater kinetics similar to the algae kinetics. This would allow for more flexibility in the wastewater framework, creating a means to investigate calculated removal efficiencies. Outputs from the wastewater framework could be calibrated from plant data under varying conditions.

Future research would also include lab and pilot scale studies. For example, calibrating the model to actual plant conditions would be very important. Likewise, determining Monod kinetics on actual wastewater streams would help produce more accurate predictions of algae growth, as the Monod kinetics were determined to be among the most sensitive. Another question to investigate would be whether or not denitrifiers can use soluble microbial products (SMP) generated in the PNR by algae as a carbon source.

Although there are some limitations and inherent assumptions built into the model, it is an important first step in understanding the mass balance relationship between algae and wastewater treatment. The model was built with 
as much flexibility as possible, allowing for expansion and adaptation to accommodate future research goals. 


\section{List of References}

Agren, G. (2004). "The C:N:P stoichiometry of autotrophs - theory and observations." Ecology Letters 7: 185-191.

Ahn, Y.-H. (2006). "Sustainable nitrogen elimination biotechnologies: A review." Process Biochemistry 41: 1709-1721.

Alptekin, E., Mustafa Canakci (2008). "Determination of the density and the viscosities of biodiesel - diesel fuel blends." Renewable Energy 33(12): 2623-2630.

Ambrose, R. B., J.L. Martin, and T.A. Wool. (2006). WASP7 Benthic Algae Model Theory and User's Guide. EPA. Washington, DC, USEPA, Office of Research and Development. EPA 600/R-06/106.

Amin, S. (2009). "Review on biofuel oil and gas production processes from microalgae." Energy Conversion and Management 50: 1834-1840.

Aresta, M., Angela Dibenedetto, Grazia Barberio (2005). "Utilization of macroalgae for enhanced $\mathrm{CO} 2$ fixation and biofuels production: development of a computing software for an LCA study." Fuel Processing Technology 86: 1679-1693.

Aslan, S., Ilgi Karapinar Kapdan (2006). "Batch kinetics of nitrogen and phosphorus removal from synthetic wastewater by algae." Ecological Engineering 28: 64-70.

Barsanti, L., \& Paolo Gualtieri (2006). Algae: Anatomy, Biochemistry, and Biotechnology. Boca Raton, FL, CRC Press.

Bloomberg, L. P. (2010). "Bloomberg: Energy and Oil Prices." Retrieved 9/28/2010, 2010. www.bloomberg.com/energy

Bhat, S. D., T.M. Aminabhavi (2007). "Pervaporation Separation Using Sodium Alginate and Its Modified Membranes - A Review." Separation and Purification Reviews 36: 203-229.

Bitton, G. (1994). Wastewater Microbiology. New York, Wiley-Liss, Inc. 
Bordel, S., Benoit Guieysse, Raul Munoz (2009). "Mechanistic Model for the Reclamation of Industrial Wastewaters Using Algal-Bacterial Photobioreactors." Environmental Science and Technology 43: 32003207.

Chisti, Y. (2007). "Biodiesel from microalgae." Biotechnology Advances 25: 294306.

Chisti, Y. (2008). "Biodiesel from microalgae beats bioethanol." Trends in Biotechnology 26(3): 126-131.

City of Tampa, F. (2010, 4/1/2010). "Advanced Wastewater Treatment Plant Facts of Interest." Wastewater. Retrieved June 6, 2010, from www.tampagov.net/dept_wastewater/information_resources.

Craggs, R., Paul McAuley, Valeria Smith (1997). "Wastewater nutrient removal by marine microalgae grown on corrugated raceway." Water Research 31(7): 1701-1707.

Crittenden, J. C. (2005). Water treatment principles and design. Hoboken, NJ, J. Wiley.

De la Noue, J., and D. Proulx (1988). "Biological tertiary treatment of urban wastewaters with chitosan-immobilized Phormidium." Applied Microbiology Biotechnology 29: 292-297.

de-Bashan, L. E., Yoav Bashan (2004). "Recent advances in removing phosphorus from wastewater and its future use as fertilizer (19972003)." Water Research 38: 4222-4246.

de-Bashan, L. E., and Yoav Bashan (2010). "Immobilized microalgae for removing pollutants: Review of practical aspects." Bioresource Technology 101: 1611-1627.

Dery, P. a. B. A. (2007) Peak Phosphorous. Energy Bulletin

Emcon Associates (1980). Methane Generation and Recovery from Landfills. Ann Arbor, MI, Ann Arbor Science Publishers, Inc.

Environmental Protection Agency. Sustainable Infrastructure for Water and Wastewater: Energy and Water. United States Environmental Protection Agency. www.epa.gov/waterinfrastructure/better management_energy.html\#basicone

Fadare, D. A., O.A. Bamiro, A.O. Oni (2010). "Energy and cost analysis of organic fertilizer production in Nigeria." Energy 35: 332-340. 
Gebrezgabher, S., Miranda P.M. Meuwissen, Bram A.M. Prins, Alfons G.J.M. Oude Lansink (2010). "Economic analysis of anaerobic digestion - a case of Green power biogas plant in The Netherlands." NJAS Wageningen Journal of Life Sciences 57: 109-115.

Gernaey, K. V., Mark C.M. van Loosdrecht, M. Henze, M. Lind, S.B. Jorgensen (2004). "Activated sludge wastewater treatment plant modeling and simulation: state of the art." Environmental Modeling and Software 19: 763-783.

Gernaey, K. V., G. Sin (2008). "Wastewater Treatment Models." Encyclopedia of Ecology: 3707-3718.

Gonzalez, C., Judith Marciniak, Santiago Villaverde, Pedro A Garcia-Encina, Raul Munoz (2008). "Microalgae-based processes for the biodegradation of pretreated piggery wastewaters." Applied Microbiology Biotechnology 80(5): 891-898.

Gonzalez, L. E., Rosa Olivia Canizares, Sandra Baena (1997). "Efficiency of ammonia and phosphorus removal from a Colombian agroindustrial wastewater by the microalgae Chlorella vulgaris and Scenedesmus dimorphus." Bioresource Technology 60: 259-262.

Grobbelaar, JU. "Algal nutrition" In: Handbook of microalgal culture: biotechnology and applied phycology. Ed. A Richmond. Blackwell: 97115.

Halterman, S. G., Dale W. Toetz (1984). "Kinetics of nitrate uptake by freshwater algae." Hydrobiologia 114(3): 209-214.

Henze, M., P. Harremoes, J. la Cour Jansen, E. Arvin (2002). Wastewater Treatment: Biological and Chemical Processes. Berlin, Springer.

Hoffman, J. P. (1998). "Minireview: Wastewater treatment with suspended and nonsuspended algae." Journal of Phycology 34: 757-763.

isee systems, i. (2010). "Model Building and Simulation Tutorials." from www.iseesystems.com.

Jasinski, S. M. (2006, Jan 2006). "Phosphate Rock." Mineral Commodity Summaries. Retrieved Apr 12 2010, 2010, from http://minerals.usgs.gov/minerals/pubs/commodity/phosphate_rock/ph ospmcs06.pdf. 
Kamilya, D., Sudipto Sarkar, Tapas K. Maiti, Sukumar Bandyopadhyay, Bimal C. Mal (2006). "Growth and nutrient removal rates of Spirulina platensis and Nostoc muscorum in fish culture effluent: a laboratory-scale study." Aquaculture Research 37: 1594-1597.

Lee, K., Choul-Gyun Lee (2001). "Effect of Light/Dark Cycles on Wastewater Treatments by Microalgae." Biotechnology Bioprocess Engineering 6: 194-199.

Lee, Y. (2001). "Microalgal mass culture systems and methods: their limitation and potential." Journal of Applied Phycology 13: 307-315.

Lee, Y.-K. (2004). Algal Nutrition: Heterotrophic Carbon Nutrition. Handbook of microalgal culture: biotechnology and applied phycology. A. Richmond. Oxford, Blackwell Science: 116-124.

Lopez-Vazquez, C. M., Christine M. Hooijmans, Damir Brdjanovic, Huub J. Gijzen, Mark C.M. van Loosdrecht (2008). "Factors affecting the microbial populations at full-scale enhanced biological phosphorus removal (EBPR) wastewater treatment plants in The Netherlands." Water Research 42: 2349-2360.

Maurer, M., P. Schwegler, and T.A. Larsen (2003). "Nutrients in urine: energetic aspects of removal and recovery." Water Science and Technology 48(1): 37-46.

Miao, X., Qingyu Wu (2004). "High yield bio-oil production from fast pyrolysis by metabolic controlling of Chlorella protothecoides." Journal of Biotechnology 110: 85-93.

Molina Grima, E., E.-H. Belarbi, F.G. Acien Fernandez, A. Robles Medina, Y. Chisti (2003). "Recovery of microalgal biomass and metabolites: process options and economics." Biotechnology Advances 20: 491515.

Mulbry, W., E. Kebede Westhead, C. Pizarro, L. Sikora (2005). "Recycling of manure nutrients: use of algal biomass from dairy manure treatment as a slow release fertilizer." Bioresource Technology 96: 451-458.

Mulbry, W., S. Kondrad, C. Pizarro (2006). "Biofertilizers from algal treatment of dairy and swine manure effluents: characterization of algal biomass as slow release fertilizer." Journal of Vegetable Science 12(3): 107-125. 
Mulbry, W., S. Kondrad, C. Pizarro, E. Kebede Westhead (2008). "Treatment of dairy manure effluent using freshwater algae: algal productivity and recovery of manure nutrients using pilot scale algal turf scrubber." Bioresource Technology 99: 8137-8142.

Mulkerrins, D., A.D.W. Dobson, E. Colleran (2004). "Parameters affecting biological phosphate removal from wastewaters." Environmental International 30: 249-259.

Multiple (2000). Carbon Dioxide Emissions from the Generation of Electric Power in the United States. Washington, D.C., Department of Energy and Environmental Protection Agency: 21.

Novak, J. T., David E. Brune (1985). "Inorganic carbon limited growth kinetics of some freshwater algae." Water Research 19(2): 215-225.

Ogbonna, J. C., Hideo Tanaka (1996). "Night Biomass Loss and Changes in Biochemical Composition of Cells during Light/Dark Cyclic Culture of Chlorella pyrenoidosa." Journal of Fermentation and Bioengineering 82(6): 558-564.

Ogbonna, J. C., Hitoshi Yoshizawa, Hideo Tanaka (2000). "Treatment of high strength organic wastewater by a mixed culture of photosynthetic microorganisms." Journal of Applied Phycology 12(3-5): 277-284.

Olguin, E. J. (2003). "Phycoremediation: key issues for cost-effective nutrient removal processes." Biotechnology Advances 22: 81-91.

Ong, S.-C., Chien-Ya Kao, Sheng-Yi Chiu, Ming-Ta Tsai, Chih-Sheng Lin (2010). "Characterization of the thermal-tolerant mutants of Chlorella sp. with high growth rate and application in outdoor photobioreactor cultivation." Bioresource Technology 101: 2880-2883.

Parson, S. A., Jennifer A. Smith (2008). "Phosphorus Removal and Recovery from Municipal Wastewaters." Elements 4: 109-112.

Powell, N., Andy Shilton, Yusuf Chisti, Steven Pratt (2008). "Factors influencing luxury uptake of phosphorus by microalgae in waste stabilization ponds." Environmental Science and Technology 42: 5958-5962.

Powell, N., Andy Shilton, Yusuf Chisti, Steven Pratt (2009). "Towards a luxury uptake process via microalgae - Defining the polyphosphate dynamics." Water Research 43: 4207-4213. 
Qin, J. (2005). Bio-Hydrocarbons from Algae: Impacts of temperature, light, and salinity on algae growth, Australian Government, Rural Industries Research and Development Corporation.

Ratledge, C., and Zvi Cohen (2008). "Microbial and algal oils: Do they have a future for biodiesel or as commodity oils?" Lipid Technology 20(7): 155-160.

Redfield, A.C. (1934) "On the proportions of organic derivations in sea water and their relation to the composition of plankton" In James Johnstone Memorial Volume. Ed. RJ Daniel. University Press of Liverpool, 177192

Rittman, B., and Perry L. McCarty (2001). Environmental Biotechnology: Principles and Applications. New York, McGraw-Hill.

Rybicki, S. (1997). Report No 1. Phosphorus Removal from Wastewater, A Literature Review. Advanced Wastewater Treatment. E. Plaza, E. Levlin, B. Hultman. Stockholm, Royal Institute of Technology. 1.

Saidou, H., A. Korchef, S. Ben Moussa, M. Ben Amor (2009). "Struvite precipitation by the dissolved $\mathrm{CO} 2$ degasification technique: impact of the airflow rate and $\mathrm{pH}$." Chemosphere 74: 338-343.

Silberman, L. (2010, 06/18/2010). "Innovation: A Lean, Green Machine." Inc. from www.inc.com/magazine/20100501/innovation-a-lean-greenmachine.html.

Tam, N. F. Y., and Y.S. Wong (1996). "Effect of ammonia concentrations on growth of Chlorella vulgaris and nitrogen removal from media." Bioresource Technology 57(1): 45-50.

Tran, N. H., J.R. Bartlett, G.S.K. Kannangara, A.S. Milev, H. Volk, M.A. Wilson (2010). "Catalytic upgrading of biorefinery oil from micro-algae." Fuel 89: 265-274.

Travieso, L., F. Benitez, P. Weiland, E. Sanchez, R. Dupeyron, A.R. Dominguez (1996). "Experiments on Immobilization of Microalgae for Nutrient Removal in Wastewater Treatments." Bioresource Technology 55: 181-186.

Wilkie, A., and Walter Mulbry (2002). "Recovery of dairy manure nutrients by benthic freshwater algae." Bioresource Technology 84: 81-91. 
Xiong, W., Chunfang Gao, Dong Yan, Chao Wu, Qingyu Wu (2010). "Double $\mathrm{CO} 2$ fixation in photosynthesis-fermentation model enhances algal lipid synthesis for biodiesel production." Bioresource Technology 101: 2287-2293.

Yang, C., Qiang Hua, Kazuyuki Shimizu (2000). "Energetics and carbon metabolism during growth of microalgal cells under photoautotrophic, mixotrophic, and cyclic light-autotrophic/dark-heterotrophic conditions." Biochemical Engineering Journal 6: 87-102.

Zamalloa, C., E. Vulsteke, J. Albrecht, and Willy Verstraete (2010). "The technoeconomic potential of renewable energy through the anaerobic digestion of microalgae." Bioresource Technology.

Zaslavskaia, L. A., J.C. Lippmeier, C. Shih, D. Ehrhardt, A.R. Grossman, K.E. Apt (2001). "Trophic Conversion of an Obligate Photoautotrophic Organism Through Metabolic Engineering." Science 292(5524): 20732075.

Zimmo, O. R., N.P. van der Steen, H.J. Gijzen (2004). "Nitrogen mass balance across pilot-scale algae and duckweed-based wastewater stabilization ponds." Water Research 38: 913-920. 


\section{Bibliography}

Change, J. a. B. L. (2001). "Nitrification/Denitrification in Intermittent Aeration Process for Swine Wastewater Treatment." Journal of Environmental Engineering 127(8).

Combres, C., G. Laliberte, J. Sevrin Reyssac, J. de la Noue (2006). "Effect of acetate on growth and ammonium uptake in the microalga Scenedesmus obliquus." Physiologia Plantarum 91(4): 729-734.

Deaton, M. L., and James J. Winebrake (2000). Dynamic Modeling of Environmental Systems. New York, Springer.

Doran, M. D., William C. Boyle (1979). "Phosphorus Removal by Activated Algae." Water Research 13: 805-812.

Harwood, J., and Irina Guschina (2009). "The versatility of algae and their lipid metabolism." Biochimie 91: 679-684.

Kooijman, S. A. L. M., T. Anderson, B.W. Kooi (2004). "Dynamic energy budget representations of stoichiometric constraints on population dynamics." Ecology 85(5): 1230-1243.

Lavoie, A., and J. De la Noue (1985). "Hyperconcentrated cultures of Scenedesmus obliquus. A new approach for wastewater biological tertiary treatment?" Water Research 19: 1437-1442.

Metzger, P., C. Largeau (2005). "Botryococcus braunii: a rich source for hydrocarbons and related ether lipids." Applied Microbiology Biotechnology 66: 486-496.

Stensel, H. D., R.C. Loehr, A.W. Lawrence (1973). "Biological Kinetics of Suspended Growth Denitrification." Journal of Water Pollution Control Federation 45(2): 249-261.

Yang, X., Xiaoqi Zeng, Yupend Ji, Qun Liu (2003). "Effects of Sodium Nitrate and Sodium Acetate Concentrations on the Growth and Fatty Acid Composition of Brachiomonas submarina." Oceanic and Coastal Sea Research 2(1): 75-78. 


\section{Appendices}




\section{Appendix A: List of Variables}

\section{Water Flow}

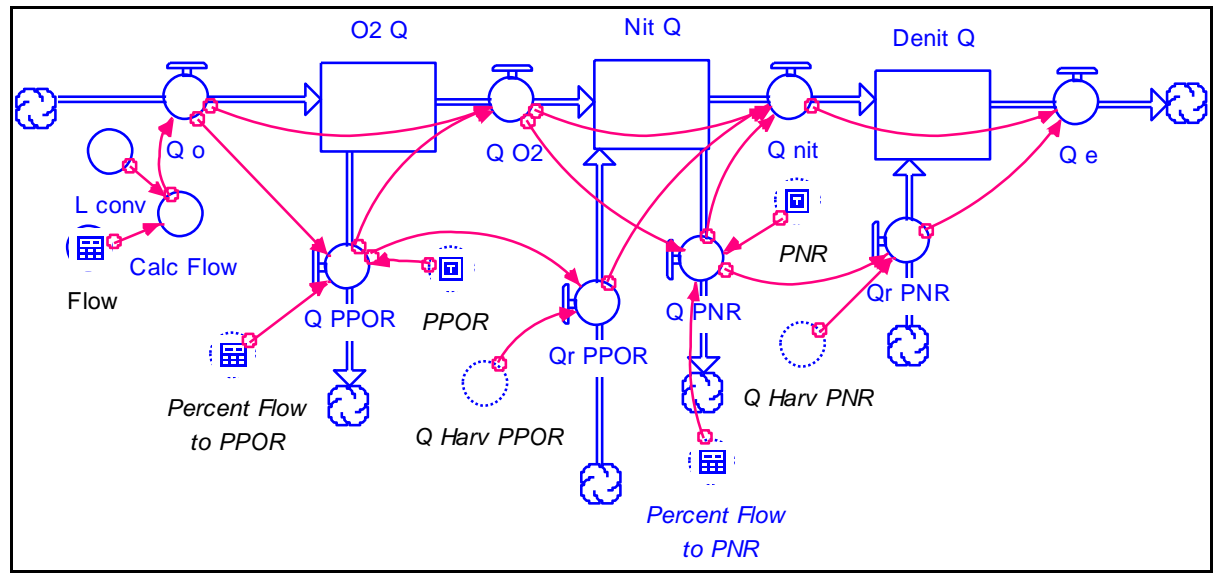

Figure A1. Detailed view of the water balance.

Table A1. List of variables in the water balance framework.

\begin{tabular}{|l|l|l|}
\hline Notation in Model & Description & Units or Value \\
\hline Q_o & Influent flow to plant & L/day \\
\hline Q_O2 & Flow from cBOD reactor & L/day \\
\hline Q_nit & Flow from nitrification reactor & L/day \\
\hline Q_e & Effluent flow from plant & L/day \\
\hline Q_PPOR & Flow to PPOR & L/day \\
\hline Qr_PPOR & Flow returned to plant from PPOR & L/day \\
\hline Q_PNR & Flow to PNR & L/day \\
\hline Qr_PNR & Flow returned to plant from PNR & L/day \\
\hline O2_Q & Stock for water in cBOD reactor & L \\
\hline Nit_Q & Stock for water in nitrification reactor & L \\
\hline Denit_Q & Stock for water in denitrification reactor & L \\
\hline Flow & Flow entered on interface & GPD \\
\hline L_conv & Converter for gallons to liters & L/gall \\
\hline Calc_Flow & Converter to put flow into liters & L/day \\
\hline Percent Flow to PPOR & $\begin{array}{l}\text { Converter entered on interface; amount } \\
\text { of water diverted to PPOR }\end{array}$ & $\%$ \\
\hline
\end{tabular}




\section{Appendix A (Continued)}

Table A1. (cont.)

\begin{tabular}{|l|l|l|}
\hline Notation in Model & Description & $\begin{array}{l}\text { Units or } \\
\text { Value }\end{array}$ \\
\hline PPOR & Switch for turning on/off water flow to PPOR & unitless \\
\hline Q_Harv_PPOR & $\begin{array}{l}\text { Flow of water leaving system with algae } \\
\text { harvest in PPOR }\end{array}$ & L/day \\
\hline Percent Flow to PNR & $\begin{array}{l}\text { Converter entered on interface; amount of } \\
\text { water diverted to PNR }\end{array}$ & $\%$ \\
\hline PNR & Switch for turning on/off water flow to PPOR & unitless \\
\hline Q_Harv_PNR & $\begin{array}{l}\text { Flow of water leaving system with algae } \\
\text { harvest in PNR }\end{array}$ & L/day \\
\hline
\end{tabular}

Table A2. List of equations in the water balance framework.

\begin{tabular}{|c|c|c|c|}
\hline Notation & Equation & $\begin{array}{l}\text { Initial } \\
\text { Value }\end{array}$ & Component \\
\hline Q_O = & Calc_Flow & $\mathrm{n} / \mathrm{a}$ & Flow \\
\hline O2_Q(t) = & O2_Q(t - dt) + (Q_o - Q_O2 - Q_PPOR ) * dt & 0 & Stock \\
\hline Q_O2 = & Q_0-Q_PPOR & $\mathrm{n} / \mathrm{a}$ & Flow \\
\hline Q_PPOR = & (Q_o*Percent_Flow_to_PPOR) ${ }^{*}$ PPOR & $\mathrm{n} / \mathrm{a}$ & Flow \\
\hline Nit_Q(t) = & $\begin{array}{l}\text { Nit_Q(t - dt) + (Q_O2 + Qr_PPOR - Q_nit - } \\
Q_{-} \text {PNR) * dt }\end{array}$ & 0 & Stock \\
\hline Qr_PPOR = & Q_PPOR-Q_Harv_PPOR & $\mathrm{n} / \mathrm{a}$ & Flow \\
\hline Q_PNR = & $\mathrm{PNR}^{*}\left(\mathrm{Q}\right.$ _O2 ${ }^{*}$ Percent_Flow_to_PNR $)$ & $\mathrm{n} / \mathrm{a}$ & Flow \\
\hline Q_nit $=$ & Q_O2+Qr_PPOR-Q_PNR & $\mathrm{n} / \mathrm{a}$ & Flow \\
\hline Denit $Q(t)=$ & Denit_Q(t - dt $)+\left(\mathrm{Q} \_ \text {nit }+ \text { Qr_PNR - Q_e }\right)^{*} \mathrm{dt}$ & 0 & Stock \\
\hline Q_e = & Q_nit+Qr_PNR & $\mathrm{n} / \mathrm{a}$ & Flow \\
\hline Qr_PNR = & Q_PNR-Q_Harv_PNR & $\mathrm{n} / \mathrm{a}$ & Flow \\
\hline
\end{tabular}




\section{Appendix A (Continued)}

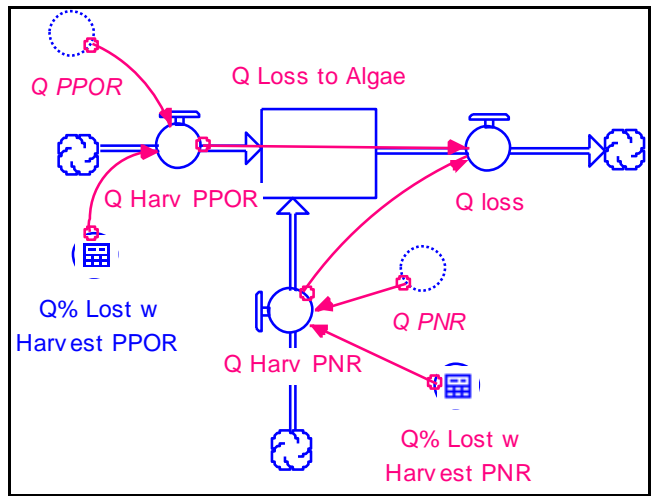

Figure A2. Detailed view of water loss to algae harvest.

Table A3. List of variables within water loss to algae harvest framework.

\begin{tabular}{|l|l|l|}
\hline Notation in Model & Description & $\begin{array}{l}\text { Units or } \\
\text { Value }\end{array}$ \\
\hline Q_Harv_PPOR & $\begin{array}{l}\text { Flow of water leaving system with } \\
\text { algae harvest in PPOR }\end{array}$ & L/day \\
\hline Qr_PPOR & Flow returned to plant from PPOR & L/day \\
\hline Q\%_Lost_w_Harvest_PPOR & $\begin{array}{l}\text { The percentage of the water flow to } \\
\text { the PPOR that's removed during } \\
\text { harvesting }\end{array}$ & unitless \\
\hline Q_Harv_PNR & $\begin{array}{l}\text { Flow of water leaving system with } \\
\text { algae harvest in PNR }\end{array}$ & L/day \\
\hline Q_PNR & Flow to PNR & L/day \\
\hline Q\%_Lost_w_Harvest_PNR & $\begin{array}{l}\text { The percentage of the water flow to } \\
\text { the PNR that's removed during } \\
\text { harvesting }\end{array}$ & L/day \\
\hline Q_loss & Total water lost to algae harvesting & L/day \\
\hline Q_Loss_to_Algae & $\begin{array}{l}\text { stock to track water volume lost to } \\
\text { algae harvest }\end{array}$ & L \\
\hline
\end{tabular}

Table A4. List of equations in water loss to algae harvest framework.

\begin{tabular}{|c|c|c|c|}
\hline Notation & Equation & $\begin{array}{l}\text { Initial } \\
\text { Value }\end{array}$ & Component \\
\hline Q_Harv_PPOR $=$ & $\mathrm{Q} \%$ Lost w Harvest PPOR ${ }^{\star} \mathrm{Q}$ PPOR & $\mathrm{n} / \mathrm{a}$ & flow \\
\hline $\begin{array}{r}\text { Q_Loss_to_Algae } \\
=\end{array}$ & $\begin{array}{l}\text { Q_Loss_to_Algae }(\mathrm{t}-\mathrm{dt})+ \\
(\mathrm{Q} \text { _Harv_PPOR }+ \text { Q_Harv_PNR }- \\
\text { Q_loss) }{ }^{*} \mathrm{dt}\end{array}$ & 0 & stock \\
\hline Q_Harv_PNR $=$ & Q_PNR ${ }^{*} Q \%$ LLost_w_Harvest_PNR & $\mathrm{n} / \mathrm{a}$ & flow \\
\hline Q_loss = & Q_Harv_PNR+Q_Harv_PPOR & $\mathrm{n} / \mathrm{a}$ & flow \\
\hline
\end{tabular}




\section{Appendix A (Continued)}

Phosphorous Flow through Treatment Plant

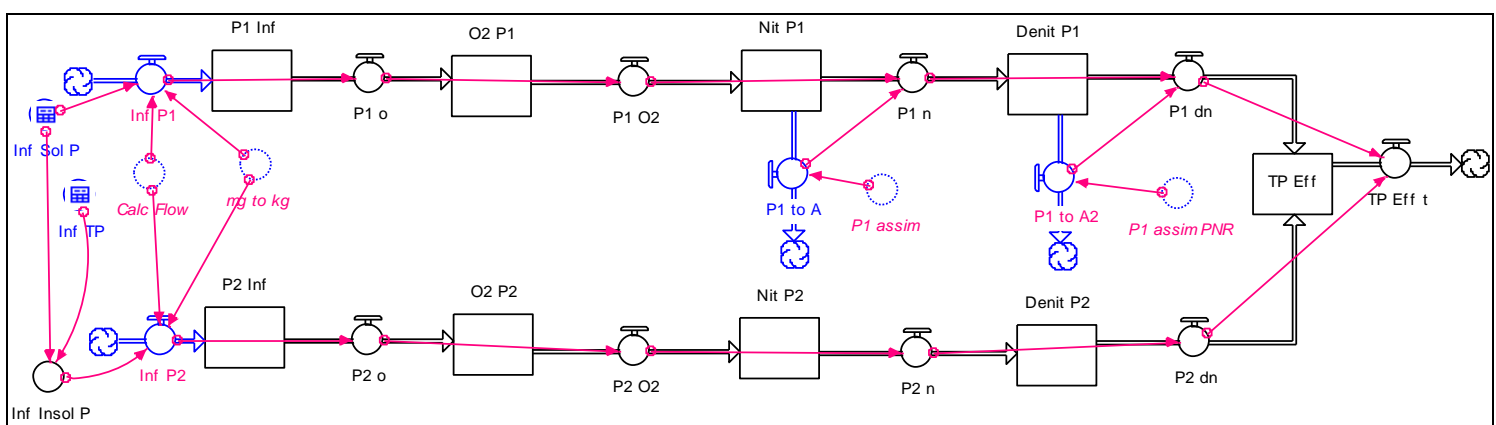

Figure A3. Phosphorous flow through treatment plant.

Table A5. List of variables in phosphorous flow framework.

\begin{tabular}{|l|l|l|}
\hline Notation in Model & Description & $\begin{array}{l}\text { Units or } \\
\text { Value }\end{array}$ \\
\hline Inf_P1 & Flow of influent soluble P & $\mathrm{kg} /$ day \\
\hline P1_Inf & Stock of soluble P & $\mathrm{kg}$ \\
\hline P1_0 & Flow of soluble P in influent & $\mathrm{kg} /$ day \\
\hline O2_P1 & Stock of soluble P & $\mathrm{kg}$ \\
\hline P1_O2 & Flow of soluble P out of CBOD reactor & $\mathrm{kg} /$ day \\
\hline Nit_P1 & Stock of soluble P & $\mathrm{kg}$ \\
\hline P1_n & Flow of soluble P out of nitrification reactor & $\mathrm{kg} /$ day \\
\hline Denit_P1 & Stock of soluble P & $\mathrm{kg}$ \\
\hline P1_dn & $\begin{array}{l}\text { Flow of soluble P out of denitrification } \\
\text { reactor }\end{array}$ & $\mathrm{kg} /$ day \\
\hline Inf_P2 & Flow of influent nonsoluble P & $\mathrm{kg} /$ day \\
\hline P2_Inf & Stock of nonsoluble P & $\mathrm{kg}$ \\
\hline P2_o & Flow of nonsoluble P in influent & $\mathrm{kg} /$ day \\
\hline O2_P2 & Stock of nonsoluble P & $\mathrm{kg}$ \\
\hline P2_O2 & Flow of nonsoluble P out of cBOD reactor & $\mathrm{kg} /$ day \\
\hline Nit_P2 & Stock of nonsoluble P & $\mathrm{kg}$ \\
\hline P2_n & $\begin{array}{l}\text { Flow of nonsoluble P out of nitrification } \\
\text { reactor }\end{array}$ & $\mathrm{kg} /$ day \\
\hline Denit_P2 & Stock of nonsoluble P & $\mathrm{kg}$ \\
\hline P2_dn & $\begin{array}{l}\text { Flow of nonsoluble P out of denitrification } \\
\text { reactor }\end{array}$ & $\mathrm{kg} /$ day \\
\hline
\end{tabular}




\section{Appendix A (Continued)}

Table A5. (cont.)

\begin{tabular}{|l|l|l|}
\hline Notation in Model & Description & $\begin{array}{l}\text { Units or } \\
\text { Value }\end{array}$ \\
\hline TP_Eff & Stock of total phosphorous & $\mathrm{kg}$ \\
\hline TP_Eff_t & Flow of effluent total phosphorous & $\mathrm{kg} / \mathrm{day}$ \\
\hline Inf_Sol_P & Influent soluble P & $\mathrm{mg} / \mathrm{L}$ \\
\hline Inf_TP & Influent TP & $\mathrm{mg} / \mathrm{L}$ \\
\hline Calc_Flow & Water flow into wastewater plant & $\mathrm{L} / \mathrm{day}$ \\
\hline mg_kg & mg to kg converter & $1000 \mathrm{mg} / \mathrm{kg}$ \\
\hline P1_to_A & Soluble P routed to algae, PPOR & $\mathrm{kg} / \mathrm{day}$ \\
\hline P1_to_A_2 & Soluble P routed to algae, PNR & $\mathrm{kg} / \mathrm{day}$ \\
\hline P1_assim & Soluble P assimilated in PPOR & $\mathrm{kg} / \mathrm{day}$ \\
\hline P1_assim_PNR & Soluble P assimilated in PNR & $\mathrm{kg} / \mathrm{day}$ \\
\hline
\end{tabular}

Table A6. List of equations in the phosphorous flow framework.

\begin{tabular}{|c|c|c|c|}
\hline Notation & Equation & $\begin{array}{l}\text { Initial } \\
\text { Value }\end{array}$ & Component \\
\hline Inf_P1 = & Calc_Flow*Inf_Sol_P/mg_to_kg & $\mathrm{n} / \mathrm{a}$ & flow \\
\hline P1 $\operatorname{lnf}(t)=$ & $P 1 \operatorname{Inf}(\mathrm{t}-\mathrm{dt})+(\operatorname{Inf} \mathrm{P} 1-\mathrm{P} 1 \mathrm{o}){ }^{*} d t$ & 0 & stock \\
\hline P1_o= & Inf_P1 & $\mathrm{n} / \mathrm{a}$ & flow \\
\hline O2_P1(t) = & $\mathrm{O} 2 \_\mathrm{P} 1(\mathrm{t}-\mathrm{dt})+\left(\mathrm{P} 1 \_0-\mathrm{P} 1 \_\mathrm{O} 2\right){ }^{*} \mathrm{dt}$ & 0 & stock \\
\hline $\mathrm{P} 1 \_02=$ & P1_o & $n / a$ & flow \\
\hline Nit_P1(t) = & Nit_P1 $(t-d t)+\left(P 1 \_O 2-P 1 \_n-P 1 \_t o \_A\right){ }^{*} d t$ & 0 & stock \\
\hline$P 1$ to $A=$ & P1_assim & $\mathrm{n} / \mathrm{a}$ & flow \\
\hline P1_n = & P1_O2-P1_to_A & $\mathrm{n} / \mathrm{a}$ & flow \\
\hline Denit_P1 $(\mathrm{t})=$ & $\begin{array}{l}\text { Denit_P1 (t - dt) + (P1_n - P1_dn - P1_to_A2) * } \\
\mathrm{dt}\end{array}$ & 0 & stock \\
\hline P1_dn = & $\mathrm{P} 1 \_\mathrm{n}-\mathrm{P} 1 \_$to $\_$A2 & $\mathrm{n} / \mathrm{a}$ & flow \\
\hline P1_to_A2 = & $\mathrm{P} 1$ assim PNR & $\mathrm{n} / \mathrm{a}$ & flow \\
\hline TP_Eff $(\mathrm{t})=$ & $\begin{array}{l}\text { TP_Eff(t }-\overline{d t})+\left(P 2 \_d n+P 1 \_d n-T P \_E f f \_t\right){ }^{*} \\
d t\end{array}$ & 0 & stock \\
\hline TP_Eff_t $=$ & $\mathrm{P} 1 \_d n+P 2 \_d n$ & $\mathrm{n} / \mathrm{a}$ & flow \\
\hline Inf_P2 = & Calc_Flow*Inf_Insol_P/mg_to_kg & $\mathrm{n} / \mathrm{a}$ & flow \\
\hline P2_Inf(t) = & $P 2 \_\operatorname{lnf}(t-d t)+\left(\operatorname{Inf} \_P 2-P 2 \_0\right)^{*} d t$ & 0 & stock \\
\hline
\end{tabular}




\section{Appendix A (Continued)}

Table A6. (cont.).

\begin{tabular}{|c|c|c|c|}
\hline Notation & Equation & $\begin{array}{l}\text { Initial } \\
\text { Value }\end{array}$ & Component \\
\hline $\mathrm{P} 2 \_0=$ & Inf_P2 & $\mathrm{n} / \mathrm{a}$ & flow \\
\hline O2_P2(t) = & O2_P2 $(\mathrm{t}-\mathrm{dt})+\left(\mathrm{P} 2 \_\mathrm{O}-\mathrm{P} 2 \_\mathrm{O} 2\right){ }^{*} \mathrm{dt}$ & 0 & stock \\
\hline $\mathrm{P} 2 \_\mathrm{O} 2=$ & $\mathrm{P} 2 \mathrm{O}$ & $\mathrm{n} / \mathrm{a}$ & flow \\
\hline Nit_P2(t) $=$ & Nit_P2 $(\mathrm{t}-\mathrm{dt})+\left(\mathrm{P} 2 \_\mathrm{O} 2-\mathrm{P} 2 \_\mathrm{n}\right){ }^{*} \mathrm{dt}$ & 0 & stock \\
\hline P2_n = & $\mathrm{P} 2 \_\mathrm{O} 2$ & $\mathrm{n} / \mathrm{a}$ & flow \\
\hline Denit_P2 $(\mathrm{t})=$ & Denit_P2 $(\mathrm{t}-\mathrm{dt})+\left(\mathrm{P} 2 \_n-\mathrm{P} 2 \_\mathrm{dn}\right){ }^{*} \mathrm{dt}$ & 0 & stock \\
\hline P2_dn = & $\mathrm{P} 2 \mathrm{n}$ & $\mathrm{n} / \mathrm{a}$ & flow \\
\hline
\end{tabular}

Phosphorous Mass Balance

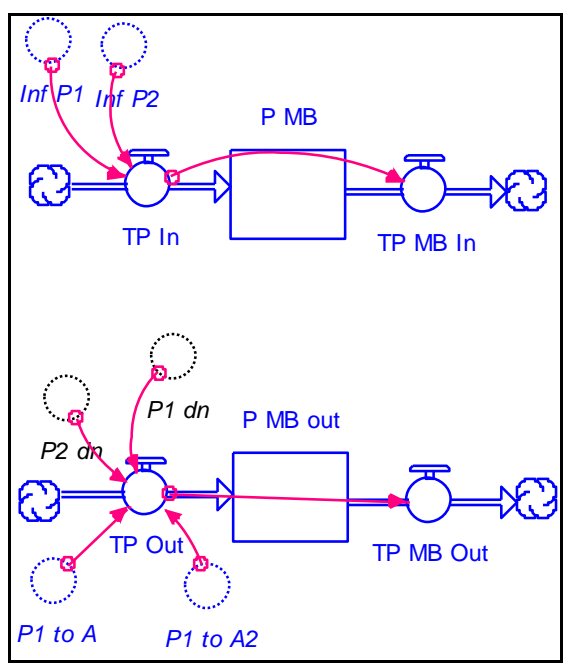

Figure A4. Phosphorous mass balance framework in STELLA model.

Table A7. List of variables in phosphorous mass balance framework.

\begin{tabular}{|l|l|l|}
\hline Notation in Model & Description & $\begin{array}{l}\text { Units or } \\
\text { Value }\end{array}$ \\
\hline TP_In & Flow of total P entering the system & $\mathrm{kg} /$ day \\
\hline Inf_P1 & Flow of influent soluble P & $\mathrm{kg} /$ day \\
\hline Inf_P2 & Flow of influent nonsoluble P & $\mathrm{kg} /$ day \\
\hline P_MB & Stock of total P entering the system & $\mathrm{kg}$ \\
\hline
\end{tabular}




\section{Appendix A (Continued)}

Table A7. (cont.)

\begin{tabular}{|l|l|l|}
\hline Notation in Model & Description & $\begin{array}{l}\text { Units or } \\
\text { Value }\end{array}$ \\
\hline TP_MB_In & Flow of total P entering the system & $\mathrm{kg} / \mathrm{day}$ \\
\hline P2_dn & Flow of effluent nonsoluble P & $\mathrm{kg} / \mathrm{day}$ \\
\hline P1_dn & Flow of effluent soluble P & $\mathrm{kg} / \mathrm{day}$ \\
\hline TP_Out & Flow of total P leaving the system & $\mathrm{kg} / \mathrm{day}$ \\
\hline TP_MB_Out & Flow of total P leaving the system & $\mathrm{kg} / \mathrm{day}$ \\
\hline P1_to_A & Flow of soluble P assimilated in PPOR & $\mathrm{kg} / \mathrm{day}$ \\
\hline P1_to_A2 & Flow of soluble P assimilated in PNR & $\mathrm{kg} / \mathrm{day}$ \\
\hline P_MB_Out & Stock of total P leaving the system & $\mathrm{kg}$ \\
\hline
\end{tabular}

Table A8. List of equations in phosphorous mass balance framework.

\begin{tabular}{|c|c|c|c|}
\hline Notation & Equation & $\begin{array}{l}\text { Initial } \\
\text { Value }\end{array}$ & Component \\
\hline TP $\_n=$ & Inf_P1+Inf_P2 & $\mathrm{n} / \mathrm{a}$ & flow \\
\hline $\mathrm{P} \_\mathrm{MB}=$ & $P \_M B(t-d t)+\left(T P \_I n-T P \_M B \_I n\right) * d t$ & 0 & stock \\
\hline TP $M B$ In $=$ & TP $\ln$ & $\mathrm{n} / \mathrm{a}$ & flow \\
\hline TP $\_$Out $=$ & $\mathrm{P} 1 \_\mathrm{dn}+\mathrm{P} 1 \_$to $A+\mathrm{P} 1 \_$to $\_\mathrm{A} 2+\mathrm{P} 2 \_\mathrm{dn}$ & $\mathrm{n} / \mathrm{a}$ & flow \\
\hline P_MB_Out $=$ & $\begin{array}{l}\text { P_MB_out }(\mathrm{t}-\overline{\mathrm{M}} \mathrm{t})+\left(\overline{\mathrm{TP}} \_ \text {Out }-\mathrm{TP} \_\mathrm{MB} \_ \text {Out }\right) \text { * } \\
\mathrm{dt}\end{array}$ & 0 & stock \\
\hline TP_MB_Out = & TP_Out & $\mathrm{n} / \mathrm{a}$ & flow \\
\hline
\end{tabular}

\section{Nitrogen Flow through Treatment Plant - Organic N and Ammonia}

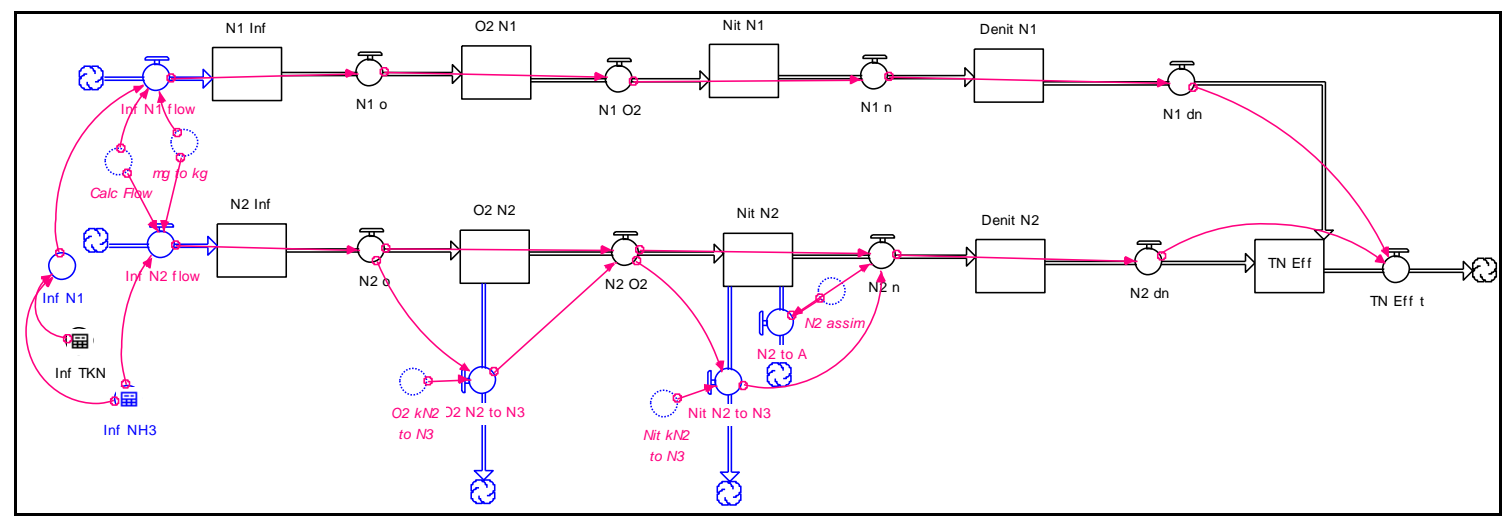

Figure A5. Nitrogen flow framework for organic $\mathrm{N}$ and ammonia in the STELLA model. 


\section{Appendix A (Continued)}

Table A9. List of variables in the nitrogen flow framework for organic $\mathrm{N}$ and ammonia.

\begin{tabular}{|l|l|l|}
\hline Notation in Model & Description & Units or Value \\
\hline Inf_N1_flow & Flow of influent organic N & $\mathrm{kg} /$ day \\
\hline N1_Inf & Stock of influent organic N & $\mathrm{kg}$ \\
\hline N1_o & Flow of influent organic N & $\mathrm{kg} /$ day \\
\hline O2_N1 & Stock of organic N in cBOD reactor & $\mathrm{kg}$ \\
\hline N1_O2 & Flow of organic N from cBOD reactor & $\mathrm{kg} /$ day \\
\hline Nit_N1 & Stock of organic N in nitrification reactor & $\mathrm{kg}$ \\
\hline Denit_N1 & Stock of organic N in denitrification reactor & $\mathrm{kg}$ \\
\hline N1_dn & $\begin{array}{l}\text { Flow of organic N from denitrification } \\
\text { reactor }\end{array}$ & $\mathrm{kg} /$ day \\
\hline mg_to_kg & Conversion from mg to kg & $1000 \mathrm{mg} / \mathrm{kg}$ \\
\hline Calc_Flow & Influent water flow & $\mathrm{L} /$ day \\
\hline Inf_N2_flow & Flow of influent ammonia & $\mathrm{kg} /$ day \\
\hline N2_Inf & Stock of influent ammonia & $\mathrm{kg}$ \\
\hline N2_o & Flow of influent ammonia & $\mathrm{kg} /$ day \\
\hline O2_N2 & Stock of ammonia in cBOD reactor & $\mathrm{kg}$ \\
\hline N2_O2 & Flow of ammonia from cBOD reactor & $\mathrm{kg} /$ day \\
\hline Nit_N2 & Stock of ammonia in nitrification reactor & $\mathrm{kg}$ \\
\hline N2_n & Flow of ammonia from nitrification reactor & $\mathrm{kg} /$ day \\
\hline Denit_N2 & Stock of ammonia in denitrification reactor & $\mathrm{kg}$ \\
\hline N2_dn & $\begin{array}{l}\text { Flow of ammonia from denitrification } \\
\text { reactor }\end{array}$ & $\mathrm{kg} /$ day \\
\hline TN_Eff & Stock of effluent total nitrogen & $\mathrm{kg}$ \\
\hline TN_Eff_t & Flow of effluent TN & $\mathrm{kg} /$ day \\
\hline Inf_NH3 & Influent ammonia concentration & $\mathrm{mg} / \mathrm{L}$ \\
\hline Inf_TKN & Influent TKN concentration & $\mathrm{mg} / \mathrm{L}$ \\
\hline Inf_N1 & Influent organic N concentration & $\mathrm{mg} / \mathrm{L}$ \\
\hline O2_N2_to_N3 & Flow of ammonia to nitrate in cBOD reactor & $\mathrm{kg} /$ day \\
\hline O2_kN2_to_N3 & Rate of conversion of ammonia to nitrate & $/ \mathrm{day}$ \\
\hline Nit_kN2_to_N3 & Rate of conversion of ammonia to nitrate & $/$ day \\
\hline Nit_N2_to_N3 & Flow of ammonia to nitrate in nitrification & $\mathrm{kg} /$ day \\
\hline N2_to_A & Flow of ammonia assimilated into algae & $\mathrm{kg} /$ day \\
\hline N2_assim & Flow of ammonia assimilated into algae & $\mathrm{kg} /$ day \\
\hline & & \\
\hline
\end{tabular}




\section{Appendix A (Continued)}

Table A10. List of equations in the nitrogen flow framework for organic $\mathrm{N}$ and ammonia.

\begin{tabular}{|c|c|c|c|}
\hline Notation & Equation & $\begin{array}{l}\text { Initial } \\
\text { Value }\end{array}$ & Component \\
\hline Inf_N1_flow $=$ & Calc_Flow*Inf_N1/mg_to_kg & $\mathrm{n} / \mathrm{a}$ & flow \\
\hline N1_Inf $(\mathrm{t})=$ & $\begin{array}{l}\text { N1_Inf(t - dt) + (Inf_N1_flow - N1_o) * } \\
d t\end{array}$ & 0 & stock \\
\hline $\mathrm{N} 1 \_0=$ & Inf_N1_flow & $\mathrm{n} / \mathrm{a}$ & flow \\
\hline $\mathrm{O} 2 \_\mathrm{N} 1(\mathrm{t})=$ & $\mathrm{O} 2 \_\mathrm{N} 1(\mathrm{t}-\mathrm{dt})+\left(\mathrm{N} 1 \_\mathrm{o}-\mathrm{N} 1 \_\mathrm{O} 2\right){ }^{*} \mathrm{dt}$ & 0 & stock \\
\hline $\mathrm{N} 1 \_\mathrm{O} 2=$ & N1_o & $\mathrm{n} / \mathrm{a}$ & flow \\
\hline Nit_N1 $(t)=$ & Nit_N1 $(\mathrm{t}-\mathrm{dt})+\left(\mathrm{N} 1 \_\mathrm{O} 2-\mathrm{N} 1 \_\mathrm{n}\right){ }^{*} \mathrm{dt}$ & 0 & stock \\
\hline $\mathrm{N} 1 \_n=$ & $\mathrm{N} 1 \_\mathrm{O} 2$ & $\mathrm{n} / \mathrm{a}$ & flow \\
\hline Denit_N1(t) = & Denit_N1 $(t-d t)+\left(N 1 \_n-N 1 \_d n\right){ }^{*} d t$ & 0 & stock \\
\hline $\mathrm{N} 1 \_\mathrm{dn}=$ & N1_n & $\mathrm{n} / \mathrm{a}$ & flow \\
\hline Inf_N2_flow $=$ & Calc_Flow*Inf_NH3/mg_to_kg & $\mathrm{n} / \mathrm{a}$ & flow \\
\hline $\mathrm{N} 2 \_\operatorname{lnf}(\mathrm{t})=$ & $\begin{array}{l}\text { N2_Inf(t - dt })+\left(\operatorname{Inf} \_N 2 \_f l o w-N 2 \_0\right) \text { * } \\
d t\end{array}$ & 0 & stock \\
\hline $\mathrm{N} 2 \_\mathrm{O}=$ & Inf_N2_flow & $\mathrm{n} / \mathrm{a}$ & flow \\
\hline $\mathrm{O} 2 \_\mathrm{N} 2(\mathrm{t})=$ & $\begin{array}{l}\mathrm{O} 2 \_\mathrm{N} 2(\mathrm{t}-\mathrm{dt})+\left(\mathrm{N} 2 \_\mathrm{o}-\mathrm{N} 2 \_\mathrm{O} 2-\right. \\
\left.\mathrm{O} 2 \_\mathrm{N} 2 \_t \mathrm{to} \_\mathrm{N} 3\right){ }^{*} \mathrm{dt}\end{array}$ & 0 & stock \\
\hline $\mathrm{O} 2 \_\mathrm{N} 2$ to_N3 = & N2_o*Nit_Rate_in_cBOD & $\mathrm{n} / \mathrm{a}$ & flow \\
\hline $\mathrm{N} 2 \_\mathrm{O} 2=$ & $\mathrm{N} 2 \_0-\mathrm{O} 2 \_\mathrm{N} 2$ to $\mathrm{N} 3$ & $\mathrm{n} / \mathrm{a}$ & flow \\
\hline Nit_N2(t) = & $\begin{array}{l}\text { Nit_N2(t - dt) }+\left(\mathrm{N} 2 \_\mathrm{O} 2-\mathrm{N} 2{ }^{\mathrm{n}}-\right. \\
\mathrm{N} 2 \text { to_A - Nit_N2_to_N3) }{ }^{*} \mathrm{dt}\end{array}$ & 0 & stock \\
\hline Nit_N2_to_N3 = & N2_O2*Nit_Rate_in_Nit_Reactor & $\mathrm{n} / \mathrm{a}$ & flow \\
\hline N2_to_A $=$ & N2_assim & $\mathrm{n} / \mathrm{a}$ & flow \\
\hline $\mathrm{N} 2 \_n=$ & N2_O2-N2_to_A - Nit_N2_to_N3 & $\mathrm{n} / \mathrm{a}$ & flow \\
\hline Denit_N2 $(t)=$ & Denit_N2 $(t-d t)+\left(N 2 \_n-N 2 \_d n\right){ }^{*} d t$ & 0 & stock \\
\hline N2 $d n=$ & N2_n & $\mathrm{n} / \mathrm{a}$ & flow \\
\hline$T N \_E f f(t)=$ & $\begin{array}{l}\text { TN_Eff(t - dt })+\left(\mathrm{N} 1 \_\mathrm{dn}+\mathrm{N} 2 \_\mathrm{dn}+\right. \\
\left.\mathrm{N} 3 \_\mathrm{dn}+\mathrm{N} 4 \_\mathrm{dn}-\mathrm{TN} \_\mathrm{Eff} \mathrm{t}\right){ }^{*} \mathrm{dt}\end{array}$ & 0 & stock \\
\hline TN_Eff_t $=$ & $\mathrm{N} 1 \_\mathrm{dn}+\mathrm{N} 2 \_\mathrm{dn}+\mathrm{N} 3 \_\mathrm{dn}+\mathrm{N} 4 \_\mathrm{dn}$ & $\mathrm{n} / \mathrm{a}$ & flow \\
\hline
\end{tabular}




\section{Appendix A (Continued)}

Nitrogen Flow through Treatment Plant - NOx and Nitrogen Gas

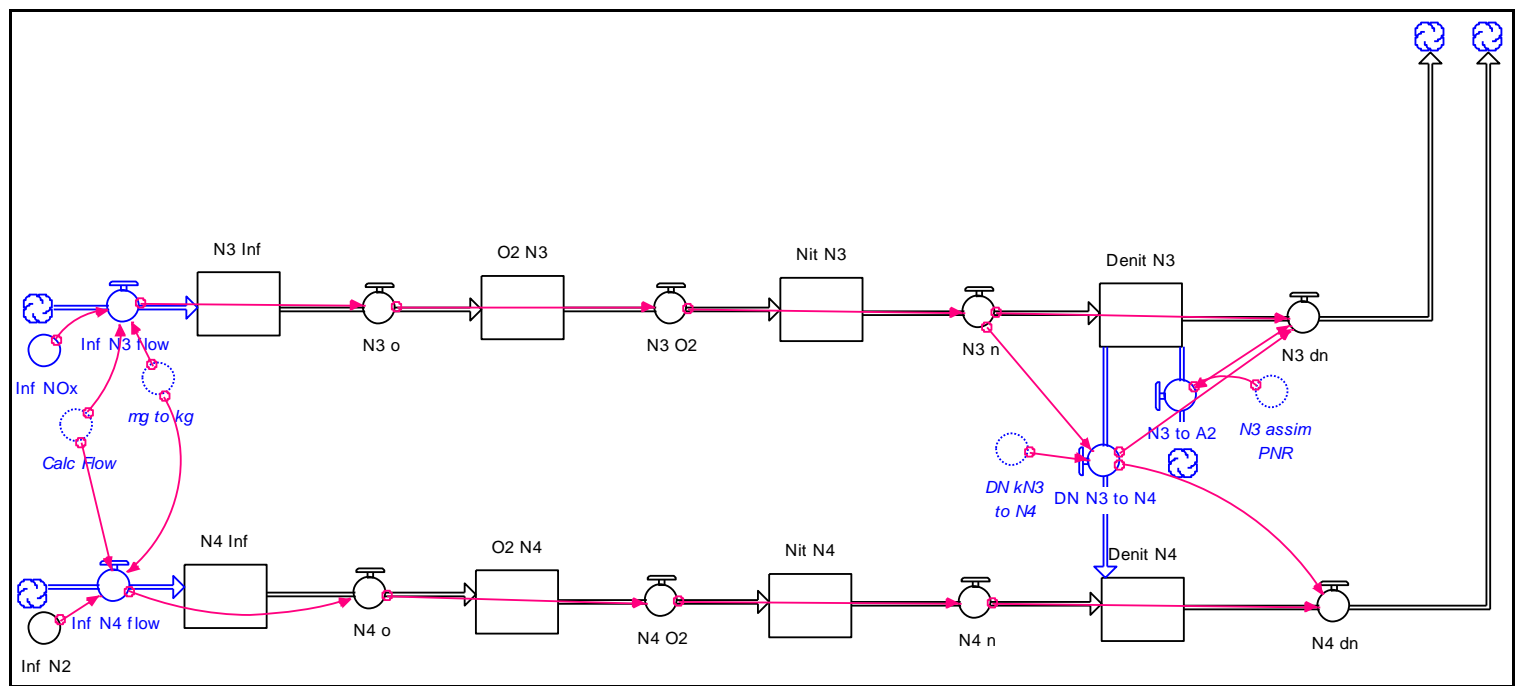

Figure A6. Nitrogen flow framework for organic $\mathrm{N}$ and ammonia in the STELLA model.

Table A11. List of variables in the nitrogen flow framework for nitrate and nitrogen gas.

\begin{tabular}{|l|l|l|}
\hline Notation in Model & Description & Units or Value \\
\hline Inf_NOx & Influent concentration of NOx & $\mathrm{mg} / \mathrm{L}$ \\
\hline Calc_Flow & Water flow through plant & L/day \\
\hline mg_to_kg & Conversion of mg to $\mathrm{kg}$ & $1000 \mathrm{mg} / \mathrm{kg}$ \\
\hline Inf_N3_flow & Flow of influent NOx & $\mathrm{kg} / \mathrm{day}$ \\
\hline N3_Inf & Stock of influent NOx & $\mathrm{kg}$ \\
\hline N3_o & Flow of influent NOx & $\mathrm{kg} / \mathrm{day}$ \\
\hline O2_N3 & Stock of NOx in CBOD reactor & $\mathrm{kg}$ \\
\hline N3_O2 & Flow of NOx from cBOD reactor & $\mathrm{kg} /$ day \\
\hline Nit_N3 & Stock of NOx in nitrification reactor & $\mathrm{kg}$ \\
\hline N3_n & Flow of NOx from nitrification reactor & $\mathrm{kg} /$ day \\
\hline Denit_N3 & Stock of NOx in denitrification reactor & $\mathrm{kg}$ \\
\hline N3_dn & $\begin{array}{l}\text { Flow of NOx from denitrification } \\
\text { reactor }\end{array}$ & $\mathrm{kg} / \mathrm{day}$ \\
\hline Inf_N2 & Influent concentration of N2 (gas) & $\mathrm{mg} / \mathrm{L}$ \\
\hline Inf_N4_flow & Flow of influent N2 & $\mathrm{kg} /$ day \\
\hline
\end{tabular}




\section{Appendix A (Continued)}

Table A11. (cont.)

\begin{tabular}{|l|l|l|}
\hline Notation in Model & Description & $\begin{array}{l}\text { Units or } \\
\text { Value }\end{array}$ \\
\hline N4_Inf & Stock of influent N2 & $\mathrm{kg}$ \\
\hline N4_0 & Flow of influent N2 & $\mathrm{kg} /$ day \\
\hline O2_N4 & Stock of N2 in cBOD reactor & $\mathrm{kg}$ \\
\hline N4_O2 & Flow of N2 from CBOD reactor & $\mathrm{kg} /$ day \\
\hline Nit_N4 & Stock of N2 in nitrification reactor & $\mathrm{kg}$ \\
\hline N4_n & Flow of N2 from nitrification reactor & $\mathrm{kg} /$ day \\
\hline Denit_N4 & Stock of N2 in denitrification reactor & $\mathrm{kg}$ \\
\hline N4_dn & Flow of N2 from denitrification reactor & $\mathrm{kg} /$ day \\
\hline DN_kN3_to_N4 & Rate of conversion of NOx to N2 & $/$ day \\
\hline DN_N3_to_N4 & Flow of NOx to N2 & $\mathrm{kg} /$ day \\
\hline N3_toA2 & Flow of NOx to algae & $\mathrm{kg} /$ day \\
\hline N3_assim_PNR & $\begin{array}{l}\text { Flow of NOx assimilated by algae in } \\
\text { PNR }\end{array}$ & $\mathrm{kg} /$ day \\
\hline
\end{tabular}

Table A12. List of equations in the nitrogen flow framework for nitrate and nitrogen gas.

\begin{tabular}{|c|c|c|c|}
\hline Notation & Equation & $\begin{array}{l}\text { Initial } \\
\text { Value }\end{array}$ & Component \\
\hline Inf_N3_flow $=$ & Calc_Flow*Inf_NOx/mg_to $\mathrm{kg}$ & $\mathrm{n} / \mathrm{a}$ & flow \\
\hline N3 $\operatorname{lnf}(\mathrm{t})=$ & N3 $\operatorname{lnf}(\mathrm{t}-\mathrm{dt})+\left(\operatorname{Inf} \mathrm{N} 3\right.$ flow $\left.-\mathrm{N} 3 \_0\right){ }^{*} \mathrm{dt}$ & 0 & stock \\
\hline $\mathrm{N} 3 \mathrm{O}=$ & Inf_N3_flow & $\mathrm{n} / \mathrm{a}$ & flow \\
\hline $\mathrm{O} 2 \mathrm{~N} 3(\mathrm{t})=$ & $\begin{array}{l}\text { O2_N3(t - dt) + (N3_o + O2_N2_to_N3 - } \\
\text { N3_O2) * dt }\end{array}$ & 0 & stock \\
\hline N3_O2 = & $\mathrm{O} 2$ N2_to_N3+N3_o & $\mathrm{n} / \mathrm{a}$ & flow \\
\hline Nit_N3(t) $=$ & $\begin{array}{l}\text { Nit_N3(t-dt) + (N3_O2 + Nit_N2_to_N3 - } \\
\text { N3_n })^{*} d t\end{array}$ & 0 & stock \\
\hline N3 $n=$ & $\mathrm{N} 3 \_\mathrm{O} 2+\mathrm{Nit}$ N2_to_N3 & $\mathrm{n} / \mathrm{a}$ & flow \\
\hline Denit_N3(t) $=$ & $\begin{array}{l}\text { Denit_N3(t - dt) +(N3_n - N3_dn - } \\
\text { N3_to_A2 - DN_N3_to_N4) * } d t\end{array}$ & 0 & stock \\
\hline N3_dn $=$ & N3_n-DN_N3_to_N4 - N3_to_A2 & $\mathrm{n} / \mathrm{a}$ & flow \\
\hline DN_N3_to_N4 = & N3_n*Denit_Rate & $\mathrm{n} / \mathrm{a}$ & flow \\
\hline N3_to_A2 $=$ & N3_assim_PNR & $\mathrm{n} / \mathrm{a}$ & flow \\
\hline Inf_N4_flow = & Calc_Flow*Inf_N2/mg_to_kg & $\mathrm{n} / \mathrm{a}$ & flow \\
\hline N4_Inf(t) = & $\mathrm{N} 4 \_\operatorname{lnf}(\mathrm{t}-\mathrm{dt})+\left(\operatorname{Inf} \mathrm{N} 4\right.$ flow $\left.-\mathrm{N} 4 \_0\right){ }^{*} \mathrm{dt}$ & 0 & stock \\
\hline $\mathrm{N} 4 \_\mathrm{O}=$ & Inf_N4_flow & $\mathrm{n} / \mathrm{a}$ & flow \\
\hline
\end{tabular}




\section{Appendix A (Continued)}

Table A12. (cont.).

\begin{tabular}{|c|c|c|c|}
\hline Notation & Equation & $\begin{array}{l}\text { Initial } \\
\text { Value }\end{array}$ & Component \\
\hline O2_N4(t) = & $\mathrm{O} 2 \_\mathrm{N} 4(\mathrm{t}-\mathrm{dt})+\left(\mathrm{N} 4 \_0-\mathrm{N} 4 \_\mathrm{O} 2\right){ }^{*} \mathrm{dt}$ & 0 & stock \\
\hline $\mathrm{N} 4 \_\mathrm{O} 2=$ & N4_o & $\mathrm{n} / \mathrm{a}$ & flow \\
\hline Nit_N4 $(t)=$ & Nit_N4 $(t-d t)+\left(N 4 \_O 2-N 4 \_n\right) * d t$ & 0 & stock \\
\hline $\mathrm{N} 4 \mathrm{n}=$ & N4_O2 & $\mathrm{n} / \mathrm{a}$ & flow \\
\hline Denit_N4 $(\mathrm{t})=$ & $\begin{array}{l}\text { Denit_N4(t - dt) + (N4_n + DN_N3_to_N4 - } \\
\text { N4_dn }{ }^{*} \mathrm{dt}\end{array}$ & 0 & stock \\
\hline $\mathrm{N} 4 \_\mathrm{dn}=$ & $\mathrm{N} 4 \_\mathrm{n}+\mathrm{DN}$ N3_to_N4 & $\mathrm{n} / \mathrm{a}$ & flow \\
\hline
\end{tabular}

\section{Nitrogen Mass Balance}

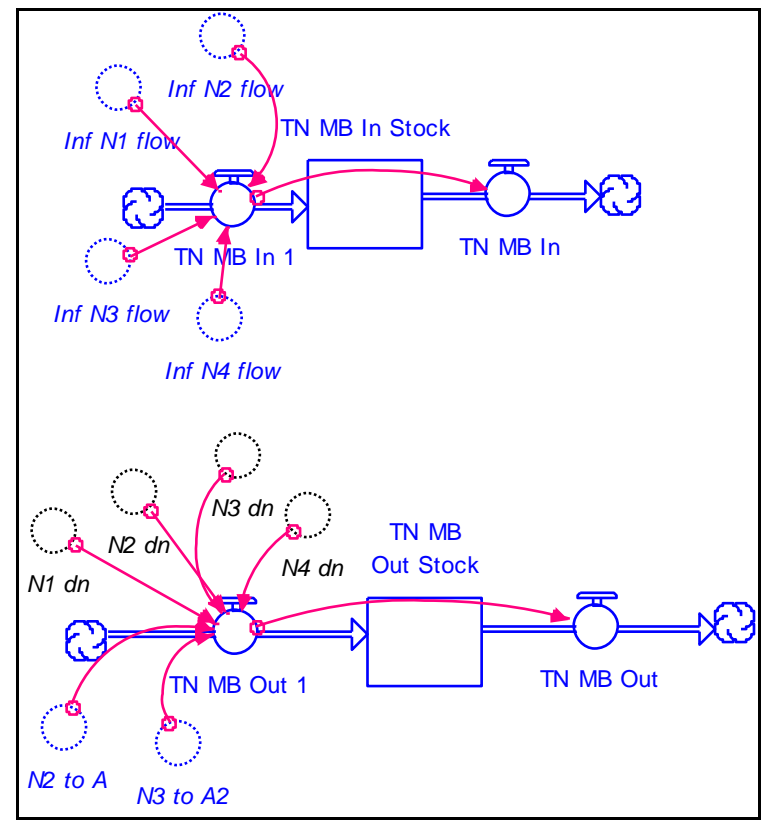

Figure A7. Nitrogen mass balance in STELLA model.

Table A13. List of variables in nitrogen mass balance.

\begin{tabular}{|l|l|l|}
\hline Notation in Model & Description & $\begin{array}{l}\text { Units or } \\
\text { Value }\end{array}$ \\
\hline TN_MB_In_1 & Flow of total N species entering system & $\mathrm{kg} /$ day \\
\hline TN_MB_In_Stock & Stock of total N species entering system & $\mathrm{kg}$ \\
\hline TN_MB_In & Flow of total N species entering system & $\mathrm{kg} /$ day \\
\hline Inf_N1_flow & Flow of organic N entering system & $\mathrm{kg} /$ day \\
\hline Inf_N2_flow & Flow of ammonia entering system & $\mathrm{kg} /$ day \\
\hline Inf_N3_flow & Flow of NOx entering system & $\mathrm{kg} /$ day \\
\hline
\end{tabular}




\section{Appendix A (Continued)}

Table A13. (cont.).

\begin{tabular}{|l|l|l|}
\hline Notation in Model & Description & Units or Value \\
\hline Inf_N4_flow & Flow of influent N2 & $\mathrm{kg} /$ day \\
\hline N4_Inf & Stock of influent N2 & $\mathrm{kg}$ \\
\hline N4_0 & Flow of influent N2 & $\mathrm{kg} /$ day \\
\hline O2_N4 & Stock of N2 in CBOD reactor & $\mathrm{kg}$ \\
\hline N4_O2 & Flow of N2 from cBOD reactor & $\mathrm{kg} /$ day \\
\hline Nit_N4 & Stock of N2 in nitrification reactor & $\mathrm{kg}$ \\
\hline N4_n & Flow of N2 from nitrification reactor & $\mathrm{kg} /$ day \\
\hline Denit_N4 & Stock of N2 in denitrification reactor & $\mathrm{kg}$ \\
\hline N4_dn & Flow of N2 from denitrification reactor & $\mathrm{kg} /$ day \\
\hline DN_kN3_to_N4 & Rate of conversion of NOx to N2 & $/$ day \\
\hline DN_N3_to_N4 & Flow of NOx to N2 & $\mathrm{kg} /$ day \\
\hline N3_toA2 & Flow of NOx to algae & $\mathrm{kg} /$ day \\
\hline N3_assim_PNR & Flow of NOx assimilated by algae in PNR & $\mathrm{kg} /$ day \\
\hline
\end{tabular}

Table A14. List of equations in nitrogen mass balance.

\begin{tabular}{|c|c|c|c|}
\hline Notation & Equation & $\begin{array}{l}\text { Initial } \\
\text { Value }\end{array}$ & Component \\
\hline TN_MB_In_1 = & $\begin{array}{l}\text { Inf_N1_flow+Inf_N2_flow+Inf_N3_fl } \\
\text { ow+Inf_N4_flow }\end{array}$ & $\mathrm{n} / \mathrm{a}$ & flow \\
\hline TN_MB_In_Stock = & $\begin{array}{l}\text { TN_MB_In_Stock }(t-d t)+ \\
\left(T N \_M B \_I n \_1-T N \_M B \_I n\right){ }^{*} d t\end{array}$ & 0 & stock \\
\hline TN_MB_In $=$ & TN_MB_In_1 & $\mathrm{n} / \mathrm{a}$ & flow \\
\hline TN_MB_Out_1 = & $\begin{array}{l}\mathrm{N} 1 \_\mathrm{dn}+\mathrm{N} 2 \text { 2 dn+N2_to_A+N3_dn+N } \\
\text { 3_to_A2+N4_dn }\end{array}$ & $\mathrm{n} / \mathrm{a}$ & flow \\
\hline TN_MB_Out_Stock = & $\begin{array}{l}\text { TN_MB_Out_Stock }(t-d t)+ \\
\text { (TN_MB_Out_1 - TN_MB_Out) }{ }^{*} d t\end{array}$ & 0 & stock \\
\hline TN & TN_MB_Out_1 & $\mathrm{n} / \mathrm{a}$ & flow \\
\hline
\end{tabular}




\section{Appendix A (Continued)}

Carbon Flow through Treatment Plant - Soluble and Nonsoluble Carbon

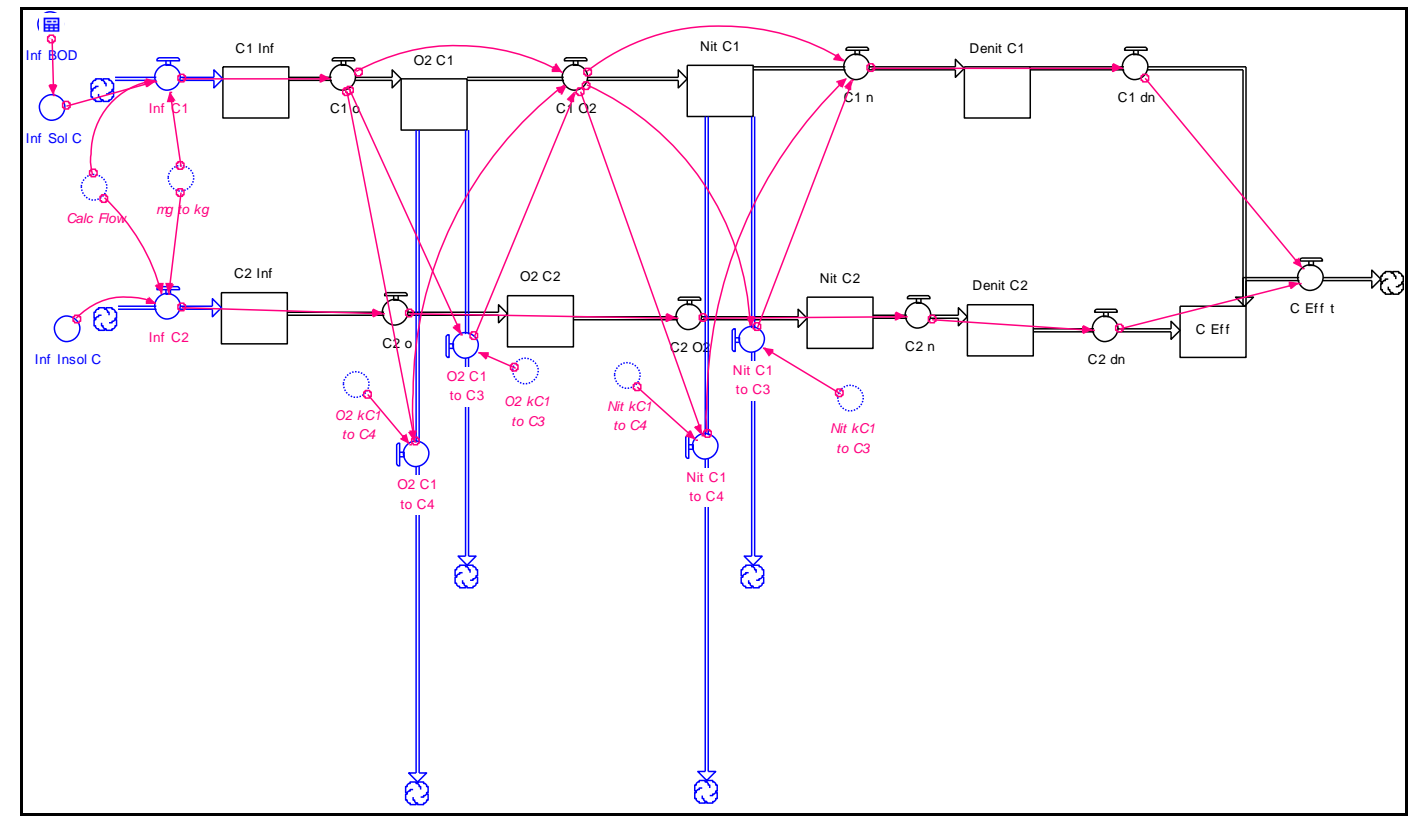

Figure A8. Flow of soluble and nonsoluble carbon species in STELLA model.

Table A15. List of variables in soluble and nonsoluble carbon species model framework.

\begin{tabular}{|l|l|l|}
\hline $\begin{array}{l}\text { Notation in } \\
\text { Model }\end{array}$ & Description & Units or Value \\
\hline Inf_BOD & Influent concentration of BOD, i.e. soluble C & $\mathrm{mg} / \mathrm{L}$ \\
\hline Inf_Sol_C & Influent concentration of BOD, i.e. soluble C & $\mathrm{mg} / \mathrm{L}$ \\
\hline Calc_Flow & Flow of water through system & L/day \\
\hline mg_to_kg & Conversion of mg to $\mathrm{kg}$ & $1000 \mathrm{mg} / \mathrm{kg}$ \\
\hline Inf_C1 & Flow of influent soluble C & $\mathrm{kg} / \mathrm{day}$ \\
\hline C1_Inf & Stock of influent soluble C & $\mathrm{kg}$ \\
\hline C1_o & Flow of influent soluble C & $\mathrm{kg} / \mathrm{day}$ \\
\hline O2_C1 & Stock of soluble C in cBOD reactor & $\mathrm{kg}$ \\
\hline C1_O2 & Flow of soluble C from cBOD reactor & $\mathrm{kg} / \mathrm{day}$ \\
\hline Nit_C1 & Stock of soluble C in nitrification reactor & $\mathrm{kg}$ \\
\hline C1_n & Flow of soluble C from nitrification reactor & $\mathrm{kg} / \mathrm{day}$ \\
\hline Denit_C1 & Stock of soluble C in denitrification reactor & $\mathrm{kg}$ \\
\hline C1_dn & $\begin{array}{l}\text { Flow of soluble C from denitrification reactor; } \\
\text { effluent }\end{array}$ & $\mathrm{kg} / \mathrm{day}$ \\
\hline Inf_Insol_C & Influent concentration of nonsoluble C & $\mathrm{mg} / \mathrm{L}$ \\
\hline
\end{tabular}




\section{Appendix A (Continued)}

Table A15. (cont.).

\begin{tabular}{|c|c|c|}
\hline $\begin{array}{l}\text { Notation in } \\
\text { Model }\end{array}$ & Description & Units or Value \\
\hline Inf_C2 & Flow of influent insoluble $\mathrm{C}$ & $\mathrm{kg} /$ day \\
\hline C2_Inf & Stock of influent insoluble C & $\mathrm{kg}$ \\
\hline $\mathrm{C} 2 \_0$ & Flow of influent insoluble $\mathrm{C}$ & $\mathrm{kg} / \mathrm{day}$ \\
\hline $\mathrm{O} 2 \_\mathrm{C} 2$ & Stock of insoluble $\mathrm{C}$ in $\mathrm{cBOD}$ reactor & $\mathrm{kg}$ \\
\hline $\mathrm{C} 2 \_\mathrm{O} 2$ & Flow of insoluble $\mathrm{C}$ from $\mathrm{cBOD}$ reactor & kg/day \\
\hline Nit_C2 & Stock of insoluble $\mathrm{C}$ in nitrification reactor & $\mathrm{kg}$ \\
\hline $\mathrm{C} 2 \_\mathrm{n}$ & Flow of insoluble $\mathrm{C}$ from nitrification reactor & $\mathrm{kg} /$ day \\
\hline Denit_C2 & Stock of insoluble $\mathrm{C}$ in denitrification reactor & $\mathrm{kg}$ \\
\hline C2_dn & Flow of insoluble $\mathrm{C}$ from denitrification reactor & $\mathrm{kg} /$ day \\
\hline C_Eff & Stock of effluent total carbon from the system & $\mathrm{kg}$ \\
\hline C_Eff_t & Flow of effluent total carbon from the system & $\mathrm{kg} /$ day \\
\hline O2_kC1_to_C4 & $\begin{array}{l}\text { Rate of conversion of soluble carbon to carbon } \\
\text { dioxide in cBOD reactor }\end{array}$ & /day \\
\hline O2_C1_to_C4 & $\begin{array}{l}\text { Flow of soluble carbon to carbon dioxide from } \\
\text { cBOD reactor }\end{array}$ & $\mathrm{kg} / \mathrm{day}$ \\
\hline O2_kC1_to_C3 & $\begin{array}{l}\text { Rate of conversion of soluble carbon to organic } \\
\text { carbon in cBOD reactor }\end{array}$ & /day \\
\hline O2_C1_to_C3 & $\begin{array}{l}\text { Flow of soluble carbon to organic carbon from } \\
\text { cBOD reactor }\end{array}$ & $\mathrm{kg} /$ day \\
\hline Nit_kC1_to_C4 & $\begin{array}{l}\text { Rate of conversion of soluble carbon to carbon } \\
\text { dioxide in nitrification reactor }\end{array}$ & /day \\
\hline Nit_C1_to_C4 & $\begin{array}{l}\text { Flow of soluble carbon to carbon dioxide from } \\
\text { nitrification reactor }\end{array}$ & $\mathrm{kg} / \mathrm{day}$ \\
\hline Nit_kC1_to_C3 & $\begin{array}{l}\text { Rate of conversion of soluble carbon to organic } \\
\text { carbon in nitrification reactor }\end{array}$ & /day \\
\hline Nit_C1_toC3 & $\begin{array}{l}\text { Flow of soluble carbon to organic carbon from } \\
\text { nitrification reactor }\end{array}$ & kg/day \\
\hline O2_kC1_to_C4 & $\begin{array}{l}\text { Rate of conversion of soluble carbon to carbon } \\
\text { dioxide in cBOD reactor }\end{array}$ & /day \\
\hline O2_C1_to_C4 & $\begin{array}{l}\text { Flow of soluble carbon to carbon dioxide from } \\
\text { cBOD reactor }\end{array}$ & kg/day \\
\hline O2_kC1_to_C3 & $\begin{array}{l}\text { Rate of conversion of soluble carbon to organic } \\
\text { carbon in cBOD reactor }\end{array}$ & /day \\
\hline O2_C1_to_C3 & $\begin{array}{l}\text { Flow of soluble carbon to organic carbon from } \\
\text { cBOD reactor }\end{array}$ & kg/day \\
\hline Nit_kC1_to_C4 & $\begin{array}{l}\text { Rate of conversion of soluble carbon to carbon } \\
\text { dioxide in nitrification reactor }\end{array}$ & /day \\
\hline Nit_C1_to_C4 & $\begin{array}{l}\text { Flow of soluble carbon to carbon dioxide from } \\
\text { nitrification reactor }\end{array}$ & $\mathrm{kg} /$ day \\
\hline
\end{tabular}




\section{Appendix A (Continued)}

Table A15. (cont.).

\begin{tabular}{|l|l|l|}
\hline $\begin{array}{l}\text { Notation in } \\
\text { Model }\end{array}$ & Description & Units or Value \\
\hline Nit_kC1_to_C3 & $\begin{array}{l}\text { Rate of conversion of soluble carbon to organic } \\
\text { carbon in nitrification reactor }\end{array}$ & /day \\
\hline Nit_C1_to_C3 & $\begin{array}{l}\text { Flow of soluble carbon to organic carbon from } \\
\text { nitrification reactor }\end{array}$ & $\mathrm{kg} / \mathrm{day}$ \\
\hline
\end{tabular}

Table A16. List of equations in soluble and nonsoluble carbon species model framework.

\begin{tabular}{|c|c|c|c|}
\hline Notation & Equation & $\begin{array}{l}\text { Initial } \\
\text { Value }\end{array}$ & Component \\
\hline Inf_C1 $=$ & Calc_Flow*Inf_Sol_C/mg_to $\mathrm{kg}$ & $\mathrm{n} / \mathrm{a}$ & flow \\
\hline C1_Inf(t) = & $\mathrm{C} 1 \_\operatorname{lnf}(\mathrm{t}-\mathrm{dt})+\left(\operatorname{Inf} \_\mathrm{C} 1-\mathrm{C} 1 \_0\right){ }^{*} \mathrm{dt}$ & 0 & stock \\
\hline $\mathrm{C} 1 \mathrm{O}=$ & $\operatorname{lnf} \mathrm{C} 1$ & $\mathrm{n} / \mathrm{a}$ & flow \\
\hline $\mathrm{O} 2 \_\mathrm{C} 1(\mathrm{t})=$ & $\begin{array}{l}\mathrm{O} 2 \text { C1 } 1(\mathrm{t}-\mathrm{dt})+\left(\mathrm{C} 1-\mathrm{O}-\mathrm{C} 1 \_\mathrm{O} 2-\right. \\
\mathrm{O} 2[\mathrm{C} 1 \text { to_C3-O2_C1_to_C } 4)^{*} \mathrm{dt}\end{array}$ & 0 & stock \\
\hline $\mathrm{O} 2 \_\mathrm{C} 1 \_$to $\mathrm{C} 4=$ & $\mathrm{C} 1 \_\mathrm{O}^{*} \mathrm{O} 2$ kC1_to_C4 & $\mathrm{n} / \mathrm{a}$ & flow \\
\hline $\mathrm{O} 2$ C1_to_C3 = & C1_o*O2_kC1_to_C3 & $n / a$ & flow \\
\hline $\mathrm{C} 1 \mathrm{O} 2=$ & $\mathrm{C} 1 \mathrm{0}-\mathrm{O} 2 \mathrm{C} 1$ to $\mathrm{C} 4-\mathrm{O} 2 \mathrm{C}_{1}$ to $\mathrm{C} 3$ & $\mathrm{n} / \mathrm{a}$ & flow \\
\hline Nit_C1 $(t)=$ & $\begin{array}{l}\text { Nit_C1(t - dt) + (C1_O2 - C1_n - } \\
\text { Nit_C1_to_C3 - Nit_C1_to_C4) * dt }\end{array}$ & 0 & stock \\
\hline Nit_C1_to_C4 $=$ & C1_O2*Nit_kC1_to_C4 & $\mathrm{n} / \mathrm{a}$ & flow \\
\hline Nit_C1_to_C3 = & Nit_kC1_to_C3*C1_O2 & $\mathrm{n} / \mathrm{a}$ & flow \\
\hline C1_n = & C1_O2-Nit_C1_to_C3-Nit_C1_to_C4 & $\mathrm{n} / \mathrm{a}$ & flow \\
\hline Denit_C1 $(\mathrm{t})=$ & Denit_C1 $(\mathrm{t}-\mathrm{dt})+\left(\mathrm{C} 1 \_\mathrm{n}-\mathrm{C} 1 \_\mathrm{dn}\right){ }^{*} \mathrm{dt}$ & 0 & stock \\
\hline C1_dn = & C1_n & $\mathrm{n} / \mathrm{a}$ & flow \\
\hline Inf_C2 = & Calc_Flow*Inf_Insol_C/mg_to_kg & $\mathrm{n} / \mathrm{a}$ & flow \\
\hline $\mathrm{C} 2 \_\operatorname{lnf}(\mathrm{t})=$ & $\mathrm{C} 2 \_\operatorname{lnf}(\mathrm{t}-\mathrm{dt})+\left(\operatorname{Inf} \_\mathrm{C} 2-\mathrm{C} 2 \_\mathrm{o}\right){ }^{*} \mathrm{dt}$ & 0 & stock \\
\hline $\mathrm{C} 2 \_\mathrm{O}=$ & Inf_C2 & $\mathrm{n} / \mathrm{a}$ & flow \\
\hline $\mathrm{O} 2 \_\mathrm{C} 2(\mathrm{t})=$ & $\mathrm{O} 2 \_\mathrm{C} 2(\mathrm{t}-\mathrm{dt})+\left(\mathrm{C} 2 \_\mathrm{O}-\mathrm{C} 2 \_\mathrm{O} 2\right){ }^{*} \mathrm{dt}$ & 0 & stock \\
\hline $\mathrm{C} 2-02=$ & C2_o & $\mathrm{n} / \mathrm{a}$ & flow \\
\hline Nit_C2 $(t)=$ & Nit $C 2(t-d t)+\left(C 2 \_O 2-C 2-n\right)^{*} d t$ & 0 & stock \\
\hline $\mathrm{C} 2 \mathrm{n}=$ & $\mathrm{C} 2 \mathrm{O}_{2}$ & $\mathrm{n} / \mathrm{a}$ & flow \\
\hline Denit_C2 $(\mathrm{t})=$ & Denit_C2 $(t-d t)+\left(C 2 \_n-C 2 \_d n\right){ }^{*} d t$ & 0 & stock \\
\hline $\mathrm{C} 2 \mathrm{dn}=$ & $\mathrm{C} 2 \_\mathrm{n}$ & $\mathrm{n} / \mathrm{a}$ & flow \\
\hline C_Eff $(t)=$ & $\begin{array}{l}\text { C_Eff(t }-d t)+\left(C 1 \_d n+C 3 \_d n+C 4 \_d n\right. \\
\left.+C 2 \_d n-C \_E f f \_t\right)^{*} d t\end{array}$ & 0 & stock \\
\hline C_Eff_t $=$ & $\mathrm{C} 1 \_\mathrm{dn}+\mathrm{C} 2 \mathrm{dn}+\mathrm{C} 3 \_\mathrm{dn}+\mathrm{C} 4 \mathrm{dn}$ & $\mathrm{n} / \mathrm{a}$ & flow \\
\hline
\end{tabular}




\section{Appendix A (Continued)}

Carbon Flow through Treatment Plant - Organic Carbon and Carbon Dioxide

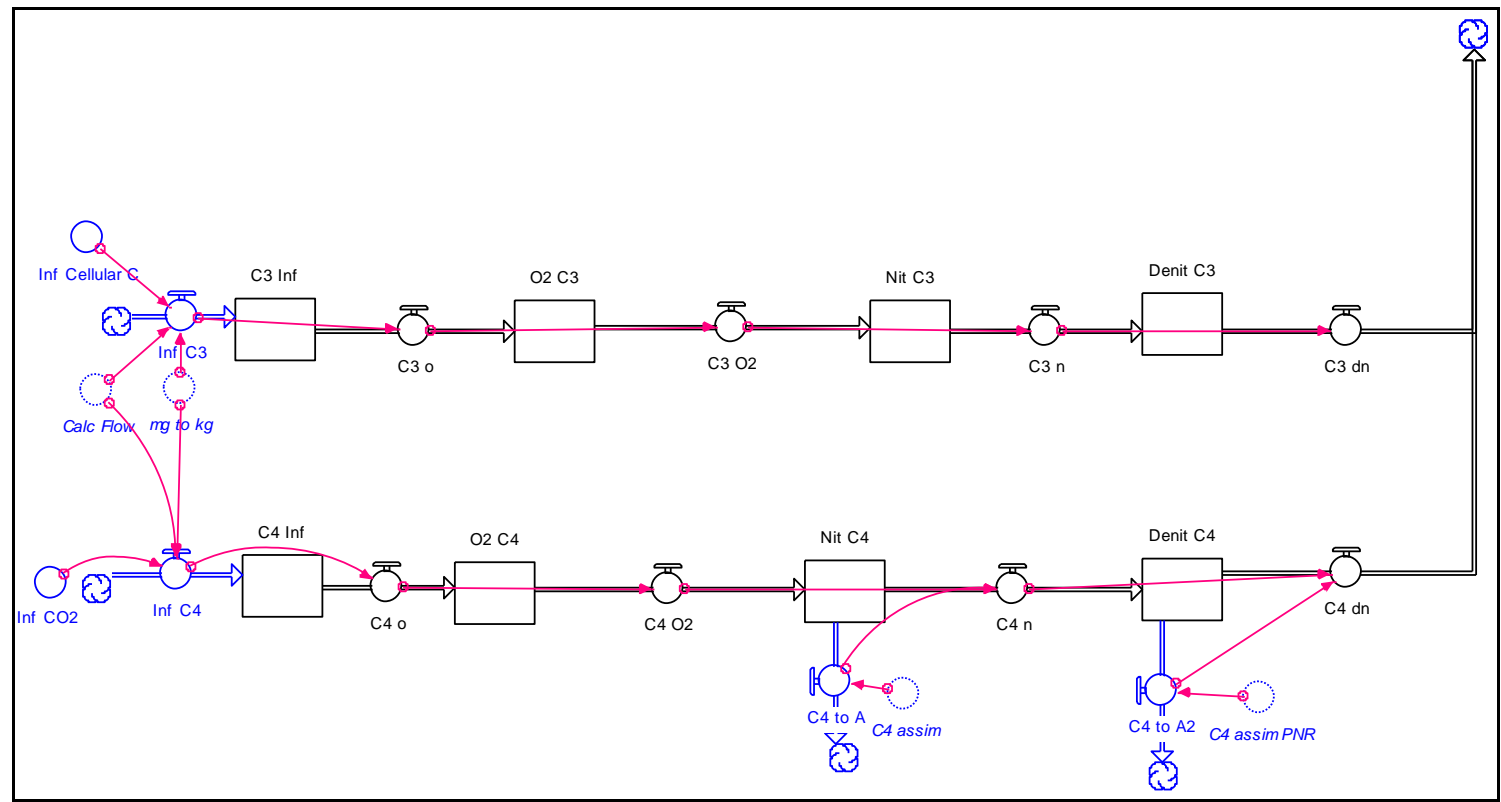

Figure A9. Flow of organic carbon and carbon dioxide in STELLA model.

Table A17. List of variables in organic carbon and carbon dioxide species model framework.

\begin{tabular}{|l|l|l|}
\hline $\begin{array}{l}\text { Notation in } \\
\text { Model }\end{array}$ & Description & Units or Value \\
\hline Inf_Cellular_C & Concentration of influent cellular C & $\mathrm{mg} / \mathrm{L}$ \\
\hline Inf_C3 & Flow of influent cellular C & $\mathrm{kg} / \mathrm{day}$ \\
\hline C3_Inf & Stock of influent cellular C & $\mathrm{kg}$ \\
\hline C3_0 & Flow of influent cellular C & $\mathrm{kg} / \mathrm{day}$ \\
\hline O2_C3 & Stock of cellular C in cBOD reactor & $\mathrm{kg}$ \\
\hline C3_O2 & Flow of cellular C from cBOD reactor & $\mathrm{kg} / \mathrm{day}$ \\
\hline Nit_C3 & Stock of cellular C in nitrification reactor & $\mathrm{kg}$ \\
\hline C3_n & Flow of cellular C from nitrification reactor & $\mathrm{kg} / \mathrm{day}$ \\
\hline Denit_C3 & Stock of cellular C in denitrification reactor & $\mathrm{kg}$ \\
\hline C3_dn & Flow of cellular C from denitrification reactor & $\mathrm{kg} / \mathrm{day}$ \\
\hline Calc_Flow & Flow of water through system & $\mathrm{L} / \mathrm{day}$ \\
\hline mg_to_kg & Conversion of mg to $\mathrm{kg}$ & $1000 \mathrm{mg} / \mathrm{kg}$ \\
\hline Inf_CO2 & Concentration of influent CO2 & $\mathrm{mg} / \mathrm{L}$ \\
\hline Inf_C4 & Flow of influent CO2 & $\mathrm{kg} / \mathrm{day}$ \\
\hline C4_Inf & Stock of influent CO2 & $\mathrm{kg}$ \\
\hline
\end{tabular}




\section{Appendix A (Continued)}

Table A17. (cont.).

\begin{tabular}{|l|l|l|}
\hline $\begin{array}{l}\text { Notation in } \\
\text { Model }\end{array}$ & Description & Units or Value \\
\hline C4_o & Flow of influent CO2 & $\mathrm{kg} /$ day \\
\hline O2_C4 & Stock of CO2 in cBOD reactor & $\mathrm{kg}$ \\
\hline C4_O2 & Flow of CO2 from cBOD reactor & $\mathrm{kg} /$ day \\
\hline Nit_C4 & Stock of CO2 in nitrification reactor & $\mathrm{kg}$ \\
\hline C4_n & Flow of CO2 from nitrification reactor & $\mathrm{kg} /$ day \\
\hline Denit_C4 & Stock of CO2 in denitrification reactor & $\mathrm{kg}$ \\
\hline C4_dn & Flow of CO2 from denitrification reactor & $\mathrm{kg} /$ day \\
\hline C4_to_A & Flow of CO2 assimilated in algae in PPOR & $\mathrm{kg} /$ day \\
\hline C4_assim & Flow of CO2 assimilated in algae in PPOR & $\mathrm{kg} /$ day \\
\hline C4_to_A2 & Flow of CO2 assimilated in algae in PNR & $\mathrm{kg} /$ day \\
\hline C4_assim_PNR & Flow of CO2 assimilated in algae in PNR & $\mathrm{kg} /$ day \\
\hline
\end{tabular}

Table A18. List of equations in organic carbon and carbon dioxide species model framework.

\begin{tabular}{|c|c|c|c|}
\hline Notation & Equation & $\begin{array}{l}\text { Initial } \\
\text { Value }\end{array}$ & Component \\
\hline Inf_C3 $=$ & Calc_Flow*Inf_Cellular_C/mg_to_kg & $\mathrm{n} / \mathrm{a}$ & flow \\
\hline C3 $\inf (t)=$ & C3 $\operatorname{lnf}(\mathrm{t}-\mathrm{dt})+\left(\operatorname{Inf} \_\mathrm{C} 3-\mathrm{C} 3 \_0\right)^{*} \mathrm{dt}$ & 0 & stock \\
\hline C3 $0=$ & Inf_C3 & $\mathrm{n} / \mathrm{a}$ & flow \\
\hline $\mathrm{O} 2 \_\mathrm{C} 3(\mathrm{t})=$ & $\begin{array}{l}\text { O2_C3(t - dt })+\left(\mathrm{C} 3 \_0+\text { O2_C1_to_C3 - }\right. \\
\text { C3_O2) }{ }^{*} d t\end{array}$ & 0 & stock \\
\hline $\mathrm{C} 3 \_\mathrm{O} 2=$ & $\mathrm{C} 3 \_0+\mathrm{O} 2$ C1 1 to $\mathrm{C} 3$ & $\mathrm{n} / \mathrm{a}$ & flow \\
\hline Nit_C3 $(t)=$ & $\begin{array}{l}\text { Nit_C3(t - dt) +(C3_O2 + Nit_C1_to_C3 - } \\
\text { C3_n })^{*} \mathrm{dt}\end{array}$ & 0 & stock \\
\hline C3_n $=$ & C3_O2+Nit_C1_to_C3 & $\mathrm{n} / \mathrm{a}$ & flow \\
\hline Denit_C3 $(t)=$ & Denit_C3 $(\mathrm{t}-\mathrm{dt})+\left(\mathrm{C} 3 \_\mathrm{n}-\mathrm{C} 3 \_\mathrm{dn}\right)^{*} \mathrm{dt}$ & 0 & stock \\
\hline C3_dn $=$ & C3_n & $\mathrm{n} / \mathrm{a}$ & flow \\
\hline Inf_C4 = & Calc_Flow*Inf_CO2/mg_to_kg & $\mathrm{n} / \mathrm{a}$ & flow \\
\hline$C 4 \_\operatorname{lnf}(\mathrm{t})=$ & $\mathrm{C} 4 \_\operatorname{Inf}(\mathrm{t}-\mathrm{dt})+\left(\operatorname{Inf} \_\mathrm{C} 4-\mathrm{C} 4 \_0\right) * \mathrm{dt}$ & 0 & stock \\
\hline C4_o = & Inf_C4 & $\mathrm{n} / \mathrm{a}$ & flow \\
\hline $\mathrm{O} 2 \_\mathrm{C} 4(\mathrm{t})=$ & $\begin{array}{l}\text { O2_C4(t - dt) + (C4_o + O2_C1_to_C4 - } \\
\text { C4_O2) * dt }\end{array}$ & 0 & stock \\
\hline C4_O2 = & C4_o+O2_C1_to_C4 & $\mathrm{n} / \mathrm{a}$ & flow \\
\hline Nit_C4 $(\mathrm{t})=$ & $\begin{array}{l}\text { Nit_C4(t - dt) + (C4_O2 + Nit_C1_to_C4 - } \\
\text { C4_n - C4_to_A }) * \overline{d t}\end{array}$ & 0 & stock \\
\hline
\end{tabular}




\section{Appendix A (Continued)}

Table A18. (cont.).

\begin{tabular}{|r|l|c|l|}
\hline Notation & Equation & $\begin{array}{l}\text { Initial } \\
\text { Value }\end{array}$ & Component \\
\hline C4_to_A $=$ & C4_assim & n/a & flow \\
\hline C4_n $=$ & C4_O2+Nit_C1_to_C4-C4_to_A & n/a & flow \\
\hline Denit_C4(t) $=$ & $\begin{array}{l}\text { Denit_C4(t }- \text { dt) }+(\text { C4_n }- \text { C4_dn - } \\
\text { C4_to_A2) }{ }^{*} d t\end{array}$ & 0 & stock \\
\hline C4_to_A2 $=$ & C4_assim_PNR & n/a & flow \\
\hline C4_dn $=$ & C4_n-C4_to_A2 & n/a & flow \\
\hline
\end{tabular}

\section{Carbon Mass Balance}

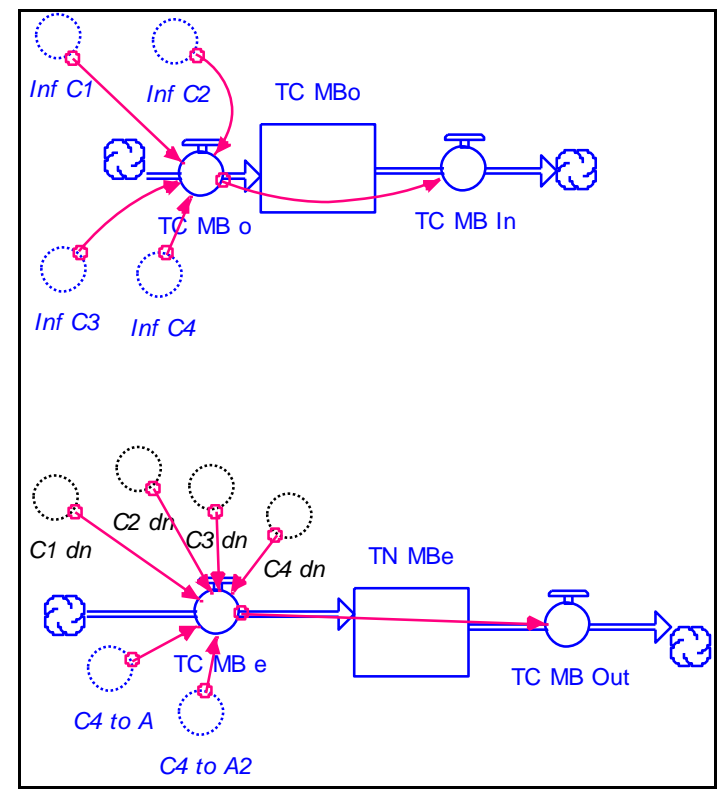

Figure A10. Carbon mass balance in STELLA model.

Table A19. List of variables in carbon mass balance framework.

\begin{tabular}{|l|l|l|}
\hline $\begin{array}{l}\text { Notation in } \\
\text { Model }\end{array}$ & Description & $\begin{array}{l}\text { Units or } \\
\text { Value }\end{array}$ \\
\hline Inf_C1 & Flow of influent soluble carbon & $\mathrm{kg} / \mathrm{day}$ \\
\hline Inf_C2 & Flow of influent nonsoluble carbon & $\mathrm{kg} / \mathrm{day}$ \\
\hline Inf_C3 & Flow of influent cellular carbon & $\mathrm{kg} / \mathrm{day}$ \\
\hline Inf_C4 & Flow of influent CO2 & $\mathrm{kg} / \mathrm{day}$ \\
\hline TC_MB_o & Flow of influent total carbon species & $\mathrm{kg} / \mathrm{day}$ \\
\hline TC_Mbo & Stock of total influent carbon species & $\mathrm{kg}$ \\
\hline TC_MB_In & Flow of influent total carbon species & $\mathrm{kg} / \mathrm{day}$ \\
\hline
\end{tabular}




\section{Appendix A (Continued)}

Table A19. (cont.).

\begin{tabular}{|l|l|l|}
\hline $\begin{array}{l}\text { Notation in } \\
\text { Model }\end{array}$ & Description & $\begin{array}{l}\text { Units or } \\
\text { Value }\end{array}$ \\
\hline C1_dn & Flow of effluent soluble carbon & $\mathrm{kg} / \mathrm{day}$ \\
\hline C2_dn & Flow of effluent insoluble carbon & $\mathrm{kg} / \mathrm{day}$ \\
\hline C3_dn & Flow of effluent cellular carbon & $\mathrm{kg} / \mathrm{day}$ \\
\hline C4_dn & Flow of effluent CO2 & $\mathrm{kg} / \mathrm{day}$ \\
\hline C4_to_A & Flow of CO2 assimilated to algae in PPOR & $\mathrm{kg} / \mathrm{day}$ \\
\hline C4_to_A2 & Flow of CO2 assimilated to algae in PNR & $\mathrm{kg} / \mathrm{day}$ \\
\hline TC_MB_e & Flow of total effluent carbon species & $\mathrm{kg} / \mathrm{day}$ \\
\hline TN_Mbe & Stock of total effluent carbon species & $\mathrm{kg}$ \\
\hline TC_MB_Out & Flow of total effluent carbon species & $\mathrm{kg} / \mathrm{day}$ \\
\hline
\end{tabular}

Table A20. List of equations in carbon mass balance framework.

\begin{tabular}{|c|c|c|c|}
\hline Notation & Equation & $\begin{array}{l}\text { Initial } \\
\text { Value }\end{array}$ & Component \\
\hline $\mathrm{TC} M \mathrm{MB}_{\mathrm{O}}=$ & Inf $\_$C1+Inf $C$ C2 $+\operatorname{lnf} \_$C3 $+\operatorname{lnf} \_$C4 & $\mathrm{n} / \mathrm{a}$ & flow \\
\hline$T C \_M b o(t)=$ & 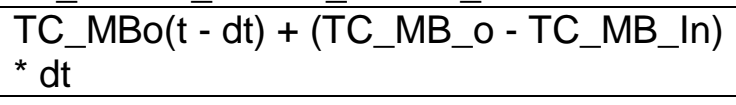 & 0 & stock \\
\hline TC_MB_In $=$ & TC_MB_O & $\mathrm{n} / \mathrm{a}$ & flow \\
\hline TC_MB_e $=$ & $\begin{array}{l}\text { C1_dn+C2 } 2 d n+C 3 \_d n+C 4 \_d n+C 4 \text { to }-A+ \\
\text { C4_to_A2 }\end{array}$ & $\mathrm{n} / \mathrm{a}$ & flow \\
\hline$T N \_M b e(t)=$ & $\begin{array}{l}\text { TN_MBe }(t-d t)+\left(T C \_M B \_e-\right. \\
\text { TC_MB_Out) * } d t\end{array}$ & 0 & stock \\
\hline TC MB Out $=$ & $\mathrm{TC} M B \mathrm{e}$ & $\mathrm{n} / \mathrm{a}$ & flow \\
\hline
\end{tabular}




\section{Appendix A (Continued)}

Specific Growth Rate in the PPOR

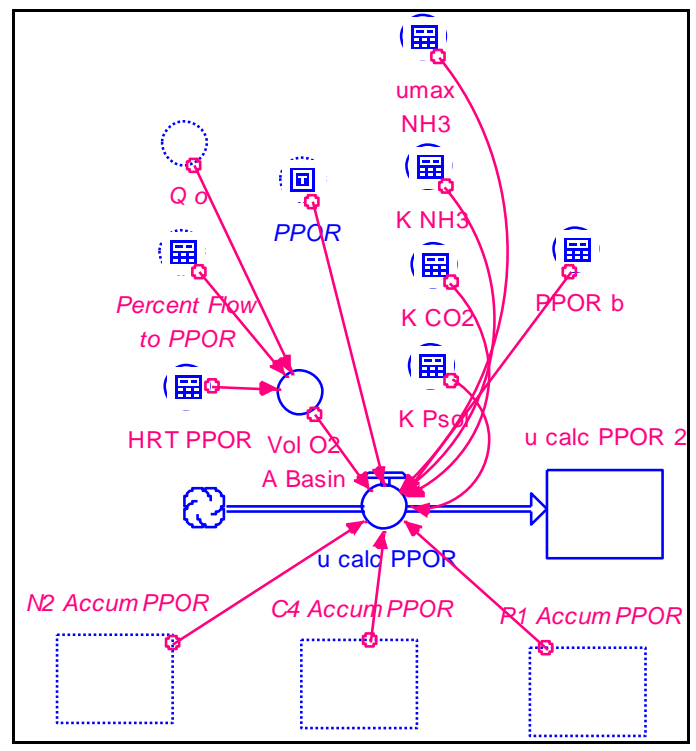

Figure A11. Calculated specific growth rate in the PPOR.

Table A21. List of variables in calculating specific growth rate in the PPOR.

\begin{tabular}{|l|l|l|}
\hline Notation in Model & Description & $\begin{array}{l}\text { Units or } \\
\text { Value }\end{array}$ \\
\hline Q_0 & Flow of water from BOD reactor & L/day \\
\hline Percent_Flow_to_PPOR & $\begin{array}{l}\text { Percent of water from BOD reactor } \\
\text { diverted to PPOR }\end{array}$ & unitless \\
\hline HRT_PPOR & HRT of the PPOR & days \\
\hline Vol_O2_Basin & volume of the PPOR & $\mathrm{L}$ \\
\hline PPOR & Switch to divert water to PPOR & unitless \\
\hline umax NH3 & umax for growth on NH3 & $/$ day \\
\hline K_NH3 & half saturation constant for ammonia & $\mathrm{kg} / \mathrm{L}$ \\
\hline K_CO2 & $\begin{array}{l}\text { half saturation constant for carbon } \\
\text { dioxide }\end{array}$ & $\mathrm{kg} / \mathrm{L}$ \\
\hline K_Psol & $\begin{array}{l}\text { half saturation constant for soluble } \\
\text { phosphorous }\end{array}$ & $\mathrm{kg} / \mathrm{L}$ \\
\hline PPOR_b & decay rate of algae in PPOR & $/$ day \\
\hline U_calc_PPOR & $\begin{array}{l}\text { calculated } \mu \text { in PPOR for growth on } \\
\text { ammonia }\end{array}$ & $/$ day \\
\hline u_calc_PPOR_2 & stock for calculated $\mu$ & $/$ day \\
\hline N2_Accum_PPOR & nitrogen accumulated in the PPOR & $\mathrm{kg}$ \\
\hline C4_Accum_PPOR & carbon accumulated in the PPOR & $\mathrm{kg}$ \\
\hline P1_Accum_PPOR & phosphorous accumulated in the PPOR & $\mathrm{kg}$ \\
\hline
\end{tabular}




\section{Appendix A (Continued)}

Table A22. List of equations in calculating specific growth rate in the PPOR.

\begin{tabular}{|c|c|c|c|}
\hline Notation & Equation & $\begin{array}{l}\text { Initial } \\
\text { Value }\end{array}$ & Component \\
\hline Vol_O2_A_Basin = & $\begin{array}{l}\text { HRT_PPOR }{ }^{*} \text { Percent_Flow_to_PP } \\
\left.\mathrm{OR}^{*} \overline{\mathrm{Q}} \_0\right)\end{array}$ & $\mathrm{n} / \mathrm{a}$ & converter \\
\hline u_calc_PPOR = & 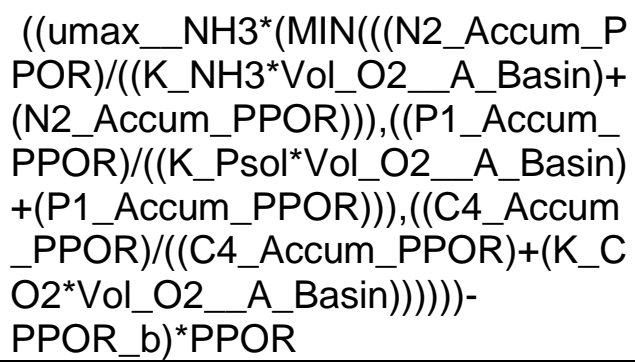 & $\mathrm{n} / \mathrm{a}$ & flow \\
\hline u_calc_PPOR_2 $(\mathrm{t})=$ & $\begin{array}{l}\text { u_calc_PPOR_2 }(\mathrm{t}-\mathrm{dt})+ \\
\left(\mathrm{u} \_ \text {calc_PPOR }\right){ }^{*} \mathrm{dt}\end{array}$ & 0 & stock \\
\hline N2_Accum_PPOR $(\mathrm{t})=$ & N2_to_Algae*HRT_PPOR & 0 & stock \\
\hline C4_Accum_PPOR $(\mathrm{t})=$ & C4_to_Algae*HRT_PPOR & 0 & stock \\
\hline $\mathrm{P} 1$ Accum_PPOR $(\mathrm{t})=$ & P1_to_Algae*HRT_PPOR & 0 & stock \\
\hline
\end{tabular}

SRT in PPOR

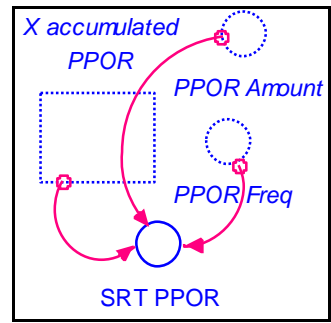

Figure A12. SRT in the PPOR.

Table A23. List of variables for SRT framework in the PPOR.

\begin{tabular}{|l|l|l|}
\hline Notation in Model & Description & $\begin{array}{l}\text { Units or } \\
\text { Value }\end{array}$ \\
\hline X_accumulated_PPOR & mass of algae in PPOR & $\mathrm{kg}$ \\
\hline PPOR_Amount & mass of algae removed from PPOR & $\mathrm{kg}$ \\
\hline PPOR_Freq & frequency of algae removal from PPOR & days \\
\hline SRT_PPOR & time algae remains in the PPOR & days \\
\hline
\end{tabular}




\section{Appendix A (Continued)}

Table A24. List of equations for SRT framework in the PPOR.

\begin{tabular}{|r|l|l|l|}
\hline Notation & Equation & $\begin{array}{c}\text { Initial } \\
\text { Value }\end{array}$ & Component \\
\hline X_accumulated_PPOR $=$ & $\begin{array}{l}\text { X_accumulated_PNR(t-dt) }+ \\
\left(\begin{array}{l}\text { X_generated_PNR }- \\
\text { Harvest_Rate_PNR })^{*} \mathrm{dt}\end{array}\right.\end{array}$ & 10 & stock \\
\hline SRT_PPOR $=$ & $\begin{array}{l}\text { X_accumulated_PPOR/(PPOR_A } \\
\text { mount/PPOR_Freq) }\end{array}$ & n/a & converter \\
\hline
\end{tabular}

\section{Algae Growth in PPOR}

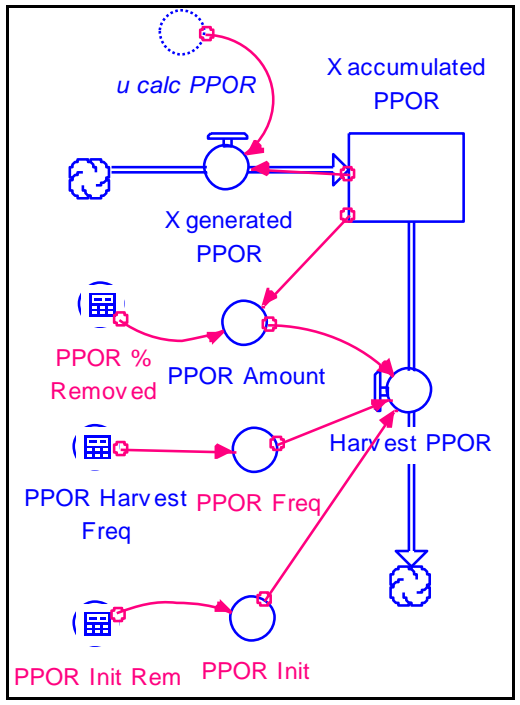

Figure A13. Algae growth framework in the PPOR in the STELLA model.

Table A25. List of variables for algae growth in the PPOR.

\begin{tabular}{|l|l|l|}
\hline Notation in Model & Description & $\begin{array}{l}\text { Units or } \\
\text { Value }\end{array}$ \\
\hline u_calc_PPOR & calculated specific growth rate in PPOR & $/$ day \\
\hline X_generated_PPOR & algae growth & $\mathrm{kg} /$ day \\
\hline $\begin{array}{l}\text { X_accumulated } \\
\text { PPOR }\end{array}$ & mass of algae in PPOR & $\mathrm{kg}$ \\
\hline PPOR_Amount & mass of algae removed from PPOR & $\mathrm{kg}$ \\
\hline PPOR_\%_Removed & $\begin{array}{l}\text { percent of accumulated algae in PPOR to } \\
\text { be removed }\end{array}$ & unitless \\
\hline PPOR Harvest Freq & frequency of algae harvesting & days \\
\hline PPOR Freq & frequency of algae harvesting & days \\
\hline & & \\
PPOR Init Rem & initial harvest time & days \\
\hline
\end{tabular}




\section{Appendix A (Continued)}

Table A25. (cont.).

\begin{tabular}{|l|l|l|}
\hline Notation in Model & Description & $\begin{array}{l}\text { Units or } \\
\text { Value }\end{array}$ \\
\hline PPOR Init & initial harvest time & days \\
\hline Harvest PPOR & flow of algae being harvested & $\mathrm{kg} /$ day \\
\hline
\end{tabular}

Table A26. List of equations for algae growth in the PPOR.

\begin{tabular}{|r|l|c|l|}
\hline Notation & Equation & $\begin{array}{c}\text { Initial } \\
\text { Value }\end{array}$ & Component \\
\hline X_generated_PPOR $=$ & $\begin{array}{l}\text { X_accumulated_PPOR }{ }^{*} \text { u_calc_P } \\
\text { POR }\end{array}$ & n/a & flow \\
\hline X_accumulated_PPOR $(\mathrm{t})=$ & $\begin{array}{l}\text { X_accumulated_PNR(t }-\mathrm{dt})+ \\
(\text { X_generated_PNR }-\end{array}$ & & \\
\hline Harvest_Rate_PNR $)^{*} \mathrm{dt}$ & 10 & stock \\
\hline Harvest_PPOR $=$ & $\begin{array}{l}\text { Pulse((PPOR_Amount),PPOR_In } \\
\text { it,PPOR_Freq) }\end{array}$ & n/a & flow \\
\hline
\end{tabular}

Nitrogen Utilization in the PPOR

Figure A14. Nitrogen utilization in the PPOR.

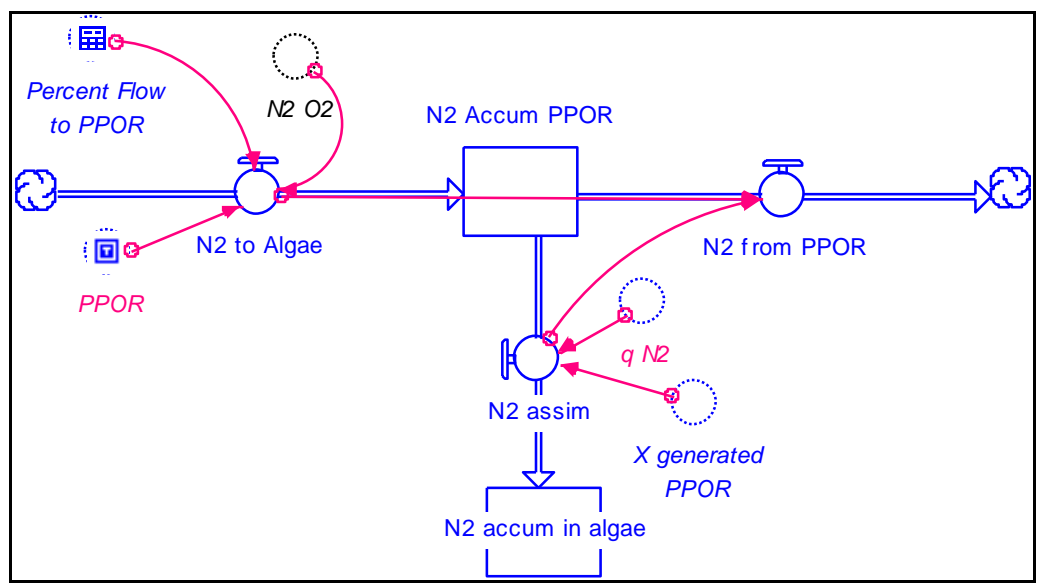

Table A27. List of variables in nitrogen utilization framework in the PPOR .

\begin{tabular}{|l|l|l|}
\hline Notation in Model & Description & $\begin{array}{l}\text { Units or } \\
\text { Value }\end{array}$ \\
\hline $\begin{array}{l}\text { Percent Flow to } \\
\text { PPOR }\end{array}$ & percent of flow diverted from water flow to plant & unitless \\
\hline PPOR & switch to turn on PPOR & unitless \\
\hline N2 to Algae & flow of nitrogen to PPOR & $\mathrm{kg} /$ day \\
\hline N2 O2 & flow of nitrogen from BOD reactor & $\mathrm{kg} /$ day \\
\hline N2 Accum PPOR & nitrogen available in the PPOR & $\mathrm{kg}$ \\
\hline N2 from PPOR & flow of nitrogen leaving the PPOR & $\mathrm{kg} /$ day \\
\hline
\end{tabular}




\section{Appendix A (Continued)}

Table A27. (cont.).

\begin{tabular}{|l|l|l|}
\hline Notation in Model & Description & $\begin{array}{l}\text { Units or } \\
\text { Value }\end{array}$ \\
\hline N2 assim & flow of nitrogen assimilated in algae & $\mathrm{kg} / \mathrm{day}$ \\
\hline q N2 & nitrogen substrate utilization rate & $\mathrm{kg} / \mathrm{kg}$-day \\
\hline X generated PPOR & algae growth in PPOR & $\mathrm{kg}$ \\
\hline N2 accum in algae & amount of nitrogen accumulated in algae & $\mathrm{kg}$ \\
\hline
\end{tabular}

Table A28. List of equations in nitrogen utilization framework in the PPOR.

\begin{tabular}{|c|c|c|c|}
\hline Notation & Equation & $\begin{array}{l}\text { Initial } \\
\text { Value }\end{array}$ & Component \\
\hline $\mathrm{N} 2$ to & $\begin{array}{l}\text { N2_O2 }{ }^{*} \text { Percent_Flow_to_PPOR }{ }^{*} \text { PP } \\
\text { OR }\end{array}$ & $\mathrm{n} / \mathrm{a}$ & flow \\
\hline $\begin{array}{r}\text { N2_Accum_PPO } \\
\mathrm{R}(\mathrm{t})=\end{array}$ & $\begin{array}{l}\text { N2_Accum_PPOR(t-dt) + } \\
\text { (N2_to_Algae - N2_from_PPOR - } \\
\text { N2_assim)* dt }\end{array}$ & $\begin{array}{l}\text { N2_to Al } \\
\text { gae* } \mathrm{HRT} \\
\text { PPOR }\end{array}$ & stock \\
\hline $\mathrm{N} 2$ assim $=$ & $\mathrm{X}$ ggenerated_PPOR ${ }^{*} \mathrm{q}$ N2 & $\mathrm{n} / \mathrm{a}$ & flow \\
\hline $\begin{array}{r}\text { N2_accum_in_alg } \\
\text { ae }(\mathrm{t})=\end{array}$ & $\begin{array}{l}\text { N2_accum_in algae }(\mathrm{t}-\mathrm{dt})+ \\
(\mathrm{N} 2 \text { assim) } * \mathrm{dt}\end{array}$ & N2_assim & stock \\
\hline N2_from_PPOR $=$ & N2_to_Algae-N2_assim & $n / a$ & flow \\
\hline
\end{tabular}

Carbon Utilization in the PPOR

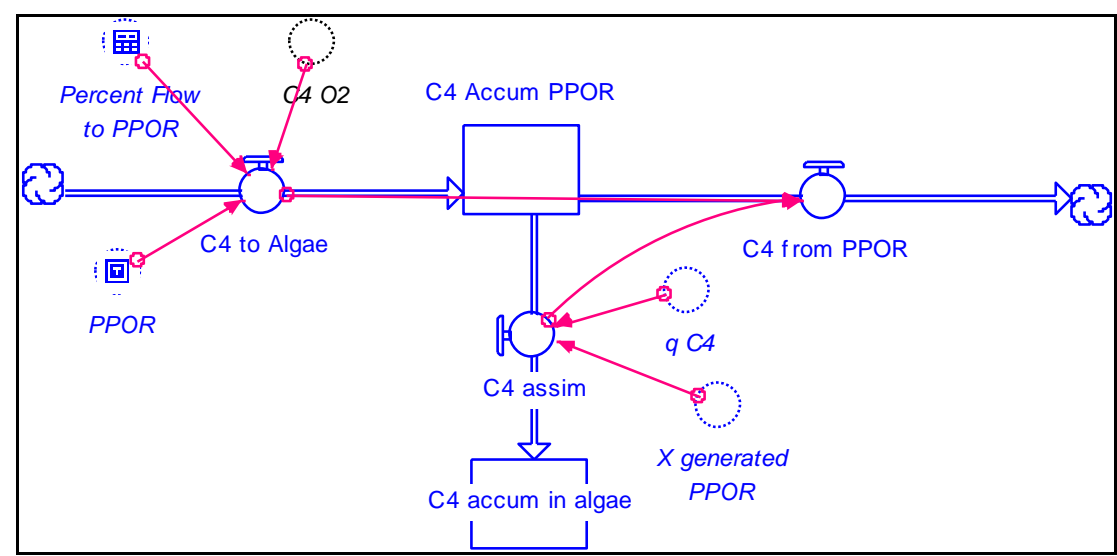

Figure A15. Carbon utilization in the PPOR. 


\section{Appendix A (Continued)}

Table A29. List of variables in carbon utilization framework in the PPOR .

\begin{tabular}{|l|l|l|}
\hline Notation in Model & Description & $\begin{array}{l}\text { Units or } \\
\text { Value }\end{array}$ \\
\hline $\begin{array}{l}\text { Percent Flow to } \\
\text { PPOR }\end{array}$ & $\begin{array}{l}\text { percent of flow diverted from water flow to } \\
\text { plant }\end{array}$ & unitless \\
\hline C4 O2 & flow of carbon from BOD reactor & $\mathrm{kg} /$ day \\
\hline PPOR & switch to turn on PPOR & unitless \\
\hline C4 to Algae & flow of carbon to PPOR & $\mathrm{kg} /$ day \\
\hline C4 Accum PPOR & mass of carbon available in PPOR & $\mathrm{kg}$ \\
\hline C4 from PPOR & flow of carbon leaving PPOR & $\mathrm{kg} /$ day \\
\hline C4 assim & amount of carbon assimilated in algae & $\mathrm{kg} /$ day \\
\hline q C4 & carbon substrate utilization rate & $\mathrm{kg} / \mathrm{kg}$-day \\
\hline X generated PPOR & algae growth in PPOR & $\mathrm{kg} /$ day \\
\hline C4 accum in algae & carbon accumulated in algae & $\mathrm{kg}$ \\
\hline
\end{tabular}

Table A30. List of equations in carbon utilization framework in the PPOR .

\begin{tabular}{|c|c|c|c|}
\hline Notation & Equation & $\begin{array}{l}\text { Initial } \\
\text { Value }\end{array}$ & Component \\
\hline C4_to_Algae $=$ & $\begin{array}{l}\text { C4_O2*Percent_Flow_to_PPOR } \\
\text { PPOR }\end{array}$ & $\mathrm{n} / \mathrm{a}$ & flow \\
\hline $\begin{array}{r}\text { C4_Accum_PPOR }(\mathrm{t}) \\
=\end{array}$ & $\begin{array}{l}\text { C4_Accum_PPOR(t - dt) + } \\
\text { (C4_to_Algae - C4_from_PPOR - } \\
\text { C4_assim)* dt }\end{array}$ & $\begin{array}{l}\text { C4_to_Alg } \\
\text { ae*HRT_- } \\
\text { PPOR }\end{array}$ & stock \\
\hline C4_assim $=$ & $\mathrm{X}$ _generated_PPOR ${ }^{*} q \_C 4$ & $\mathrm{n} / \mathrm{a}$ & flow \\
\hline $\begin{array}{r}\text { C4_accum_in_algae(t } \\
\text { = }\end{array}$ & $\begin{array}{l}\text { C4_accum_in_algae }(t-d t)+ \\
(\text { C4_assim) } * \text { dt }\end{array}$ & 0 & stock \\
\hline C4_from_PPOR = & C4_to_Algae-C4_assim & $\mathrm{n} / \mathrm{a}$ & flow \\
\hline
\end{tabular}




\section{Appendix A (Continued)}

Phosphorous Utilization in PPOR

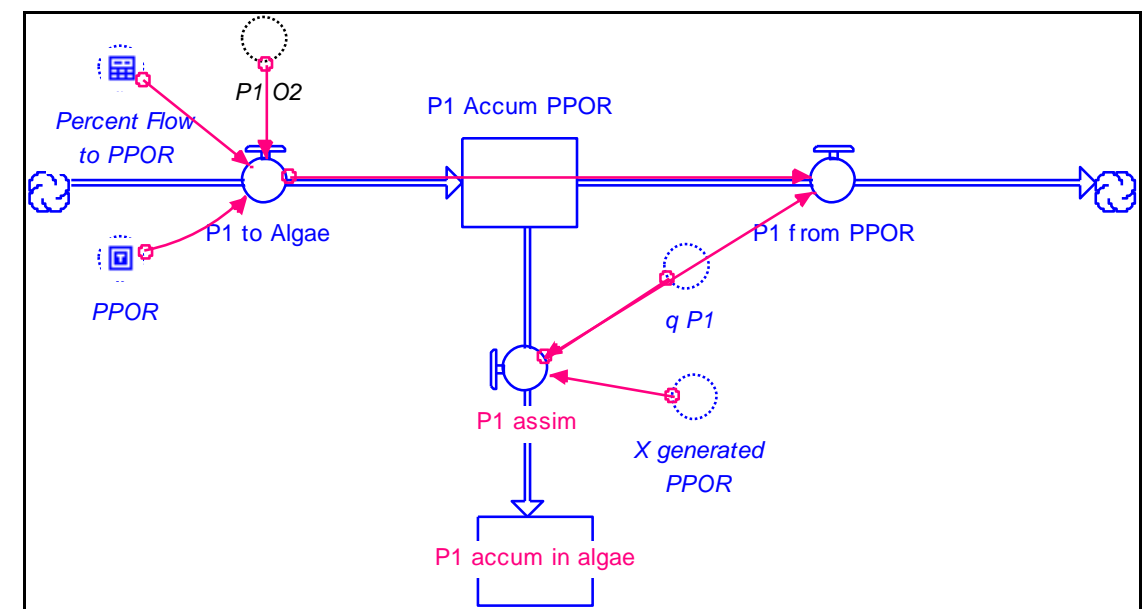

Figure A16. Phosphorous utilization in the PPOR.

Table A31. List of variables in phosphorous utilization framework in the PPOR.

\begin{tabular}{|l|l|l|}
\hline Notation in Model & Description & $\begin{array}{l}\text { Units or } \\
\text { Value }\end{array}$ \\
\hline $\begin{array}{l}\text { Percent Flow to } \\
\text { PPOR }\end{array}$ & $\begin{array}{l}\text { percent of flow diverted from water flow } \\
\text { to plant }\end{array}$ & unitless \\
\hline PPOR & switch to turn on PPOR & unitless \\
\hline P1 to Algae & flow of phosphorous to PPOR & $\mathrm{kg} /$ day \\
\hline P1 O2 & flow of phosphorous from BOD reactor & $\mathrm{kg} / \mathrm{day}$ \\
\hline P1 Accum PPOR & phosphorous available in the PPOR & $\mathrm{kg}$ \\
\hline P1 from PPOR & flow of phosphorous leaving the PPOR & $\mathrm{kg} /$ day \\
\hline P1 assim & flow of phosphorous assimilated in algae & $\mathrm{kg} /$ day \\
\hline q P1 & phosphorous substrate utilization rate & $\mathrm{kg} / \mathrm{kg}$-day \\
\hline X generated PPOR & algae growth in PPOR & $\mathrm{kg}$ \\
\hline P1 accum in algae & $\begin{array}{l}\text { amount of phosphorous accumulated in } \\
\text { algae }\end{array}$ & $\mathrm{kg}$ \\
\hline
\end{tabular}




\section{Appendix A (Continued)}

Table A32. List of equations in phosphorous utilization framework in the PPOR.

\begin{tabular}{|c|c|c|c|}
\hline Notation & Equation & $\begin{array}{l}\text { Initial } \\
\text { Value }\end{array}$ & Component \\
\hline P1_to_Algae = & $\begin{array}{l}\text { P1_O2*Percent_Flow_to_PPOR }{ }^{*} \text { PP } \\
\text { OR }\end{array}$ & $\mathrm{n} / \mathrm{a}$ & flow \\
\hline $\begin{array}{r}\text { P1_Accum_PPOR } \\
(\mathrm{t})=\end{array}$ & $\begin{array}{l}\mathrm{P} 1 \text { Accum_PPOR }(\mathrm{t}-\mathrm{dt})+ \\
(\mathrm{P} 1 \text { to_Algae }-\mathrm{P} 1 \text { from_PPOR }- \\
\mathrm{P} 1 \text {-assim) }{ }^{*} \mathrm{dt}\end{array}$ & $\begin{array}{l}\text { P1_to_A } \\
\text { lgae* }{ }^{\star} \mathrm{HR} \\
\text { T_PPO } \\
\text { R }\end{array}$ & stock \\
\hline P1_assim = & X_generated_PPOR ${ }^{*} \mathrm{q}$ P1 & $\mathrm{n} / \mathrm{a}$ & flow \\
\hline $\begin{array}{r}\text { P1_accum_in_alga } \\
\mathrm{e}(\mathrm{t})=\end{array}$ & $\begin{array}{l}\mathrm{P} 1 \text { accum_in_algae }(\mathrm{t}-\mathrm{dt})+ \\
(\mathrm{P} 1 \text { _assim }) * \mathrm{dt}\end{array}$ & 0 & stock \\
\hline P1_from_PPOR $=$ & P1_to_Algae-P1_assim & $\mathrm{n} / \mathrm{a}$ & flow \\
\hline
\end{tabular}

Substrate Utilization Rate in PPOR

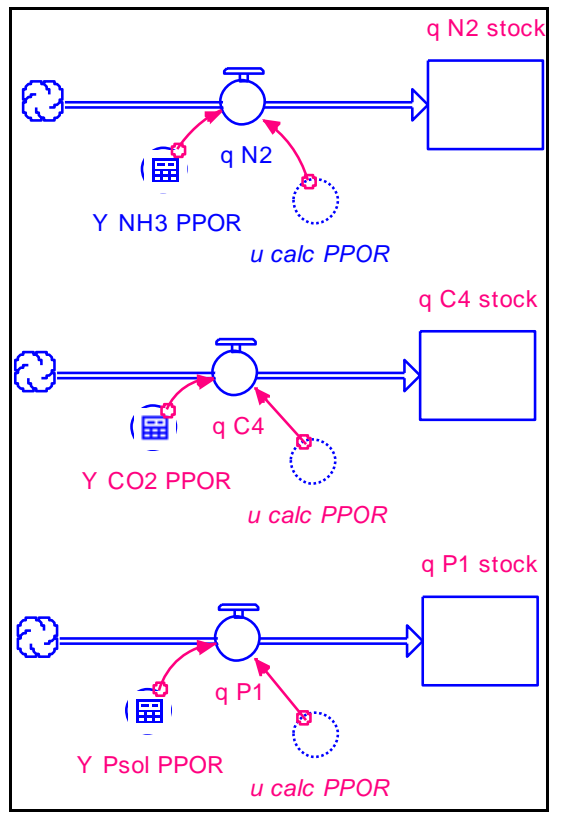

Figure A17. Substrate utilization rate in the PPOR in STELLA model. 


\section{Appendix A (Continued)}

Table A33. List of variables for substrate utilization rate framework in the PPOR.

\begin{tabular}{|l|l|l|}
\hline Notation in Model & Description & $\begin{array}{l}\text { Units or } \\
\text { Value }\end{array}$ \\
\hline Y_NH3 PPOR & half saturation constant for ammonia & unitless \\
\hline q_N2 & nitrogen substrate utilization rate & unitless \\
\hline q_N2_stock & accumulation of q & $\mathrm{kg} / \mathrm{day}$ \\
\hline u_calc_PPOR & calculated specific growth rate in PPOR & $\mathrm{kg} / \mathrm{day}$ \\
\hline Y_CO2 PPOR & half saturation constant for carbon & $\mathrm{kg}$ \\
\hline q_C4 & carbon substrate utilization rate & $\mathrm{kg} / \mathrm{day}$ \\
\hline q_C4_stock & accumulation of q & $\mathrm{kg} / \mathrm{day}$ \\
\hline Y_Psol PPOR & half saturation constant for phosphorous & $\mathrm{kg} / \mathrm{kg}$-day \\
\hline q_P1 & phosphorous substrate utilization rate & $\mathrm{kg}$ \\
\hline q_P1_stock & accumulation of q & $\mathrm{kg}$ \\
\hline
\end{tabular}

Table A34. List of equations for substrate utilization rate framework in the PPOR.

\begin{tabular}{|r|l|l|l|}
\hline Notation & Equation & $\begin{array}{l}\text { Initial } \\
\text { Value }\end{array}$ & Component \\
\hline q_N2 $=$ & u_calc_PPOR/Y_NH3_PPOR & $\mathrm{n} / \mathrm{a}$ & flow \\
\hline q_N2_stock $(\mathrm{t})=$ & q_N2_stock $(\mathrm{t}-\mathrm{dt})+\left(\mathrm{q} \_\mathrm{N} 2\right){ }^{*} \mathrm{dt}$ & 0 & stock \\
\hline q_C4 $=$ & u_calc_PPOR/Y_CO2_PPOR & $\mathrm{n} / \mathrm{a}$ & flow \\
\hline q_C4_stock $(\mathrm{t})=$ & q_C4_stock $(\mathrm{t}-\mathrm{dt})+\left(\mathrm{q} \_\mathrm{C} 4\right){ }^{*} \mathrm{dt}$ & 0 & stock \\
\hline q_P1 $=$ & u_calc_PPOR/Y_Psol_PPOR & $\mathrm{n} / \mathrm{a}$ & flow \\
\hline q_P1_stock $(\mathrm{t})=$ & q_P1_stock $(\mathrm{t}-\mathrm{dt})+(\mathrm{q} \text { _P1 })^{*} \mathrm{dt}$ & 0 & stock \\
\hline
\end{tabular}




\section{Appendix A (Continued)}

Specific Growth Rate in PNR

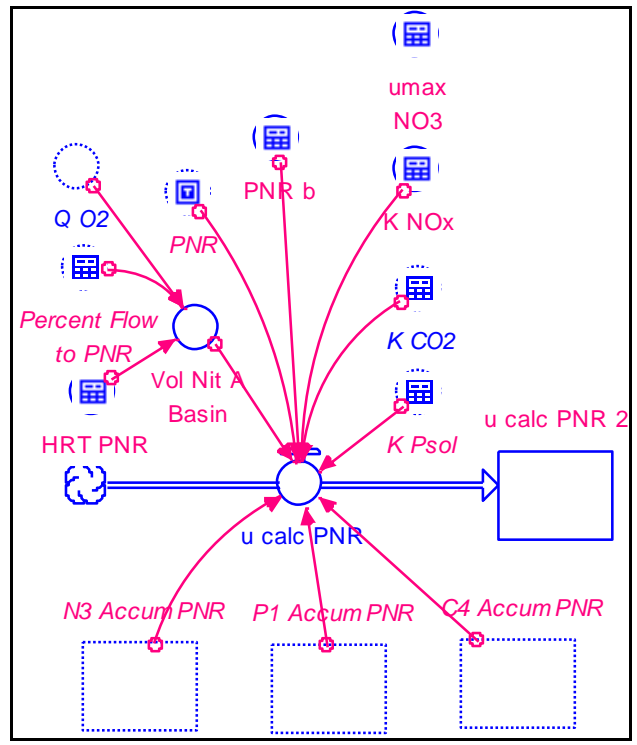

Figure A18. Specific growth rate in the PNR.

Table A35. List of variables for specific growth rate in the PNR.

\begin{tabular}{|l|l|l|}
\hline Notation in Model & Description & $\begin{array}{l}\text { Units or } \\
\text { Value }\end{array}$ \\
\hline Q_O2 & Flow of water from nitrification reactor & L/day \\
\hline Percent_Flow_to_PNR & $\begin{array}{l}\text { Percent of water from nitrification reactor } \\
\text { diverted to PNR }\end{array}$ & unitless \\
\hline HRT_PNR & HRT of the PNR & days \\
\hline Vol_Nit_Basin & volume of the PNR & $\mathrm{L}$ \\
\hline PNR & Switch to divert water to PNR & unitless \\
\hline umax NO3 & umax for growth on NO3 & $/$ day \\
\hline K_Nox & half saturation constant for nitrate & $\mathrm{kg} / \mathrm{L}$ \\
\hline K_CO2 & $\begin{array}{l}\text { half saturation constant for carbon } \\
\text { dioxide }\end{array}$ & $\mathrm{kg} / \mathrm{L}$ \\
\hline K_Psol & $\begin{array}{l}\text { half saturation constant for soluble } \\
\text { phosphorous }\end{array}$ & $\mathrm{kg} / \mathrm{L}$ \\
\hline PNR_b & decay rate of algae in PNR & $/$ day \\
\hline U_calc_PNR & calculated $\mu$ in PNR for growth on nitrate & $/$ day \\
\hline U_calc_PNR_2 & stock for calculated $\mu$ & $/$ day \\
\hline N3_Accum_PNR & nitrogen accumulated in the PNR & $\mathrm{kg}$ \\
\hline C4_Accum_PNR & carbon accumulated in the PNR & $\mathrm{kg}$ \\
\hline P1_Accum_PNR & phosphorous accumulated in the PNR & $\mathrm{kg}$ \\
\hline
\end{tabular}




\section{Appendix A (Continued)}

Table A36. List of equations for specific growth rate in the PNR.

\begin{tabular}{|c|c|c|c|}
\hline Notation & Equation & Initial Value & Component \\
\hline Vol_Nit_A_Basin $=$ & $\begin{array}{l}\mathrm{HRT}_{\text {Ho_PNR }}{ }^{*}\left(\mathrm{Q}_{-} \mathrm{O} 2^{*} \text { Percent_Flow_ }\right. \\
\text { to }\end{array}$ & $\mathrm{n} / \mathrm{a}$ & converter \\
\hline u_calc_PNR = & 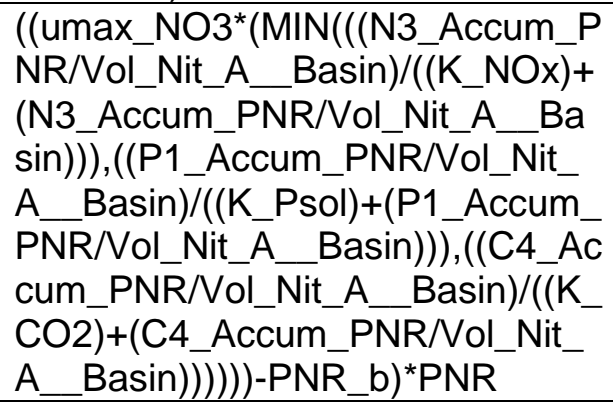 & $\mathrm{n} / \mathrm{a}$ & flow \\
\hline u_calc_PNR_2(t) = & $\begin{array}{l}\text { u_calc_PNR_2 }(t-d t)+ \\
\left(u \_c a l c \_P N R\right){ }^{*} d t\end{array}$ & 0 & stock \\
\hline N3_Accum_PNR $(t)=$ & $\begin{array}{l}\text { N3_accum_in_PNR }(\mathrm{t}-\mathrm{dt})+ \\
\left(\mathrm{N} 3 \_ \text {assim_PNR }{ }^{*} \mathrm{dt}\right.\end{array}$ & $\begin{array}{l}\text { N3_to_PNR } \\
{ }^{*} \mathrm{HRT} \text { _PNR }\end{array}$ & stock \\
\hline C4_Accum_PNR $(\mathrm{t})=$ & $\begin{array}{l}\text { C4_accum_in_PNR }(\mathrm{t}-\mathrm{dt})+ \\
(\mathrm{C} 4 \text { _assim_PNR) * dt }\end{array}$ & $\begin{array}{l}\text { C4_to_PNR } \\
{ }^{*} \mathrm{HRT} \text { _PNR }\end{array}$ & stock \\
\hline P1_Accum_PNR $(t)=$ & $\begin{array}{l}\text { P1_accum_in_PNR }(\mathrm{t}-\mathrm{dt})+ \\
\left(\mathrm{P} 1 \text { 1_assim_PNR) }{ }^{*} \mathrm{dt}\right.\end{array}$ & $\begin{array}{l}\text { P1_to_PNR } \\
\text { *HRT_PNR }\end{array}$ & stock \\
\hline
\end{tabular}

SRT in PNR

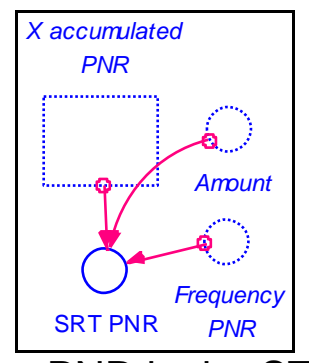

Figure A19. SRT framework in the PNR in the STELLA model.

Table A37. List of variables for SRT framework in the PNR.

\begin{tabular}{|l|l|l|}
\hline Notation in Model & Description & $\begin{array}{l}\text { Units or } \\
\text { Value }\end{array}$ \\
\hline X_accumulated_PNR & mass of algae in PNR & $\mathrm{kg}$ \\
\hline Amount & mass of algae removed from PNR & $\mathrm{kg}$ \\
\hline Frequency_PNR & frequency of algae removal from PNR & days \\
\hline SRT_PNR & time algae remains in the PNR & days \\
\hline
\end{tabular}




\section{Appendix A (Continued)}

Table A38. List of equations for SRT framework in the PNR.

\begin{tabular}{|c|c|c|c|}
\hline Notation & Equation & $\begin{array}{l}\text { Initial } \\
\text { Value } \\
\end{array}$ & Component \\
\hline $\begin{array}{r}\text { X_accumulated__ } \\
\operatorname{PNR}(\mathrm{t})=\end{array}$ & $\begin{array}{l}\text { X_accumulated_PNR }(\mathrm{t}-\mathrm{dt})+ \\
(\text { X_generated_PNR }- \text { Harvest_Rate_PNR }) \text { * } \\
\mathrm{dt}\end{array}$ & 10 & stock \\
\hline SRT_PNR $=$ & $\begin{array}{l}\text { X_accumulated_PNR/(Amount/Frequency } \\
\text { PNR) }\end{array}$ & $\mathrm{n} / \mathrm{a}$ & converter \\
\hline
\end{tabular}

\section{Algae Growth in PNR}

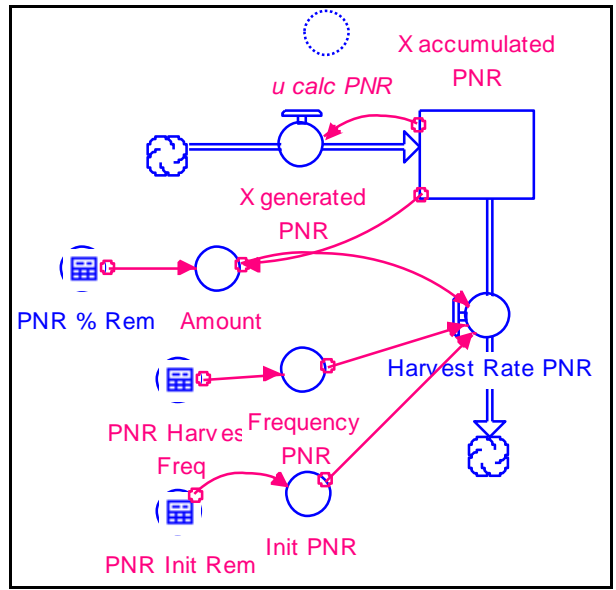

Figure A20. Algae growth framework in the PNR.

Table A39. List of variables for algae growth in the PNR.

\begin{tabular}{|l|l|l|}
\hline Notation in Model & Description & $\begin{array}{l}\text { Units or } \\
\text { Value }\end{array}$ \\
\hline U_calc_PNR & calculated specific growth rate in PNR & /day \\
\hline X_generated_PNR & algae growth & $\mathrm{kg} /$ day \\
\hline $\begin{array}{l}\text { X_accumulated } \\
\text { PNR }\end{array}$ & mass of algae in PNR & $\mathrm{kg}$ \\
\hline Amount & mass of algae removed from PNR & $\mathrm{kg}$ \\
\hline PPOR_\%_Rem & $\begin{array}{l}\text { percent of accumulated algae in PNR to be } \\
\text { removed }\end{array}$ & unitless \\
\hline PNR Harvest Freq & frequency of algae harvesting & days \\
\hline Frequency PNR & frequency of algae harvesting & days \\
\hline PNR Init Rem & initial harvest time & days \\
\hline Init PNR & initial harvest time & days \\
\hline $\begin{array}{l}\text { Harvest Rate } \\
\text { PPOR }\end{array}$ & flow of algae being harvested & $\mathrm{kg} /$ day \\
\hline
\end{tabular}




\section{Appendix A (Continued)}

Table A40. List of equations for algae growth in the PNR.

\begin{tabular}{|c|c|c|c|}
\hline Notation & Equation & $\begin{array}{l}\text { Initial } \\
\text { Value }\end{array}$ & Component \\
\hline X_generated_PNR $=$ & X_accumulated_PNR* ${ }^{*}$ __calc_PNR & $\mathrm{n} / \mathrm{a}$ & flow \\
\hline $\begin{array}{r}\text { X_accumulated_PN } \\
R(\mathrm{t})=\end{array}$ & $\begin{array}{l}\text { X_accumulated_PNR }(\mathrm{t}-\mathrm{dt})+ \\
(\text { X_generated_PNR - } \\
\text { Harvest_Rate_PNR) }{ }^{*} \mathrm{dt}\end{array}$ & 10 & stock \\
\hline Harvest_PNR = & $\begin{array}{l}\text { Pulse((Amount), Init_PNR,Frequency_P } \\
\text { NR) }\end{array}$ & $\mathrm{n} / \mathrm{a}$ & flow \\
\hline
\end{tabular}

\section{Nitrogen Utilization in PNR}

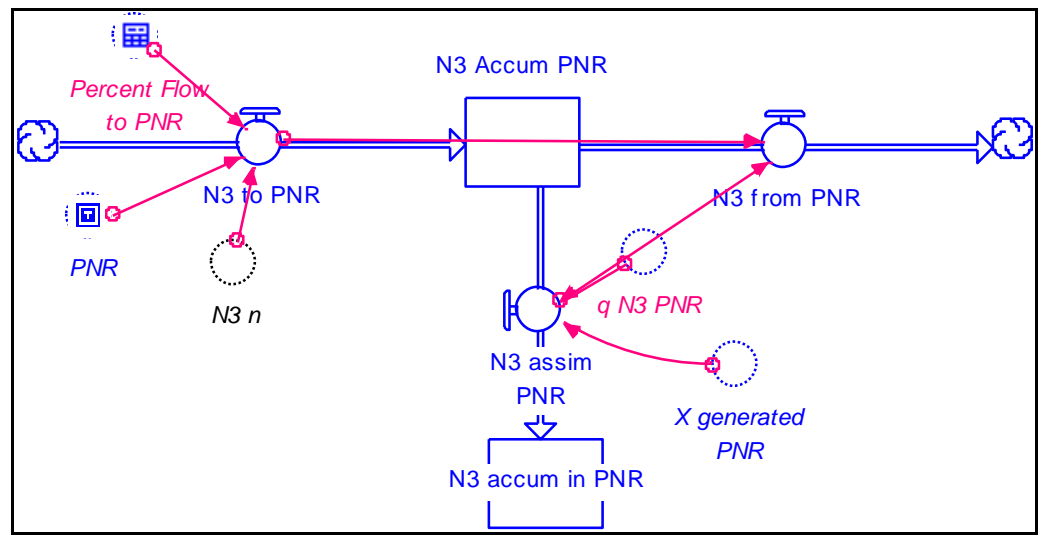

Figure A21. Nitrogen utilization framework for the PNR.

Table A41. List of variables in nitrogen utilization framework in the PNR.

\begin{tabular}{|l|l|l|}
\hline Notation in Model & Description & $\begin{array}{l}\text { Units or } \\
\text { Value }\end{array}$ \\
\hline Percent Flow to PNR & $\begin{array}{l}\text { percent of flow diverted from water flow to } \\
\text { plant }\end{array}$ & unitless \\
\hline PNR & switch to turn on PNR & unitless \\
\hline N3 to PNR & flow of nitrogen to PNR & $\mathrm{kg} /$ day \\
\hline N3 n & flow of nitrogen from nitrification reactor & $\mathrm{kg} /$ day \\
\hline N3 Accum PNR & nitrogen available in the PNR & $\mathrm{kg}$ \\
\hline
\end{tabular}




\section{Appendix A (Continued)}

Table A41. (cont).

\begin{tabular}{|l|l|l|}
\hline Notation in Model & Description & $\begin{array}{l}\text { Units or } \\
\text { Value }\end{array}$ \\
\hline N3 from PNR & flow of nitrogen leaving the PNR & $\mathrm{kg} / \mathrm{day}$ \\
\hline N3 assim & flow of nitrogen assimilated in algae & $\mathrm{kg} / \mathrm{day}$ \\
\hline q N3 PNR & nitrogen substrate utilization rate & $\mathrm{kg} / \mathrm{kg}$-day \\
\hline X generated PNR & algae growth in PNR & $\mathrm{kg}$ \\
\hline N3 accum in algae & amount of nitrogen accumulated in algae & $\mathrm{kg}$ \\
\hline
\end{tabular}

Table A42. List of equations in nitrogen utilization framework in the PNR.

\begin{tabular}{|c|c|c|c|}
\hline Notation & Equation & $\begin{array}{l}\text { Initial } \\
\text { Value }\end{array}$ & Component \\
\hline N3_to_PNR $=$ & N3_n*PNR*Percent_Flow_to_PNR & $\mathrm{n} / \mathrm{a}$ & Flow \\
\hline $\begin{array}{r}\text { N3_Accum_PN } \\
R(t)=\end{array}$ & $\begin{array}{l}\text { N3_Accum_PNR(t-dt) }+(\mathrm{N} 3 \text { to_PNR - } \\
\text { N3_from_PNR - N3_assim_PNR) }{ }^{*} \mathrm{dt}\end{array}$ & $\begin{array}{l}\text { N3_to_PN } \\
R^{*}{ }^{*}{ }^{2} \bar{T} \_P \\
\text { NR }\end{array}$ & Stock \\
\hline $\begin{array}{r}\text { N3_assim_PNR } \\
=\end{array}$ & X_generated_PNR*q_N3_PNR & $\mathrm{n} / \mathrm{a}$ & Flow \\
\hline $\begin{array}{r}\text { N3_accum_in_ } \\
\operatorname{PNR}(\mathrm{t})=\end{array}$ & $\begin{array}{l}\text { N3_accum_in_PNR }(\mathrm{t}-\mathrm{dt})+ \\
\left(\mathrm{N} 3 \_ \text {assim_PNR }{ }^{*} \mathrm{dt}\right.\end{array}$ & $\begin{array}{c}\text { N3_assim } \\
\text { PNR }\end{array}$ & Stock \\
\hline $\begin{array}{r}\text { N3_from_PPO } \\
R=\end{array}$ & N3_to_PNR-N3_assim_PNR & $\mathrm{n} / \mathrm{a}$ & Flow \\
\hline
\end{tabular}

Carbon Utilization in the PNR

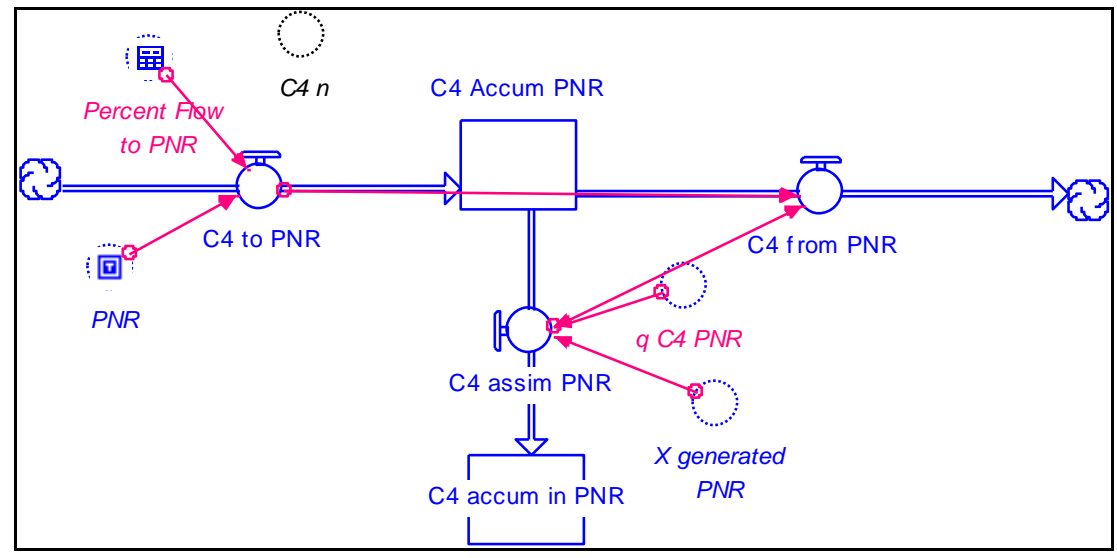

Figure A22. Carbon utilization framework in the PNR. 


\section{Appendix A (Continued)}

Table A43. List of variables in carbon utilization framework in the PNR.

\begin{tabular}{|l|l|l|}
\hline Notation in Model & Description & $\begin{array}{l}\text { Units or } \\
\text { Value }\end{array}$ \\
\hline $\begin{array}{l}\text { Percent Flow to } \\
\text { PNR }\end{array}$ & percent of flow diverted from water flow to plant & Unitless \\
\hline C4 $\mathrm{n}$ & flow of carbon from nitrification reactor & $\mathrm{kg} /$ day \\
\hline PNR & switch to turn on PNR & Unitless \\
\hline C4 to PNR & flow of carbon to PNR & $\mathrm{kg} /$ day \\
\hline C4 Accum PNR & mass of carbon available in PNR & $\mathrm{Kg}$ \\
\hline C4 from PNR & flow of carbon leaving PNR & $\mathrm{kg} /$ day \\
\hline & & \\
C4 assim PNR & amount of carbon assimilated in algae & $\mathrm{kg} /$ day \\
\hline q C4 PNR & carbon substrate utilization rate & $\mathrm{kg} / \mathrm{kg}$-day \\
\hline X generated PNR & algae growth in PNR & $\mathrm{kg} /$ day \\
\hline C4 accum in PNR & carbon accumulated in algae & $\mathrm{Kg}$ \\
\hline
\end{tabular}

Table A44. List of equations in carbon utilization framework in the PNR.

\begin{tabular}{|c|c|c|c|}
\hline Notation & Equation & $\begin{array}{l}\text { Initial } \\
\text { Value }\end{array}$ & Component \\
\hline C4_to $P N R=$ & $\mathrm{C} 4 \mathrm{n}^{*} \mathrm{PNR}{ }^{*}$ Percent_Flow to PNR & $\mathrm{n} / \mathrm{a}$ & Flow \\
\hline $\begin{array}{r}\text { C4_Accum_PN } \\
R(t)=\end{array}$ & $\begin{array}{l}\text { C4_Accum_PNR }(\mathrm{t}-\mathrm{dt})+(\mathrm{C} 4 \text { to } \mathrm{PNR}- \\
\text { C4_from_PNR - C4_assim_PNR) }{ }^{*} \mathrm{dt}\end{array}$ & $\begin{array}{l}\text { C4_to_P } \\
\text { NR* }{ }^{\star} \mathrm{R} T \\
\text { PNR }\end{array}$ & Stock \\
\hline $\begin{array}{r}\text { C4_assim_PNR } \\
=\end{array}$ & X_generated_PNR ${ }^{*}$ q_C4_PNR & $\mathrm{n} / \mathrm{a}$ & Flow \\
\hline $\begin{array}{l}\text { C4_accum_in_ } \\
\text { PNR }(\mathrm{t})=\end{array}$ & $\begin{array}{l}\text { C4_accum_in_PNR(t - dt) + } \\
\text { (C4_assim_PNR)* dt }\end{array}$ & 0 & Stock \\
\hline C4_from_PNR & C4_to_PNR-C4_assim_PNR & $\mathrm{n} / \mathrm{a}$ & Flow \\
\hline
\end{tabular}




\section{Appendix A (Continued)}

Phosphorous Utilization in the PNR

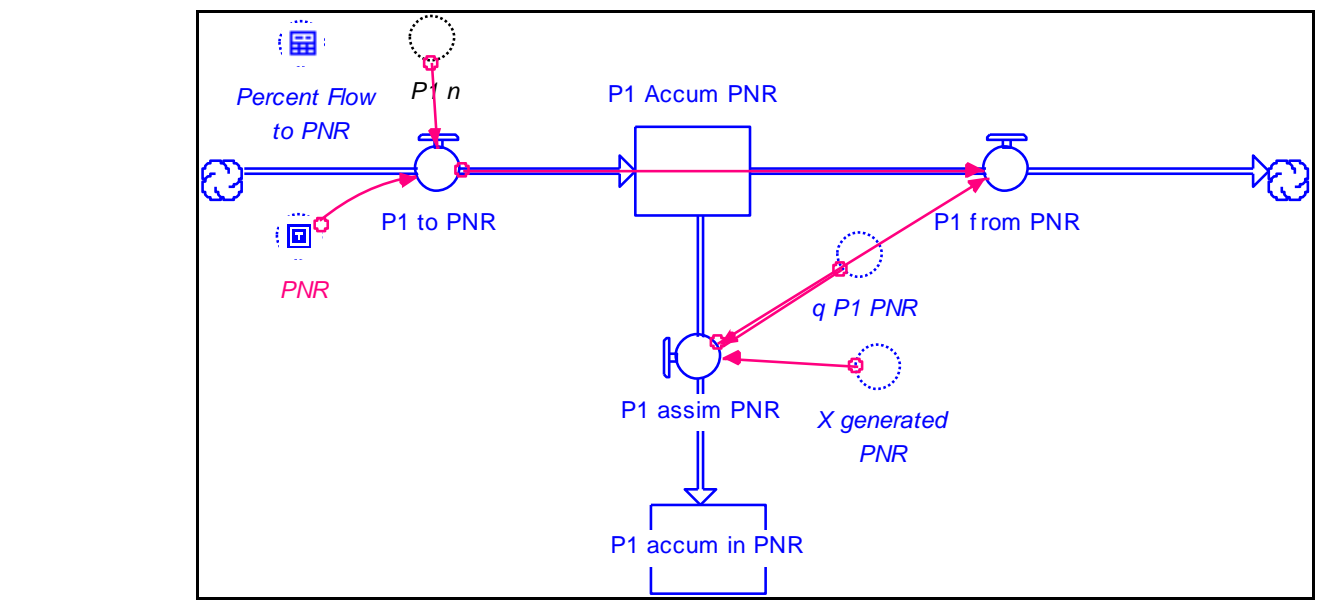

Figure A23. Phosphorous utilization framework in the PNR.

Table A45. List of variables in phosphorous utilization framework in the PNR.

\begin{tabular}{|l|l|l|}
\hline Notation in Model & Description & $\begin{array}{l}\text { Units or } \\
\text { Value }\end{array}$ \\
\hline Percent Flow to PNR & $\begin{array}{l}\text { percent of flow diverted from water flow to } \\
\text { plant }\end{array}$ & unitless \\
\hline PNR & switch to turn on PNR & unitless \\
\hline P1 to PNR & flow of phosphorous to PNR & $\mathrm{kg} /$ day \\
\hline P1 n & $\begin{array}{l}\text { flow of phosphorous from nitrification } \\
\text { reactor }\end{array}$ & $\mathrm{kg} /$ day \\
\hline P1 Accum PNR & phosphorous available in the PNR & $\mathrm{kg}$ \\
\hline P1 from PNR & flow of phosphorous leaving the PNR & $\mathrm{kg} /$ day \\
\hline P1 assim PNR & flow of phosphorous assimilated in algae & $\mathrm{kg} /$ day \\
\hline q P1 PNR & phosphorous substrate utilization rate & $\mathrm{kg} / \mathrm{kg}$-day \\
\hline X generated PNR & algae growth in PNR & $\mathrm{kg}$ \\
\hline P1 accum in PNR & $\begin{array}{l}\text { amount of phosphorous accumulated in } \\
\text { algae }\end{array}$ & $\mathrm{kg}$ \\
\hline
\end{tabular}




\section{Appendix A (Continued)}

Table A46. List of equations in phosphorous utilization framework in the PNR.

\begin{tabular}{|c|c|c|c|}
\hline Notation & Equation & Initial Value & Component \\
\hline P1_to_PNR = & PNR ${ }^{*}$ P1_n*Percent_Flow to PNR & $\mathrm{n} / \mathrm{a}$ & flow \\
\hline $\begin{array}{r}\mathrm{P} 1 \_ \text {Accum_PN } \\
\mathrm{R}(\mathrm{t})=\end{array}$ & $\begin{array}{l}\mathrm{P} 1 \_ \text {Accum_PNR }(\mathrm{t}-\mathrm{dt})+\overline{\mathrm{P} 1 \_ \text {to_PNR }} \\
-\mathrm{P} 1 \text { from_PNR }-\mathrm{P} 1 \_ \text {assim_PNR }{ }^{*} \\
\mathrm{dt}\end{array}$ & $\begin{array}{l}\text { P1_to_PNR* } \\
\text { HRT_PNR }\end{array}$ & stock \\
\hline $\begin{array}{r}\text { P1_assim_PNR } \\
=\end{array}$ & X_generated_PNR* ${ }^{*}$ _P1_PNR & $\mathrm{n} / \mathrm{a}$ & flow \\
\hline $\begin{array}{r}P 1 \_ \text {accum_in_ } \\
\operatorname{PNR}(\mathrm{t})=\end{array}$ & $\begin{array}{l}P 1 \text { accum_in_PNR }(t-d t)+ \\
\left(P 1 \_ \text {assim_PNR }\right)^{*} d t\end{array}$ & 0 & stock \\
\hline $\begin{array}{r}\text { P1_from_PNR } \\
=\end{array}$ & P1_to_PNR-P1_assim_PNR & $\mathrm{n} / \mathrm{a}$ & flow \\
\hline
\end{tabular}

Substrate Utilization Rate in the PNR

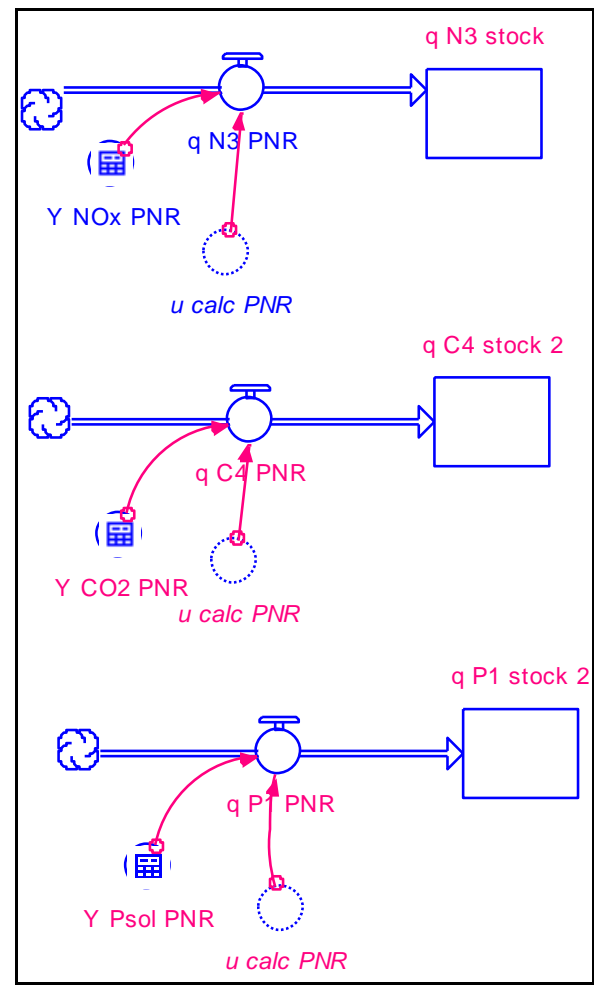

Figure A24. Substrate utilization rate framework in the PNR. 


\section{Appendix A (Continued)}

Table A47. List of variables for substrate utilization rate framework in the PNR.

\begin{tabular}{|l|l|l|}
\hline Notation in Model & Description & $\begin{array}{l}\text { Units or } \\
\text { Value }\end{array}$ \\
\hline Y_NOx PNR & half saturation constant for nitrate & unitless \\
\hline q_N3_PNR & nitrogen substrate utilization rate & unitless \\
\hline q_N3_stock & accumulation of q & $\mathrm{kg} /$ day \\
\hline u_calc_PNR & calculated specific growth rate in PNR & $\mathrm{kg} /$ day \\
\hline Y_CO2 PNR & half saturation constant for carbon & $\mathrm{kg}$ \\
\hline q_C4_PNR & carbon substrate utilization rate & $\mathrm{kg} /$ day \\
\hline q_C4_stock_2 & accumulation of q & $\mathrm{kg} /$ day \\
\hline Y_PsolPNR & half saturation constant for phosphorous & $\mathrm{kg} / \mathrm{kg}$-day \\
\hline q_P1_PNR & phosphorous substrate utilization rate & $\mathrm{kg}$ \\
\hline q_P1_stock_2 & accumulation of q & $\mathrm{kg}$ \\
\hline
\end{tabular}

Table A48. List of equations for substrate utilization rate framework in the PNR.

\begin{tabular}{|r|l|l|l|}
\hline Notation & Equation & $\begin{array}{l}\text { Initial } \\
\text { Value }\end{array}$ & Component \\
\hline q_N3_PNR $=$ & U_calc_PNR/Y_NOx_PNR & n/a & flow \\
\hline q_N3_stock $(t)=$ & q_N3_stock $(t-d t)+(\text { q_N3_PNR })^{*} d t$ & 0 & stock \\
\hline q_C4_PNR $=$ & U_calc_PNR/Y_CO2_PNR & n/a & flow \\
\hline q_C4_stock_2 $(t)=$ & q_C4_stock_2(t - dt $)+(\text { q_C4_PNR })^{*}$ dt & 0 & stock \\
\hline q_P1_PNR $=$ & U_calc_PNR/Y_Psol_PNR & n/a & flow \\
\hline q_P1_stock_2(t) $=$ & q_P1_stock_2(t - dt $)+(\text { q_P1_PNR })^{*}$ dt & 0 & stock \\
\hline
\end{tabular}




\section{Appendix A (Continued)}

Cost Savings from Reduced Aeration

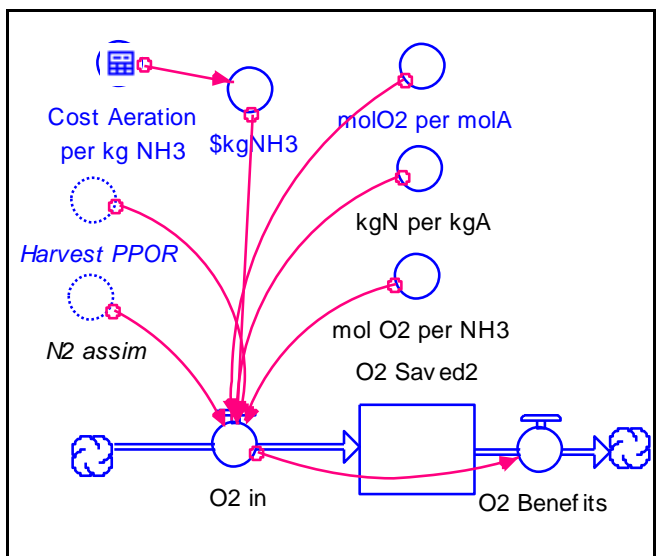

Figure A25. Cost savings from reduced aeration framework in the STELLA model.

Table A49. List of variables for cost savings from reduced aeration.

\begin{tabular}{|l|l|l|}
\hline Notation in Model & Description & $\begin{array}{l}\text { Units or } \\
\text { Value }\end{array}$ \\
\hline $\begin{array}{l}\text { Cost Aeration per kg } \\
\mathrm{NH} 3\end{array}$ & estimated cost to nitrify $\mathrm{kg} \mathrm{NH} 3$ & $\$ / \mathrm{kg}$ \\
\hline$\$ \mathrm{kgNH} 3$ & estimated cost to nitrify $\mathrm{kg} \mathrm{NH} 3$ & $\$ / \mathrm{kg}$ \\
\hline Harvest PPOR & algae harvested from PPOR & $\mathrm{kg} /$ day \\
\hline $\mathrm{N} 2$ assim & nitrogen assimilated by algae in PPOR & $\mathrm{kg} /$ day \\
\hline O2 in & oxygen savings calculated & $\$ /$ day \\
\hline molO2 per molA & $\begin{array}{l}\text { stoichiometric ratio of oxygen to algae } \\
\text { during growth }\end{array}$ & unitless \\
\hline $\mathrm{kgN}$ per kgA & $\begin{array}{l}\text { stoichiometric ratio of oxygen to algae } \\
\text { during growth }\end{array}$ & unitless \\
\hline molO2 per NH3 & stoichiometric ratio of oxygen to nitrogen & unitless \\
\hline O2 Saved2 & stock of oxygen saved & $\$$ \\
\hline O2 Benefits & oxygen savings calculated & $\$ /$ day \\
\hline
\end{tabular}

Table A50. List of equations for cost savings from reduced aeration.

\begin{tabular}{|c|c|c|c|}
\hline Notation & Equation & $\begin{array}{l}\text { Initial } \\
\text { Value }\end{array}$ & Component \\
\hline $\mathrm{O} 2$ in $=$ & 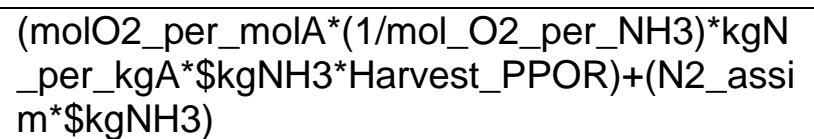 & $\mathrm{n} / \mathrm{a}$ & flow \\
\hline $\mathrm{O} 2$ saved $2(\mathrm{t})=$ & $\mathrm{O} 2$ Saved2 $(\mathrm{t}-\mathrm{dt})+(\mathrm{O} 2 \text { in - O2 Benefits })^{*} \mathrm{dt}$ & 0 & stock \\
\hline O2 Benefits = & $\mathrm{O} 2$ in & $\mathrm{n} / \mathrm{a}$ & flow \\
\hline
\end{tabular}




\section{Appendix A (Continued)}

Cost Savings from Reduced Chemical Demand

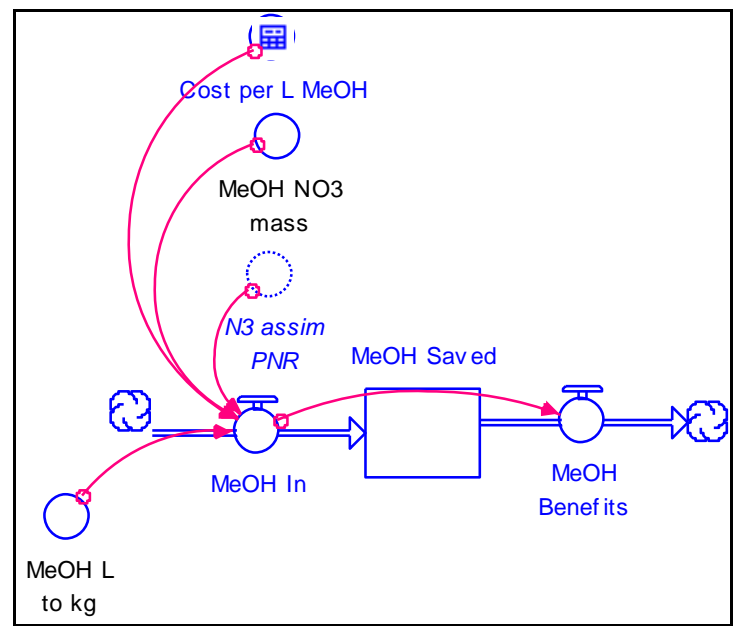

Figure A26. Cost savings from reduced chemical demand framework.

Table A51. List of variables for cost savings from reduced chemical demand.

\begin{tabular}{|l|l|l|}
\hline Notation in Model & Description & $\begin{array}{l}\text { Units or } \\
\text { Value }\end{array}$ \\
\hline Cost per L MeOH & cost of methanol per liter & $\$ / \mathrm{L}$ \\
\hline $\mathrm{MeOH}$ NO3 mass & $\begin{array}{l}\text { stoichiometric ratio of methanol to } \\
\text { nitrate (mass) }\end{array}$ & unitless \\
\hline $\mathrm{N} 3$ assim PNR & nitrate assimilated in the PNR & $\mathrm{kg} / \mathrm{day}$ \\
\hline $\mathrm{MeOH} \mathrm{L}$ to kg & amount of methanol (volume) per mass & $\mathrm{L} / \mathrm{kg}$ \\
\hline $\mathrm{MeOH}$ per $\mathrm{NO} 3$ & $\begin{array}{l}\text { stoichiometric ratio of methanol to } \\
\text { nitrate (moles) }\end{array}$ & unitless \\
\hline $\mathrm{MeOH}$ In & $\begin{array}{l}\text { flow of cost savings from reduced } \\
\text { methanol }\end{array}$ & $\$ /$ day \\
\hline $\mathrm{MeOH}$ Saved & $\begin{array}{l}\text { stock of cost savings from reduced } \\
\text { methanol }\end{array}$ & $\$$ \\
\hline $\mathrm{MeOH}$ Benefits & $\begin{array}{l}\text { flow of cost savings from reduced } \\
\text { methanol }\end{array}$ & $\$ /$ day \\
\hline
\end{tabular}

Table A52. List of equations for cost savings from reduced chemical demand.

\begin{tabular}{|c|c|c|c|}
\hline Notation & Equation & $\begin{array}{l}\text { Initial } \\
\text { Value }\end{array}$ & Component \\
\hline $\mathrm{MeOI}$ & $\begin{array}{l}\left(\mathrm{MeOH} \_\mathrm{NO} 3 \text { mass }{ }^{*}(\mathrm{~N} 3 \text { assim_ } \mathrm{PNR})^{*}\right. \\
\text { Cost_per_L_MeOH)/MeOH_L to_kg }\end{array}$ & $n / a$ & flow \\
\hline $\begin{array}{r}\mathrm{MeOH} \_ \text {Saved }(\mathrm{t}) \\
=\end{array}$ & $\begin{array}{l}\mathrm{MeOH} \_ \text {Saved }(\mathrm{t}-\mathrm{dt})+(\mathrm{MeOH} \mathrm{In}- \\
\mathrm{MeOH} \text { Benefits) }{ }^{*} \mathrm{dt}\end{array}$ & 0 & stock \\
\hline $\mathrm{MeOH}$ Benefits $=$ & $\mathrm{MeOH} \mathrm{In}$ & $n / a$ & flow \\
\hline
\end{tabular}




\section{Appendix A (Continued)}

\section{Biogas Calculations}

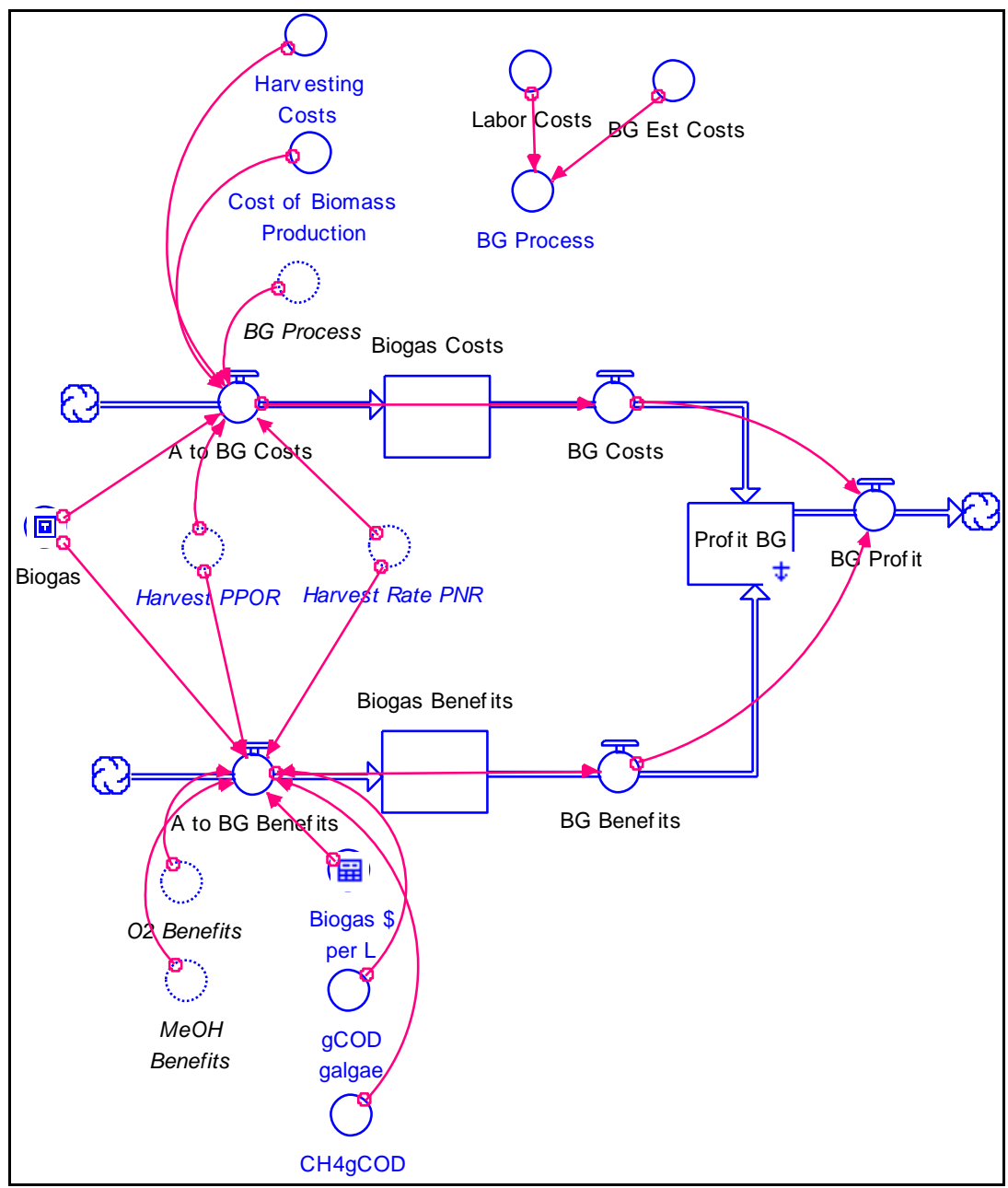

Figure A27. Biogas processing framework in the STELLA model.

Table A53. List of variables for biogas processing framework.

\begin{tabular}{|l|l|l|}
\hline Notation in Model & Description & $\begin{array}{l}\text { Units or } \\
\text { Value }\end{array}$ \\
\hline Harvesting Costs & cost of harvesting biomass & $\$ / \mathrm{kg}$ \\
\hline $\begin{array}{l}\text { Cost of Biomass } \\
\text { Production }\end{array}$ & cost of biomass production & $\$ / \mathrm{kg}$ \\
\hline BG Process & biogas total processing costs & $\$ / \mathrm{kg}$ \\
\hline Labor Costs & cost of labor in processing costs & $\$ / \mathrm{kg}$ \\
\hline BG Est Costs & cost of biogas production & $\$ / \mathrm{kg}$ \\
\hline A to BG Costs & total costs of biogas production & $\$ / \mathrm{kg}$ \\
\hline Biogas Costs & stock of total costs & $\$$ \\
\hline
\end{tabular}




\section{Appendix A (Continued)}

Table A53. (cont.)

\begin{tabular}{|l|l|l|}
\hline Notation in Model & Description & $\begin{array}{l}\text { Units or } \\
\text { Value }\end{array}$ \\
\hline BG Costs & total costs of biogas production & $\$ / \mathrm{kg}$ \\
\hline Biogas & switch to turn on biogas processing & unitless \\
\hline Harvest PPOR & flow of algae from PPOR & $\mathrm{kg} /$ day \\
\hline Harvest Rate PNR & flow of algae from PNR & $\mathrm{kg} /$ day \\
\hline Profit BG & stock of total costs minus total benefits & $\$$ \\
\hline BG Profit & flow of overall profit & $\$ /$ day \\
\hline MeOH Benefits & cost savings from reduced chemical additives & $\$ /$ day \\
\hline O2 Benefits & cost savings from reduced aeration & $\$ /$ day \\
\hline CH4gCOD & methane production per unit COD & $\mathrm{L} / \mathrm{kg}$ \\
\hline gCOD_galgae & mass of COD per mass of algae & $\mathrm{kg} / \mathrm{kg}$ \\
\hline Biogas $\$$ per L & sale price of biogas per L & $\$ / \mathrm{L}$ \\
\hline A to BG Benefits & total benefits of biogas production & $\$ /$ day \\
\hline Biogas Benefits & stock of total benefits of biogas production & $\$$ \\
\hline BG Benefits & total benefits of biogas production & $\$ /$ day \\
\hline
\end{tabular}

Table A54. List of equations for biogas processing framework.

\begin{tabular}{|c|c|c|c|}
\hline Notation & Equation & $\begin{array}{l}\text { Initial } \\
\text { Value }\end{array}$ & Component \\
\hline $\begin{array}{r}\text { BG_Process } \\
=\end{array}$ & BG Est Costs+Labor Costs & $\mathrm{n} / \mathrm{a}$ & converter \\
\hline $\begin{array}{l}\text { A_to_BG } \\
\text { Costs }=\end{array}$ & $\begin{array}{l}\text { Biogas }^{*}\left(\left((\text { Harvest_PPOR+Harvest_Rate_PNR })^{*}\right.\right. \\
\text { BG_Process)+((Harvest_PPOR+Harvest_Rate_- } \\
\text { PNR })^{*} \text { Cost_of_Biomass_Production)+(Harvestin } \\
\left.\text { g Costs* }{ }^{\star}(\text { Harvest_PPOR+Harvest_Rate_PNR })\right)\end{array}$ & $\mathrm{n} / \mathrm{a}$ & flow \\
\hline $\begin{array}{r}\text { Biogas } \\
\text { Costs }(\mathrm{t})=\end{array}$ & $\begin{array}{l}\text { Biogas_Costs(t - dt) + (A_to_BG_Costs - } \\
\text { BG_Costs) }{ }^{*} \mathrm{dt}\end{array}$ & 0 & stock \\
\hline BG_Costs = & A_to_BG_Costs & $\mathrm{n} / \mathrm{a}$ & flow \\
\hline $\begin{array}{l}\text { A_to_BG } \\
\text { Benefits = }\end{array}$ & 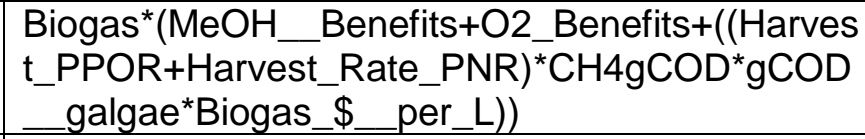 & $\mathrm{n} / \mathrm{a}$ & flow \\
\hline $\begin{array}{r}\text { Biogas } \\
\text { Benefits }(t)=\end{array}$ & $\begin{array}{l}\text { Biogas_Benefits }(\bar{t}-\overline{d t})+\left(\bar{A} \_t o \_B G \_B e n e f i t s-\right. \\
\text { BG_Benefits }{ }^{*} d t\end{array}$ & 0 & stock \\
\hline BG_Benefits & A_to_BG_Benefits & $\mathrm{n} / \mathrm{a}$ & flow \\
\hline $\begin{array}{r}\text { Profit_BG(t) } \\
=\end{array}$ & $\begin{array}{l}\text { Profit_BG(t - dt) +(BG_Costs + BG_Benefits - } \\
\text { BG_Profit) * dt }\end{array}$ & 0 & stock \\
\hline BG_Profit $=$ & BG_Benefits-BG_Costs & $\mathrm{n} / \mathrm{a}$ & flow \\
\hline
\end{tabular}




\section{Appendix A (Continued)}

\section{Biodiesel Calculations}

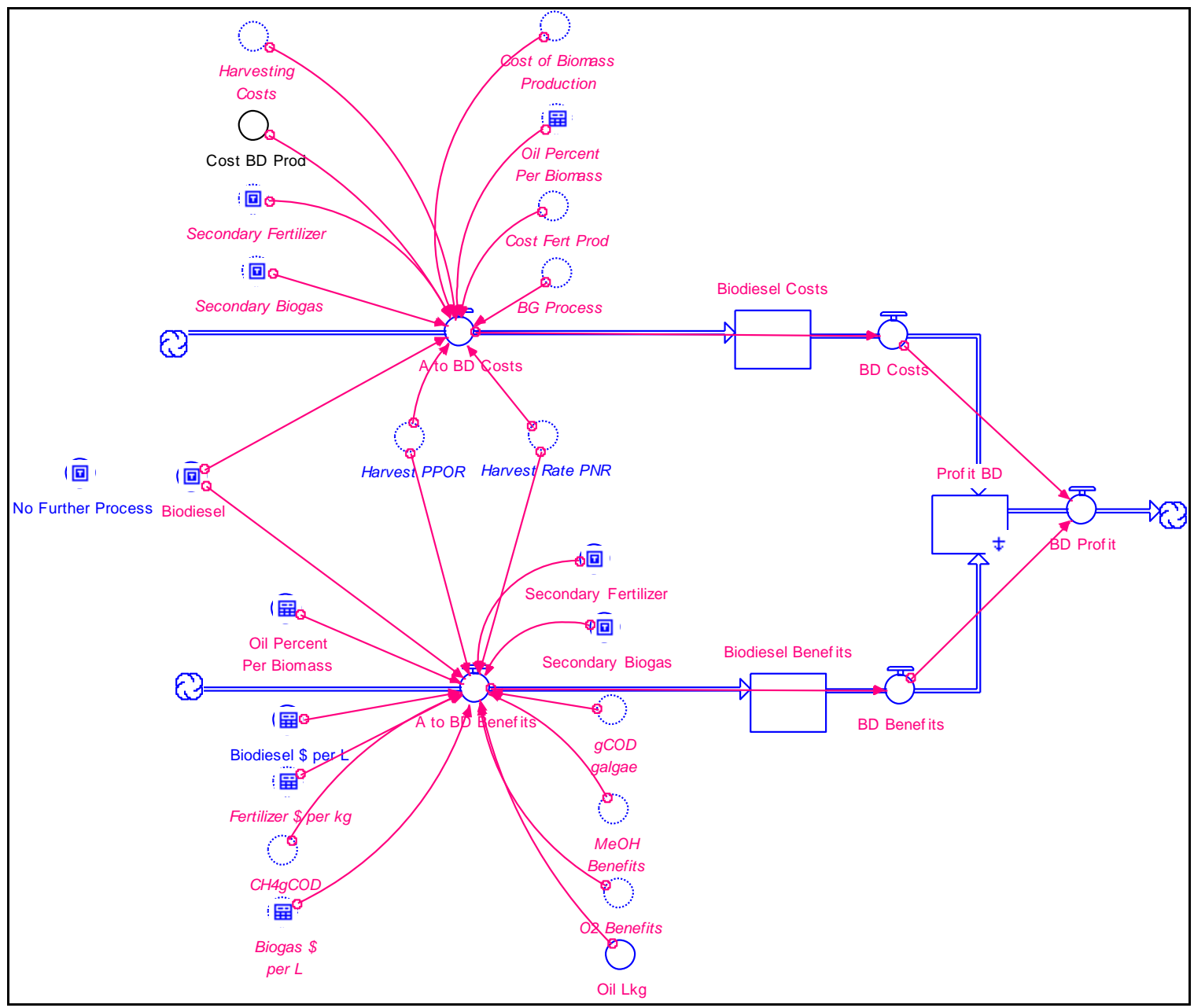

Figure A28. Biodiesel processing framework in the STELLA model.

Table A55. List of variables for biodiesel processing framework.

\begin{tabular}{|l|l|l|}
\hline Notation in Model & Description & $\begin{array}{l}\text { Units or } \\
\text { Value }\end{array}$ \\
\hline Harvesting Costs & cost of harvesting biomass & $\$ / \mathrm{kg}$ \\
\hline $\begin{array}{l}\text { Cost of Biomass } \\
\text { Production }\end{array}$ & cost of biomass production & $\$ / \mathrm{kg}$ \\
\hline Secondary Fertilizer & $\begin{array}{l}\text { switch to turn on further processing to } \\
\text { fertilizer }\end{array}$ & unitless \\
\hline Secondary Biogas & $\begin{array}{l}\text { switch to turn on further processing to } \\
\text { biogas }\end{array}$ & unitless \\
\hline Cost BD Production & cost of biodiesel production & $\$ / \mathrm{kg}$ \\
\hline
\end{tabular}




\section{Appendix A (Continued)}

Table A55. (cont.)

\begin{tabular}{|l|l|l|}
\hline Notation in Model & Description & $\begin{array}{l}\text { Units or } \\
\text { Value }\end{array}$ \\
\hline $\begin{array}{l}\text { Oil Percent Per } \\
\text { Biomass }\end{array}$ & percent of biomass that is oil & unitless \\
\hline Cost Fert Prod & cost of fertilizer production & $\$ / \mathrm{kg}$ \\
\hline BG Process & cost of biogas production & $\$ / \mathrm{kg}$ \\
\hline A to BD Costs & flow of biodiesel costs & $\$ /$ day \\
\hline Biodiesel Costs & stock of biodiesel costs & $\$$ \\
\hline BD Costs & flow of biodiesel costs & $\$ /$ day \\
\hline Harvest PPOR & flow of algae harvested from PPOR & $\mathrm{kg} /$ day \\
\hline Harvest Rate PNR & flow of algae harvested from PNR & $\mathrm{kg} /$ day \\
\hline Biodiesel & switch to turn on biodiesel processing & $\mathrm{unitless}$ \\
\hline No Further Process & $\begin{array}{l}\text { switch to turn off any further processing of } \\
\text { biomass }\end{array}$ & $\mathrm{unitless}$ \\
\hline Biodiesel $\$$ per L & cost of biodiesel per volume of biodiesel & $\$ / \mathrm{L}$ \\
\hline Fertilizer \$ per kg & cost of fertilizer per kg produced & $\$ / \mathrm{kg}$ \\
\hline CH4gCOD & methane production per unit COD & $\mathrm{L} / \mathrm{kg}$ \\
\hline Biogas $\$$ per L & sale price of biogas per L & $\$ / \mathrm{L}$ \\
\hline gCODgalgae & mass of COD per mass of algae & $\mathrm{kg} / \mathrm{kg}$ \\
\hline MeOH Benefits & cost savings from reduced chemical additives & $\$ /$ day \\
\hline O2 Benefits & cost savings from reduced aeration & $\$ /$ day \\
\hline Oil Lkg & density of biodiesel & $\mathrm{L} / \mathrm{kg}$ \\
\hline A to BD Benefits & flow of biodiesel benefits & $\$ /$ day \\
\hline Biodiesel Benefits & stock of biodiesel benefits & $\$$ \\
\hline BD Benefits & flow of biodiesel benefits & $\$ /$ day \\
\hline Profit BD & stock of biodiesel profit & $\$$ \\
\hline BD Profit & flow of biodiesel profit & $\$ /$ day \\
\hline
\end{tabular}




\section{Appendix A (Continued)}

Table A56. List of equations for biodiesel processing framework.

\begin{tabular}{|c|c|c|c|}
\hline Notation & Equation & $\begin{array}{l}\text { Initial } \\
\text { Value }\end{array}$ & Component \\
\hline $\begin{array}{l}\text { A_to_BD } \\
\text { Costs }=\end{array}$ & 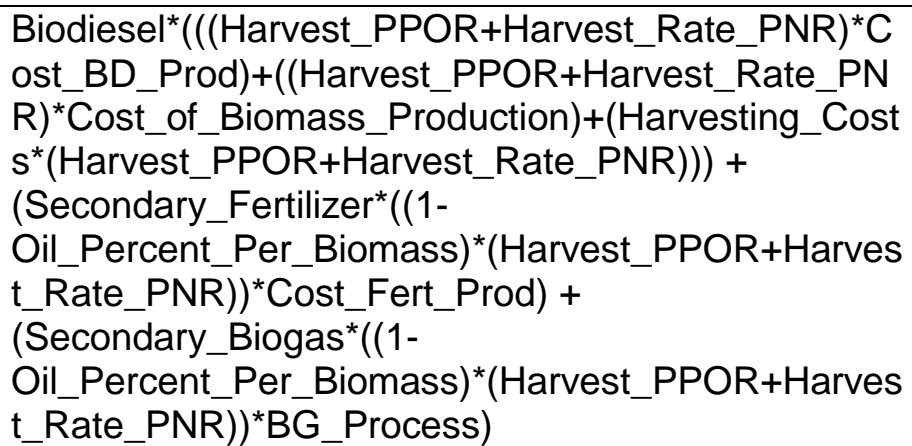 & $n / a$ & flow \\
\hline $\begin{array}{l}\text { Biodiesel } \\
\text { Costs }(\mathrm{t})=\end{array}$ & $\begin{array}{l}\text { Biodiesel_Costs }(\mathrm{t}-\mathrm{dt})+(\text { A_to_BD_Costs - } \\
\text { BD_Costs }{ }^{*} \mathrm{dt}\end{array}$ & 0 & stock \\
\hline $\begin{array}{r}\text { BD_Costs } \\
=\end{array}$ & A to BD Costs & $\mathrm{n} / \mathrm{a}$ & flow \\
\hline $\begin{array}{l}\text { A_to_BD_ } \\
\text { Benefits = }\end{array}$ & 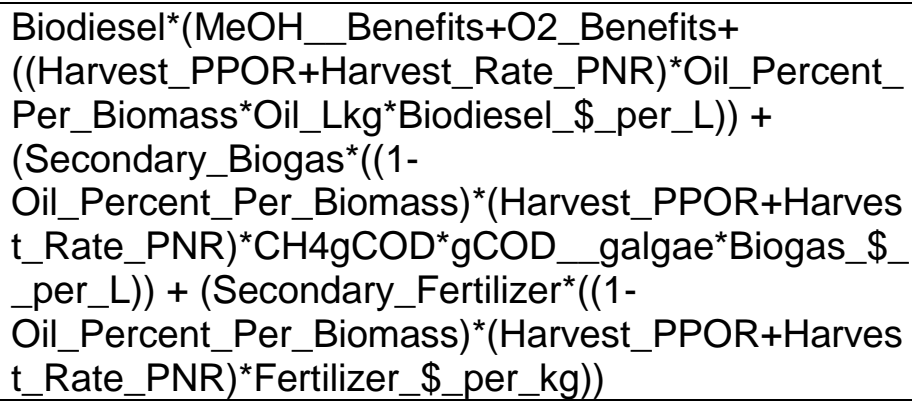 & $\mathrm{n} / \mathrm{a}$ & flow \\
\hline $\begin{array}{r}\text { Biodiesel } \\
\text { Benefits }(\mathrm{t}) \\
=\end{array}$ & $\begin{array}{l}\text { Biodiesel_Benefits }(\mathrm{t}-\mathrm{dt})+(\text { A_to_BD_Benefits - } \\
\text { BD_Benefits }){ }^{*} \mathrm{dt}\end{array}$ & 0 & stock \\
\hline $\begin{array}{r}\text { BD_- } \\
\text { Benefits }=\end{array}$ & A_to_BD_Benefits & $\mathrm{n} / \mathrm{a}$ & flow \\
\hline $\begin{array}{r}\text { Profit_BD } \\
(\mathrm{t})=\end{array}$ & $\begin{array}{l}\text { Profit_BD(t - dt })+\left(B D \_C o s t s+B D \_B e n e f i t s-\right. \\
\text { BD_Profit }) * d t\end{array}$ & 0 & stock \\
\hline $\begin{array}{r}\text { BD_Profit } \\
=\end{array}$ & BD_Benefits-BD_Costs & $\mathrm{n} / \mathrm{a}$ & flow \\
\hline
\end{tabular}




\section{Appendix A (Continued)}

\section{Fertilizer Calculations}

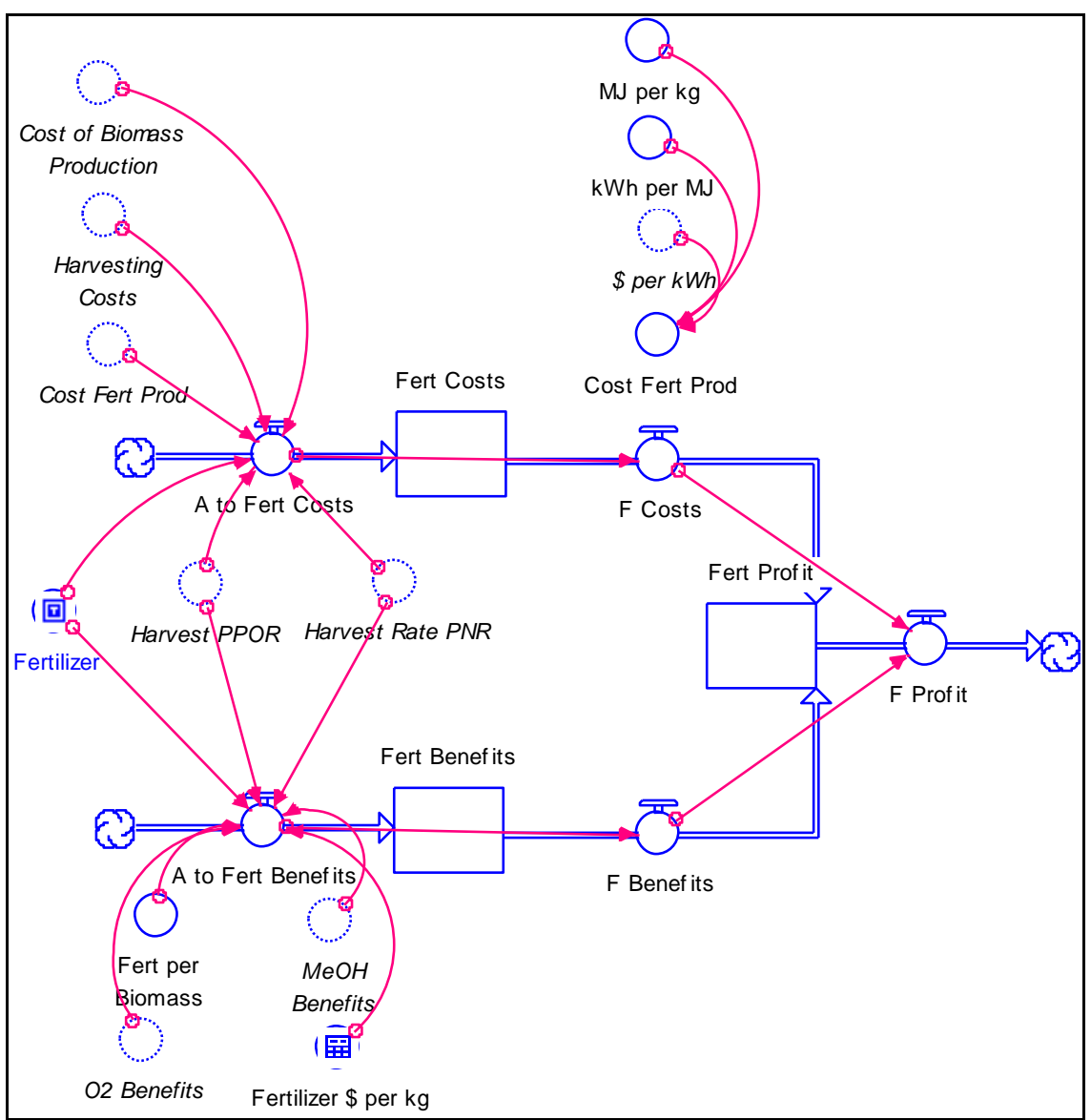

Figure A29. Fertilizer processing framework in the STELLA model.

Table A57. List of variables for fertilizer processing framework.

\begin{tabular}{|l|l|l|}
\hline Notation in Model & Description & $\begin{array}{l}\text { Units or } \\
\text { Value }\end{array}$ \\
\hline Harvesting Costs & cost of harvesting biomass & $\$ / \mathrm{kg}$ \\
\hline $\begin{array}{l}\text { Cost of Biomass } \\
\text { Production }\end{array}$ & cost of biomass production & $\$ / \mathrm{kg}$ \\
\hline Cost Fert Prod & cost of fertilizer production & $\$ / \mathrm{kg}$ \\
\hline A to Fert Costs & flow of costs of fertilizer production & $\$ /$ day \\
\hline Fert Costs & stock of fertilizer costs & $\$$ \\
\hline MJ per kg & energy required for fertilizer production & $\mathrm{MJ} / \mathrm{kg}$ \\
\hline kWh per MJ & conversion of kWh to MJ & $\mathrm{kWh} / \mathrm{MJ}$ \\
\hline$\$$ per kWh & cost of kWh & $\$ / \mathrm{kWh}$ \\
\hline F Costs & flow of costs of fertilizer production & $\$ /$ day \\
\hline
\end{tabular}




\section{Appendix A (Continued)}

Table A57. (cont.)

\begin{tabular}{|l|l|l|}
\hline Notation in Model & Description & $\begin{array}{l}\text { Units or } \\
\text { Value }\end{array}$ \\
\hline Fertilizer & switch to turn on fertilizer processing & unitless \\
\hline Harvest PPOR & flow of algae from PPOR & $\mathrm{kg} /$ day \\
\hline Harvest Rate PNR & flow of algae from PNR & $\mathrm{kg} /$ day \\
\hline Fert Profit & stock of fertilizer profit & $\$$ \\
\hline F Profit & flow of fertilizer profits & $\$ /$ day \\
\hline O2 Benefits & flow of benefits from reduced aeration & $\$ /$ day \\
\hline MeOH Benefits & flow of benefits from reduced chemical additives & $\$ /$ day \\
\hline Fert per Biomass & fraction of biomass converted to fertilizer & unitless \\
\hline Fertilizer \$ per kg & market price of fertilizer & $\$ / \mathrm{kg}$ \\
\hline A to Fert Benefits & flow of fertilizer benefits & $\$ /$ day \\
\hline Fert Benefits & stock of fertilizer benefits & $\$$ \\
\hline F Benefits & flow of fertilizer benefits & $\$ /$ day \\
\hline
\end{tabular}

Table A58. List of equations for fertilizer processing framework.

\begin{tabular}{|c|c|c|c|}
\hline Notation & Equation & $\begin{array}{l}\text { Initial } \\
\text { Value }\end{array}$ & Component \\
\hline $\begin{array}{c}\text { Cost_Fert } \\
\text { Prod }=\end{array}$ & MJ per $\mathrm{kg}^{*} \mathrm{kWh}$ per $\mathrm{MJ}^{*} \$$ per $\mathrm{kWh}$ & $\mathrm{n} / \mathrm{a}$ & converter \\
\hline $\begin{array}{c}\text { A_to_Fert } \\
\text { _Costs }=\end{array}$ & $\begin{array}{l}\text { Fertilizer }^{*}\left(\left((\text { Harvest_PPOR+Harvest_Rate_PNR })^{*} \text { Co }\right.\right. \\
\text { st_Fert_Prod)+((Harvest_PPOR+Harvest_Rate_PN } \\
\text { R) }{ }^{*} \text { Cost_of_Biomass_Production)+(Harvesting_Cost } \\
\left.\left.\mathrm{s}^{*}(\text { Harvest_PPOR+Harvest_Rate_PNR })\right)\right)\end{array}$ & $\mathrm{n} / \mathrm{a}$ & flow \\
\hline $\begin{array}{r}\text { Fert } \\
\text { Costs }(\mathrm{t})=\end{array}$ & Fert_Costs $(\mathrm{t}-\mathrm{dt})+($ A_to_Fert_Costs $-\mathrm{F}$ _Costs $){ }^{*} \mathrm{dt}$ & 0 & stock \\
\hline F_Costs $=$ & A_to_Fert_Costs & $\mathrm{n} / \mathrm{a}$ & flow \\
\hline $\begin{array}{r}\text { A_to_Fert } \\
\text {-Benefits } \\
=\end{array}$ & $\begin{array}{l}\text { Fertilizer* }{ }^{*}(\mathrm{MeOH} / \text { Benefits+O2_Benefits+((Harvest } \\
\text { PPOR+Harvest_Rate_PNR })^{*} \text { Fert_per_Biomass }{ }^{*} \text { Fer } \\
\text { tilizer_\$_per_kg) })\end{array}$ & $\mathrm{n} / \mathrm{a}$ & flow \\
\hline $\begin{array}{r}\text { Fert_Bene } \\
\text { fits }(t)=\end{array}$ & $\begin{array}{l}\text { Fert_Benefits }(t-d t)+(\text { A_to_Fert_Benefits - } \\
\text { F_Benefits }){ }^{*} d t\end{array}$ & 0 & stock \\
\hline $\begin{array}{r}\text { F_Benefits } \\
=\end{array}$ & A_to_Fert_Benefits & $\mathrm{n} / \mathrm{a}$ & flow \\
\hline $\begin{array}{r}\text { Fert_Profit } \\
(\mathrm{t})=\end{array}$ & $\begin{array}{l}\text { Fert_Profit(t - dt) + (F_Costs + F_Benefits - F_Profit) } \\
\text { * dt }\end{array}$ & 0 & stock \\
\hline F_Profit $=$ & F_Benefits-F_Costs & $\mathrm{n} / \mathrm{a}$ & flow \\
\hline
\end{tabular}




\section{Appendix B: List of Equations}

Biodiesel_Benefits $(t)=$ Biodiesel_Benefits $(t-d t)+\left(A \_t o \_B D \_B e n e f i t s-\right.$

BD_Benefits) * dt

INIT Biodiesel_Benefits $=0$

INFLOWS:

A_to_BD_Benefits $=$ Biodiesel $^{*}\left(\mathrm{MeOH}\right.$ _Benefits $+\mathrm{O} 2 \_$Benefits +

$\left(\left(\left(\right.\right.\right.$ Harvest_PPOR/(DT_1 ${ }^{*}$ PPOR_Freq) $)+\left(\right.$ Harvest_Rate_PNR/(DT_1 ${ }^{*}$ Frequency_

(PNR))) ${ }^{*}$ Oil_Percent_Per_Biomass*Oil_Lkg*Biodiesel_\$_per_L)) +

(Secondary_Biogas ${ }^{*}(\overline{1}$ -

Oil_Percent_Per_Biomass $)^{*}\left(\left(\right.\right.$ Harvest_PPOR/(DT_1 $\left.\left.{ }^{*} P P O R \_F r e q\right)\right)+($ Harvest_Rat e_PNR/(DT_1 ${ }^{*}$ Frequency_PNR $\left.)\right){ }^{*} \mathrm{CH} 4 \mathrm{gCOD}{ }^{*} g \bar{C} \mathrm{OD} \_$galgae*Biogas_\$_per_ $L))+\left(\right.$ Secondary_Fertilizer ${ }^{*}((1-$

Oil_Percent_Per_Biomass $)^{*}\left(\left(\right.\right.$ Harvest_PPOR/(DT_1 $\left.\left.{ }^{*} P P O R \_F r e q\right)\right)+($ Harvest_Rat e_PNR/(DT_1*Frequency_PNR)))*Fertilizer_\$_per_kg))

OUTFLOWS:

BD_Benefits = A_to_BD_Benefits

Biodiesel_Costs $(\mathrm{t})=$ Biodiesel_Costs $(\mathrm{t}-\mathrm{dt})+($ A_to_BD_Costs - BD_Costs $){ }^{*} \mathrm{dt}$

INIT Biodiesel_Costs $=0$

INFLOWS:

A to BD_Costs =

Biodiese $^{\bar{*}}(((($ Harvest_PPOR/(DT_1*PPOR_Freq $))+($ Harvest_Rate_PNR/(DT_1*F requency_PNR $)))^{\star}$ Cost_BD_Prod $)+\left(\left(\left(\right.\right.\right.$ Harvest_PPOR/(DT_-1 ${ }^{*}$ PPOR_Freq) $)+(\mathrm{Ha}$ rvest_Rate_PNR/(DT_1 ${ }^{\star}$ Frequency_PNR $\left.\left.)\right)\right)^{*}$ Cost_of_Biomass_Production $)+(\mathrm{Ha}$ rvesting_Costs* $(($ Harvest_PPOR/(DT_1*PPOR_Freq) $)+($ Harvest_Rate_PNR/(DT $1^{*}$ Frequency_PNR $\left.\left.\left.)\right)\right)\right)+\left(\right.$ Secondary_Fertilizer* ${ }^{*}((1-$

Oil_Percent_Per_Biomass $)^{*}\left(\left(\right.\right.$ Harvest_PPOR/(DT_1 $\left.\left.{ }^{*} P P O R \_F r e q\right)\right)+($ Harvest_Rat e_PNR/(DT_1 ${ }^{*}$ Frequency_PNR $\left.\left.\left.)\right)\right)\right)^{*}$ Cost_Fert_Prod $)+\left(\right.$ Secondary_Biogas ${ }^{*}((1-$

Oil_Percent_Per_Biomass $)^{\star}\left(\left(\right.\right.$ Harvest_PPOR/(DT_1 $\left.\left.{ }^{*} P P O R \_F r e q\right)\right)+($ Harvest_Rat e_PNR/(DT_1 ${ }^{*}$ Frequency_PNR $\left.\left.\left.)\right)\right)\right)^{*}$ BG_Process)

OUTFLOWS:

BD_Costs = A_to_BD_Costs

Biogas_Benefits $(\mathrm{t})=$ Biogas_Benefits $(\mathrm{t}-\mathrm{dt})+($ A_to_BG_Benefits $-\mathrm{BG}$ _Benefits $)$

${ }^{*} \mathrm{dt}$

INIT Biogas_Benefits $=0$

INFLOWS:

A to BG_Benefits =

Biogas* $\left(\overline{M e O H} \_\right.$Benefits+O2_Benefits+(((Harvest_PPOR/(DT_1*PPOR_Freq $\left.)\right)$

$+($ Harvest_Rate_PNR/(DT_1*Frequency_PNR $)){ }^{*} \mathrm{CH} 4 \mathrm{gCOD}{ }^{*} \mathrm{gCOD}$ _galgae ${ }^{*} \mathrm{Bi}$ ogas_\$_per_L))

OUTFLOWS:

BG_Benefits = A_to_BG_Benefits

Biogas_Costs $(\mathrm{t})=$ Biogas_Costs $(\mathrm{t}-\mathrm{dt})+($ A_to_BG_Costs - BG_Costs $){ }^{*} \mathrm{dt}$ 


\section{Appendix B (Continued)}

INIT Biogas_Costs $=0$

INFLOWS:

A_to_BG_Costs =

Biogas ${ }^{*}((($ Harvest_PPOR/(DT_1*PPOR_Freq) $)+($ Harvest_Rate_PNR/(DT_1*Fre quency_PNR $)))^{*}$ BG_Process $)+((($ Harvest_PPOR/(DT_1*PPOR_Freq $))+($ Harves t_Rate_PNR/(DT_1 ${ }^{*}$ Frequency_PNR $\left.\left.)\right)\right)^{*}$ Cost_of_Biomass_Production)+(Harves ting_Costs* $(($ Harvest_PPOR/(DT_1*PPOR_Freq $))+($ Harvest_Rate_PNR/(DT_1*F requency_PNR)))))

OUTFLOWS:

BG_Costs $=$ A_to_BG_Costs

C1_Conc $(\mathrm{t})=\overline{\mathrm{C}} 1 \_$Conc $(\mathrm{t}-\mathrm{dt})+\left(\mathrm{C} 1 \_\mathrm{Eff}-\mathrm{C} 1\right.$ _Discharge_Conc $){ }^{*} \mathrm{dt}$

INIT C1 Conc $=\overline{0}$

INFLOWS:

C1 Eff = C1_dn

OUTFLOWS:

C1_Discharge_Conc $=$ C1_Eff ${ }^{*} \mathrm{mg}$ to _kg/Calc_Flow

C1_Inf(t) $=$ C1_Inf $(\mathrm{t}-\mathrm{dt})+\left(\operatorname{Inf} \_\mathrm{C} 1-\mathrm{C} 1 \_0\right){ }^{*} \mathrm{dt}$

INIT C1_Inf $=\overline{0}$

INFLOWS:

Inf_C1 = Calc_Flow ${ }^{\star}$ Inf_Sol_C/mg_to_kg

OUTFLOWS:

C1_o = Inf_C1

$\mathrm{C} 2 \_\operatorname{Inf}(\mathrm{t})=\mathrm{C} 2 \_\operatorname{Inf}(\mathrm{t}-\mathrm{dt})+\left(\operatorname{Inf} \_\mathrm{C} 2-\mathrm{C} 2 \_0\right){ }^{*} \mathrm{dt}$

INIT C2 Inf $=0$

INFLOWS:

Inf_C2 = Calc_Flow ${ }^{*}$ Inf_Insol_C/mg_to_kg

OUTFLOWS:

C2_o = Inf_C2

C3 $\operatorname{Inf}(\mathrm{t})=\mathrm{C} 3 \operatorname{lnf}(\mathrm{t}-\mathrm{dt})+\left(\operatorname{Inf} \_\mathrm{C} 3-\mathrm{C} 3 \_0\right){ }^{*} \mathrm{dt}$

INIT C3 Inf $=0$

INFLOWS:

Inf_C3 = Calc_Flow ${ }^{*}$ Inf_Cellular_C/mg_to_kg

OUTFLOWS:

C3_0 = Inf_C3

C4_accum_in_algae $(\mathrm{t})=\mathrm{C} 4 \_$accum_in_algae $(\mathrm{t}-\mathrm{dt})+\left(\mathrm{C} 4 \_a s s i m\right){ }^{*} \mathrm{dt}$

INIT C4_accum_in_algae $=0$

INFLOWS:

C4_assim $=$ X_generated_PPOR ${ }^{*}$ q_C4

C4_accum_in_PNR $(\mathrm{t})=\mathrm{C} 4$ accum_in_PNR $(\mathrm{t}-\mathrm{dt})+\left(\mathrm{C} 4 \_\right.$assim_PNR $)$* $\mathrm{dt}$

INIT C4_accum_in_PNR $=0$

INFLOWS:

C4_assim_PNR $=$ X_generated_PNR ${ }^{*}$ q_C4_PNR 


\section{Appendix B (Continued)}

C4_Accum_PNR $(\mathrm{t})=\mathrm{C} 4$ _Accum_PNR $(\mathrm{t}-\mathrm{dt})+(\mathrm{C} 4$ to _PNR - C4_from_PNR -

C4_assim_PNR) * $\mathrm{dt}$

INIT C4_Accum_PNR $=$ C4_to_PNR*HRT_PNR

INFLOWS:

C4_to_PNR $=$ C4_n*PNR*Percent_Flow_to_PNR

OUTFLOWS:

C4_from_PNR $=$ C4_to_PNR-C4_assim_PNR

C4_assim_PNR $=$ X_generated_PNR ${ }^{*}$ q_C4_PNR

C4_Accum_PPOR $(\mathrm{t})=\mathrm{C} 4$ Accum_PPOR $(\mathrm{t}-\mathrm{dt})+(\mathrm{C} 4$ _to_Algae -

C4_from_PPOR - C4_assim) * $\mathrm{dt}$

INIT C4_Accum_PPOR $=$ C4_to_Algae*HRT_PPOR

INFLOWS:

C4_to_Algae $=$ C4_O2*Percent_Flow_to_PPOR ${ }^{*} P P O R$

OUTFLOWS:

C4_from_PPOR $=$ C4_to_Algae-C4_assim

C4_assim $=$ X_generated_PPOR ${ }^{*}$ q_C4

C4_Inf(t) $=$ C4_Inf(t - dt $)+\left(\operatorname{Inf} \_C 4-C 4 \_0\right){ }^{*} \mathrm{dt}$

INIT C4_Inf $=\overline{0}$

INFLOWS:

Inf_C4 = Calc_Flow ${ }^{*}$ Inf_CO2/mg_to_kg

OUTFLOWS:

C4_0 = Inf C4

C_Eff $(t)=\bar{C} \_E f f(t-d t)+\left(C 1 \_d n+C 3 \_d n+C 4 \_d n+C 2 \_d n-C \_E f f \_t\right) * d t$

INIT C_Eff $=0$

INFLOWS:

C1_dn $=$ C1_n

C3_dn $=$ C3_n

C4_dn $=$ C4_n-C4_to_A2

$\mathrm{C} 2 \_\mathrm{dn}=\mathrm{C} 2 \mathrm{n}$

OUTFLOWS:

C_Eff_t $=$ C1_dn+C2_dn $+\mathrm{C} 3 \_d n+C 4 \_d n$

Denit_C1 $(\mathrm{t})=$ Denit_C1 $(\mathrm{t}-\mathrm{dt})+\left(\mathrm{C} 1 \_\bar{n}-\mathrm{C} 1 \_\mathrm{dn}\right){ }^{*} \mathrm{dt}$

INIT Denit_C1 $=0$

INFLOWS:

C1_n = C1_O2-Nit_C1_to_C3-Nit_C1_to_C4

OUTFLOWS:

C1_dn = C1_n

Denit_C2 $(\mathrm{t})=$ Denit_C2 $(\mathrm{t}-\mathrm{dt})+\left(\mathrm{C} 2 \_\mathrm{n}-\mathrm{C} 2 \_\mathrm{dn}\right){ }^{*} \mathrm{dt}$

INIT Denit_C2 $=0$

INFLOWS:

$\mathrm{C} 2 \_\mathrm{n}=\mathrm{C} 2 \_\mathrm{O} 2$

OUTFLOWS:

C2_dn = C2_n 


\section{Appendix B (Continued)}

Denit_C3 $(\mathrm{t})=$ Denit_C3 $(\mathrm{t}-\mathrm{dt})+\left(\mathrm{C} 3 \_\mathrm{n}-\mathrm{C} 3 \_\mathrm{dn}\right){ }^{*} \mathrm{dt}$

INIT Denit_C3 $=0$

INFLOWS:

C3_n = C3_O2+Nit_C1_to_C3

OUTFLOWS:

C3_dn = C3 n

Denit_C4 $(\mathrm{t})=$ Denit_C4 $(\mathrm{t}-\mathrm{dt})+\left(\mathrm{C} 4 \_\mathrm{n}-\mathrm{C} 4 \_\mathrm{dn}-\mathrm{C} 4\right.$ _to_A2 $){ }^{*} \mathrm{dt}$

INIT Denit_C4 $=0$

INFLOWS:

C4_n = C4_O2+Nit_C1_to_C4-C4_to_A

OUTFLOWS:

C4_dn $=$ C4_n-C4_to_A2

C4_to_A2 $=$ C4_assim_PNR

Denit_N1 $(\mathrm{t})=$ Denit_N1 $(\mathrm{t}-\mathrm{dt})+\left(\mathrm{N} 1 \_\mathrm{n}-\mathrm{N} 1 \_\mathrm{dn}\right){ }^{*} \mathrm{dt}$

INIT Denit_N1 $=0$

INFLOWS:

$\mathrm{N} 1 \_\mathrm{n}=\mathrm{N} 1 \_\mathrm{O} 2$

OUTFLOWS:

N1_dn $=$ N1_n

Denit_N2 $(\mathrm{t})=$ Denit_N2 $(\mathrm{t}-\mathrm{dt})+\left(\mathrm{N} 2 \_\mathrm{n}-\mathrm{N} 2 \_\mathrm{dn}\right){ }^{*} \mathrm{dt}$

INIT Denit_N2 $=0$

INFLOWS:

$\mathrm{N} 2 \_\mathrm{n}=\mathrm{N} 2 \_\mathrm{O} 2-\mathrm{N} 2$ to_A - Nit_N2_to_N3

OUTFLOWS:

$\mathrm{N} 2 \mathrm{dn}=\mathrm{N} 2 \mathrm{n}$

Denit_N3 $(\mathrm{t})=$ Denit_N3(t-dt) $+\left(\mathrm{N} 3 \_n-N 3 \_d n-N 3 \_t o \_A 2-D N \_N 3 \_t o \_N 4\right){ }^{*} \mathrm{dt}$

INIT Denit_N3 $=0$

INFLOWS:

$\mathrm{N} 3 \mathrm{n}=\mathrm{N} 3 \mathrm{O} 2+\mathrm{Nit} \mathrm{N} 2$ to $\mathrm{N} 3$

OUTFLOWS:

N3_dn $=$ N3 $n$-DN_N3_to_N4 - N3_to_A2

N3_to_A2 $=$ N3_assim_PNR

DN_N3 to N4 $=$ N3 $n * \bar{D}$ Denit Rate

Denit $N 4(t)=$ Denit_N4 $(\mathrm{t}-\mathrm{dt})+\left(\mathrm{N} 4 \_\mathrm{n}+\mathrm{DN} \_\mathrm{N} 3\right.$ to $\left.\mathrm{N} 4-\mathrm{N} 4 \_\mathrm{dn}\right){ }^{*} \mathrm{dt}$

INIT Denit N4 = 0

INFLOWS:

$\mathrm{N} 4 \mathrm{n}=\mathrm{N} 4 \_\mathrm{O} 2$

DN_N3_to_N4 = N3_n*Denit_Rate

OUTFLOWS:

N4_dn $=$ N4_n+DN_N3 to N4

Denit_P1 $(\mathrm{t})=$ Denit_P1 $(\mathrm{t}-\overline{\mathrm{d} t})+\left(\mathrm{P} 1 \_\mathrm{n}-\mathrm{P} 1 \_\mathrm{dn}-\mathrm{P} 1 \_t \mathrm{t} \_\mathrm{A} 2\right){ }^{*} \mathrm{dt}$

INIT Denit_P1 $=0$

INFLOWS: 


\section{Appendix B (Continued)}

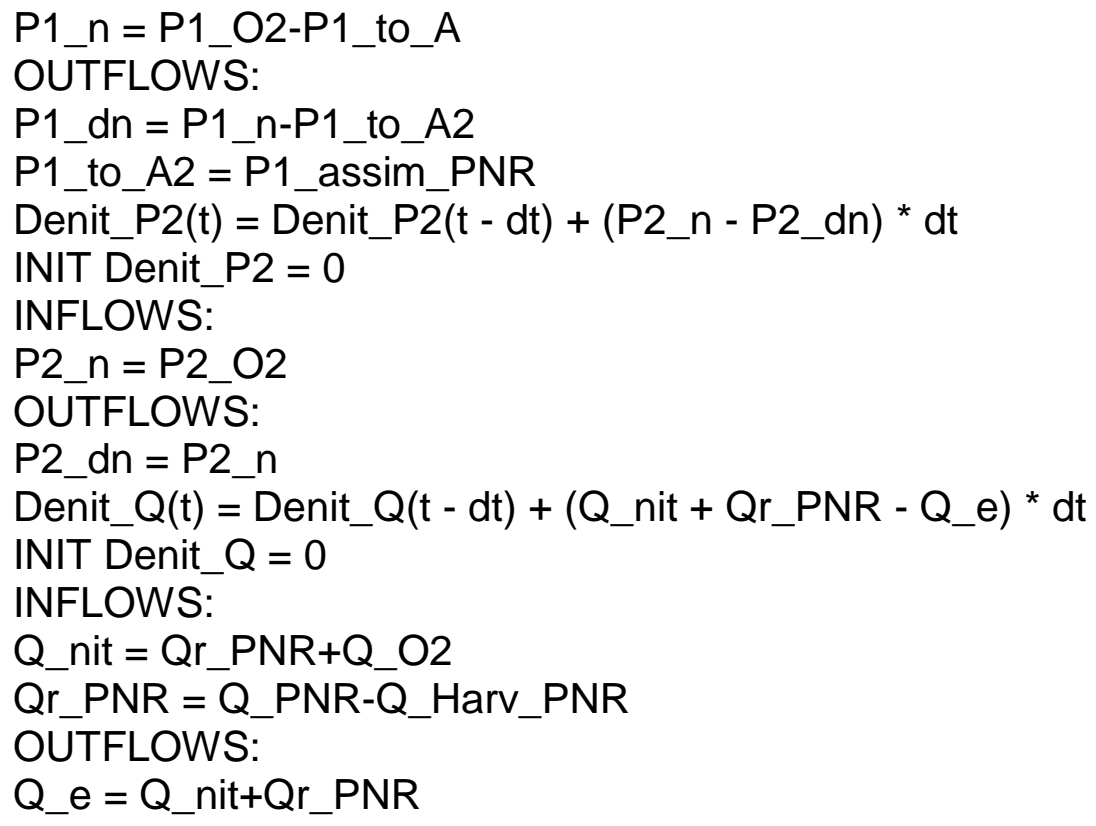




\section{Appendix B (Continued)}

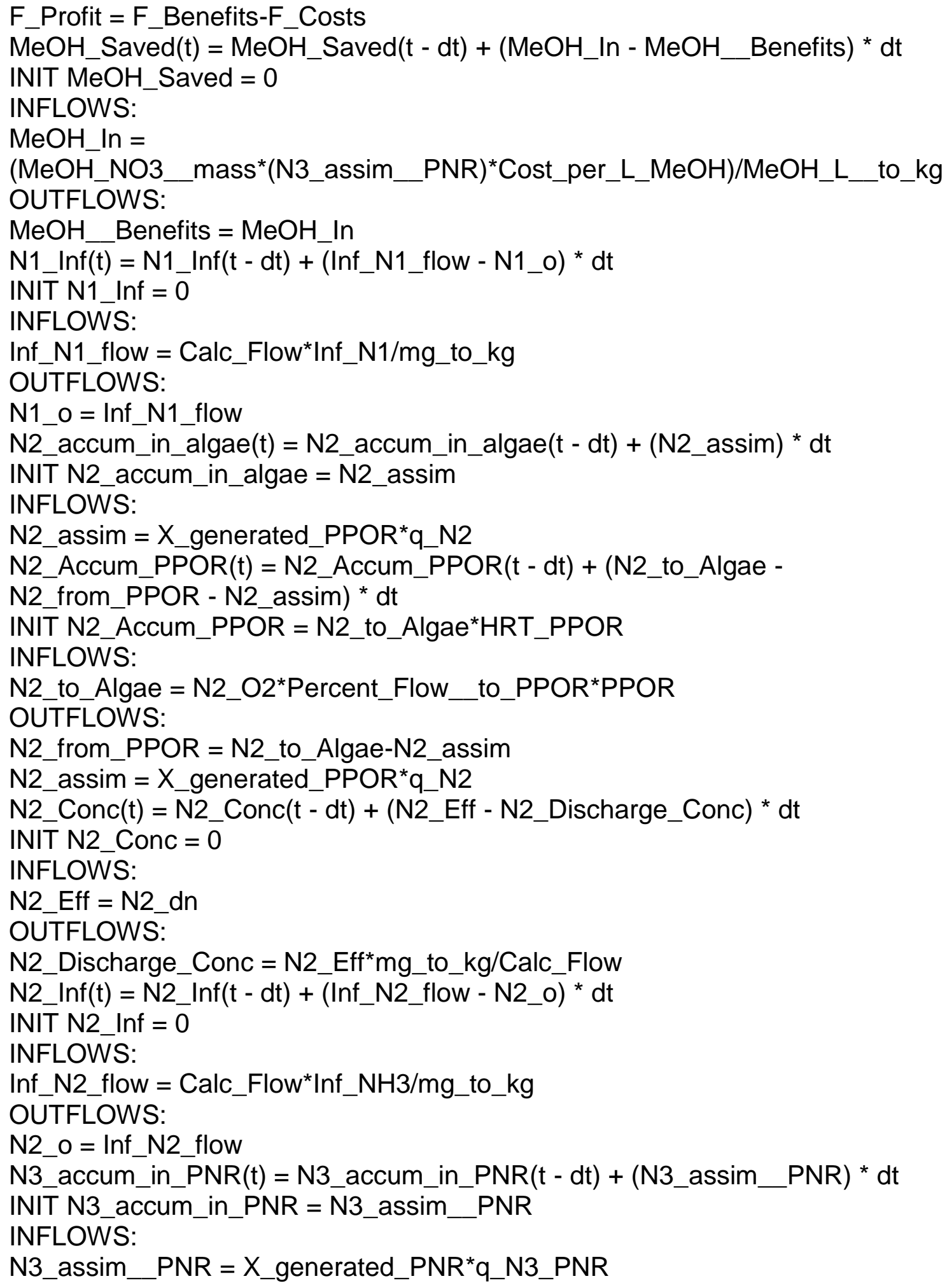




\section{Appendix B (Continued)}

$\mathrm{N} 3 \_$Accum_PNR $(\mathrm{t})=\mathrm{N} 3 \_$Accum_PNR $(\mathrm{t}-\mathrm{dt})+(\mathrm{N} 3$ to $2 P N R-\mathrm{N} 3$ from_PNR N3_assim_PNR) * $d t$

INIT N3_Accum_PNR $=$ N3_to_PNR*HRT_PNR

INFLOWS:

N3_to_PNR $=$ N3_n ${ }^{*}$ PNR ${ }^{*}$ Percent_Flow_to_PNR

OUTFLOWS:

N3_from_PNR $=$ N3_to_PNR-N3_assim_PNR

N3_assim_PNR $=\bar{X} \_$generated_PNR ${ }^{*} q \_N 3 \_P N R$

N3_Inf $(\mathrm{t})=$ N3_Inf $(\mathrm{t}-\mathrm{dt})+\left(\right.$ Inf_N3_flow $\left.-\mathrm{N} 3 \_0\right){ }^{*} \mathrm{dt}$

INIT N3 Inf $=\overline{0}$

INFLOWS:

Inf_N3_flow $=$ Calc_Flow ${ }^{*}$ Inf_NOx/mg_to_kg

OUTFLOWS:

N3_o = Inf_N3_flow

$\mathrm{N} 4 \_\operatorname{Inf}(\mathrm{t})=\mathrm{N} 4 \_\operatorname{Inf}(\mathrm{t}-\mathrm{dt})+\left(\right.$ Inf_N4_flow - N4_o ${ }^{*} \mathrm{dt}$

INIT N4_Inf $=\overline{0}$

INFLOWS:

Inf_N4_flow = Calc_Flow ${ }^{*}$ Inf_N2/mg_to_kg

OUTFLOWS:

N4_o = Inf_N4_flow

Nit_C1 $(\mathrm{t})=$ Nit_C1 $(\mathrm{t}-\mathrm{dt})+\left(\mathrm{C} 1 \_\mathrm{O} 2-\mathrm{C} 1 \_\mathrm{n}-\mathrm{Nit}+\mathrm{C} 1 \_t o \_C 3-\mathrm{Nit} C 1\right.$-to_C4 ${ }^{*} \mathrm{dt}$

INIT Nit_C1 $=\overline{0}$

INFLOWS:

$\mathrm{C} 1 \mathrm{O} 2=\mathrm{C} 1$ o-O2 $\mathrm{C} 1$ to $\mathrm{C} 4-\mathrm{O} 2$ C 1 to $\mathrm{C} 3$

OUTFLOWS:

C1_n = C1_O2-Nit_C1_to_C3-Nit_C1_to_C4

Nit_C1_to_C3 $=$ Nit_kC1_to_C3 ${ }^{*} \mathrm{C} 1$-O2

Nit_C1_to_C4 $=$ C1_O2 ${ }^{*} \mathrm{Nit} \mathrm{kC} 1$ to $\mathrm{C} 4$

Nit_C2(t) $=$ Nit_C2 $(\mathrm{t}-\mathrm{dt})+\left(\mathrm{C} 2 \_-\overline{\mathrm{O}} 2-\mathrm{C} 2 \_n\right){ }^{*} \mathrm{dt}$

INIT Nit_C2 $=0$

INFLOWS:

$\mathrm{C} 2 \mathrm{O} 2$ = $\mathrm{C} 2 \_\mathrm{O}$

OUTFLOWS:

$\mathrm{C} 2 \mathrm{n}=\mathrm{C} 2 \mathrm{O} 2$

Nit_C3 $(t)=$ Nit_C3 $(t-d t)+($ C3_O2 + Nit_C1_to_C3 - C3_n $){ }^{*} \mathrm{dt}$

INIT Nit_C3 $=\overline{0}$

INFLOWS:

C3 O 2 = C3 $0+\mathrm{O} 2$ C 1 to $\mathrm{C} 3$

Nit_C1_to_C3 $=$ Nit_kC1_to_C3 ${ }^{*}$ C1_O2

OUTFLOW':

$\mathrm{C} 3 \mathrm{n}=\mathrm{C} 3 \mathrm{O} 2+\mathrm{Nit} \mathrm{C} 1$ to $\mathrm{C} 3$

Nit_C4 $(\mathrm{t})=$ Nit_C4 $(\mathrm{t}-\mathrm{dt})+\left(\mathrm{C} 4 \_\mathrm{O} 2+\right.$ Nit_C1_to_C4 - C4_n - C4_to_A ${ }^{*} \mathrm{dt}$

INIT Nit C4 $=0$ 


\section{Appendix B (Continued)}

INFLOWS:

C4_O2 = C4_0+O2_C1_to_C4

Nit_C1_to_C4 $=\mathrm{C} 1$-O2 ${ }^{\star} \mathrm{Nit}$-kC1_to_C4

OUTFLOTWS:

C4_n = C4_O2+Nit_C1_to_C4-C4_to_A

C4_to_A $=$ C4 assim

Nit_N1 $(\mathrm{t})=\mathrm{Nit}-\mathrm{N} 1(\mathrm{t}-\mathrm{dt})+\left(\mathrm{N} 1 \_\mathrm{O} 2-\mathrm{N} 1 \_\mathrm{n}\right){ }^{*} \mathrm{dt}$

INIT Nit_N1 $=0$

INFLOWS:

N1_O2 = N1_o

OUTFLOWS:

$\mathrm{N} 1 \_\mathrm{n}=\mathrm{N} 1 \_\mathrm{O} 2$

Nit_N2 $(\mathrm{t})=\mathrm{Nit} \_\mathrm{N} 2(\mathrm{t}-\mathrm{dt})+\left(\mathrm{N} 2 \_\mathrm{O} 2-\mathrm{N} 2 \_\mathrm{n}-\mathrm{N} 2 \text {-to_A - Nit_N2_to_N3 }\right)^{*} \mathrm{dt}$

INIT Nit_N2 $=0$

INFLOWS:

N2_O2 = N2_o-O2_N2_to_N3

OUTFLOWS:

$\mathrm{N} 2 \_\mathrm{n}=\mathrm{N} 2 \_\mathrm{O} 2-\mathrm{N} 2$ to_A - Nit_N2_to_N3

$\mathrm{N} 2$ to $\mathrm{A}=\mathrm{N} 2$ _assim

Nit_N2_to_N3 $=$ N2_O2 ${ }^{*}$ Nit_Rate_in_Nit_Reactor

$\mathrm{Nit} \_\mathrm{N} 3(\mathrm{t})=\mathrm{Nit} \_\mathrm{N} 3(\mathrm{t}-\mathrm{dt})+\left(\overline{\mathrm{N}} 3 \_\mathrm{O} 2+\mathrm{Nit}-\mathrm{N} 2 \_t 0 \_\mathrm{N} 3-\mathrm{N} 3 \_\mathrm{n}\right){ }^{*} \mathrm{dt}$

INIT Nit_N3 $=\overline{0}$

INFLOWS:

$\mathrm{N} 3 \_\mathrm{O} 2=\mathrm{O} 2 \_\mathrm{N} 2 \_$to_N3+N3_o

Nit_N2_to_N3 $=\bar{N} 2$ O $2{ }^{*}$ Nit_Rate_in_Nit_Reactor

OUTFLOWS:

N3_n $=$ N3_O2+Nit_N2_to_N3

Nit_N4 $(\mathrm{t})=$ Nit_N4 $(\mathrm{t}-\mathrm{dt})+\left(\mathrm{N} 4 \_\mathrm{O} 2-\mathrm{N} 4 \_\mathrm{n}\right){ }^{*} \mathrm{dt}$

INIT Nit $\mathrm{N} 4=\overline{0}$

INFLOWS:

$\mathrm{N} 4 \_\mathrm{O} 2$ = N4_O

OUTFLOWS:

$\mathrm{N} 4$ n $=\mathrm{N} 4$-O2

Nit_P1 $(\mathrm{t})=$ Nit_P1 $(\mathrm{t}-\mathrm{dt})+\left(\mathrm{P} 1 \_\mathrm{O} 2-\mathrm{P} 1 \_\mathrm{n}-\mathrm{P} 1 \_t 0 \_A\right){ }^{*} \mathrm{dt}$

INIT Nit_P1 $=\overline{0}$

INFLOWS:

P1_O2 = P1_o

OUTFLOWS:

$\mathrm{P} 1 \_\mathrm{n}=\mathrm{P} 1$ O2-P1_to_A

P1_to_A $=$ P1_assim

Nit_P2 $(\mathrm{t})=$ Nit_P2 $(\mathrm{t}-\mathrm{dt})+\left(\mathrm{P} 2 \_\mathrm{O} 2-\mathrm{P} 2 \_\mathrm{n}\right){ }^{*} \mathrm{dt}$

INIT Nit_P2 $=\overline{0}$

INFLOWS: 


\section{Appendix B (Continued)}

$\mathrm{P} 2 \mathrm{O} 2$ = P2 0

OUTFLOWS:

$\mathrm{P} 2 \mathrm{n}=\mathrm{P} 2 \mathrm{O} 2$

Nit_Q $(\mathrm{t})=\overline{N i t} \_\mathrm{Q}(\mathrm{t}-\mathrm{dt})+\left(\mathrm{Q} \_\mathrm{O} 2+\mathrm{Qr} \_P P O R-Q \_\right.$it $\left.-\mathrm{Q} \_P N R\right){ }^{*} \mathrm{dt}$

INIT Nit_Q $=0$

INFLOWS:

Q_O2 $=$ Q_0-Q_PPOR

Qr_PPOR $=$ Q_PPOR-Q_Harv_PPOR

OUTFLOWS:

$Q$ nit $=$ Qr_PNR+Q_O2

Q_PNR $=\overline{P N R}^{*}\left(\left(\mathrm{Q} \_\mathrm{O} 2^{*}\right.\right.$ Percent_Flow_to_PNR $)+\mathrm{Q}$ _PPOR $)$

$\mathrm{O} 2 \_\mathrm{C} 1(\mathrm{t})=\mathrm{O} 2 \_\mathrm{C} 1(\mathrm{t}-\mathrm{dt})+\left(\mathrm{C} 1 \_\mathrm{O}-\mathrm{C} 1 \_\mathrm{O} 2-\mathrm{O} 2\right.$ C1_to_C3 - O2_C1_to_C4 $)$ * $\mathrm{dt}$

INIT O2_C1 = 0

INFLOWS:

C1_o=Inf_C1

OUTFLOWS:

C1_O2 = C1_0-O2_C1_to_C4-O2_C1_to_C3

$\mathrm{O} 2$ C1 to $\mathrm{C} 3=\overline{\mathrm{C}} 1 \mathrm{O}^{*} \mathrm{O} 2$ - $\mathrm{kC} 1$ to $\_$C3

$\mathrm{O} 2$ C1 to $\mathrm{C} 4=\mathrm{C} 1$ - ${ }^{*} \mathrm{O} 2$ - $\mathrm{kC} 1$ to $\mathrm{C} 4$

$\mathrm{O} 2 \_\mathrm{C} 2(\mathrm{t})=\mathrm{O} 2 \_\mathrm{C} 2(\mathrm{t}-\mathrm{dt})+\left(\mathrm{C} 2 \_0-\mathrm{C} 2 \_\mathrm{O} 2\right){ }^{*} \mathrm{dt}$

INIT O2_C2 = 0

INFLOWS:

C2_o = Inf C2

OUTFLOWS:

$\mathrm{C} 2 \_\mathrm{O} 2=\mathrm{C} 2 \_0$

$\mathrm{O} 2 \_\mathrm{C} 3(\mathrm{t})=\mathrm{O} 2 \_\mathrm{C} 3(\mathrm{t}-\mathrm{dt})+\left(\mathrm{C} 3 \_0+\mathrm{O} 2 \_\mathrm{C} 1 \_\mathrm{to} \_\mathrm{C} 3-\mathrm{C} 3 \_\mathrm{O} 2\right){ }^{*} \mathrm{dt}$

INIT O2 $\mathrm{C} 3=\overline{0}$

INFLOWS:

C3_0 = Inf C3

O2_C1_to_C3 $=$ C1_o*O2_kC1_to_C3

OUTFLOWS:

C3_O2 = C3_0+O2_C1_to_C3

$\mathrm{O} 2 \_\mathrm{C} 4(\mathrm{t})=\mathrm{O} 2 \_\mathrm{C} 4(\mathrm{t}-\mathrm{dt})+\left(\mathrm{C} 4 \_\mathrm{O}+\mathrm{O} 2\right.$ C1_to_C4 - C4_O2 $){ }^{*} \mathrm{dt}$

INIT O2 $\mathrm{C} 4=0$

INFLOWS:

C4_o = Inf_C4

O2_C1_to_C4 = C1_o*O2_kC1_to_C4

OUTFLOWS:

$\mathrm{C} 4 \_\mathrm{O} 2=\mathrm{C} 4 \_0+\mathrm{O} 2$ C 1 to $\mathrm{C} 4$

O2 $N 1(\mathrm{t})=\mathrm{O} 2 \_\mathrm{N} 1(\mathrm{t}-\mathrm{dt})+\left(\mathrm{N} 1 \_\mathrm{O}-\mathrm{N} 1 \_\mathrm{O} 2\right){ }^{*} \mathrm{dt}$

INIT O2 N1 $=0$

INFLOWS: 


\section{Appendix B (Continued)}

N1_o = Inf_N1_flow

OUTFLOWS:

$\mathrm{N} 1 \_\mathrm{O} 2=\mathrm{N} 1 \_0$

$\mathrm{O} 2 \_\mathrm{N} 2(\mathrm{t})=\mathrm{O} 2 \_\mathrm{N} 2(\mathrm{t}-\mathrm{dt})+\left(\mathrm{N} 2 \_\mathrm{O}-\mathrm{N} 2 \_\mathrm{O} 2-\mathrm{O} 2 \_\mathrm{N} 2 \_\mathrm{to} \_\mathrm{N} 3\right){ }^{*} \mathrm{dt}$

INIT O2 N2 = 0

INFLOWS:

N2_o = Inf_N2_flow

OUTFLOWS:

$\mathrm{N} 2 \_\mathrm{O} 2$ = N2_0-O2_N2_to_N3

$\mathrm{O} 2$ N2 to $\mathrm{N} 3=\mathrm{N} 2$ o* Nit_Rate_in_cBOD

$\mathrm{O} 2 \mathrm{~N} 3(\mathrm{t})=\mathrm{O} 2 \_\mathrm{N} 3(\mathrm{t}-\mathrm{dt})+\left(\mathrm{N} 3 \_\mathrm{o}+\mathrm{O} 2 \_\mathrm{N} 2\right.$ to_N3 - N3_O2 ${ }^{*} \mathrm{dt}$

INIT O2_N3 $=0$

INFLOWS:

N3 $0=$ Inf N3 flow

O2_N2_to_N3 = N2_O*Nit_Rate_in_cBOD

OUTFLOWS:

$\mathrm{N} 3 \_\mathrm{O} 2=\mathrm{O} 2 \mathrm{~N} 2$ to $\mathrm{N} 3+\mathrm{N} 3$

$\mathrm{O} 2 \_\mathrm{N} 4(\mathrm{t})=\mathrm{O} 2 \_\mathrm{N} 4(\mathrm{t}-\mathrm{dt})+\left(\overline{\mathrm{N}} 4 \_\mathrm{O}-\mathrm{N} 4 \_\mathrm{O} 2\right){ }^{*} \mathrm{dt}$

INIT O2 N4 = 0

INFLOWS:

N4_o = Inf_N4_flow

OUTFLOWS:

$\mathrm{N} 4 \mathrm{O} 2=\mathrm{N} 4 \_$

$\mathrm{O} 2 \_\mathrm{P} 1(\mathrm{t})=\mathrm{O} 2 \_\mathrm{P} 1(\mathrm{t}-\mathrm{dt})+\left(\mathrm{P} 1 \_0-\mathrm{P} 1 \_\mathrm{O} 2\right){ }^{*} \mathrm{dt}$

INIT O2 P1 = 0

INFLOWS:

P1_o=Inf_P1

OUTFLOWS:

$\mathrm{P} 1 \mathrm{O} 2=\mathrm{P} 10$

$\mathrm{O} 2 \_\mathrm{P} 2(\mathrm{t})=\mathrm{O} 2 \_\mathrm{P} 2(\mathrm{t}-\mathrm{dt})+\left(\mathrm{P} 2 \_0-\mathrm{P} 2 \_\mathrm{O} 2\right){ }^{*} \mathrm{dt}$

INIT O2_P2 $=0$

INFLOWS:

P2_o = Inf P2

OUTFLOWS:

$\mathrm{P} 2 \mathrm{O} 2=\mathrm{P} 2 \mathrm{O}$

$\mathrm{O} 2 \_\mathrm{Q}(\mathrm{t})=\mathrm{O} 2 \mathrm{Q}(\mathrm{t}-\mathrm{dt})+\left(\mathrm{Q} \_\mathrm{O}-\mathrm{Q} \_\mathrm{O} 2-\mathrm{Q} \_P P O R\right)$ * $\mathrm{dt}$

INIT O2 $Q=0$

INFLOWS:

Q_o = Calc_Flow

OUTFLOWS:

$Q \mathrm{O} 2=\mathrm{Q}$ o-Q $\mathrm{PPOR}$

$\mathrm{Q}$ PPPOR $=(\mathrm{Q} \text { _o*Percent_Flow_to_PPOR })^{*} \mathrm{PPOR}$

$\mathrm{O} 2$ Saved2 $(\mathrm{t})=\mathrm{O} 2$ _Saved2 $(\mathrm{t}-\overline{\mathrm{dt}})+(\mathrm{O} 2$ in $-\mathrm{O} 2$ B Benefits $){ }^{*} \mathrm{dt}$ 


\section{Appendix B (Continued)}

INIT O2_Saved2 $=0$

INFLOWS:

$\mathrm{O} 2$ in =

(molO2_per_molA* $\left(1 / \mathrm{mol} O \mathrm{O} 2\right.$ pper_NH3) ${ }^{*} \mathrm{kgN} \_$per_kgA ${ }^{*} \$ \mathrm{kgNH}{ }^{*}($ Harvest_PPO

R/(DT_1*PPOR_Freq)))+(N2_assim*\$kgNH3)

OUTFLOWS:

O2_Benefits $=02$ _ in

$\mathrm{P} 1 \_$accum_in_algae $(\mathrm{t})=\mathrm{P} 1 \_$accum_in_algae $(\mathrm{t}-\mathrm{dt})+\left(\mathrm{P} 1 \_a s s i m\right){ }^{*} \mathrm{dt}$

INIT P1 accum in algae $=\overline{0}$

INFLOWS:

$P 1 \_$assim $=X$ X generated_PPOR ${ }^{*} q \_P 1$

$P 1 \_$accum_in_PNR $(t)=P 1 \_a c c u m \_i n \_P N R(t-d t)+\left(P 1 \_a s s i m \_P N R\right) * d t$

INIT P1_accum_in_PNR $=\overline{0}$

INFLOWS:

$\mathrm{P} 1$ assim $\mathrm{PNR}=\mathrm{X}$ generated $\mathrm{PNR}^{*} \mathrm{q} P \mathrm{P} 1 \mathrm{PNR}$

$P 1 \_A c c u m \_P N R(t)=P 1 \_A c c u m \_P N R(t-d t)+\left(P 1 \_t o \_P N R-P 1 \_f r o m \_P N R\right.$ -

$P 1 \_$assim_PNR) ${ }^{*} \mathrm{dt}$

INIT P1_Accum_PNR $=$ P1_to_PNR*HRT_PNR

INFLOWS:

P1_to_PNR $=$ PNR ${ }^{*} P 1 \_n^{*}$ Percent_Flow_to_PNR

OUTFLOWS:

P1_from_PNR $=$ P1_to_PNR-P1_assim_PNR

$P 1 \_$assim_PNR $=$X_generated_PNR ${ }^{*} q-P 1 \_P N R$

$P 1 \_A c c u m \_P P O R(t)=P 1 \_A c c u m \_P P O R(t-d t)+\left(P 1 \_t o \_A l g a e-\right.$

P1 from_PPOR - P1_assim) ${ }^{*} \mathrm{dt}$

INIT P1_Accum_PPOR = P1_to_Algae*HRT_PPOR

INFLOWS:

$\mathrm{P} 1$ to_Algae $=\mathrm{P} 1 \_\mathrm{O}{ }^{*}$ Percent_Flow_to_PPOR ${ }^{\star} \mathrm{PPOR}$

OUTFLOWS:

$\mathrm{P} 1$ from_PPOR $=\mathrm{P} 1$ to_Algae-P1_assim

$P 1 \_$assim $=X$ Xenerated_PPOR ${ }^{*} q \_P 1$

$P 1 \_\operatorname{Inf}(\mathrm{t})=\mathrm{P} 1 \_\operatorname{Inf}(\mathrm{t}-\mathrm{dt})+\left(\operatorname{Inf} \_\mathrm{P} 1-\mathrm{P} 1 \_0\right){ }^{*} \mathrm{dt}$

INIT P1 Inf $=\overline{0}$

INFLOWS:

Inf_P1 = Calc_Flow ${ }^{*}$ Inf_Sol_P $/$ mg_to_kg

OUTFLOWS:

$\mathrm{P} 1 \_0=\operatorname{lnf} \mathrm{P} 1$

P2 $\operatorname{Inf}(\mathrm{t})=\mathrm{P} 2 \_\operatorname{Inf}(\mathrm{t}-\mathrm{dt})+\left(\operatorname{Inf} \_\mathrm{P} 2-\mathrm{P} 2 \_0\right){ }^{*} \mathrm{dt}$

INIT P2 Inf $=0$

INFLOWS:

Inf_P2 = Calc_Flow ${ }^{*}$ Inf_Insol_P/mg_to_kg

OUTFLOWS:

P2_o = Inf_P2 


\section{Appendix B (Continued)}

Profit_BD $(\mathrm{t})=$ Profit_BD $(\mathrm{t}-\mathrm{dt})+($ BD_Costs + BD_Benefits - BD_Profit $){ }^{*} \mathrm{dt}$ INIT Profit_BD $=0$

INFLOWS:

BD_Costs $=$ A_to_BD_Costs

BD Benefits $=A$ to BD Benefits

OUTFLOWS:

BD_Profit $=$ BD_Benefits $-B D \_$Costs

Profit_BG $(\mathrm{t})=$ Profit_BG(t- $\overline{\mathrm{dt}})+($ BG_Costs + BG_Benefits - BG_Profit $){ }^{*} \mathrm{dt}$ INIT Profit_BG $=0$

INFLOWS:

BG_Costs $=$ A to_BG_Costs

BG_Benefits = A_to_BG_Benefits

OUTFLOWS:

BG_Profit $=$ BG_Benefits-BG_Costs

$P \quad \overline{M B}(t)=P M B(t-d t)+(T P I n-T P M B I n)$ * $d t$

INIT P_MB $=0$

INFLOW':

TP_In = Inf_P1+Inf_P2

OUTFLOWS:

TP_MB_In $=$ TP_In

$P \_\bar{M} \_$out $(\mathrm{t})=\mathrm{P} \_\mathrm{MB} \_$out $(\mathrm{t}-\mathrm{dt})+\left(\mathrm{TP} \_\right.$Out $-\mathrm{TP} \_\mathrm{MB} \_$Out $){ }^{*} \mathrm{dt}$

INIT P_MB_out $=0$

INFLOWS:

TP Out $=\mathrm{P} 1$ dn+P1 to $A+P 1$ to $A 2+P 2 d n$

OUTFLOWS:

TP_MB_Out $=$ TP_Out

q_C 4 stock $(\mathrm{t})=\mathrm{q}$ C4_stock $(\mathrm{t}-\mathrm{dt})+\left(\mathrm{q} \_\mathrm{C} 4\right){ }^{*} \mathrm{dt}$

INIT q_C4_stock $=0$

INFLOWS:

q_C4 $=u$ calc_PPOR/Y_CO2_PPOR

q_C4_stock_2(t) = q_C4_stock_2 $(\mathrm{t}-\mathrm{dt})+\left(\mathrm{q} \_\mathrm{C} 4 \_P N R\right){ }^{*} \mathrm{dt}$

INIT q_C4_stock_2 =0

INFLOWS:

q_C4_PNR $=$ u_calc_PNR/Y_CO2_PNR

Q_Loss_to_Algae $(\mathrm{t})=\mathrm{Q}$ LLoss_to_Algae $(\mathrm{t}-\mathrm{dt})+(\mathrm{Q}$ _Harv_PPOR +

Q_Harv_PNR - Q_loss) * $\mathrm{dt}$

INIT Q_Loss_to_Algae $=0$

INFLOWS:

Q Harv_PPOR $=Q \%$ Lost $w$ Harvest PPOR ${ }^{\star} Q$ PPOR

Q_Harv_PNR $=$ Q_PNR ${ }^{\star} Q \%$ _Lost_w_Harvest_PNR

OUTTFLOWS:

Q_loss $=$ Q_Harv_PNR+Q_Harv_PPOR

$\mathrm{q} \_\mathrm{N} 2 \_\operatorname{stock}(\mathrm{t})=\mathrm{q} \_\mathrm{N} 2 \_\operatorname{stock}(\mathrm{t}-\mathrm{dt})+\left(\mathrm{q} \_\mathrm{N} 2\right){ }^{*} \mathrm{dt}$ 


\section{Appendix B (Continued)}

INIT q_N2_stock $=0$

INFLOWS:

$\mathrm{q} \_\mathrm{N} 2=\mathrm{u} \_\mathrm{calc}$ PPPOR/Y_NH3_PPOR

q_N3_stock $(\mathrm{t})=\mathrm{q} \_\mathrm{N} 3 \_$stock $(\mathrm{t}-\mathrm{dt})+\left(\mathrm{q} \_\mathrm{N} 3 \_P N R\right){ }^{*} \mathrm{dt}$

INIT q_N3_stock $=0$

INFLOWS:

q_N3_PNR $=$ u_calc_PNR/Y_NOx_PNR

q_P1_stock $(\mathrm{t})=\mathrm{q}$-P1_stock $(\mathrm{t}-\mathrm{dt})+\left(\mathrm{q} \_\mathrm{P} 1\right){ }^{*} \mathrm{dt}$

INIT q_P1_stock $=0$

INFLOWS:

q_P1 $=$ u_calc_PPOR/Y_Psol_PPOR

q_P1_stock_2(t) = q_P1_stock_2 $(\mathrm{t}-\mathrm{dt})+\left(\mathrm{q} \_P 1 \_P N R\right){ }^{*} \mathrm{dt}$

INIT q_P1_stock_2 =0

INFLOWS:

q_P1_PNR $=$ u_calc_PNR/Y_Psol_PNR

TC $\overline{M B o}(\mathrm{t})=\mathrm{T} \bar{C} \_\mathrm{MBo}(\mathrm{t}-\mathrm{dt})+\left(\mathrm{TC} \_\mathrm{MB} \_0-\mathrm{TC} \_\mathrm{MB} \_\mathrm{In}\right){ }^{*} \mathrm{dt}$

INIT TC MBo $=0$

INFLOWS:

TC_MB_0 = Inf_C1+Inf_C2+Inf_C3+Inf_C4

OUTFLOWS:

TC_MB_In = TC_MB_o

$T N \_C o n c(t)=T N \_C o n c(t-d t)+\left(T N \_E f f \_t-T N \_D i s c h a r g e \_C o n c\right){ }^{*} d t$

INIT TN_Conc $=\overline{0}$

INFLOWS:

TN_Eff $t=\mathrm{N} 1 \_\mathrm{dn}+\mathrm{N} 2 \_\mathrm{dn}+\mathrm{N} 3 \_d n+\mathrm{N} 4 \_\mathrm{dn}$

OUTFLOWS:

TN_Discharge_Conc $=$ TN_Eff_t ${ }^{*} \mathrm{mg} \_$to $\mathrm{kg} / \mathrm{Calc}$ Flow

$T N \_E f f(t)=T N \_E f f(t-d t)+\left(N 1 \_d n+N 2 \_d n+N 3 \_d n+N 4 \_d n-T N \_E f f \_t\right){ }^{*} d t$

INIT TN Eff $=0$

INFLOWS:

$\mathrm{N} 1 \_\mathrm{dn}=\mathrm{N} 1 \_\mathrm{n}$

$\mathrm{N} 2 \mathrm{dn}=\mathrm{N} 2 \mathrm{n}$

N3_dn $=$ N3_n-DN_N3_to_N4 - N3_to_A2

$\mathrm{N} 4 \mathrm{dn}=\mathrm{N} 4 \mathrm{n}+\mathrm{DN} \mathrm{N} 3$ to $\mathrm{N} 4$

OUTFLOWS:

TN_Eff $t=N 1 \_d n+N 2 \_d n+N 3 \_d n+N 4 \_d n$

$T N \_\operatorname{MBe}(t)=T N \_M B e(t-d t)+\left(T C \_M B \_e-T C \_M B \_O u t\right) * d t$

INIT TN MBe $=\overline{0}$

INFLOWS:

TC $M B \_e=C 1 \_d n+C 2 \_d n+C 3 \_d n+C 4 \_d n+C 4$ to $A+C 4$ to $A 2$

OUTFLŌWS:

TC_MB_Out $=$ TC_MB_e

$T N \_M B \_I n \_S t o c k(t)=T N \_M B \_I n \_S t o c k(t-d t)+\left(T N \_M B \_I n \_1-T N \_M B \_I n\right){ }^{*} d t$ 


\section{Appendix B (Continued)}

INIT TN_MB_In_Stock $=0$

INFLOWS:

TN_MB_In_1=Inf_N1_flow+Inf_N2_flow+Inf_N3_flow+Inf_N4_flow OUTFLOW'S:

$T N \_M B \_I n=T N \_M B \_I n \_1$

$T N \_M B \_$Out_Stock $(\mathrm{t})=T \mathrm{~N} \_M B \_$Out_Stock $(\mathrm{t}-\mathrm{dt})+\left(\mathrm{TN} \_M B \_O u t \_1\right.$ -

TN_MB_Out) ${ }^{*} \mathrm{dt}$

INIT TN_MB_Out_Stock $=0$

INFLOWS:

TN_MB_Out_1 = N1_dn+N2_dn+N2_to_A+N3_dn+N3_to_A2+N4_dn

OUTFLOWS:

TN_MB_Out $=$ TN_MB_Out_1

$T P \_$Conc $(\mathrm{t})=T P \_$Conc $(\mathrm{t}-\overline{\mathrm{dt}})+\left(T P \_E f f \_t-T P \_D i s c h a r g e \_C o n c\right){ }^{*} \mathrm{dt}$

INIT TP Conc $=\overline{0}$

INFLOWS:

TP_Eff_t $=$ P1_dn+P2_dn

OUTFLOWS:

TP_Discharge_Conc $=$ TP_Eff_t ${ }^{*} \mathrm{mg} \_$to $\mathrm{kg} / \mathrm{Calc}$ _Flow

$T P \_E f f(t)=T P \_E f f(t-d t)+\left(P 2 \_d n+P 1 \_d n-T P \_E f f \_t\right){ }^{*} d t$

INIT TP $E f f=0$

INFLOWS:

$\mathrm{P} 2 \_\mathrm{dn}=\mathrm{P} 2 \mathrm{n}$

P1_dn = P1_n-P1_to_A2

OUTFLOWS:

$T P \_E f f \_t=P 1 \_d n+P 2 \_d n$

u_calc_PNR_2 $(\mathrm{t})=\mathrm{u}$ _calc_PNR_2 $(\mathrm{t}-\mathrm{dt})+\left(\mathrm{u} \_ \text {calc_PNR }\right)^{*} \mathrm{dt}$

INIT U_calc_PNR_2 =0

INFLOWS:

U_calc_PNR =

((umax_NO3* $\left(\mathrm{MIN}\left(\left(\left(\mathrm{N} 3 \_\right.\right.\right.\right.$Accum_PNR/Vol_PNR_1) /(K_NOx $)+\left(\mathrm{N} 3 \_\right.$Accum_PNR/

Vol_PNR_1))),((P1_Accum_PNR/Vol_PNR_1)/((K_Psol) $+\left(\mathrm{P} 1 \_\right.$Accum_PNR/Vol

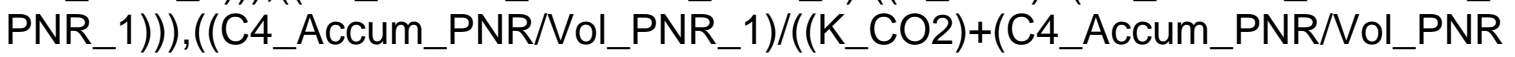
-1)))) ))-PNR_b $)^{*}$ PNR

u_calc_PPOR_2 $(t)=u \_c a l c \_P P O R \_2(t-d t)+\left(u \_c a l c \_P P O R\right) * d t$

INIT U_calc_PPOR_2 = 0

INFLOWS:

U_calc_PPOR $=$

((umax_NH3* $\left(\mathrm{MIN}\left(\left(\left(\mathrm{N} 2 \_\right.\right.\right.\right.$Accum_PPOR $) /\left(\left(\mathrm{K} \_\mathrm{NH} 3^{*}\right.\right.$ Vol_PPOR_1 $)+\left(\mathrm{N} 2 \_\right.$Accum

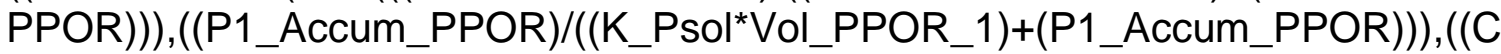
4_Accum_PPOR $\left.\left.\left./\left(\left(\mathrm{C} 4 \_A c c u m \_P P O R\right)+\left(K \_C O 2 * \operatorname{Vol} \_P P O R \_1\right)\right)\right)\right)\right)-$

PPOR_b) ${ }^{\star}$ PPOR

$X \_$accumulated_PNR $(\mathrm{t})=\mathrm{X}$ _accumulated_PNR $(\mathrm{t}-\mathrm{dt})+\left(\mathrm{X} \_\right.$generated_PNR -

Harvest_Rate_PNR) ${ }^{*} \mathrm{dt}$ 


\section{Appendix B (Continued)}

INIT X_accumulated_PNR $=10$

INFLOWS:

$X$ Xenerated_PNR $=$ X_accumulated_PNR ${ }^{*}$ __calc_PNR

OUTFLOWS:

Harvest_Rate_PNR $=$ Pulse $(($ Amount),Init_PNR,Frequency_PNR $)$

$X$ accumulated PPOR $(t)=X$ _accumulated_PPOR $(t-d t)+\left(X \_\right.$generated_PPOR

- Harvest_PPOR) * dt

INIT X_accumulated_PPOR $=10$

INFLOWS:

$X \_g e n e r a t e d \_P P O R=X \_a c c u m u l a t e d \_P P O R^{*} u \_c a l c \_P P O R$

OUTFLOWS:

Harvest_PPOR $=$ Pulse((PPOR_Amount),PPOR_Init,PPOR_Freq)

$\$ \mathrm{kgNH} 3=$ Cost_Aeration_per_kg_NH3

$\$ \_$per_kWh $=.12$

$\$$ per_quantity_O2 $=10$

Amount $=$ X_accumulated_PNR ${ }^{*}$ PNR_\%_Rem

BG_Est_Costs $=.048$

BG_Process $=.1$

Biodiesel $=1$

Biodiesel_\$_per_L $=3.15$

Biogas $=1$

Biogas_\$_per_L $=7.92^{*} 10^{\wedge}-5$

BOD_Rem_BOD_Reactor $=.79$

BOD_Rem_Nit_Reactor $=.85$

Calc Flow $=$ Flow GPD $*$ _ conv

$\mathrm{CH} 4 \mathrm{gCOD}=487$

Cost_Aeration_per_kg_NH3 $=.2369$

Cost_BD_Prod $=71$

Cost_Fert_Prod $=$ MJ_per_kg*kWh_per_MJ ${ }^{*} \$ \_p e r \_k W h$

Cost_of_Biomass_Production $=3$

Cost_per_L_MeOH $=3.5$

Denit_Rate $=.48$

DT_1 = 100

Fertilizer $=1$

Fertilizer_\$_per_kg $=3$

Fert_per_Biomass $=.5$

Flow_GPD $=96000000$

Frequency_PNR $=$ PNR_Harvest_Freq

gCOD_galgae $=1.545$

Harvesting_Costs $=.12$

HRT_DN_Basin $=$ Vol_Denit_Basin/Calc_Flow

HRT_Nit_Basin $=$ Vol_Nit_Basin/Calc_Flow

HRT_O2_Basin $=$ Vol_O2_Basin/Calc_Flow 


\section{Appendix B (Continued)}

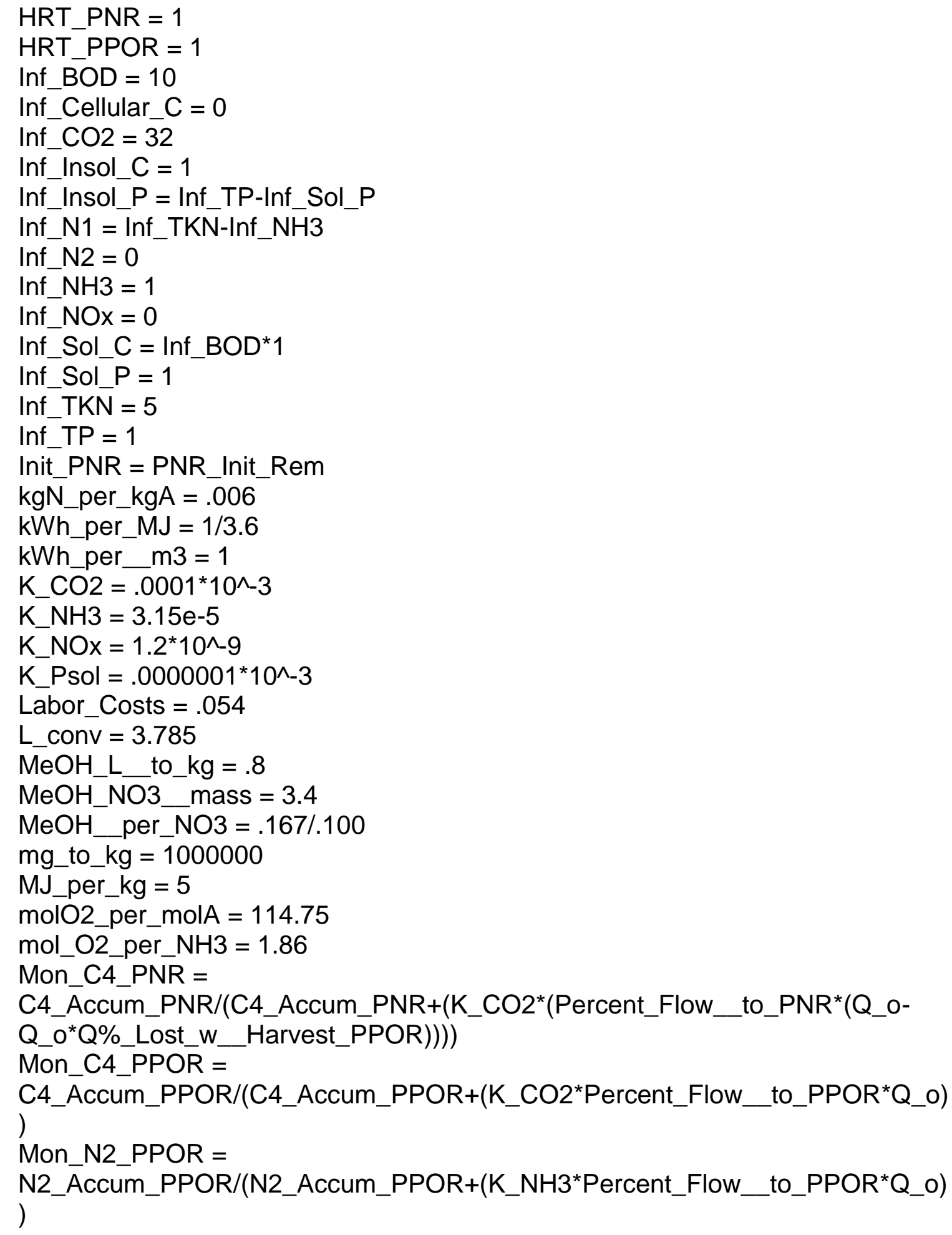




\section{Appendix B (Continued)}

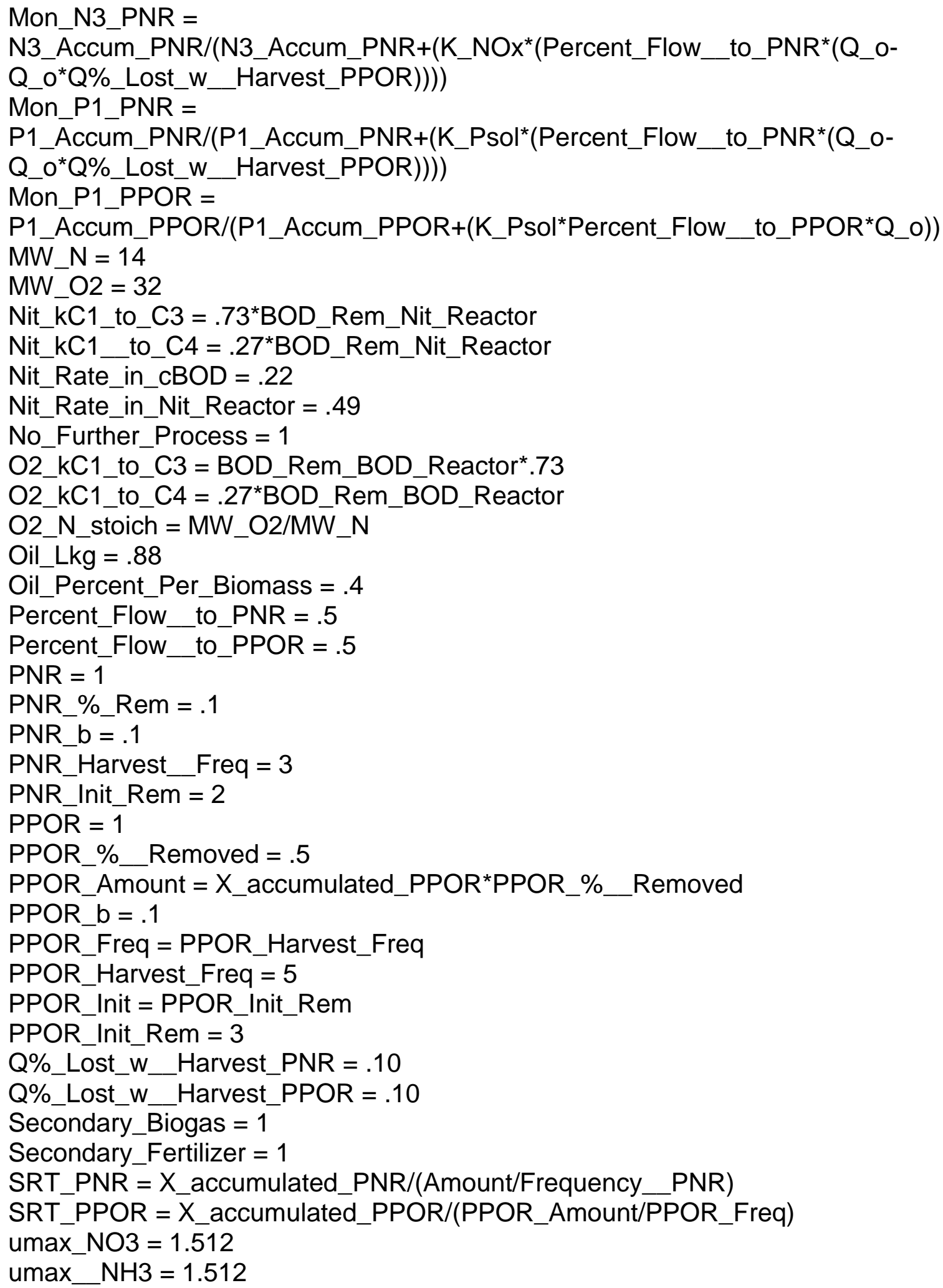




\section{Appendix B (Continued)}

Vol_Denit_Basin $=500000{ }^{*} 3.785$

Vol_Nit_Basin $=5000000 * 3.785$

Vol_O2_Basin $=5000000 * 3.785$

Vol PNR $=$ Vol PNR $1^{*} .264$

Vol_PNR_1 = HRT_PNR* $\left(\left(\right.\right.$ Percent_Flow_to_PNR* ${ }^{\star}\left(Q \_0-\right.$

Q_o*Q\%_Lost_w_Harvest_PPOR))

Vol PPOR $=$ Vol PPOR $1^{\star} .264$

Vol_PPOR_1 $=$ HRT_PPOR ${ }^{\star}\left(\right.$ Percent_Flow_to_PPOR $\left.^{*} \mathrm{Q} \_0\right)$

$Y \_C O 2 \_P N R=1.96$

$Y$ CO2 PPOR $=1.96$

$\mathrm{Y} N \mathrm{NH} 3 \mathrm{PPOR}=15.26$

Y_NOx_PNR $=15.26$

Y_Psol_PNR $=78.37$

Y_Psol_PPOR $=78.37$ 


\section{Appendix C: Extra Figures}

\section{Influent Wastewater Characteristics}

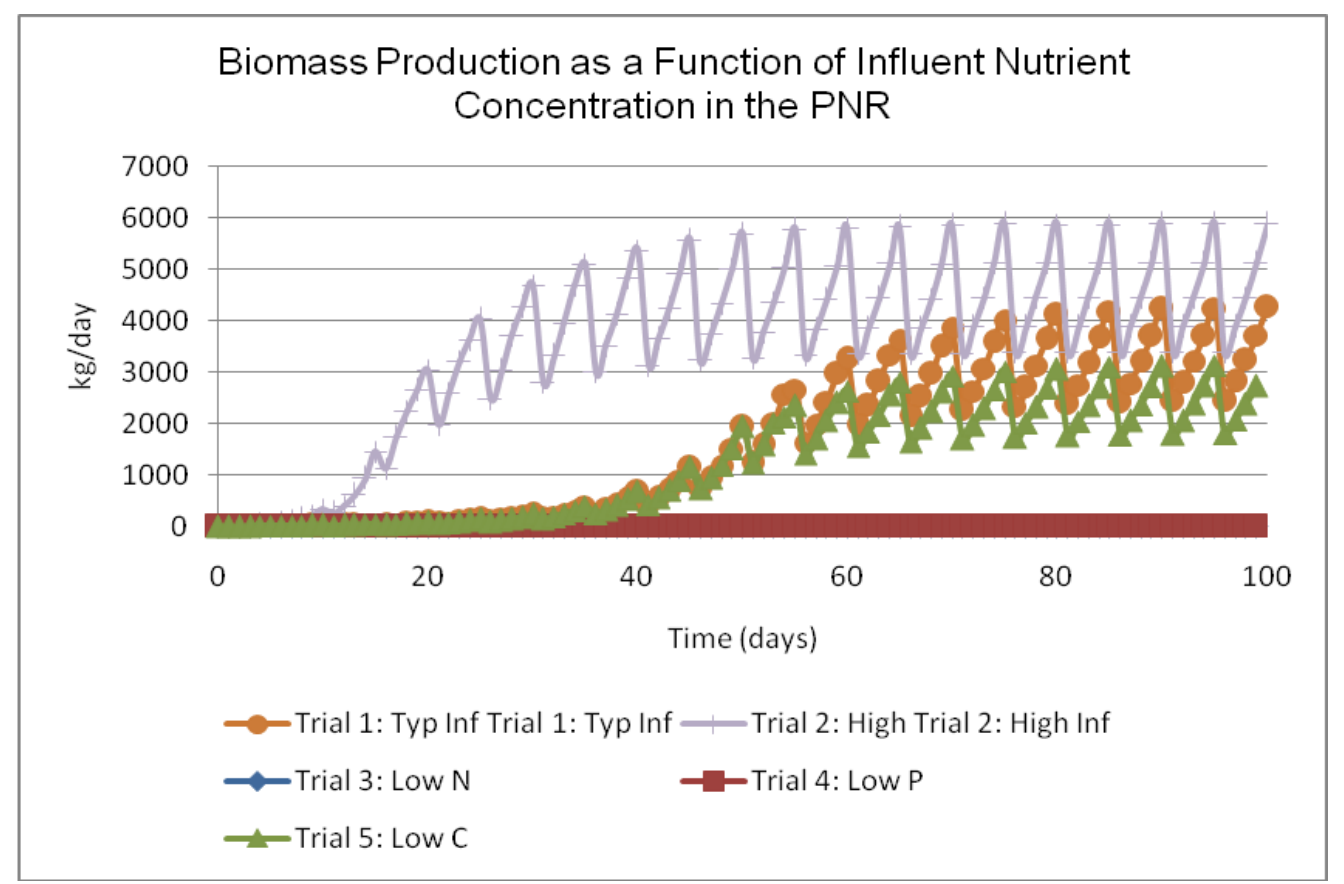

Figure $\mathrm{C} 1$. Biomass production as a function of influent nutrient concentration in the PNR. 


\section{Appendix C (Continued)}

\section{Specific Growth Rate and Harvest Rate}

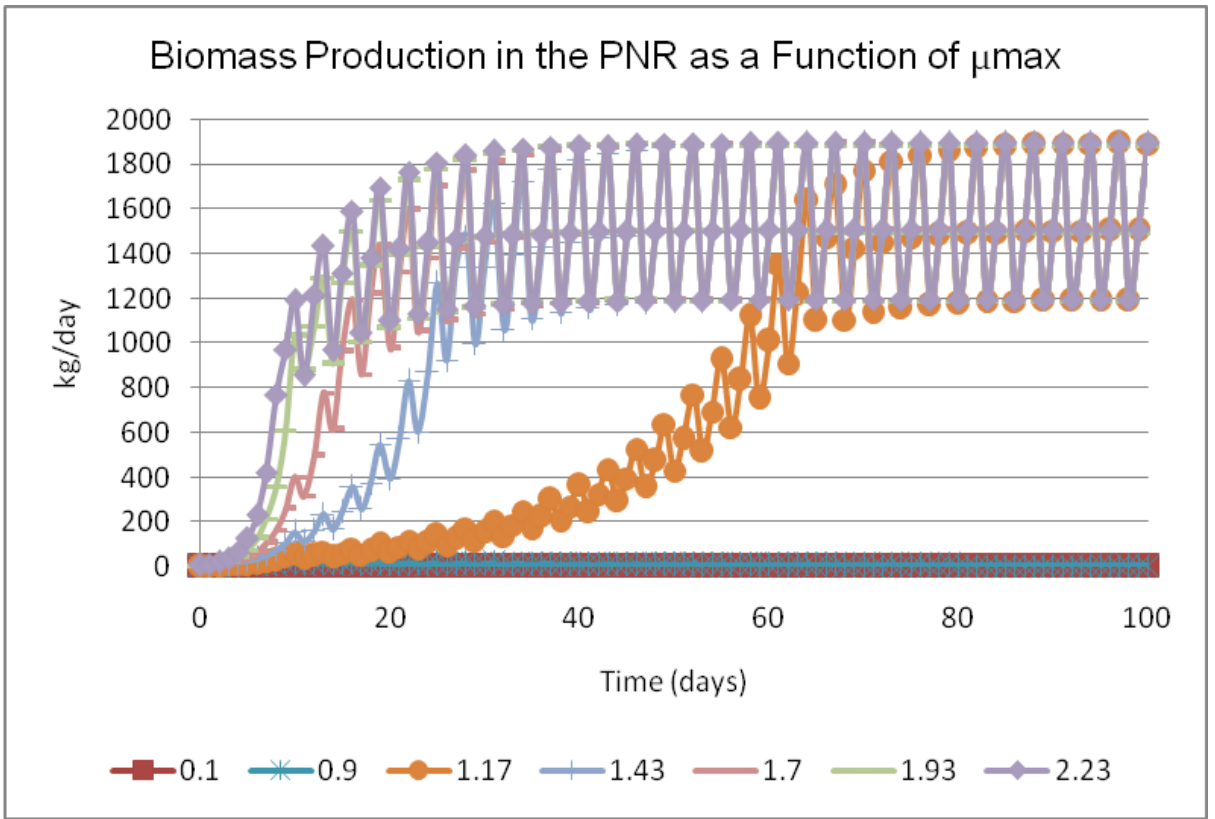

Figure C2. Biomass production in the PNR as a function of umax.

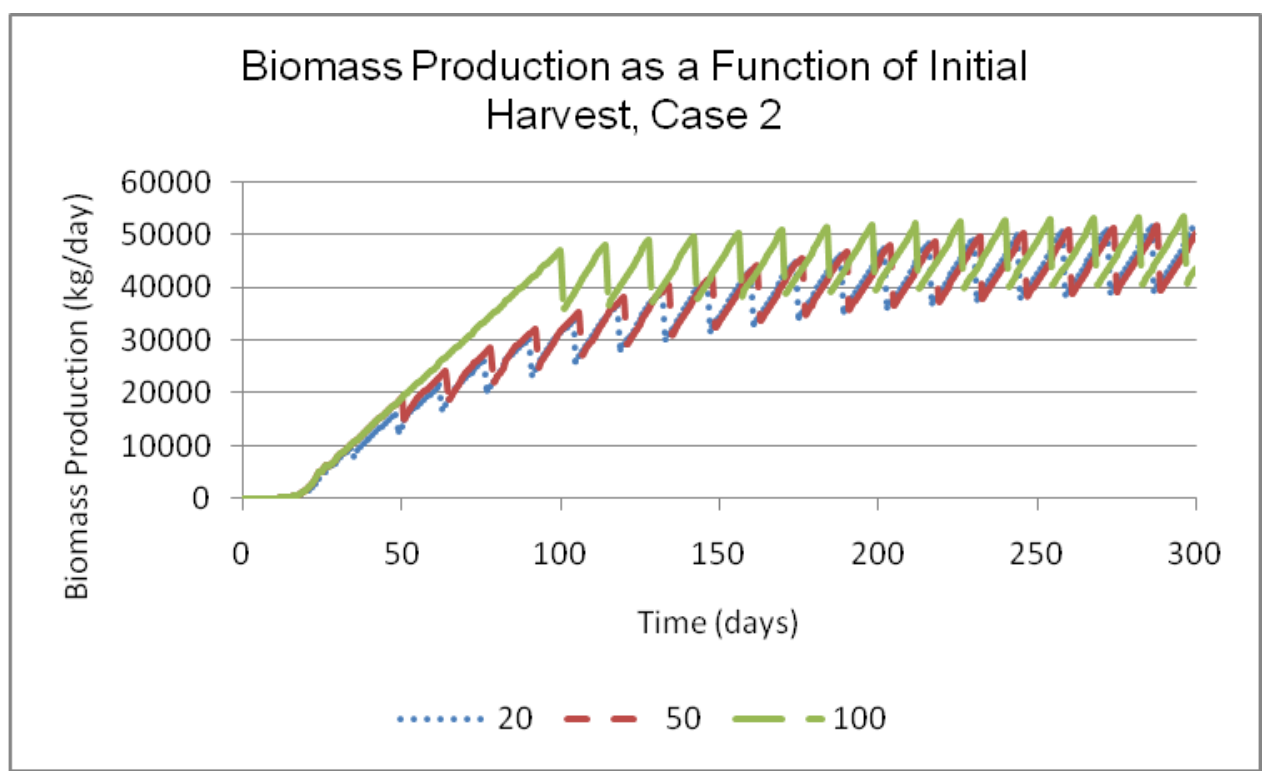

Figure C3. Biomass production as a function of initial harvest rate, Case 2. 


\begin{abstract}
About the Author
Ivy Cormier was born in Massachusetts and earned her Bachelor of Science in Environmental Science from the University of San Francisco. Throughout her academic career, Ivy has studied in Washington, D.C., Mexico, Australia, Brazil, and the Netherlands. Her research experience includes a study to optimize the growth of select algae species on high strength waste streams at the UNESCO-IHE Institute for Water Education. She has worked as a Pilot Technician for a biological wastewater treatment company, studying the effectiveness of a novel process with municipal and industrial wastewater streams. Ivy was most recently the Operating Permit Coordinator in the On-Site Sewage Treatment and Disposal System Program at the Hillsborough Health Department.
\end{abstract}

